\title{
Identifizierung und molekulare Charakterisierung des lysosomalen Matrixproteins Serincarboxypeptidase 1
}

\author{
Dissertation \\ zur Erlangung des Doktorgrades \\ der Mathematisch-Naturwissenschaftlichen Fakultäten \\ der Georg-August-Universität zu Göttingen
}

vorgelegt von

Katrin Kollmann

aus Bad Hersfeld

Göttingen 2007 
D7

Referent: Prof. Dr. Dr. K. von Figura

Institut für Biochemie II, Zentrum Biochemie und Molekulare Zellbiologie der Georg-August-Universität zu Göttingen

Korreferent: Prof. Dr. G. H. Braus

Institut für Mikrobiologie und Genetik

der Georg-August-Universität zu Göttingen

Tag der mündlichen Prüfung: 24.01.2008 
Meiner Familie 



\section{Inhaltsverzeichnis}

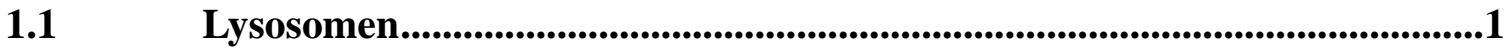

1.2 Synthese und Transport löslicher lysosomaler Proteine................................2

1.2.1 Biosynthese und N-Glykosylierung löslicher lysosomaler Proteine ................2

1.2.2 Synthese von Mannose-6-phosphat-Resten an N-Glykanen löslicher

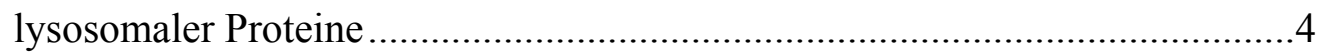

1.2.3 Mannose-6-phosphat-Rezeptor-vermittelte Sortierungswege löslicher

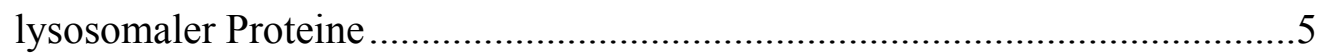

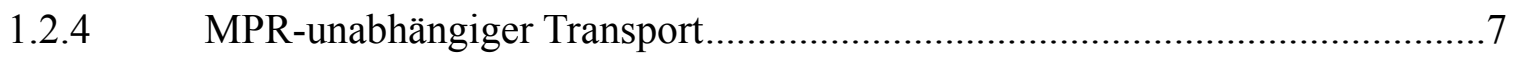

$1.3 \quad$ Lysosomale Speicherkrankheiten .................................................................8

1.4 Proteomanalyse lysosomaler Proteine .......................................................9

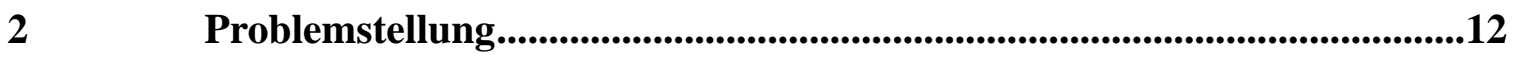

$3 \quad$ Material und Methoden............................................................................13

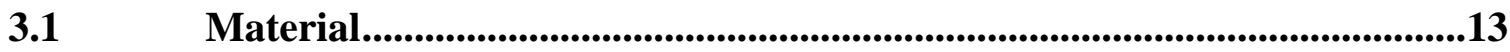

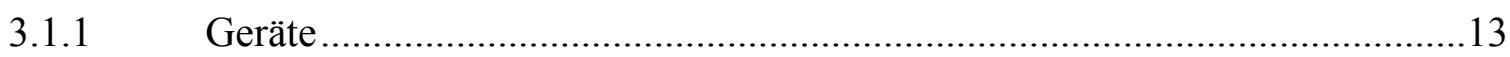

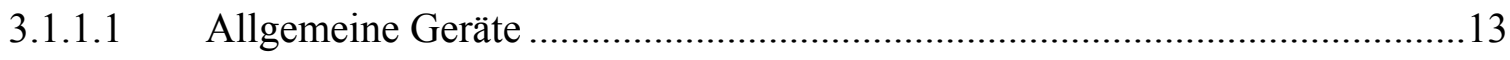

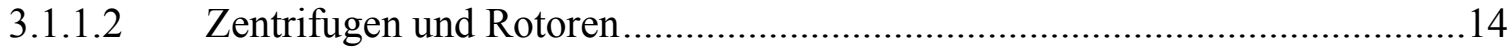

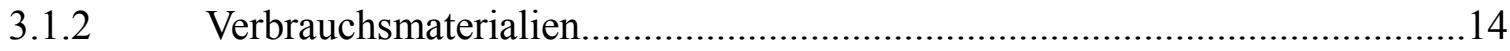

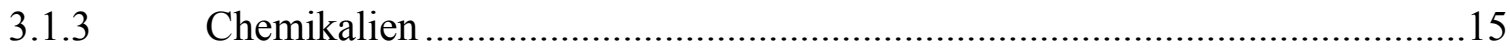

3.1.4 Kits zur Bearbeitung von DNA und Proteinen ..........................................20

3.1.5 Enzyme zum Bearbeitung von DNA, RNA und Proteinen...........................20

3.1.6 Proteaseinhibitoren und Proteinstandards .................................................2

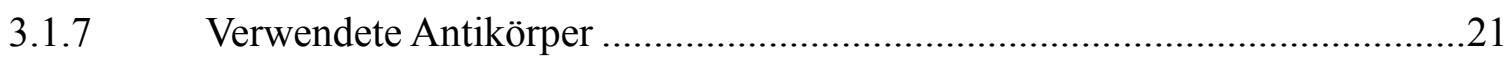

3.1.7.1 Sekundärantikörper für Western Blot Analyse.............................................21

3.1.7.2 Sekundärantikörper für Immunfluoreszenz ….........................................21

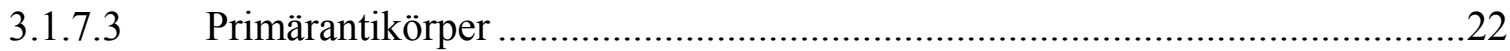




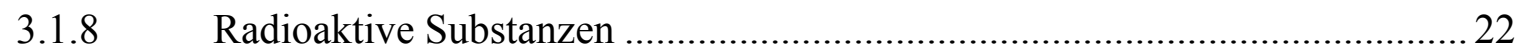

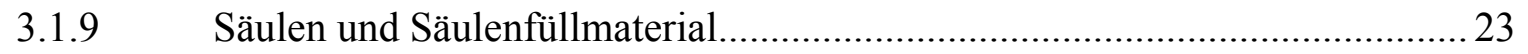

3.1.10 Vektoren, Oligonukleotidprimer und DNA-Standards ................................ 23

3.1.11 Häufig verwendete Puffer und Lösungen..................................................... 24

3.1.12 Medien zum Arbeiten mit Bakterienkulturen ................................................ 24

3.1.13 Verwendete Zellkulturmedien und Reagenzien..........................................25

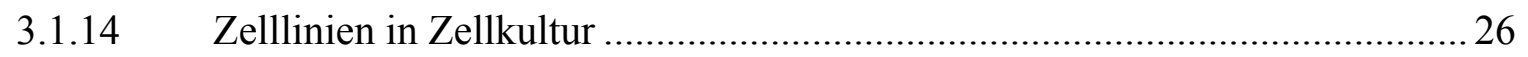

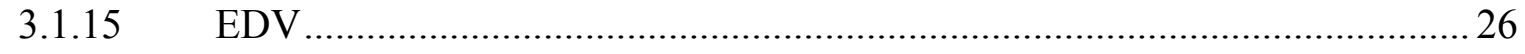

Molekularbiologische Methoden............................................................. 28

3.2.1 Allgemeine Methoden zum Arbeiten mit DNA und RNA ............................. 28

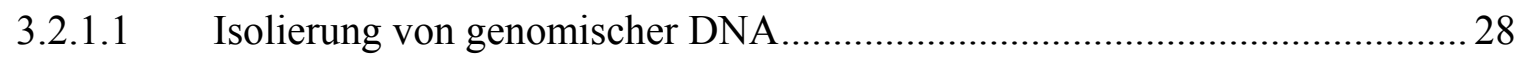

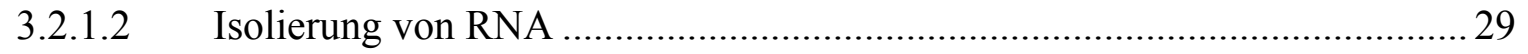

3.2.1.3 Konzentrationsbestimmung von DNA und RNA .........................................2 29

3.2.1.4 DNA-Amplifikation über Polymerase-Ketten-Reaktion............................... 29

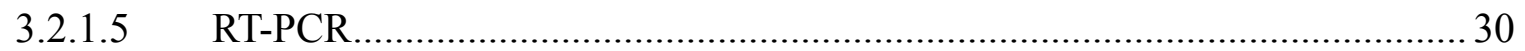

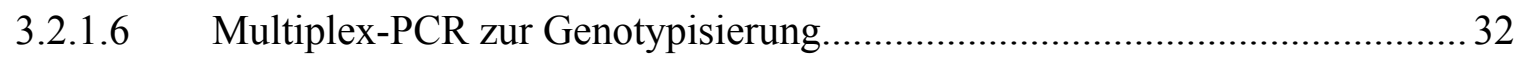

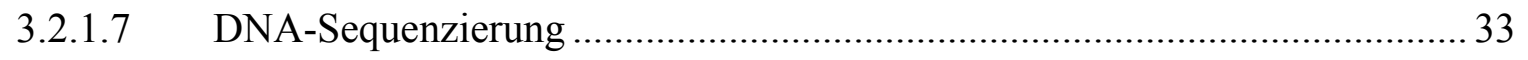

3.2.1.8 Spaltung von DNA mit Restriktionsendonukleasen ...................................... 33

3.2.1.9 Auftrennung von DNA in Agarosegelen .................................................... 34

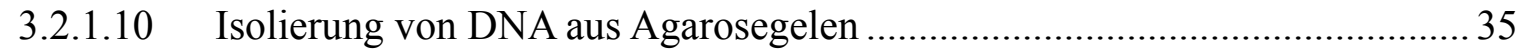

3.2.1.11 Auftrennung von RNA in Agarosegelen ..................................................... 35

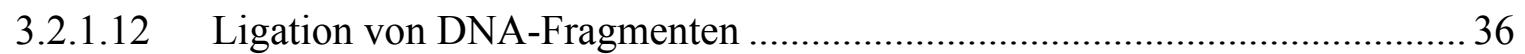

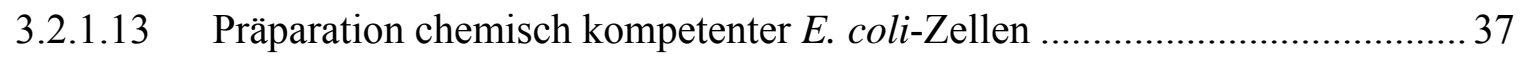

3.2.1.14 Transformation chemisch kompetenter E. coli-Zellen mit Plasmid-DNA ..... 37

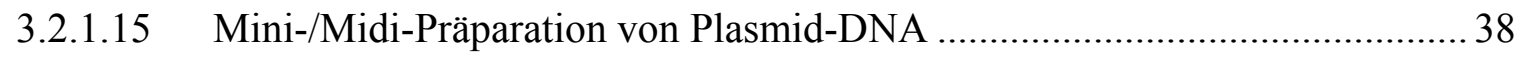

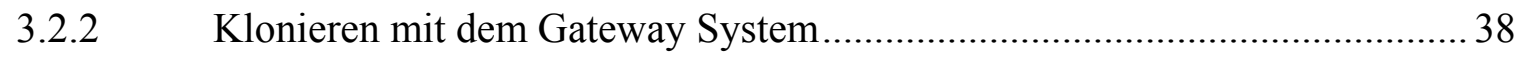

3.2.2.1 Insertion von cDNA durch BP-Rekombination........................................... 39

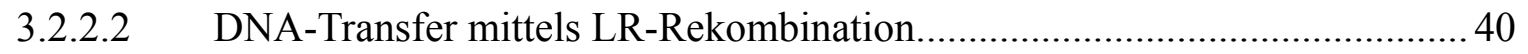

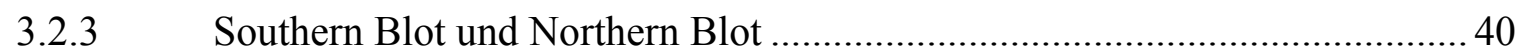

3.2.3.1 Transfer von DNA/RNA auf Hybond ${ }^{\mathrm{TM}}-\mathrm{N}$ Membranen .................................. 41

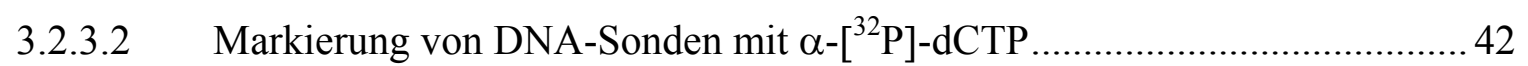


3.2.3.3 Hybridisierung der Blots mit radioaktiv markierten DNA-Sonden 43

3.3 Zellbiologische Methoden. .44

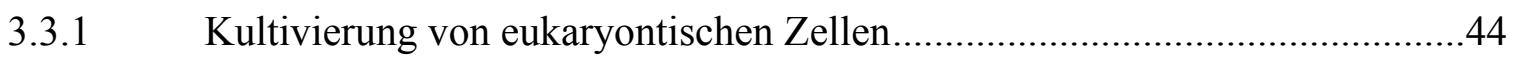

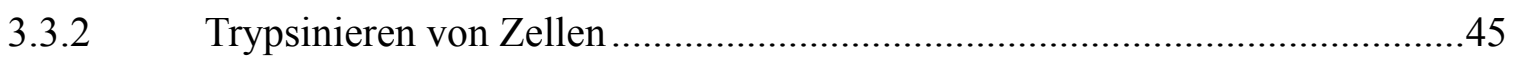

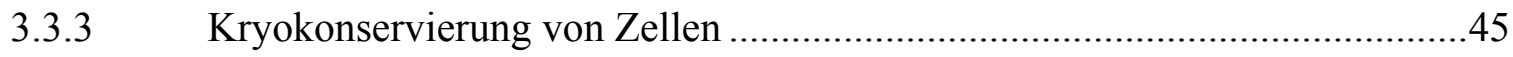

3.3.4 Auftauen und Revitalisieren von Zellen .....................................................45

3.3.5 Transfektion mit dem FuGENE ${ }^{\mathrm{TM}} 6$-Transfektionsreagenz ..........................46

3.3.6 Isolierung von Zellklonen nach stabiler Transfektion ................................46

3.3.7 Inkubation von Fibroblasten mit M6P-markierten Proteinen ........................47

3.3.8 Kultivierung von stabil transfizierten Zellen zur Ernte von rekombinanten

Proteinen aus Zellmedium ......................................................................4 47

3.3.9 Isolierung von mausembryonalen Fibroblasten (MEF) ..............................48

3.3.10 Kultivierung und mitotische Inaktivierung von Neomycin-resistenten

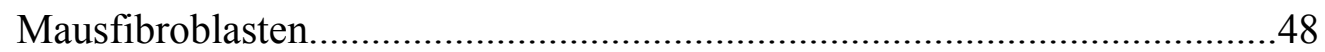

3.3.11 Kultivierung embryonaler Mausstammzellen..........................................49

Histochemische Methoden............................................................................50

3.4.1 Einbetten von Mausgewebe in Paraffin und Anfertigen von

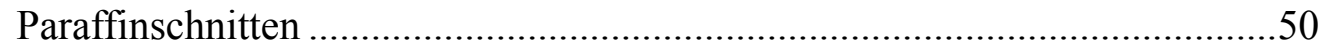

3.4.2 Hämatoxylin-Eosin-Färbung von Gewebeschnitten ...................................51

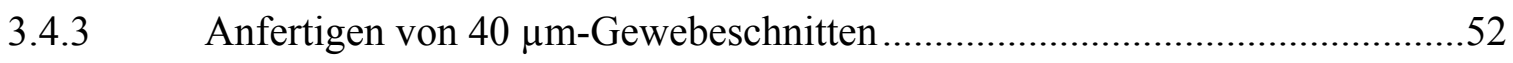

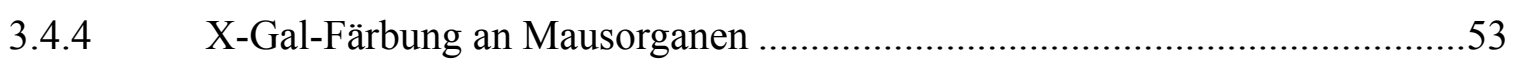

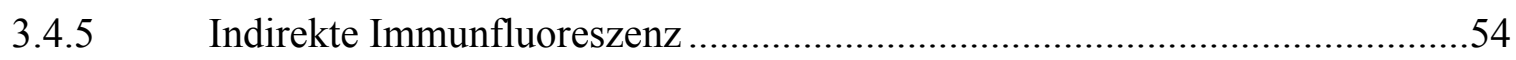

3.5 Proteinbiochemische Methoden...............................................................55

3.5.1 Aufreinigung von überexprimiertem Protein aus Zellkulturüberständen .......55

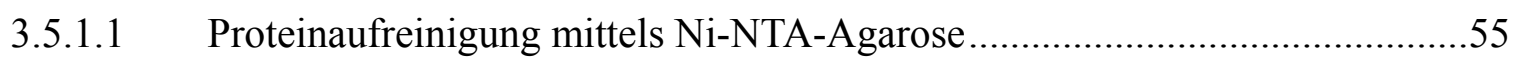

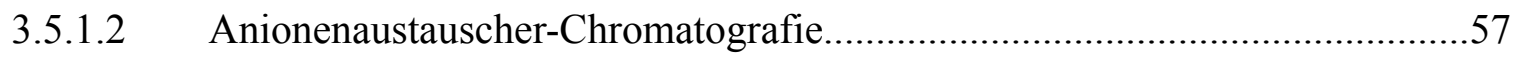

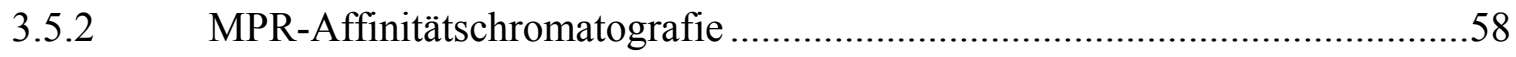

3.5.3 Gelfiltrationschromatografie lysosomaler Proteine ....................................60

3.5.4 Herstellung von Gewebe- und Zellhomogenaten .......................................61

3.5.5 Proteinkonzentrationsbestimmung mittels Bio-Rad DC Protein Assay (Mikroansatz) 


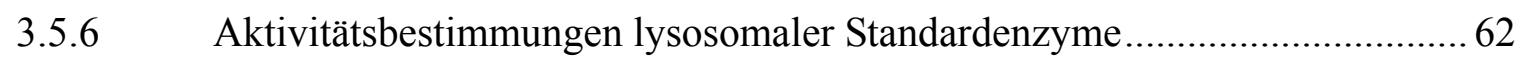

3.5.7 Aktivitätsbestimmung der lysosomalen Serincarboxypeptidasen ................... 64

3.5.8 Aktivitätsbestimmung der Succinatdehydrogenase ......................................6 65

3.5.9 Aktivitätsbestimmung der 5'AMPase und der Glucose-6-Phosphatase.......... 66

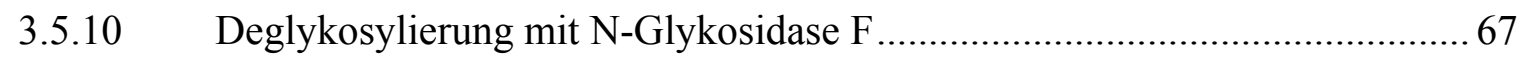

3.5.11 Anreicherung von Lysosomen Tyloxapol-behandelter Mäuse durch

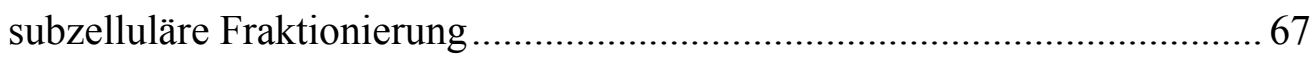

3.5.12 Untersuchung der Stabilität der lysosomalen Vesikel ................................... 69

3.5.13 Untersuchung der Lysosomen durch Percoll ${ }^{\mathrm{TM}}$-Dichtegradienten ................. 70

3.5.14 Metabolische Markierung von Proteinen (Pulse Chase) ................................ 71

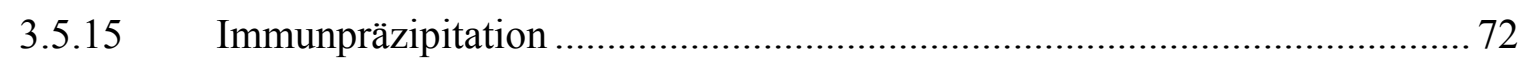

3.5.16 SDS-Polyacrylamid-Gelelektrophorese (SDS-PAGE) .................................. 74

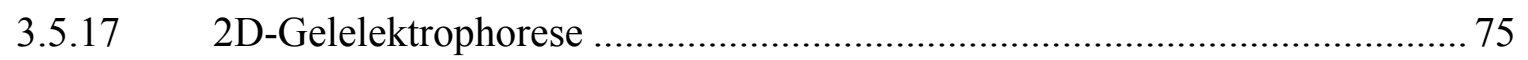

3.5.18 Färbung von Polyacrylamid-Gelen mit kolloidaler Coomassie-Lösung ......... 77

3.5.19 Färbung von Polyacrylamid-Gelen mit Silberfärbung .................................. 78

3.5.20 Western Blot Analyse (Semidry-Methode) ….............................................. 79

3.6 Tierexperimentelle Methoden .............................................................. 81

3.6.1 Immunisierung von Kaninchen und Ratten zur Generierung von Antiseren . 81

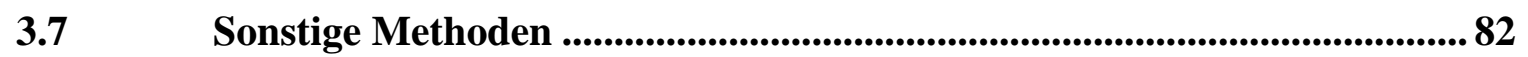

3.7.1 MALDI-TOF-MS Analyse zur Identifikation von Proteinen.......................... 82

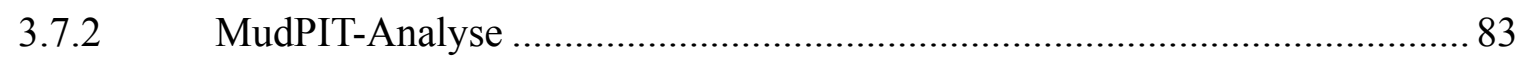

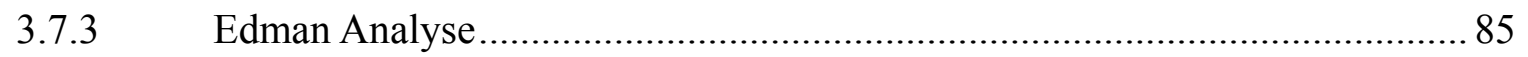

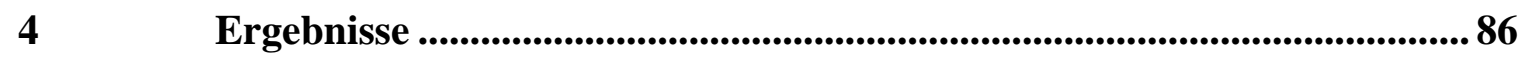

4.1 Proteomanalyse M6P-markierter Proteine ...................................................86 86

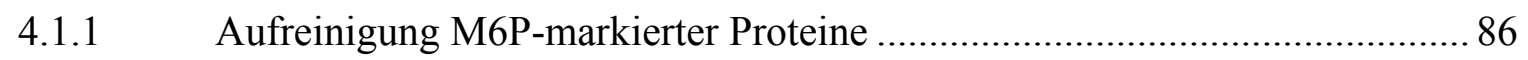

4.1.2 Identifizierung von M6P-markierten Proteinen durch 2D-Gelelektrophorese

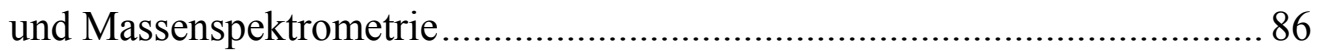

4.1.3 Identifizierung von M6P-haltigen Proteinen durch MudPIT-Analyse ............ 89

4.1.4 Generierung von cDNA der neu identifizierten Proteine .............................. 93

4.1.5 Expression der identifizierten Proteine in BKH Zellen und Analyse der M6P-Rezeptorbindung der exprimierten Proteine 
4.1.6 Internalisation der putativ lysosomalen Kandidatenproteine

in Fibroblasten

4.2 Bioinformatische Analyse der Scpep1 ................................................100

4.2.1 Das Scpep1-Gen aus Maus und seine Transkripte......................................100

4.2.2 Die Scpep1, eine Serincarboxypeptidase der Familie S10 ...........................101

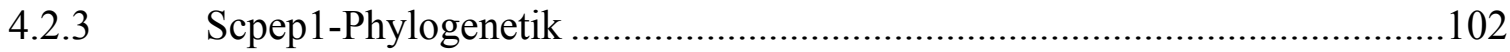

4.2.4 Sequenzvergleich von Scpep1 mit anderen Serincarboxypeptidasen...........104

4.3 Etablierung des Scpep1-Gene Trap Mausmodell RST426 .......................109

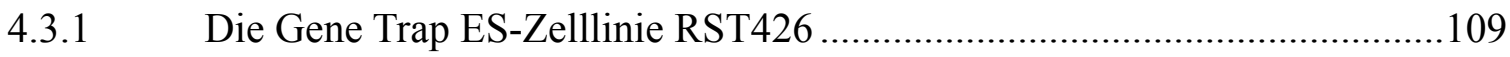

4.3.2 Generierung von Chimären durch Retransfer der transgenen ES-Zellen und Verpaarung der Nachkommen zur Etablierung des RST426 Mausstamms .. 111

4.3.3 Verifizierung des Scpep1-Gene Trap durch RT-PCR ................................... 112

4.3.4 Nachweis der Gene Trap Insertionsstelle durch PCR auf

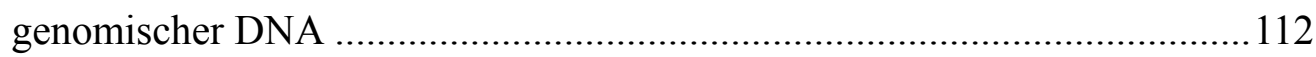

4.3.5 Genotypisierung des RST426 Mausmodells durch Southern Blot Analyse

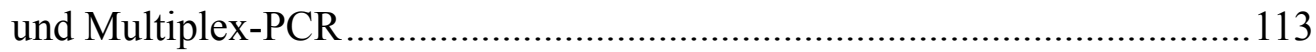

4.4 Lokalisation und Expression der Scpep1 ...........................................116

4.4.1 Aufreinigung des Scpep1-Proteins zu Herstellung von

$\alpha$-Scpep1-Antiseren

4.4.1.1 Zweistufige Aufreinigung des Scpep1-Proteins mittels Ni-NTA- und Ionenaustauscherchromatografie

4.4.2 Lysosomale Lokalisation des Scpep1-Proteins ........................................... 118

4.4.2.1 Immundetektion endogener Scpep1 in Fibroblasten.................................... 118

4.4.2.2 Nachweis der endogenen Scpep1 nach subzellulärer Fraktionierung............119

4.4.3 Untersuchung der Scpep1-Expression in Mausgewebe ................................123

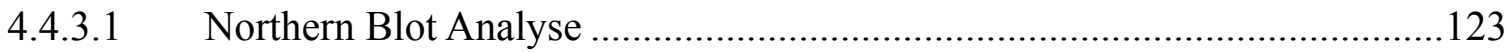

4.4.3.2 Western Blot Analyse der Scpep1-Proteinexpression in Gewebe..................124

4.4.3.3 Darstellung der Scpep1-Expression durch LacZ-Reportergenfärbung in Embryonen.

4.4.3.4 Darstellung der Scpep1-Expression durch Reportergenfärbung in adultem Gewebe 
4.5 Molekulare Charakterisierung der Scpep1 131

4.5.1 Nachweis der Scpep1-Proteinfragmente exprimiert in HT1080 131

4.5.2 N-Glykosylierung der Scpep1 exprimiert in HT1080 132

4.5.3 Biosynthese und Prozessierung der Scpep1 134

4.5.4 Inhibierung der Scpep1-Prozessierung durch $\mathrm{NH}_{4} \mathrm{Cl}$.................................. 135

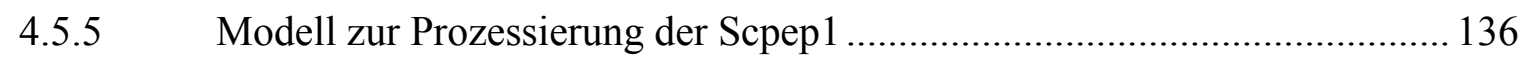

4.5.6 Analyse der endogenen Scpep1 durch Gelfiltration-Chromatografie ........... 138

4.6 Enzymatische Aktivität der Scpep1 ...................................................... 139

4.6.1 Untersuchung des rekombinanten Scpep1-Proteins auf Carboxypeptidase Aktivität.

4.6.2 Bestimmung der Serincarboxypeptidaseaktivität in Homogenaten von embryonalen Mausfibroblasten und Geweben Scpep1-defizienter Mäuse .. 140

4.7 Phänotypische Untersuchung Scpep1-defizienter (-/-) Mäuse ................ 143

4.7.1 Makroskopisches Erscheinungsbild der Scpep1-defizienten Mäuse............. 143

4.7.2 Verhalten von Scpep1-defizienten Mäusen ................................................. 143

4.7.3 Lichtmikroskopische Untersuchung von Scpep1-defizienten

Mausgeweben 144

4.7.4 Biochemische Analyse der Scpep1-defizienten Mausgewebe 144

4.7.4.1 Untersuchung der Lysosomenmorphologie aus Scpep1-defizientem Mausgewebe.

4.7.4.2 Bestimmung der Aktivität lysosomaler Enzyme in Geweben von

Scpep1-defizienten Mäusen

4.7.5 Untersuchungen am Blut Scpep1-defizienter Mäuse .

4.7.6 Untersuchungen am Urin Scpep1-defizienter Mäuse. 150

Diskussion. 154

5.1 Identifizierung von neuen lysosomalen Matrixproteinen durch Proteomanalyse....................................................................................................... 154

5.1.1 Analyse M6P-markierter Proteine durch 2D-GE und MudPIT.................... 154

5.1.2 Eigenschaften der vier Kandidatenproteine ............................................. 158

5.2 Molekulare und funktionelle Charakterisierung der Scpep1 .................. 160

5.2.1 Gewebespezifische Expression der murinen Scpep1 ................................. 160 
5.2.2 Biosynthese und Prozessierung der Scpep1 161

5.2.3 Funktionelle Inaktivierung der Scpep1 im Gene Trap Mausmodell RST426 163

5.2.4 Identifizierung der enzymatischen Aktivität der Scpep1 ..............................164

5.2.5 Scpep1-defiziente Mäuse zeigen keinen pathologischen Phänotyp..............167

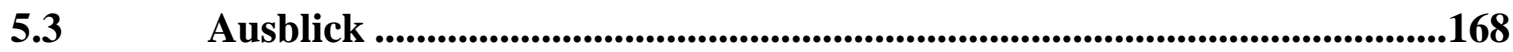

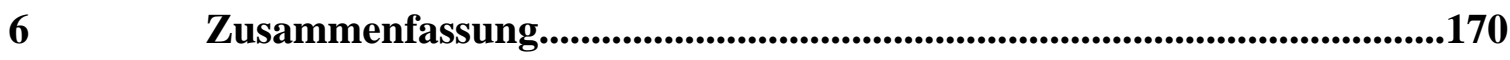

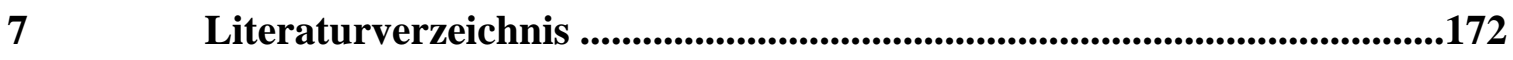

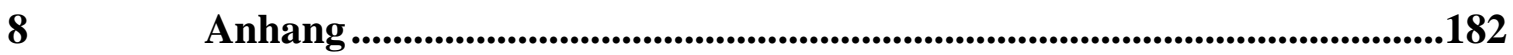

8.1 Ergebnisse der Proteomanalyse ...........................................................182

8.2 Primer zur Klonierung der Nukleotidsequenzen in den

Vektor pDONR221 ...............................................................................186

8.3 Primer zur weiteren Untersuchung der Scpep1 .....................................189

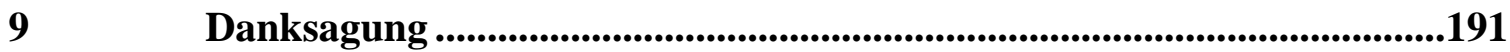




\section{Verzeichnis der Abkürzungen}

\begin{tabular}{|c|c|}
\hline Abb. & Abbildung \\
\hline AP & Adaptorprotein \\
\hline AS & Aminosäuren \\
\hline ATP & Adenosintriphosphat \\
\hline $\mathrm{bp}$ & Basenpaare \\
\hline bzw. & beziehungsweise \\
\hline${ }^{\circ} \mathrm{C}$ & Grad Celsius \\
\hline $\mathrm{CBZ}$ & Benzyloxycarbonyl \\
\hline cDNA & komplementäre DNA \\
\hline $\mathrm{Ci}$ & Curie $\left(2,22 \times 10^{6}\right.$ counts per minute $)$ \\
\hline cpm & counts per minute \\
\hline 2D-GE & 2D-Gelelektrophorese \\
\hline $\mathrm{dH}_{2} \mathrm{O}$ & destilliertes Wasser \\
\hline DMEM & Dulbecco's Modified Eagle Medium \\
\hline DNA & Desoxyribonukleinsäure \\
\hline dNTP & Desoxyribonukleotide \\
\hline E. coli & Escherichia coli \\
\hline ER & Endoplasmatisches Reticulum \\
\hline ERT & Enzymersatztheraphie \\
\hline ES & Embryonale Stammzellen \\
\hline ESI & Elektrospray-Ionisation \\
\hline et al. & et alii (lat. und andere) \\
\hline FKS & fötales Kälberserum \\
\hline G418 & Geneticin ${ }^{\circledR} 418$ \\
\hline Gal & Galactose \\
\hline \multirow[t]{2}{*}{ gi } & "GenInfo Identifier" \\
\hline & (sequence identification number in $\mathrm{NCBI}$ ) \\
\hline GlcNAc & N-Acetylglucosamin \\
\hline G6P & Glucose-6-Phosphat \\
\hline
\end{tabular}


h

HPLC

ID

IEF

$\mathrm{kb}$

$\mathrm{kDa}$

LB

LSD

M

MALDI

Man

$\mathrm{mA}$

MEF

$\min$

M6P

MPR

mRNA

MS

MudPIT

MW

neo

OD

PBS

PCR

$\mathrm{pH}$

pI

PNS

RER

RNA

rpm

RT

RT-PCR
Stunde(n)

High Performance Liquid Chromatography

Identifikationsnummer

Isoelektrische Fokussierung

Kilobasenpaare

Kilo Dalton

Luria Broth

Lysosomale Speichererkrankung

Molar

Matrix unterstützte Laser-Desorption/Ionisierung

Mannose

milli Ampere

Embryonale Mausfibroblasten

Minute(n)

Mannose-6 Phosphat

Mannose-6-Phosphat-Rezeptor

messenger RNA

Massenspektrometrie

multidimensional protein identification technology

Molekulargewicht

Neomycin

Optische Dichte

Phosphat-gepufferte Kochsalzlösung

Polymerase Ketten Reaktion

negativer dekadischer Logarithmus der

Protonenkonzentration

Isoelektrischer Punkt

postnukleärer Überstand

Raues Endoplasmatisches Reticulum

Ribonukleinsäure

Umdrehungen pro Minute

Raumtemperatur

Reverse Transkriptase-PCR 


$\begin{array}{ll}\text { SDS-PAGE } & \text { SDS-Polyacrylamidgelelektrophorese } \\ \text { SSC } & \text { Standard Saline Citrate } \\ \text { Tab. } & \text { Tabelle } \\ \text { Taq } & \text { Thermophilus aquaticus } \\ \text { TBS } & \text { Tris-gepufferte Kochsalzlösung } \\ \text { TE } & \text { Tris-EDTA } \\ \text { TGN } & \text { Trans-Golgi-Netzwerk } \\ \text { TOF } & \text { time of flight } \\ \text { U } & \text { Unit } \\ \text { UDP } & \text { Uridindiphosphat } \\ \text { usw. } & \text { und so weiter } \\ \text { UV } & \text { ultraviolett } \\ \text { UZ } & \text { Ultrazentrifuge } \\ \text { V } & \text { Volt } \\ \text { Vol. } & \text { Volumen } \\ \text { v/v } & \text { Volumenverhältnis } \\ \text { WT } & \text { Wildtyp } \\ \text { w/v } & \text { Gewicht zu Volumen } \\ \times \text { g } & \times \text {-fache Erdbeschleunigung } \\ \text { z. B. } & \text { zum Beispiel } \\ \text { ZNS } & \text { Zentrales Nervensystem }\end{array}$

Die chemischen Elemente wurden mit den üblichen Symbolen abgekürzt. Die Aminosäuren wurden entweder im Drei- oder Einbuchstabencode angegeben.

Bei einigen Begriffen wurden die englischen Fachtermini verwendet, wie Blot, Insert, Template usw., da auch in der deutschen Fachliteratur eine Übersetzung dieser Begriffe unüblich und unzureichend ist. 


\section{$1 \quad$ Einleitung}

\subsection{Lysosomen}

Die intrazelluläre Kompartimentierung ist ein Hauptmerkmal eukaryontischer Zellen und dient der Abtrennung unterschiedlicher Funktionsräume, den sogenannten Organellen. Lysosomen stellen solche membranumschlossene Organellen dar und zeichnen sich insbesondere durch die terminale Degradation von Makromolekülen wie Polysacchariden, Proteinen, Nukleinsäuren und Lipiden aus (de Duve 1969; Kornfeld und Mellman 1989). Neben seiner klassischen, katabolen Funktion ist das lysosomale Kompartiment zudem an einer Vielzahl von spezialisierten, zellulären Funktionen beteiligt, z. B. an der Antigenpräsentation mittels MHC II Komplexen (Geuze 1998), an der Regulation von Hormonen und Wachstumsfaktoren (Brix et al. 2001), sowie am Knochenumbau (Saftig et al. 2000).

Das Lysosom enthält mehr als 50 hydrolytische Enzyme, wie Proteasen, Nukleasen, Glykosidasen, Lipasen, Phospholipasen, Phosphatasen und Sulfatasen, deren pH-Optimum im sauren Bereich liegt (Ohkuma und Poole 1978). Im Lumen der Lysosomen wird durch eine membrangebundene, ATP-getriebene Protonenpumpe (V-Typ $\mathrm{H}^{+}$-ATPase) ein entsprechender $\mathrm{pH}$ von 5 aufrecht erhalten (Cuppoletti et al. 1987). Zellfremde, abzubauende Makromoleküle werden von der Zelle durch Phagozytose oder Endozytose aufgenommen und $\mathrm{zu}$ den Lysosomen transportiert. Bei der Endozytose werden extrazellulär lokalisierte Makromoleküle über Clathrin-umhüllte Vesikel internalisiert (de Duve 1983) und über die frühen und späten Endosomen zu den Lysosomen transportiert (Schmid et al. 1988). Die Phagozytose wird überwiegend durch Zellen des unspezifischen Immunsystems wie Makrophagen und Granulozyten genutzt. Dabei werden Bakterien, Zellreste und andere Fremdpartikel zumeist nach der Opsonierung mit Immunglobulinen als Phagosom von dem Phagozyten eingeschlossen und nach der Verschmelzung mit Lysosomen abgebaut (Haas 2007). Der Abbau zelleigener zytosolischer Makromoleküle erfolgt indes über zwei Systeme, die Ubiquitinvermittelte Proteolyse am Proteasom (Rechsteiner 1991; Hershko und Ciechanover 1992) 
und die Autophagozytose. Bei der Autophagozytose wird zytoplasmatisches Material durch die Bildung von Membranen in autophagozytotischen Vakuolen eingeschlossen (De Duve und Wattiaux 1966; Meijer und Codogno 2004). Diese verschmelzen direkt mit den Lysosomen (Lawrence und Brown 1992) oder reifen schrittweise durch Fusion mit endosomalen Vesikeln zu sogenannten Amphisomen heran (Stromhaug und Seglen 1993; Liou et al. 1997).

Die lysosomale Membran ist durch einen hohen Gehalt an hoch glykosylierten Membranproteinen charakterisiert, die die Lysosomen vor Degradation durch die eigenen Hydrolasen schützen und somit für deren Integrität wichtig sind. Andere Membranproteine vermitteln die Interaktion der Lysosomen mit sich und anderen Membransystemen wie Endosomen, Autophagosomen und der Plasmamembran (Fukuda 1991; Peters und von Figura 1994; Hunziker und Geuze 1996). Darüber hinaus verlassen monomere Abbauprodukte wie Aminosäuren, Fettsäuren, Kohlenhydrate und Nukleoside die Lysosomen durch spezifische Transportkanäle in der lysosomalen Membran (von Figura und Hasilik 1986; Kornfeld und Mellman 1989) und stehen im Cytosol zum Aufbau neuer Makromoleküle zur Verfügung.

\subsection{Synthese und Transport löslicher lysosomaler Proteine}

\subsubsection{Biosynthese und N-Glykosylierung löslicher lysosomaler Proteine}

Die Biosynthese von Vorläuferproteinen löslicher lysosomaler Enzyme und sekretorischer Proteine erfolgt an membranständigen Ribosomen des rauen endoplasmatischen Reticulums (ER). Die Proteine besitzen hydrophobe, etwa 15 - 30 Aminosäuren lange, aminoterminale Signalsequenzen, die die kotranslationale Translokation der Polypeptidketten in das ER-Lumen initiieren (Walter und Johnson 1994). Im ER erfolgt die kotranslationale Modifikation der naszierenden Polypeptide, wobei das Signalpeptid abgespalten wird und das Peptid durch die N-glykosidische Bindung von Oligosacchariden an Asparaginresten glykosyliert wird. Die modifizierten Asparaginreste sind in der Erkennungssequenz Asn-X-Ser/Thr lokalisiert (X: alle Aminosäuren außer Prolin) (Shakin-Eshleman et al. 1996). Die Oligosaccharidgruppen werden vor der Übertragung auf die Polypeptide an dem Lipid-Träger Dolichol-Phosphat aufgebaut und 
bestehen aus zwei N-Acetylglucosamin-, neun Mannose-, und drei Glucoseresten (Kornfeld und Kornfeld 1985). Vor dem Verlassen des ERs werden die drei terminalen Glucosereste und ein Mannoserest durch die membranständigen Enzyme ER-Glucosidase I und II, sowie die $\alpha$-Mannosidase I (Lemansky et al. 1984; Kornfeld und Kornfeld 1985) abgespalten. Die Lektine Calnexin und Calreticulin binden an die neu synthetisierten, monoglykosylierten Proteine und halten diese bis zu ihrer korrekten Faltung im ER zurück (Helenius und Aebi 2001). Einige lysosomale Vorläuferproteine erhalten im ER zusätzliche, spezifische Modifikationen, die für ihre Funktion essenziell sind. So wird z. B. bei Mitgliedern der Sulfatase-Familie im ER ein stark konservierter Cysteinrest zu einem C $\alpha$-Formylglycinrest (FGly) oxidiert (von Figura et al. 1998). Die Reaktion wird durch das Formylglycin-generierende Protein (FGE) katalysiert und ist für die enzymatische Aktivität der Sulfatasen essenziell, so dass Mutationen des FGE zur Multiplen Sulfatase Defizienz (MSD) führen (Cosma et al. 2003; Dierks et al. 2003). Die lysosomalen Enzyme gelangen vom ER über Transportvesikel in den Golgi-Apparat, in dem beim Prozess des Trimmings die N-Glykane weiter modifiziert werden, wobei jedoch stets ein Pentasaccharid-Kern (GlcNAc-GlcNAc-Man3) unverändert bleibt (Kornfeld und Kornfeld 1985).

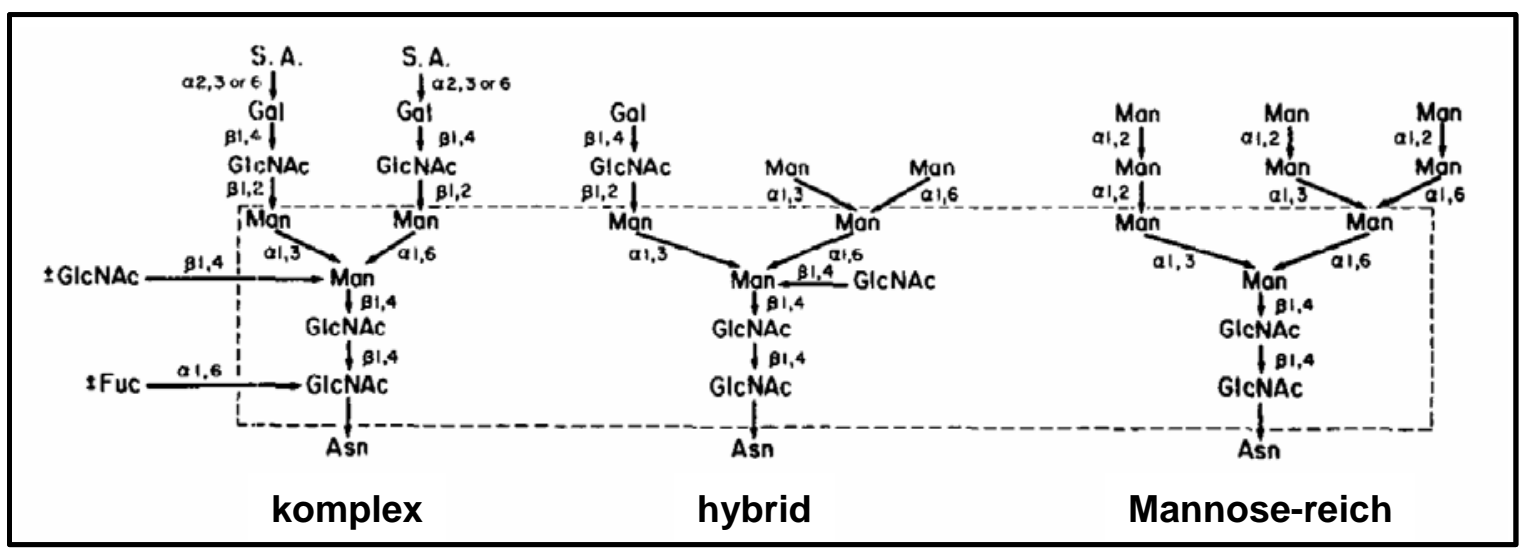

Abb. 1.1: Primärstruktur von komplexen, hybriden und Mannose-reichen N-gekoppelten Oligosacchariden

Der umrahmte Bereich umfasst den allen N-Oligosacchariden gemeinsamen Pentasaccharid-Kern, (nach Kornfeld und Kornfeld 1985). 
Die N-Glykane lysosomaler Enzymen werden vor allem zu Mannose-reichen Oligosacchariden mit endständigen Mannoseresten prozessiert und seltener zu N-Glykanen des hybriden oder komplexen Typs, während die N-Glykane sekretorischer Proteine hauptsächlich zu komplexen Oligosaccharidtypen prozessiert werden, die durch den Gehalt zusätzlicher N-Acetylglucosamine, Galactose und Sialinsäure, sowie durch ihre Fucosylierbarkeit charakterisiert sind (von Figura und Hasilik 1986; Kornfeld und Mellman 1989). Dies hängt mit der Synthese der M6P-Reste an den Oligosaccharidenketten zusammen, da diese die weitere Prozessierung der Oligosaccharide zum komplexen Typ verhindern.

\subsubsection{Synthese von Mannose-6-phosphat-Resten an N-Glykanen löslicher lysosomaler Proteine}

Der Transport der neu synthetisierten, löslichen lysosomalen Proteine in das endosomale/lysosomale Kompartiment ist von einer Mannose-6-phosphat (M6P)Modifikation der Mannose-reichen Oligosaccharid-Seitenketten abhängig. Die Synthese dieses Sortierungssignals erfolgt in zwei Stufen (Lazzarino und Gabel 1988). Durch die Golgi-N-Acetylglucosamin-1-phosphotransferase (EC 2.7.8.17, kurz: GNPT) wird zunächst im Cis-Golgi ein N-Acetylglucosamin-1-phosphatrest von UDP-N-Acetylglucosamin auf die C6-Hydroxylgruppe eines Mannoserests Mannose-reicher Oligosaccharide übertragen (Reitman und Kornfeld 1981b; Waheed et al. 1982). Es entsteht ein GlcNAc-1-phospho-6-mannose-diester, der anschließend durch die N-Acetylglucosamin-1-phosphodiester- $\alpha-\mathrm{N}$-Acetylglucosaminidase (EC 3.1.4.45, kurz: uncovering enzyme, UCE) im Trans-Golgi-Netzwerk (TGN) zu einem Phospho-6mannose-monoester hydrolysiert wird (Varki und Kornfeld 1980). Die GNPT besteht aus einem heterohexameren Komplex $\left(\alpha_{2} \beta_{2} \gamma_{2}\right)$, wobei die enzymatische Aktivität des Enzyms von den $\alpha$ - und $\beta$-Untereinheiten des Proteins und die Erkennung lysosomaler Enzyme von der $\gamma$-Untereinheit vermittelt wird (Kornfeld 2000). Defekte der GNPT führen aufgrund der Fehlsortierung lysosomaler Hydrolasen $\mathrm{zu}$ den lysosomalen Speichererkrankungen Mucolipidosis II (ML II, I-cell disease) und Pseudo-Hurler Polydystrophy (ML III) (Reitman et al. 1981; Raas-Rothschild et al. 2000; Tiede et al. 2005). Die Spezifität der Phosphorylierung lysosomaler Enzyme wird durch die GNPT 
vermittelt. Sie phosphoryliert lysosomale Enzyme etwa 100-fach effizienter als nicht lysosomale Proteine, die identische Mannose-reiche Oligosaccharide tragen (Reitman und Kornfeld 1981a). Die Identifizierung der lysosomalen Proteine ist dabei von der nativen Faltung der Proteine abhängig (Lang et al. 1984). Das Erkennungssignal besteht vermutlich aus einem dreidimensionalen Strukturmotiv aus zwei bis drei Lysinresten (Tikkanen et al. 1997).

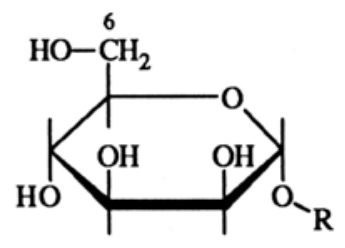

1

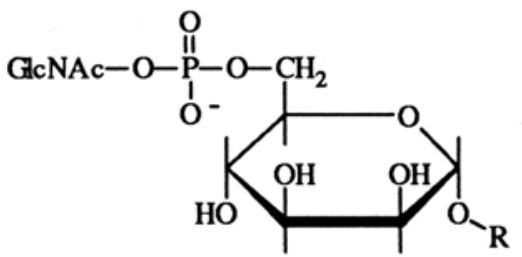

2
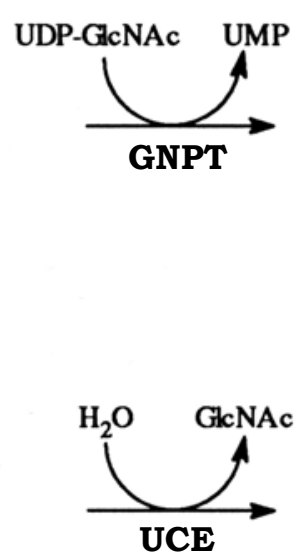

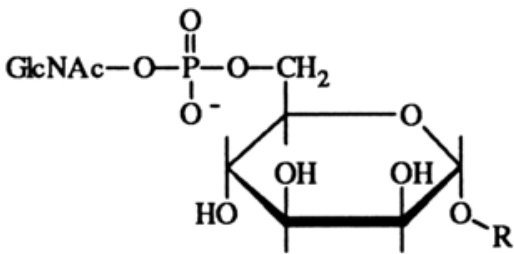

2

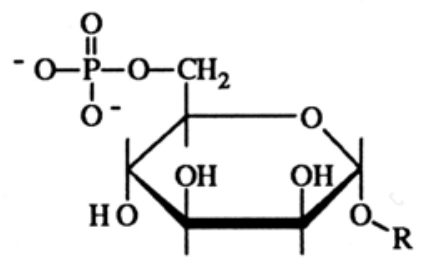

3

Abb. 1.2: Reaktionsschema zur Synthese von M6P-Resten durch die GNPT und das UCE

1: $\alpha$-D-Mannose an Mannose-reicher Oligosaccharid-Seitenkette (R), 2: GlcNAc-1-phospho-6-mannosediester, 3: Phospho-6-mannose-monoester

\subsubsection{Mannose-6-phosphat-Rezeptor-vermittelte Sortierungswege löslicher lysosomaler Proteine}

Die M6P-markierten lysosomalen Vorläuferproteine werden im TGN von zwei membranständigen Mannose-6-Phosphat-Rezeptoren (MPR) gebunden und durch die Abschnürung Clathrin-umhüllter Vesikel zu den Endosomen transportiert (Hoflack und Kornfeld 1985; von Figura und Hasilik 1986; Ghosh et al. 2003). Nach dem Verlust der Clathrin-Hülle verschmelzen die Vesikel mit der endosomalen Membran (Lemansky et al. 1987). Im Endosomen erfolgt aufgrund des niedrigen $\mathrm{pHs}(\mathrm{pH} 6)$ die Dissoziation von MPR und Protein mit anschließender Rezyklierung der MPRs zum Golgi-Komplex oder 
zur Plasmamembran (Dahms et al. 1989). Beide MPRs sind im TGN, in den frühen und späten Endosomen, sowie auf der Plasmamembran lokalisiert, jedoch nicht in den Lysosomen, so dass die Lysosomen als Organellen ohne MPR definiert sind (Kornfeld und Mellman 1989). Die MPRs sind Typ I integrale Membranglykoproteine mit einem apparenten Molekulargewicht von $300 \mathrm{kDa}$ (MPR300) bzw. $46 \mathrm{kDa}$ (MPR46). Die zytoplasmatisch lokalisierten C-Termini beider MPRs enthalten Sortierungssignale, die für den spezifischen Transport zwischen den Zellkompartimenten verantwortlich sind und von zytosolischen Adaptorproteinen (AP) erkannt werden (Ghosh et al. 2003). M6Phaltige Proteine werden über die glykosylierte, luminale Domäne der MPRs gebunden. Dies geschieht im Falle des MPR300 Kationen-unabhängig, wobei der MPR300 als Monomer vorliegt und neben M6P-haltigen lysosomalen Proteinen, Retinsäure und den nicht-glykosylierten IGF II (insulin-like growth factor II) aus dem Extrazellulärraum bindet (Sahagian et al. 1981; Steiner und Rome 1982; Morgan et al. 1987). Der MPR46 hingegen bindet seine M6P-haltigen Liganden Kationen-abhängig in homodimerer Form im Verhältnis 2 Mol M6P je Mol MPR-Dimer (Hoflack und Kornfeld 1985; Tong et al. 1988). Adaptorproteinkomplexe binden Clathrin und vermitteln die Konzentrierung und Verpackung der lysosomalen Membranproteine in Transportvesikel (Ahle und Ungewickell 1989; Scales et al. 2000). Der Transport der MPR vom TGN zu den Endosomen wird von dem Adaptorprotein AP-1 vermittelt, wohingegen die Endozytose der MPR von der Plasmamembran von dem Protein AP-2 abhängt (Ghosh et al. 2003). Die lysosomalen Vorläuferproteine werden zu den Lysosomen weitertransportiert (Luzio et al. 2007), wobei die Vorläuferproteine der lysosomalen Enzyme durch limitierte Proteolyse zu aktiven lysosomalen Hydrolasen reifen (Hasilik 1992), und das M6PSortierungssignale von den Proteinen entfernt wird (Einstein und Gabel 1991). Etwa $10 \%$ der M6P-markierten lysosomalen Enzyme entgehen im TGN dem AP-1abhängigen, spezifischen Transport zu den Endosomen und werden sezerniert. Diese fehlsortierten M6P-markierten Proteine können an der Plasmamembran durch den MPR300 gebunden, endozytiert und anschließend dem endosomalen/lysosomalen Sortierungsweg zugeführt werden. Der MPR46 ist hingegen nicht in der Lage M6Phaltige Liganden bei der Internalisation an der Plasmamembran zu endozytieren (Stein et al. 1987). 


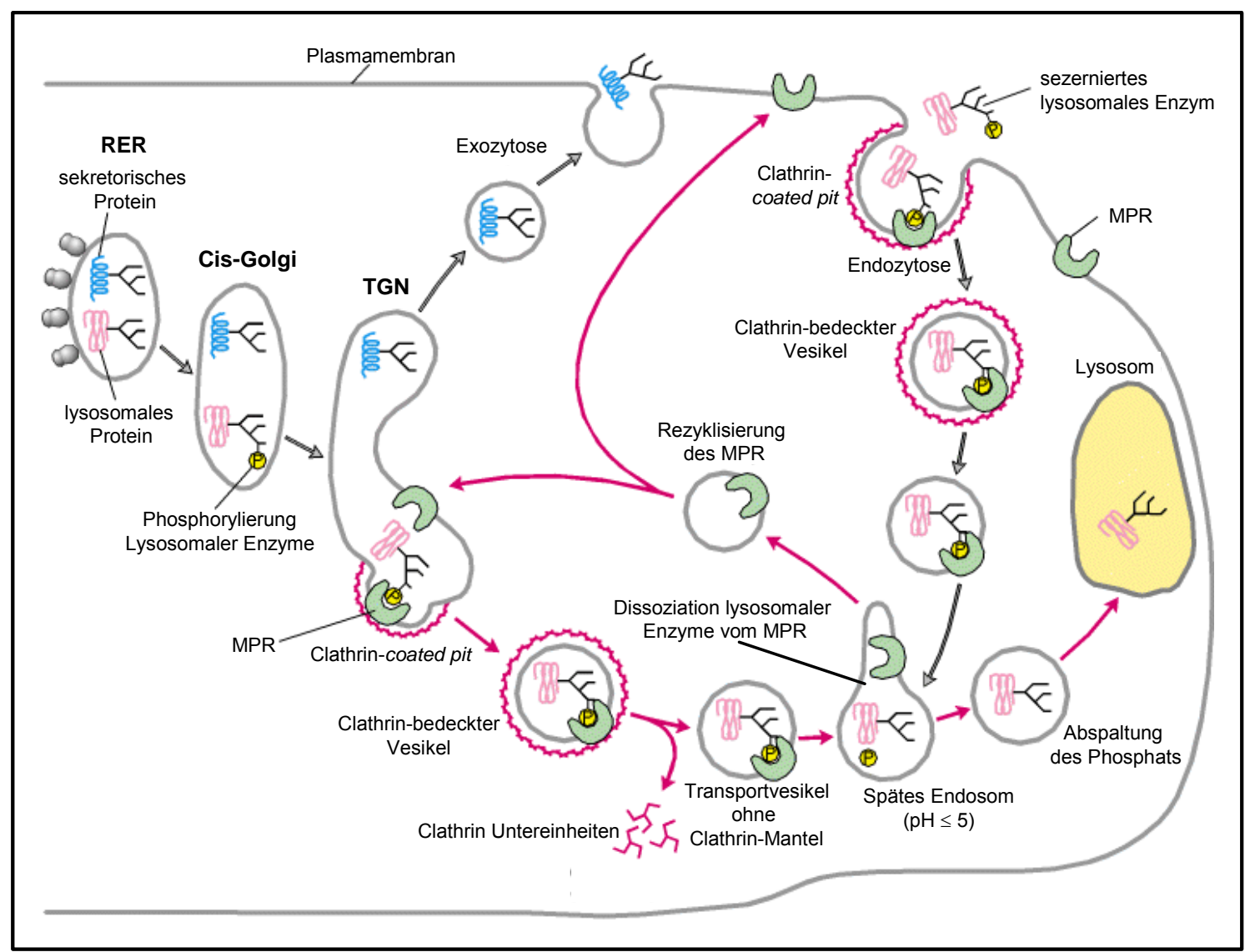

Abb. 1.3: Schematische Darstellung des MPR-vermittelten Transports lysosomaler Enzyme

Lysosomale Enzyme können mehrere Oligosaccharide tragen, die ein- oder zweimal mit M6P substituiert sind. Von den beiden MRPs MPR46 und MPR300 kann nur der MPR300 phosphorylierte Liganden endozytieren. Nach dem Verlust der Clathrin-Hülle verschmelzen die Vesikel mit den frühen Endosomen (modifiziert nach Darnell et al. 1995, S. 768).

\subsubsection{MPR-unabhängiger Transport}

Die MPRs sind für den spezifischen Transport lysosomaler Enzyme zu ihrem Bestimmungsort von großer Bedeutung. Studien an Patienten mit ML II und ML III, sowie an MPR-defizienten Mäusen und Zellen zeigten, dass einige Enzyme MPRunabhängig zu den Lysosomen gelangen. In Fibroblasten von ML II-Patienten ist die Aktivität einiger lysosomaler Enzyme erwartungsgemäß stark erniedrigt. Von anderen Enzymen findet man hingegen unerwartet hohe Aktivitäten im Lysosom, obwohl die neu synthetisierten lysosomalen Enzyme keine M6P-Modifikation erhalten (Waheed et al. 1982). Der Transport der membranassoziierten Proteine $\beta$-Glucocerebrosidase (Pohlmann et al. 1988; Waheed et al. 1988) und $\beta$-D-Galactocerebrosidase und der 
membranverankerten lysosomalen sauren Phosphatase (LAP) (Braun et al. 1989) erfolgt völlig MPR-unabhängig. Diese Hinweise sprechen für einen alternativen Transportmechanismus einiger lysosomaler Enzyme. Ein alternativer Transportweg für die $\beta$-Glucocerebrosidase wurde von Reczek et al. gefunden (Reczek et al. 2007). Dieses lysosomale Matrixprotein bindet das lysosomale, integrale Membranprotein LIMP-2 über ein Coil-Coiled-Strukturmotiv und wird mit dem LIMP-2 Protein zum Lysosom transportiert.

Auch lysosomale Membranproteine sind nicht M6P-modifiziert und gelangen unabhängig von ihrer N-Glykosylierung in das lysosomale Kompartiment (Fukuda 1991). Der Transport der Membranproteine erfolgt hauptsächlich über einen direkten, intrazellulären Weg. Vom TGN werden die Membranproteine getrennt von den MPRs in Clathrinumhüllten Transportvesikel zu den Endosomen transferiert (Hunziker und Geuze 1996; Honing et al. 1998). Als Sortierungssignale wurde bei den Proteinen LAMP-1, LAMP-2 und LIMP-1 ein Tyrosin-Motiv und bei LIMP-2 ein Dileucin-Motiv im zytoplasmatischen Ende der Membranproteine identifiziert (Peters und von Figura 1994). Einige Membranproteine, wie die LAP, werden indirekt zu den Lysosomen transportiert, wobei das Vorläuferprotein vom TGN erst zur Plasmamembran und dann durch AP-2 vermittelte Endozytose über die Endosomen zu den Lysosomen gelangt (Braun et al. 1989; Prill et al. 1993).

\subsection{Lysosomale Speicherkrankheiten}

Die lysosomalen Speicherkrankheiten (LSD) sind eine Gruppe von über 40 Erkrankungen, die durch die Akkumulation von nicht abgebauten Substraten in den Lysosomen charakterisiert sind (Gieselmann 1995; Futerman und van Meer 2004; Vellodi 2005). Lysosomale Speichererkrankungen werden hauptsächlich durch den Defekt einzelner, lysosomaler Hydrolasen verursacht. Jedoch können auch Defekte von ProteinKofaktoren, wie Enzymaktivatoren (z. B. Saposine, sphingolipid activator proteins) oder Proteinstabilisatoren (z. B. PPCA, protective protein/cathepsin A), Defekte von Transportproteinen (z. B. Sialin (Sialinsäure-Transporter)) und nicht lysosomalen Proteinen, die an der posttranslationalen Modifizierung (z.B. GNPT, siehe 1.2.2), oder der Aktivierung der neu synthetisierten, lysosomalen Proteine (z. B. FGE, siehe 1.2.1) 
beteiligt sind, zu lysosomalen Erkrankungen führen. Die Akkumulation der nicht abgebauten Makromoleküle führt zur Bildung von großen Speichervakuolen und letztendlich zu Fehlfunktionen der Zellen und der Gewebe. In Abhängigkeit von der Verteilung und der Menge des gespeicherten Substrates sind meist eine Reihe unterschiedlicher Organe betroffen.

Das klinische Erscheinungsbild der lysosomalen Speichererkrankungen ist aufgrund der unterschiedlichen Ätiologien sehr heterogen und auch bei der einzelnen Erkrankung unterscheidet man verschiedene Schweregrade. Der Verlauf ist jedoch stets progredient. Charakteristische Symptome sind Dysfunktionen des zentralen und peripheren Nervensystems, Skelettdysplasien und die Vergrößerung viszeraler Organe.

Die Möglichkeit lysosomale Enzyme durch rezeptorvermittelte Endozytose in die Lysosomen zu transportieren, erlaubt die Therapie von LSDs durch die Substitution des defekten Enzyms. Mit einer solchen Enzymersatztherapie (ERT) wurden in den neunziger Jahren zunächst Patienten mit einer milden Form der Gaucher Erkrankung erfolgreich behandelt, was die Entwicklung weiterer ERT vorantrieb. In den letzten Jahren konnte neben der enzymatischen, auch die molekulare Ursache für viele lysosomale Speichererkrankung identifiziert werden, was wiederum die Therapie dieser Erkrankungen durch gentherapeutische Ansätze ermöglicht.

\subsection{Proteomanalyse lysosomaler Proteine}

Der Begriff "Proteom" wurde 1995 von M.R. Wilkins in Analogie zu den Begriffen Genom und Transkriptom geprägt und beschreibt die Gesamtheit aller Proteine, die unter definierten Bedingungen in einem definierten Bereich wie z. B. einem Organismus, einem Gewebe, einer Zelle oder einem Zellorganell existieren (Wasinger et al. 1995; Wilkins et al. 1996).

Die Untersuchung des Proteoms eines Zellorganells erfordert eine effektive Aufreinigung der organell-spezifischen Proteine. Im Fall der lysosomalen Matrixproteine kann man sich die spezifische, posttranslationale M6P-Modifikation zu Nutze machen. Mit Hilfe von immobilisierten MPRs können M6P-markierte Proteine affinitätschromatografisch aus komplexen Proteinlösungen isoliert werden (Hoflack et al. 1987). Da die M6P- 
Markierung jedoch nach dem Transport der Proteine in das endosomale Kompartiment abgespalten wird, müssen die M6P-markierten Proteine vor der Bindung an die endogenen MPRs isoliert werden. Journet et al. (Journet et al. 2002) behandelten dazu humane U937 Zellen in Zellkultur mit Ammoniumchlorid $\left(\mathrm{NH}_{4} \mathrm{Cl}\right) . \mathrm{NH}_{4} \mathrm{Cl}$ führt zur Erhöhung des endosomalen/lysosomalen $\mathrm{pH}$-Werts auf $\mathrm{pH}$ 6,0 bis $\mathrm{pH}$ 6,3, wodurch die Dissoziation M6P-markierter Proteine von den M6P-Rezeptoren im späten Endosomen blockiert wird (Braulke et al. 1987). Dies führt wiederum dazu, dass alle MPRs besetzt bleiben und neu synthetisierte M6P-markierte Proteine sezerniert werden. Die M6P-markierten Proteine können anschließend aus dem Zellmedium aufgereinigt werden. Zur Gewinnung der M6P-markierten Proteine können zudem embryonale Mausfibroblasten (MEF) verwendet werden, die aufgrund des gezielten Ausschaltens der Gene für den MPR300 und MPR46 M6P-markierte Proteine nicht zum endosomalen/lysosomalen Kompartiment transportieren, sondern die Proteine konstitutiv sezernieren (Dittmer et al. 1998).

Da lysosomale Membranproteine kein einheitliches Sortierungssignal besitzen, werden für ihre Isolierung konventionelle Aufreinigungsverfahren eukaryontischer Zellorganellen, wie die subzelluläre Fraktionierung mittels differentieller Zentrifugation (De Duve et al. 1955) und die Dichtegradientenzentrifugation, genutzt. Um die Lysosomen dabei von anderen Organellen, insbesondere von den Mitochondrien zu trennen, wurden Methoden entwickelt, die die Dichte und Größe und somit das Sedimentationsverhalten der Lysosomen beeinflussen. Substanzen wie Tyloxapol (Triton WR 1339) und Dextran werden von den Zellen endozytiert und zu den Lysosomen transportiert (Bowers und de Duve 1967). Dadurch wird die lysosomale Dichte reduziert und die Lysosomen können durch Dichtegradientenzentrifugation von anderen Organellen getrennt werden (Leighton et al. 1968).

Im Anschluss an die Isolierung der zu untersuchenden Proteinfraktion folgt die Analyse des komplexen Proteingemisches. Die meist genutzte Methode zur Separation komplexer Proteingemische ist die 2D-Gelelektrophorese (2D-GE) (Klose 1975; O'Farrell 1975). Bei dieser Methode werden Proteine in der ersten Dimension durch isoelektrische Fokussierung (IEF) anhand eines pH-Gradienten aufgetrennt. In der zweiten Dimension erfolgt die Trennung entsprechend der molekularen Größe durch SDS-Polyacrylamid- 
Gelelektrophorese (SDS-PAGE). Die separierten Proteine werden aus dem Gel ausgeschnitten und durch tryptischen Verdau mit anschließender MALDI-TOF-MS Analyse identifiziert. Eine Limitierung der 2D-GE liegt darin, dass sich insbesondere extrem hydrophobe Transmembranproteine der Solubilisierung zur IEF entziehen und demnach in 2D-GE-Analysen unterrepräsentiert sind. Je nach Wahl des pH-Bereichs bei der IEF bzw. des Trennbereichs in der 2. Dimension entgehen der Analyse zudem extrem basische und saure bzw. sehr große und sehr kleine Proteine.

Um dieser Einschränkung der 2D-GE zu umgehen, wurde als alternative Analysemethode die multidimensional protein identification technology (MudPIT) entwickelt (Link et al. 1999; Washburn et al. 2001). Bei dieser Methode wird die komplexe Proteinmischung zunächst tryptisch verdaut. Anschließend erfolgt eine zweidimensionale Trennung der spezifischen Peptide durch ein HPLC-System. In der ersten Dimension erfolgt eine Trennung der Peptide zumeist über eine Chromatografie mit starken Ionenaustauschern, an die sich eine zweite Chromatografie mittels einer Reverse-Phase Matrix anschließt. Die Analyse der separierten Peptide erfolgt anschließend durch ESI-MS/MS.

Bis heute sind etwa 50 lysosomale Matrixproteine und 20 lysosomale Membranproteine identifiziert. Die Mehrheit der M6P-markierten, löslichen, lysosomalen Enzyme scheint identifiziert und untersucht zu sein. Vergleicht man hingegen die Zahl der identifizierten Membranproteine mit der Anzahl an Membranfunktionen, zeigt dies, dass das Proteom der lysosomalen Membran nur unzureichend charakterisiert ist (Eskelinen et al. 2003). In umfangreichen Proteomanalysen werden indes immer neue lysosomale Matrixproteine (Journet et al. 2000; Journet et al. 2002) und Membranproteine (Schroder et al. 2007) identifiziert. Die Untersuchung neu identifizierter, lysosomaler Enzyme trägt zum Verständnis der lysosomalen Funktionen bei und stellt darüber hinaus eine Möglichkeit dar, die Ursache weiterer lysosomaler Speichererkrankungen zu identifizieren. 


\section{$2 \quad$ Problemstellung}

Das lysosomale Kompartiment und seine Funktionen wurden seit der Entdeckung des Organells durch De Duve (De Duve et al. 1955) intensiv untersucht. Bis heute sind etwa 50 lysosomale Matrixproteine bekannt. Die meisten löslichen lysosomalen Enzyme sind Hydrolasen, die an der terminalen Degradation von Makromolekülen im Lysosomen beteiligt sind und MPR-abhängig zu den Lysosomen transportiert werden. Neben der klassischen katabolischen Funktion wurden jedoch auch zunehmend spezialisierte zellulären Funktionen identifiziert, an denen das lysosomale Kompartiment beteiligt ist. Die Bedeutung der löslichen lysosomalen Proteine wird dadurch deutlich, dass annähernd jeder Defekt eines lysosomalen Proteins zu einer lysosomalen Erkrankung führt. Aufgrund der klinischen Relevanz lysosomaler Speichererkrankungen und der beträchtlichen Anzahl an Lysosomen-assoziierten Erkrankungen mit unbekannter Ätiologie steht die Identifikation von neuen, lysosomalen Proteinen im allgemeinen Interesse.

Zur Identifizierung neuer lysosomaler Enzyme sollten in dieser Arbeit die Proteine der lysosomalen Matrix in ihrer Gesamtheit identifiziert werden. Mit Hilfe immobilisierter MPRs sollten die M6P-markierten Proteine aus dem Überstand von MPR-defizienten MEF affinitätschromatografisch aufgereinigt werden und anschließend durch zwei unabhängige Analyseverfahren identifiziert werden. Die Proteine sollten durch 2D-Gelelektrophorese und MALDI-TOF-MS und alternativ durch die MudPIT-Analyse identifiziert werden.

Im Anschluss an die Proteomanalyse sollten einzelne, neu identifizierte, putativ lysosomale Proteine charakterisiert und hinsichtlich ihrer Funktion untersucht werden. 


\section{$3 \quad$ Material und Methoden}

\subsection{Material}

\subsubsection{Geräte}

\subsubsection{Allgemeine Geräte}

Acrylamidgel-Elektrophoresekammer

Agarosegel-Elektrophoresekammer

Biocad-Vision ${ }^{\circledR}$ Workstation HPLC System

Bio-Photometer

Branson Sonifier 450

Durchlicht-Mikroskop

Einbettautomat Shandon Citadel ${ }^{\mathrm{TM}} 2000$

ESI-Tandem-Massenspektrometer

Esquire 3000+

Färbeautomat Shandon Varistain 24-4

Flüssigkeitsszintillationszähler 1900TR

Geltrockner Modell Gel Air Dryer

Heizblock HTM 130

LAS-1000 Gel Dokumentation System

Laser Scan-Mikroskop

Modell TCS Sp2 AOBS

Mastercycler Gradient

Mikrotom HM 355

Mikrotom SM2000R

Netzgerät Consort E835

Paraffineingießstation DDM-P-065

Phegasus Semi-Dry Western Blot Kammer
Werkstatt des Instituts

Werkstatt des Instituts

Applied Biosystems,

Framingham, USA

Eppendorf, Hamburg

Heinemann, Schwäbisch Gmünd

Zeiss, Göttingen

Thermo Scientific, Waltham, USA

Bruker Daltonik, Bremen

Thermo Scientific, Waltham, USA

Packard, Perkin Elmer, Überlingen

Biorad, München

HLC, Bovenden

Fujifilm, Düsseldorf

Leica, Heidelberg

Eppendorf, Hamburg

Microm, Volketswil, Schweiz

Leica, Heidelberg

Schütt, Göttingen

Medim Schweiz GmbH, Baar, Schweiz

Phase, Lübeck 
Phosphoimager PMI

Procise cLC sequenator

REFLEX III-Flugzeit Massenspektrometer

SMART $^{\mathrm{TM}}$ HPLC System

Spectrophotometer Cary 50 Bio

Tecan Microplate Reader Model Spectra II

Teflon Homogenisator

Transilluminator Modell ETX $20 \mathrm{M}$

Tube Gel Cell IEF 2-D Systems Modell 175

Ultimate Nanoflow-HPLC System

UV-Handlampe (312 nm, $254 \mathrm{~nm}$ )

Vakuumkonzentrator

Modell Speed Vac SVC100H

\subsubsection{Zentrifugen und Rotoren}

Kühlzentrifuge 5804R mit Rotor A-4-44

Kühlzentrifuge J2-MC mit Rotor JA10

Tischkühlzentrifuge Mikro 200R

Tischzentrifuge 5415D

Tisch-Ultrazentrifuge Modell TL-100

mit Rotor TLA-45

Ultrazentrifuge Modell Optima L90K

mit Rotoren SW 40 und Ti75
Biorad, München

Applied Biosystems,

Framingham,USA

Bruker Daltonik, Bremen

Pharmacia, Uppsala, Schweden

Varian, Darmstadt

Tecan, SLT, Crailsheim

Braun, Melsungen

LTF Labortechnik, Wasserburg

Biorad, München

LC Packings,Zürich, Schweiz

Bachofer, Reutlingen

Bachofer, Reutlingen
Eppendorf, Hamburg

Beckmann Coulter, Krefeld

Hettich Zentrifugen, Tuttlingen

Eppendorf, Hamburg

Beckmann Coulter, Krefeld

Beckmann Coulter, Krefeld

\subsubsection{Verbrauchsmaterialien}

\section{ZipTipC18 Pipettenspitzen}

Millipore, Schwalbach

Dialyseschlauch Type 8, Cut-off: 12-16 kDa, Biomol, Hamburg

Porengröße 25A

Einfrierröhrchen

Nunc, Wiesbaden 
Einmalkanülen,-spritzen

Einmalpipetten 5, 10, $20 \mathrm{ml}$

Gewebekulturflaschen, -schalen

Glaswaren für Labor

Glasperlen (4 - $5 \mathrm{~mm})$

Histosette I

Hybond $^{\mathrm{TM}}-\mathrm{N}-\mathrm{Membran}$

Mikrotomklingen

Objektträger und Deckgläschen

Parafilm ${ }^{\circledR} \mathrm{M}$

Pasteurpipetten

Präparierbesteck

Polyvinylidenfluorid (PVDF)

Transfermembran

Phospho-Imaging Plate

Spritzenaufsatzfilter $0,2 \mu \mathrm{m}$ und $0,45 \mu \mathrm{m}$

UH10-Ultrahülsen

Ultrazentrifugenröhrchen

UVetten $^{\circledR}$

Whatman-Filterpapier

Plastikreaktionsgefäße
Braun, Melsungen

Sarstedt, Nümbrecht

Greiner, Nürtingen

Schott, Mainz

Schütt, Göttingen

Simport, Beloeil, QC, Kanada

GE Healthcare, München

Thermo Scientific, Waltham, USA

Menzel-Gläser, Braunschweig

American National, Chicago, USA

Schütt, Göttingen

Neolab, Heidelberg

Whatman, Göttingen

Fujifilm, Düsseldorf

Heinemann, Duderstadt

Schleicher und Schuell, Dassel

Beckmann Coulter, Krefeld

Eppendorf, Hamburg

Whatman, Göttingen

Sarstedt, Nümbrecht

\subsubsection{Chemikalien}

Aceton

Acetonitril

Acrylamid (Rotiphorese ${ }^{\circledR}$ Gel A)

Acrylamid/Bisacrylamid-Lösung

(Rotiphorese ${ }^{\circledR}$-Gel 30)

Agar

Agarose
Roth, Karlsruhe

Merck, Darmstadt

Roth, Karlsruhe

Roth, Karlsruhe

Roth, Karlsruhe

Roth, Karlsruhe 
Albumin (BSA, bovine serum albumin)

Ameisensäure

$\varepsilon$-Aminocapronsäure

Ammoniumacetat

Ammoniumchlorid

Ammoniumhydrogencarbonat

Ammoniummolybdat-Tetrahydrat

Ammoniumperoxodisulfat (APS)

Ammoniumsulfat

Ampicillin

Ascorbinsäure

5-Brom-4-chlor-3-indoxyl- $\beta$-D-

Galactopyranosid (X-Gal)

Bisacrylamid (Rotiphorese ${ }^{\circledR}$ Gel B)

Bromphenolblau

cAMP

(cyclische Adenosin-3',5'-monophosphat)

CBZ-Ala-Phe-OH

CBZ-Gly-Leu-OH

CBZ-Leu-Phe-OH

CBZ-Phe-Ala-OH

CBZ-Phe-Leu-OH

CBZ-Phe-Phe-OH

CHAPS

Chloramphinicol

Chromschwefelsäure

Coomassie Brilliant Blue G250

Diethylpyrocarbonat (DEPC)

2,5-Dihydroxybenzoesäure (DHB)

Dimethylsulfoxid (DMSO)

Dinatriumhydrogenphosphat
Serva, Heidelberg

Merck, Darmstadt

Sigma, Deisenhofen

Merck, Darmstadt

Merck, Darmstadt

Merck, Darmstadt

Merck, Darmstadt

Merck, Darmstadt

Merck, Darmstadt

Serva, Heidelberg

Roth, Karlsruhe

Sigma, Deisenhofen

Roth, Karlsruhe

Merck, Darmstadt

Sigma, Deisenhofen

Bachem, Weil am Rhein

Bachem, Weil am Rhein

Bachem, Weil am Rhein

Bachem, Weil am Rhein

Bachem, Weil am Rhein

Bachem, Weil am Rhein

Roth, Karlsruhe

Sigma, Deisenhofen

Merck, Darmstadt

Merck, Darmstadt

Roth, Karlsruhe

Sigma, Deisenhofen

Merck, Darmstadt

Roth, Karlsruhe 
Dinatriummethylendiaminotetraacetat (EDTA) Roth, Karlsruhe

Dithiothreitol (DTT)

Roth, Karlsruhe

Eindeckmedium DPX Mountant for histology Fluka; Sigma, Deisenhofen

Eosin

Merck, Darmstadt

Essigsäure

Roth, Karlsruhe

Ethanol

Roth, Karlsruhe

Ethidiumbromid (1 \% (w/v) Lösung)

Roth, Karlsruhe

Ethylacetat

Merck, Darmstadt

Fluorescent Mounting Medium

Dako, Carpinteria, USA

Formaldehydlösung (37\%)

Merck, Darmstadt

Formamid

Merck, Darmstadt

Gelatine

Sigma, Deisenhofen

Glucose

Roth, Karlsruhe

Glucose-6-Phosphat (G6P)

Sigma, Deisenhofen

Glutaraldehyd $\left(25 \%(\mathrm{v} / \mathrm{v})\right.$ in $\left.\mathrm{dH}_{2} \mathrm{O}\right)$

Serva, Heidelberg

Glycerin

Roth, Karlsruhe

Glycin

Roth, Karlsruhe

Harnstoff

Serva, Heidelberg

Hefeextrakt

Roth, Karlsruhe

Hering-Sperma-DNA

Sigma, Deisenhofen

Histoacryl

Braun, Melsungen

Imidazol

Merck, Darmstadt

Iodacetamid

Sigma, Deisenhofen

Isopropanol

Roth, Karlsruhe

Kaliumchlorid

Roth, Karlsruhe

Kaliumdihydrogenphosphat

Merck, Darmstadt

Kaliumhexacyanidoferrat(III) (K3[Fe(CN)6]) Merck, Darmstadt

Kaliumhexacyanidoferrat(II) (K4[Fe(CN)6]) Merck, Darmstadt

Kaliumnatriumtartrat

Merck, Darmstadt

Kanamycin

Sigma, Deisenhofen

Magermilchpulver

Töpfer, Dietmannsried 
Magnesiumchlorid

Mannose-6-Phosphat (M6P)

Magnesiumsulfat

Maleinsäure

Mayers Hämalaun

2-Mercaptoethanol

Methanol

Methoxy-2-ethanol

Natriumacetat

Natriumazid

Natrium- $\beta$-glycerophosphat

Natriumcarbonat

Natriumchlorid

Natriumcitrat

Natriumdesoxycholat

Natriumdihydrogenphosphat

Natriumdodecylsulfat (SDS)

Natriumhydroxid $(\mathrm{NaOH})$

Natriumsuccinat

Natriumthiosulfatpentahydrat

Ninhydrin

2-(N-Morpholino)-Propansulfonsäure (MES) Serva, Heidelberg

3-(N-Morpholino)-Propansulfonsäure (MOPS) Serva, Heidelberg

NNN'N'-Tetramethylethylendiamin (TEMED)Serva, Heidelberg

Nonidet P-40 (NP-40)

Paraformaldehyd (PFA)

Paraplast (Roti-plast)

Pepton

Percoll $^{\mathrm{TM}}$

Pferdeserum (Normal Horse Serum)

1,10-Phenanthroline
Merck, Darmstadt

Sigma, Deisenhofen

Merck, Darmstadt

Sigma, Deisenhofen

Merck, Darmstadt

Merck, Darmstadt

Roth, Karlsruhe

Merck, Darmstadt

Merck, Darmstadt

Merck, Darmstadt

Merck, Darmstadt

Merck, Darmstadt

Roth, Karlsruhe

Merck, Darmstadt

Serva, Heidelberg

Merck, Darmstadt

Roth, Karlsruhe

Roth, Karlsruhe

Merck, Darmstadt

Merck, Darmstadt

Roth, Karlsruhe

Sigma, Deisenhofen

Sigma, Deisenhofen

Roth, Karlsruhe

Roth, Karlsruhe

GE Healthcare, München

Sigma, Deisenhofen

Merck, Darmstadt 
Phenolrot

Phosphorsäure (ortho-)

p-Iodonitrotetrazolium (violett)

p-Nitrocatecholsulfat

p-Nitrophenyl- $\beta$-D-glucopyranosid

p-Nitrophenyl- $\beta$-D-glucuronid

p-Nitrophenyl- $\alpha$-D-mannopyranosid

Polyethylenglykol 7500 (PEG)

1-Propanol

Protaminsulfat

Protein G Sepharose ${ }^{\mathrm{TM}} 4$ Fast Flow

Rattenserum (Normal Rat Serum)

Rapid-hyb ${ }^{\text {TM }}$ Buffer

Saccharose (Sucrose)

Salzsäure, rauchend

Salzsäure (37 \%)

Schwefelsäure (konz.)

Servalyt ${ }^{\circledR}$ carrier ampholytes $\mathrm{pH} 4-7$

Servalyt ${ }^{\circledR}$ carrier ampholytes $\mathrm{pH} 3-10$

Silbernitrat

Stimune Adjuvant

Trichloressigsäure (TCA)

Trifluoressigsäure (TFA)

Tris-(hydroxymethyl)-aminomethan (TRIS)

Triton X-100

Tween 20

Tyloxapol (Triton WR-1339)

Wasser, reinst

Xylol

Ziegenserum (Normal Goat Serum)

Zinn(II)chlorid
Merck, Darmstadt

Roth, Karlsruhe

Sigma, Deisenhofen

Sigma, Deisenhofen

Sigma, Deisenhofen

Sigma, Deisenhofen

Sigma, Deisenhofen

Sigma, Deisenhofen

Merck, Darmstadt

Serva, Heidelberg

GE Healthcare, München

Sigma, Deisenhofen

GE Healthcare, München

Roth, Karlsruhe

Roth, Karlsruhe

Roth, Karlsruhe

Merck, Darmstadt

Serva, Heidelberg

Serva, Heidelberg

Roth, Karlsruhe

Cedi Diagnostic, Lelystad, Niederlande

Merck, Darmstadt

Merck, Darmstadt

Roth, Karlsruhe

Serva, Heidelberg

Roth, Karlsruhe

Sigma, Deisenhofen

Baker, Deventer, Niederlande

Roth, Karlsruhe

Sigma, Deisenhofen

Roth, Karlsruhe 
Zitronensäure (kristallin)

Sigma, Deisenhofen

\subsubsection{Kits zur Bearbeitung von DNA und Proteinen}

BigDye $^{\circledR}$ Terminator v3.1 Cycle

Applied Biosystems, Foster City, USA

Sequencing Kit

BioRad DC Protein Assay

BioRad, München

Supersignal West Pico Chemiluminescent

Pierce, Rockford, USA

Substrate

QIAGEN ${ }^{\circledR}$ Plasmid Midi Kit

Qiagen, Hilden

QIAprep ${ }^{\circledR}$ Spin Miniprep Kit

Qiagen, Hilden

QIAquick $^{\circledR}$ Gel Extraction Kit

Qiagen, Hilden

Rediprime II Random Prime Labelling Kits

GE Healthcare, München

Omniscript ${ }^{\circledR}$ Reverse Transcriptase Kit

Qiagen, Hilden

RNeasy ${ }^{\circledR}$ Midi Kit

Qiagen, Hilden

Platinum ${ }^{\circledR}$ Pfx-DNA-Polymerase Kit

Invitrogen, Karlsruhe

Taq DNA-Polymerase Kit

Roche Applied Science,

Indianapolis, USA

\subsubsection{Enzyme zum Bearbeitung von DNA, RNA und Proteinen}

Proteinase K

N-Glykosidase F

Trypsin, modifiziert aus Rinderpankreas

Restriktionsendonukleasen

T4 DNA Ligase

BP Clonase ${ }^{\mathrm{TM}}$

LR Clonase $^{\mathrm{TM}}$
Roth, Karlsruhe

Roche Applied Science,

Indianapolis, USA

Serva, Heidelberg

NEB, Frankfurt am Main

NEB, Frankfurt am Main

Invitrogen, Karlsruhe

Invitrogen, Karlsruhe 


\subsubsection{Proteaseinhibitoren und Proteinstandards}

Aprotinin Biomol GmbH, Hamburg

Chymostatin Biomol GmbH, Hamburg

Dinatriummethylendiaminotetraacetat (EDTA) Roth, Karlsruhe

Iodacetamid (IAA) Sigma, Deisenhofen

Leupeptin Biomol GmbH, Hamburg

Pepstatin A Biomol GmbH, Hamburg

Phenylmethylsulfonylfluorid (PMSF) Roth, Karlsruhe

Precision Plus Protein All Blue Standard Biorad, München

Molecular Weight Standard Unstained

Biorad, München

\subsubsection{Verwendete Antikörper}

\subsubsection{Sekundärantikörper für Western Blot Analyse}

Zweitantikörper für die Western Blot Analyse wurden standardmäßig in einer Verdünnung von 1:5000 eingesetzt.

Ziege anti Kaninchen, HRP konjugiert Dianova, Hamburg

Ziege anti Maus, HRP konjugiert

Dianova, Hamburg

Ziege anti Ratte, HRP konjugiert

Dianova, Hamburg

\subsubsection{Sekundärantikörper für Immunfluoreszenz}

Zweitantikörper für die Immunfluoreszenz wurden standardmäßig 1:400 eingesetzt.

Alexa Fluor ${ }^{\circledR} 488$ goat anti-rabbit $\operatorname{IgG}(\mathrm{H}+\mathrm{L})$ Invitrogen, Karlsruhe Alexa Fluor ${ }^{\circledR} 546$ goat anti-mouse IgG $(\mathrm{H}+\mathrm{L})$ Invitrogen, Karlsruhe Alexa Fluor ${ }^{\circledR} 488$ goat anti-rat $\operatorname{IgG}(\mathrm{H}+\mathrm{L}) \quad$ Invitrogen, Karlsruhe Alexa Fluor ${ }^{\circledR} 633$ goat anti-rabbit IgG $(\mathrm{H}+\mathrm{L})$ Invitrogen, Karlsruhe 


\subsubsection{Primärantikörper}

\begin{tabular}{|c|c|c|c|c|}
\hline Name & $\begin{array}{l}\text { Antigen, } \\
\text { (H.-Name) } \\
\text { Ag-Spezies }\end{array}$ & $\begin{array}{l}\text { immun. } \\
\text { Spezies }\end{array}$ & Anwendung & Referenz \\
\hline$\alpha$-Scpep1-D2 & Scpep1, murin & $\begin{array}{l}\text { Kaninchen, } \\
\text { polyklonal }\end{array}$ & $\begin{array}{l}\text { WB 1:1000/ } \\
\text { IF } 1: 50\end{array}$ & $\begin{array}{l}\text { Eigene Produktion } \\
\text { (siehe 3.6.1) }\end{array}$ \\
\hline$\alpha-S c p e p 1-C 6$ & Scpep1, murin & $\begin{array}{l}\text { Kaninchen, } \\
\text { polyklonal }\end{array}$ & $\begin{array}{l}\text { WB 1:1000/ } \\
\text { IF } 1: 50\end{array}$ & $\begin{array}{l}\text { Eigene Produktion } \\
\text { (siehe 3.6.1) }\end{array}$ \\
\hline$\alpha$-Scpep1-Ratte & Scpep1, murin & $\begin{array}{l}\text { Ratte, } \\
\text { polyklonal }\end{array}$ & $\begin{array}{l}\text { WB } 1: 1000 / \\
\text { IF } 1: 50 / \\
\text { IP } 10 \mu \mathrm{l}\end{array}$ & $\begin{array}{l}\text { Eigene Produktion } \\
\text { (siehe 3.6.1) }\end{array}$ \\
\hline$\alpha-N P T 2$ & $\begin{array}{l}\text { Neomycin Phospho- } \\
\text { transferase } 2 \text {, } \\
\text { artifizielle Sequenz }\end{array}$ & $\begin{array}{l}\text { Kaninchen, } \\
\text { polyklonal }\end{array}$ & WB 1:1000 & $\begin{array}{l}\text { Upstate, Millipore } \\
\text { Schwalbach (Fuchs } \\
\text { et al. 1993) }\end{array}$ \\
\hline$\alpha-V 5$ & $\begin{array}{l}\text { V5-Epitop, } \\
\text { artifizielle Sequenz }\end{array}$ & $\begin{array}{l}\text { Kaninchen, } \\
\text { monoklonal }\end{array}$ & IF $1: 100$ & $\begin{array}{l}\text { Sigma, } \\
\text { Deisenhofen, } \\
\text { (Thomas et al. } \\
\text { 1988) }\end{array}$ \\
\hline$\alpha-\mathrm{V} 5$ & $\begin{array}{l}\text { V5-Epitop, } \\
\text { artifizielle Sequenz }\end{array}$ & $\begin{array}{l}\text { Maus, } \\
\text { monoklonal }\end{array}$ & WB 1:4000 & $\begin{array}{l}\text { Invitrogen, } \\
\text { Karlsruhe, (Dai und } \\
\text { Liew 2001) }\end{array}$ \\
\hline$\alpha-H i s$ & RGS-His6-Epitop & $\begin{array}{l}\text { Maus, } \\
\text { monoklonal }\end{array}$ & WB 1:3000 & $\begin{array}{l}\text { Qiagen, Hilden, } \\
\text { (Preusser-Kunze et } \\
\text { al. 2005) }\end{array}$ \\
\hline$\alpha$-CatD & $\begin{array}{l}\text { CatD (KII-S9), } \\
\text { murin }\end{array}$ & $\begin{array}{l}\text { Kaninchen, } \\
\text { polyklonal }\end{array}$ & WB 1:1000 & $\begin{array}{l}\text { Produktion Institut } \\
\text { (Braulke et al. 1987) }\end{array}$ \\
\hline$\alpha$-Porin & $\begin{array}{l}\text { Porin } \\
(31 \mathrm{HL}, \text { Anti-VDAC), } \\
\text { human }\end{array}$ & $\begin{array}{l}\text { Maus, } \\
\text { monoklonal }\end{array}$ & WB 1:1000 & $\begin{array}{l}\text { Calbiochem, } \\
\text { Darmstadt, (Babel } \\
\text { et al. 1991) }\end{array}$ \\
\hline$\alpha-h L A M P-1$ & $\begin{array}{l}\text { LAMP-1, (H4A3), } \\
\text { human }\end{array}$ & $\begin{array}{l}\text { Maus, } \\
\text { monoklonal }\end{array}$ & IF 1:25 & $\begin{array}{l}\text { Hybridomabank, } \\
\text { USA, (Chen et al. } \\
\text { 1985) }\end{array}$ \\
\hline$\alpha-m L A M P-1$ & $\begin{array}{l}\text { LAMP-1, } \\
(1 \mathrm{D} 4 \mathrm{~B}, \mathrm{CD} 107 \mathrm{a}) \\
\text { murin }\end{array}$ & $\begin{array}{l}\text { Ratte, } \\
\text { monoklonal }\end{array}$ & $\begin{array}{l}\text { WB } 1: 250 / \\
\text { IF } 1: 25\end{array}$ & $\begin{array}{l}\text { Hybridomabank, } \\
\text { USA, (Hughes und } \\
\text { August 1981) }\end{array}$ \\
\hline$\alpha-G A P D H$ & $\begin{array}{l}\text { GAPDH (FL-335), } \\
\text { (sc-25778), } \\
\text { murin }\end{array}$ & $\begin{array}{l}\text { Kaninchen, } \\
\text { polyklonal }\end{array}$ & WB 1:300 & $\begin{array}{l}\text { Santa Cruz } \\
\text { Biotechnology, } \\
\text { Heidelberg (Meyer- } \\
\text { Siegler et al. 1991) }\end{array}$ \\
\hline
\end{tabular}

Tab. 3.1: Verwendete Primärantikörper

\subsubsection{Radioaktive Substanzen}

$\left[{ }^{35} \mathrm{~S}\right]-$ Methionin/Cystein, $10 \mathrm{mCi} / \mathrm{ml}$

Hartmann Analytic GmbH,

$1000 \mathrm{mCi} / \mathrm{mmol}$

Braunschweig

$\left[{ }^{32} \mathrm{P}\right]-\mathrm{dCTP}, 10 \mathrm{mCi} / \mathrm{ml}, 3000 \mathrm{mCi} / \mathrm{mmol}$

Hartmann Analytic GmbH,

Braunschweig 


\subsubsection{Säulen und Säulenfüllmaterial}

Affigel 10

Ni-NTA-Agarose

Mobitec-Säulen- $5 \mathrm{ml}, 12 \mathrm{ml}$

Superdex 75 HR 10/30

Superdex 200 HR 10/30

Self Pack ${ }^{\circledR}$ Empty Column, Stainless Steel, (4,6 mm x $100 \mathrm{~mm}, 1,7 \mathrm{ml})$

Poros $20 \mathrm{HQ} / \mathrm{M}$ Anionenaustauscher

PepMap C18 Reverse-Phase Nano-Säule $(0.075 \times 150 \mathrm{~mm})$

Poros 10 S-Kationaustauschersäule $(1 \times 150 \mathrm{~mm})$
Biorad, München

Qiagen, Hilden

Mobitec, Göttingen

GE Healthcare, München

GE Healthcare, München

Applied Biosystems, Foster City, USA

Applied Biosystems, Foster City, USA

LC Packings, Amsterdam, Niederlande

LC Packings, Amsterdam, Niederlande

\subsubsection{Vektoren, Oligonukleotidprimer und DNA-Standards}

$\begin{array}{ll}\text { pDONR }^{\mathrm{TM}} 221 & \text { Invitrogen, Karlsruhe } \\ \text { pcDNA-DEST40 } & \text { Invitrogen, Karlsruhe } \\ \text { pcDNA3.1/Hygro }(+) & \text { Invitrogen, Karlsruhe }\end{array}$

Primer wurden von der Firmen IBA (Göttingen) und Metabion (Göttingen) bezogen.

$\begin{array}{ll}\text { TrackIt } 1 \mathrm{~kb} \text { Plus DNA Ladder } & \text { Invitrogen, Karlsruhe } \\ 0,5-10 \mathrm{~kb} \text { RNA Ladder } & \text { Invitrogen, Karlsruhe }\end{array}$ 


\subsubsection{Häufig verwendete Puffer und Lösungen}

$10 \times$ PBS:

\begin{tabular}{|c|c|}
\hline & $2 \mathrm{~g} \mathrm{KCl}$ \\
\hline & $14,4 \mathrm{~g} \mathrm{Na}_{2} \mathrm{HPO}_{4}$ \\
\hline & $2,4 \mathrm{~g} \mathrm{KH}_{2} \mathrm{PO}_{4}$ \\
\hline & mit $\mathrm{dH}_{2} \mathrm{O}$ auf 11 auffüllen, pH 6,8, autoklavieren \\
\hline $10 \times \mathrm{TBS}$ & 100 mM Tris/ $\mathrm{HCl} \mathrm{pH} 7,4$ \\
\hline & $1,5 \mathrm{M} \mathrm{NaCl}$ \\
\hline $10 \times$ TE-Puffer: & $100 \mathrm{mM}$ Tris/ $\mathrm{HCl} \mathrm{pH}$ 7,6 \\
\hline & $10 \mathrm{mM}$ EDTA \\
\hline
\end{tabular}

\subsubsection{Medien zum Arbeiten mit Bakterienkulturen}

Zur Amplifikation von Plasmid-DNA wurde der Bakterienstamm DH5 $\alpha$ ( $\mathrm{F}^{-}$, recA1, endA1, $h s d \mathrm{R} 17\left(\mathrm{r}_{\mathrm{k}}^{-}, \mathrm{m}_{\mathrm{k}}^{+}\right)$, supE44, $\lambda^{-}$, thi-1, gyrA96, relA1) verwendet.

LB-Medium:

$10 \mathrm{~g}$ Pepton aus Casein

$5 \mathrm{~g}$ Hefeextrakt

$10 \mathrm{~g} \mathrm{NaCl}$

mit $\mathrm{dH}_{2} \mathrm{O}$ auf 11 auffüllen,

pH 7,0 mit $\mathrm{NaOH}$ einstellen, autoklavieren

LB-Agarplatten:

7,5 g Agar

in 11 LB-Medium

nach Autoklavieren auf $60^{\circ} \mathrm{C}$ abkühlen lassen, ggf. Antibiotikum zusetzen und je $30 \mathrm{ml}$ in $10 \mathrm{~cm}$-Platten gießen. Nach dem Erkalten bei $4^{\circ} \mathrm{C}$ lagern. 


\begin{tabular}{lll}
\hline Antibiotikum & Stocklösung & Endkonzentration \\
\hline Ampicillin & $25 \mathrm{mg} / \mathrm{ml} \mathrm{in} \mathrm{dH}_{2} \mathrm{O}$ & $100 \mu \mathrm{g} / \mathrm{ml}$ \\
Kanamycin & $25 \mathrm{mg} / \mathrm{ml} \mathrm{dH}_{2} \mathrm{O}$ & $50 \mu \mathrm{g} / \mathrm{ml}$ \\
Chloramphinicol & $30 \mathrm{mg} / \mathrm{ml} \mathrm{in} \mathrm{Ethanol}$ & $30 \mu \mathrm{g} / \mathrm{ml}$ \\
\hline
\end{tabular}

Tab. 3.2: Verwendete Antibiotika und eingesetzte Endkonzentrationen

\subsubsection{Verwendete Zellkulturmedien und Reagenzien}

PBS (für Zellkultur)

$40 \mathrm{~g} \mathrm{NaCl}, 1 \mathrm{~g} \mathrm{KCl}, 7,2 \mathrm{Na}_{2} \mathrm{HPO}_{4}+$

$2 \mathrm{H}_{2} \mathrm{O}, 1 \mathrm{~g} \mathrm{K \textrm {KH } _ { 2 }} \mathrm{PO}_{4}$ und $0,1 \mathrm{~g}$ Phenolrot

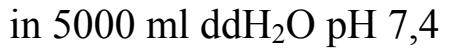

Dulbecco's Modified Eagle Medium (DMEM) Gibco Invitrogen, Karlsruhe

KnockOut ${ }^{\mathrm{TM}}$-DMEM

Waymouth's MB 752/1 Medium

DMEM (ohne Aminosäuren L-Glutamin,

L-Methionin und L-Cystein)

Fötales Kälberserum (FKS)

Hyclone Embryonic Stem (ES) Cell

Screened Fetal Bovine Serum

MEM Non-Essential Amino Acids

(10 mM Solution, $100 \times$, liquid)

L-Glutamin $(200 \mathrm{mM})(100 \times$ Stocklösung $) \quad$ Gibco Invitrogen, Karlsruhe

Penicillin/Streptomycin $(100 \times$ Stocklösung $) \quad$ Gibco Invitrogen, Karlsruhe

Hygromycin B

Neomycin (G418)

ESGRO (LIF, $10^{7} \mathrm{U} / \mathrm{ml}$,

mouse Leukemia Inhibitor Factor)

Mitomycin C

$0,05 \%$ (w/v) Trypsin-EDTA-Lösung

$0,25 \%(w / v)$ Trypsin/ 1mM EDTA
Gibco Invitrogen, Karlsruhe

Gibco Invitrogen, Karlsruhe

PAN, Aidenbach

PAN, Aidenbach

Thermo Scientific, Waltham, USA

Gibco Invitrogen, Karlsruhe

Calbiochem, Frankfurt

Sigma, Deisenhofen

Chemicon, Hofheim

Sigma, Deisenhofen

Gibco Invitrogen, Karlsruhe

Gibco Invitrogen, Karlsruhe 
FuGENE ${ }^{\mathrm{TM}} 6$ Transfektionsreagenz $\quad$ Roche Applied Science, USA

\subsubsection{Zelllinien in Zellkultur}

\begin{tabular}{|c|c|c|}
\hline Zelllinie & Beschreibung & Referenz \\
\hline MEF-23-1SV & $\begin{array}{l}\text { Primäre embryonale Mausfibroblasten, } \\
\text { defizient in MPR46 und MPR300 }\end{array}$ & $\begin{array}{l}\text { Zellen des Instituts } \\
\text { (Kasper et al.1996) }\end{array}$ \\
\hline HT1080 & Humane Fibrosarkom-Zelllinie & $\begin{array}{l}\text { Erworben bei Stratagene, } \\
\text { La Jolla, USA, (Roeser et } \\
\text { al. 2006) }\end{array}$ \\
\hline HeLa & $\begin{array}{l}\text { Humane epitheloid cervix carcinoma } \\
\text { Zelllinie }\end{array}$ & $\begin{array}{l}\text { European Collection of } \\
\text { Cell Cultures (ECACC) }\end{array}$ \\
\hline BHK-21 & baby hamster kidney cells & $\begin{array}{l}\text { European Collection of } \\
\text { Cell Cultures (ECACC) }\end{array}$ \\
\hline Humane Fibroblasten & Normale Patientenzellen & $\begin{array}{l}\text { Zellen des Instituts, } \\
\text { Diagnose }\end{array}$ \\
\hline I-cell Fibroblasten & Patientenzellen, I-cell-Phänotyp & $\begin{array}{l}\text { Zellen des Instituts, } \\
\text { Diagnose }\end{array}$ \\
\hline ES-Zellklon RST426 & $\begin{array}{l}\text { Murine embryonale Stammzellen mit } \\
\text { Gene Trap Insertion in Intron } 7 \text { des } \\
\text { Gens Scpep1 (ID: } 74617 \text { ) }\end{array}$ & $\begin{array}{l}\text { Erworben bei Mutant } \\
\text { Mouse Regional } \\
\text { Resource Center } \\
\text { (MMRRC, Davis, USA) }\end{array}$ \\
\hline Feederzellen & $\begin{array}{l}\text { Neomycin-resistente, embryonale } \\
\text { Mausfibroblasten }\end{array}$ & $\begin{array}{l}\text { Transgenic Research } \\
\text { Facility, University } \\
\text { Stanford }\end{array}$ \\
\hline RST 426 +/+ MEF & $\begin{array}{l}\text { Primäre embryonale Mausfibroblasten, } \\
\text { Kontrolle zu Scpep1-Gene Trap }\end{array}$ & $\begin{array}{l}\text { Eigene Präparation, aus } \\
\text { RST426 Embryonen } 12,5\end{array}$ \\
\hline RST 426 -/- MEF & $\begin{array}{l}\text { Primäre embryonale Mausfibroblasten, } \\
\text { Scpep1-Gene Trap }\end{array}$ & $\begin{array}{l}\text { Eigene Präparation, aus } \\
\text { RST426 Embryonen 12,5 }\end{array}$ \\
\hline
\end{tabular}

Tab. 3.3: Verwendete eukaryontische Zelllinien

\subsubsection{EDV}

\section{Software:}

Adobe Reader 8.1.0

Adobe-Photoshop 7.0

AIDA Image analysing software

Biorad QuantityOne
Adobe, San Jose, USA

Adobe, San Jose, USA

Fujifilm, Düsseldorf

BioRad, München 
Image Reader LAS

Image $\mathrm{J} 1.37 \mathrm{~V}$

Microsoft Office Standard Edition 2003

Mozilla Firefox 2.0

Vektor NTI Suite 10.3.0

Windows XP Media Centre Edition 2005
Fujifilm, Düsseldorf

NIH, Washington, USA

Microsoft, Redmond, USA

Mozilla Foundation,

Mountain View, USA

Invitrogen, Karlsruhe

Microsoft, Redmond, USA

\section{Online-Programme/Datenbanken:}

$\begin{array}{ll}\text { BayGenomics } & \text { http://www.genetrap.org/ } \\ \text { Blast } & \text { http://www.ncbi.nlm.nih.gov/blast/Blast.cgi } \\ \text { ELM } & \text { http://elm.eu.org/links.html } \\ \text { Ensembl } & \text { http://www.ensembl.org } \\ \text { EXPASY } & \text { http://www.expasy.ch/ } \\ \text { MASCOT Search } & \text { http://www.matrixscience.com/search_form_select.html } \\ \text { MEROPS } & \text { http://merops.sanger.ac.uk/ } \\ \text { NCBI Datenbanken } & \text { http://www.ncbi.nlm.nih.gov/ } \\ \text { PFAM } & \text { http://www.sanger.ac.uk/Software/Pfam/ } \\ \text { SignalP 3.0 } & \text { http://www.cbs.dtu.dk/services/SignalP/ } \\ \text { SwissModel } & \text { http://swissmodel.expasy.org/ } \\ \text { TMHMM v 2.0 } & \text { http://www.cbs.dtu.dk/services/TMHMM/ }\end{array}$




\subsection{Molekularbiologische Methoden}

\subsubsection{Allgemeine Methoden zum Arbeiten mit DNA und RNA}

Die folgenden Methoden und Vorschriften wurden, soweit nicht anders angegeben, dem Laborhandbuch Molecular Cloning (Sambrook et al. 1989) entnommen.

\subsubsection{Isolierung von genomischer DNA}

Zur Genotypisierung von Mäusen wurde genomische DNA isoliert. Drei Wochen alten Mäusen wurden bis zu $5 \mathrm{~mm}$ der Schwanzspitze mit einer scharfen Schere abgeschnitten und die Wunde wurde durch einen Tropfen Histoacryl verschlossen. Die Schwanzspitze wurde mit $500 \mu \mathrm{l}$ Lysispuffer und $50 \mu \mathrm{l}$ Proteinase K-Stocklösung versetzt und über Nacht bei $56^{\circ} \mathrm{C}$ am Schüttelinkubator verdaut. Unverdaute Anteile (z. B. Haare) wurden anschließend $5 \mathrm{~min}$ bei $14000 \mathrm{rpm}$ abzentrifugiert. Der Überstand wurde in ein neues Reaktionsgefäß überführt und mit einem Volumen Isopropanol versetzt. Beim Schwenken des Reaktionsansatzes fiel die DNA als weißes Knäuel aus. Mit einem Glasstab wurde die präzipitierte DNA aus der Lösung gefischt. Am Glasstab haftend wurde sie durch Eintauchen in eine $70 \%$-ige Ethanollösung gespült und dann luftgetrocknet. Um die DNA zu lösen, wurde sie anschließend in ein Gefäß mit $50 \mu 1 \mathrm{dH}_{2} \mathrm{O}$ getaucht. Zur Isolierung von DNA aus Zellen wurden diese pelletiert. Das Pellet wurde mit PBS und $\mathrm{dH}_{2} \mathrm{O}$ gewaschen und anschließend wie beschrieben mit Protease K verdaut.

Lysispuffer:

$100 \mathrm{mM}$ Tris/HCl pH 8

$50 \mathrm{mM}$ EDTA

$200 \mathrm{mM} \mathrm{NaCl}$

$0,5 \% \mathrm{SDS}$

Proteinase K-Stocklösung: $\quad 2 \mathrm{mg} / \mathrm{ml}$ Proteinase $\mathrm{K}$ in Lysispuffer 


\subsubsection{Isolierung von RNA}

Zur Isolierung von RNA aus eukaryontischen Zellen und Mausgewebe wurde das RNeasy ${ }^{\circledR}$ Midi Kit (Qiagen, Hilden) verwendet. Die Präparation erfolgte nach dem Herstellerprotokoll (RNeasy ${ }^{\circledR}$ Handbook, 2001). Zur RNA-Präparation wurde jeweils $200 \mathrm{mg}$ frisch entnommenes Mausgewebe eingesetzt.

\subsubsection{Konzentrationsbestimmung von DNA und RNA}

Zur Konzentrationsbestimmung von DNA- und RNA-Lösungen in $\mathrm{dH}_{2} \mathrm{O}$ erfolgte eine photometrische Messung der Absorption bei $260 \mathrm{~nm}$ gegen $\mathrm{dH}_{2} \mathrm{O}$. Eine $\mathrm{OD}_{260 \mathrm{~nm}}$ von 1 entspricht einer DNA-Konzentration von $50 \mu \mathrm{g} / \mathrm{ml}$ oder einer RNA-Konzentration von $40 \mu \mathrm{g} / \mathrm{ml}$. Die Messung wurde am Bio-Photometer (Eppendorf, Hamburg) in einer Eppendorf UVette ${ }^{\circledR}$ durchgeführt.

\subsubsection{DNA-Amplifikation über Polymerase-Ketten-Reaktion}

Die Polymerase-Ketten-Reaktion (PCR) ist eine Methode zur Amplifikation von definierten DNA-Bereichen. In einem zyklischen Prozess aus Denaturierung des DNADoppelstrangs, Anlagerung von spezifischen Oligonukleotid-Primern (Annealing) und Synthese des komplementären DNA-Strangs mittels DNA-Polymerase (Elongation) wird ein spezifischer DNA-Abschnitt exponentiell vermehrt. Dabei wird die Synthesereaktion durch Auswahl und Konzentration der Primer, Qualität des Templates, durch die Pufferbedingungen, sowie durch Zeiten und Temperaturen der einzelnen Zyklusschritte beeinflusst.

Als DNA-Template für die PCR dienten genomische DNA, Plasmid-DNA und cDNA nach reverser Transkription von RNA. Zur Isolierung von cDNA nach reverser Transkription (3.2.1.5) wurde die Platinum $^{\circledR}$ Pfx-DNA-Polymerase (Invitrogen, Karlsruhe) verwendet. Zur analytischen PCR und zur Subklonierung wurde die Taq DNA-Polymerase (Roche Applied Science, Indianapolis, USA), sowie die mitgelieferten Puffer und dNTPs verwendet. 
Ansatz Taq-PCR:

100 - 250 ng DNA-Template

$5 \mu 110 \times$ PCR Reaktionspuffer

$1 \mu \mathrm{l}$ dNTP-Mix (10 mM)

$2 \mu 110 \mu \mathrm{M}$ Primer (3'-terminal)

$2 \mu 110 \mu \mathrm{M}$ Primer (5'-terminal)

$0,5 \mu 1$ Taq DNA-Polymerase $(5 \mathrm{U} / \mu \mathrm{l})$

mit $\mathrm{dH}_{2} \mathrm{O}$ auf $50 \mu$ auffüllen

PCR-Reaktionsprotokoll:

\begin{tabular}{cc}
$2 \mathrm{~min}$ & $94^{\circ} \mathrm{C}$ \\
\hline $30 \times \quad 20 \mathrm{sec}$ & $94^{\circ} \mathrm{C}$ \\
$60 \mathrm{sec}$ & $55^{\circ} \mathrm{C}$ \\
$120 \mathrm{sec}$ & $72^{\circ} \mathrm{C}$ \\
\hline $10 \mathrm{~min}$ & $72^{\circ} \mathrm{C}$
\end{tabular}

\subsubsection{RT-PCR}

Die RT-PCR ist eine Methode zur Synthese von cDNA aus RNA. In einer zweistufigen Reaktion erfolgt zunächst die reverse Transkription mittels einer RNA-spezifischen, Primer-abhängigen DNA-Polymerase (Reverse Transkriptase) und anschließend die Amplifikation der generierten cDNA mittels PCR.

Zur Isolierung der cDNA von Kandidatenproteinen wurde das Omniscript ${ }^{\circledR}$ Reverse Transkriptase Kit (Qiagen, Hilden) verwendet. Die Reaktion erfolgte in $20 \mu 1$-Ansätzen. Es wurde $1 \mu \mathrm{g}$ Maus-RNA aus Hirn, Leber, Niere und Herz eingesetzt. Reverse Transkriptase, Puffer, dNTP-Mix und RNase-freies Wasser waren im Kit enthalten. Zur spezifischen RT-Reaktion wurden Primer eingesetzt, die die zu amplifizierende cDNA 3'-terminal flankierten. 
RT-Reaktion:

$1 \mu \mathrm{g}$ RNA

$2 \mu 110 \times$ RT-Puffer

$2 \mu 1 \mathrm{dNTP}$ Mix $(5 \mathrm{mM})$

$2 \mu 110 \mu \mathrm{M}$ Primer (3'-terminal)

$1 \mu$ l Omniscript ${ }^{\circledR}$ Reverse Transkriptase (4U)

mit RNase-freiem Wasser auf $20 \mu 1$ auffüllen

Der Ansatz wurde $90 \mathrm{~min}$ bei $37^{\circ} \mathrm{C}$ inkubiert und dann $5 \mathrm{~min}$ bei $93^{\circ} \mathrm{C}$ gekocht, um die Reverse Transkriptase zu inaktivieren. $3 \mu \mathrm{l}$ des RT-Ansatzes wurde als Template zur anschließenden PCR eingesetzt. Zur Amplifikation der cDNA des RT-Ansatzes erfolgte eine PCR mit der Platinum ${ }^{\circledR}$ Pfx-DNA-Polymerase (Invitrogen, Karlsruhe). Diese DNAPolymerase besitzt eine proofreading 3'-5'-Exonuklease-Aktivität und bietet somit eine hohe Synthesegenauigkeit. Die Pfx-Polymerase liegt in einer inaktivierten Form vor und muss durch einen initialen $94^{\circ} \mathrm{C}$-Denaturierungsschritt aktiviert werden. Die PCRReaktion erfolgte im $50 \mu$ l-Ansatz. Als Template dienten $3 \mu 1$ der RT-Reaktion.

PCR-Ansatz:

$3 \mu 1$ RT-Reaktionsprodukt

$5 \mu 110 \times$ Pfx-Amplifikationspuffer

$5 \mu 110 \times$ Enhancer Solution

$1,5 \mu \mathrm{dNTP}$ Mix $(10 \mathrm{mM})$

$1 \mu 150 \mathrm{mM} \mathrm{MgSO}_{4}$

$2 \mu 110 \mu \mathrm{M}$ Primer (3'-terminal)

$2 \mu 110 \mu \mathrm{M}$ Primer (5'-terminal)

0,6 $\mu 1$ Pfx-DNA-Polymerase (1,5 U)

mit $\mathrm{dH}_{2} \mathrm{O}$ auf $50 \mu \mathrm{l}$ auffüllen

PCR-Reaktionsprotokoll:

\begin{tabular}{rr}
$2 \mathrm{~min}$ & $94^{\circ} \mathrm{C}$ \\
\hline $35 \times \quad 20 \mathrm{sec}$ & $94^{\circ} \mathrm{C}$ \\
$30 \mathrm{sec}$ & $55^{\circ} \mathrm{C}$ \\
$180 \mathrm{sec}$ & $68^{\circ} \mathrm{C}$ \\
\hline $10 \mathrm{~min}$ & $68^{\circ} \mathrm{C}$
\end{tabular}


Um die Spezifität der PCR zu erhöhen erfolgte eine zweite, nested PCR auf das erste PCR-Produkt. Dafür wurde das gleiche Protokoll verwendet. $3 \mu \mathrm{l}$ des PCR-Produkt 1 wurden als Template eingesetzt und es wurden Primer genutzt, die die zu amplifizierende cDNA etwa 20 bp vom 5'- und 3'-Terminus des PCR-Produkt binden. Die PCRProdukte 1 und 2 wurden anschließend im Agarosegel analysiert.

\subsubsection{Multiplex-PCR zur Genotypisierung}

Der Nachweis von zwei Gen-Allelen in einer PCR zur Genotypisierung von Gene Trap Mäusen erfolgte durch eine Multiplex-PCR mit einem 5'-Oligonukleotidprimer und zwei 3'-Oligonukleotidprimern. Die PCR-Produkte wurden in einen $50 \mu$ l-Ansatz mit der Taq DNA-Polymerase (Roche Applied Science, Indianapolis, USA) generiert.

Ansatz Taq PCR:

$2-3 \mu$ l genomische DNA

$5 \mu 110 \times$ PCR Reaktionspuffer

$1 \mu \mathrm{dNTP}$ Mix $(10 \mathrm{mM})$

$1 \mu \mathrm{l} 10 \mu \mathrm{M}$ Primer 1 (3'-terminal)

$1 \mu \mathrm{l} 10 \mu \mathrm{M}$ Primer 2 (3'-terminal)

$1 \mu \mathrm{l} 10 \mu \mathrm{M}$ Primer 2 (5'-terminal)

2,5 $\mu 1 \mathrm{DMSO}$

0,5 $\mu 1$ Taq DNA-Polymerase (5 U/ $\mu \mathrm{l})$

mit $\mathrm{dH}_{2} \mathrm{O}$ auf $50 \mu \mathrm{l}$ auffüllen

PCR-Reaktionsprotokoll:

\begin{tabular}{rr}
$2 \mathrm{~min}$ & $94^{\circ} \mathrm{C}$ \\
\hline $30 \times \quad 15 \mathrm{sec}$ & $94^{\circ} \mathrm{C}$ \\
$15 \mathrm{sec}$ & $54^{\circ} \mathrm{C}$ \\
$60 \mathrm{sec}$ & $72^{\circ} \mathrm{C}$ \\
\hline $30 \mathrm{sec}$ & $72^{\circ} \mathrm{C}$
\end{tabular}




\subsubsection{DNA-Sequenzierung}

Zur Sequenzierung von DNA-Abschnitten wurde das BigDye ${ }^{\circledR}$ Terminator v3.1 Cycle Sequencing Kit (Applied Biosystems, Darmstadt) verwendet. Der Sequenzierungspremix enthält alle Komponenten für eine fluoreszenzbasierte Sequenzierungsreaktion. Die Reaktion erfolgte in einem $10 \mu 1$ Ansatz.

Sequenzierungsansatz:

$$
\begin{aligned}
& 200-400 \text { ng Template (dsDNA) } \\
& 1,5 \mu 1 \text { Sequenzierungspremix } \\
& 2 \mu 1 \text { Sequenzierungspuffer } \\
& 0,8 \mu 110 \mu \mathrm{M} \text { Sequenzierungsprimer } \\
& \text { mit } \mathrm{dH}_{2} \mathrm{O} \text { auf } 10 \mu 1 \text { auffüllen }
\end{aligned}
$$

Sequenzierungsprotokoll:

$\begin{aligned} 25 \times 10 \mathrm{sec} & 96^{\circ} \mathrm{C} \\ 5 \mathrm{sec} & 50^{\circ} \mathrm{C} \\ 4 \mathrm{~min} & 60^{\circ} \mathrm{C}\end{aligned}$

Die Sequenzierungsreaktion wurde anschließend aufgereinigt. Dazu wurden dem Ansatz $1 \mu 1125$ mM EDTA und $1 \mu 13$ M Natriumacetat zugesetzt. Die DNA wurde mit $50 \mu 1$ $100 \%$ Ethanol gefällt und nach 5 min für 15 min bei 14000 rpm pelletiert. Der Überstand wurde abgenommen. Das Pellet wurde mit $70 \mu 170 \%$-igem Ethanol gewaschen. Nach 5 min Zentrifugation bei 14000 rpm wurde der Überstand abgenommen, das Pellet wurde 2 min in der Vakuumzentrifuge Speed Vac getrocknet und in $30 \mu \mathrm{ld} \mathrm{d}_{2} \mathrm{O}$ aufgenommen. Die elektrophoretische Analyse des Sequenzierungsansatz erfolgte als Service in der Abteilung Entwicklungsbiochemie am ABI PRISM ${ }^{\circledR} 3100$ Genetic Analyzer.

\subsubsection{Spaltung von DNA mit Restriktionsendonukleasen}

Restriktionsendonukleasen spalten DNA an spezifischen Basensequenzen. Die Aktivität von Restriktionsendonukleasen wird in Units (U) angegeben. Eine Unit entspricht der Menge an Restriktionsenzym, die benötigt wird, um $1 \mu \mathrm{g}$ Lambda-DNA in einer Stunde vollständig zu schneiden. Zur Spaltung von DNA wurden Restriktionsenzyme der Firma 
New English Biolabs (NEB, Frankfurt am Main) verwendet. Das NEB Restriktionspuffer-System besteht aus enzymspezifischen Puffern, sowie aus vier NEB Basispuffern. Für einen Restriktionsverdau von Plasmid-DNA wurden $1 \mu \mathrm{g}$ DNA eingesetzt.

Restriktionsansatz:

$1 \mu \mathrm{g}$ Plasmid-DNA

$2 \mu 1$ empfohlener NEB $10 \times$ Puffer

2 U Restriktionsendonuklease

auf $20 \mu 1$ mit $\mathrm{dH}_{2} \mathrm{O}$ auffüllen

Der Ansatz wurde für $2 \mathrm{~h}$ bei $37^{\circ} \mathrm{C}$ inkubiert. Anschließend wurden die DNA-Fragmente durch Auftrennung im Agarosegel analysiert. Der Verdau genomischer DNA für die Southern Blot Analyse erfolgte über Nacht mit größerer Enzymmenge in entsprechend größerem Reaktionsvolumen.

\subsubsection{Auftrennung von DNA in Agarosegelen}

Zur Analyse und Isolierung von DNA-Fragmenten unterschiedlicher Größe erfolgte ihre Auftrennung durch Agarosegel-Elektrophorese, wobei die Agarose-Konzentration der Gele deren Trennbereich bestimmt (Tab. 3.2). Entsprechend der Größe der zu trennenden DNA-Fragmente wurde Agarose in $350 \mathrm{ml} 1 \times$ TAE-Puffer eingewogen und in der Mikrowelle aufgekocht. Nach Erkalten der Agarose-Lösung auf maximal $60^{\circ} \mathrm{C}$ wurden $0,5 \mu \mathrm{g} / \mathrm{ml}$ Ethidiumbromid zugesetzt. Die Lösung wurde in eine Gelform gegossen und bei RT weiter abgekühlt. Die horizontale Elektrophoresekammer wurde mit TAE-Puffer gefüllt und das erstarrte Gel wurde in die Kammer überführt. Die DNA-Proben wurden mit 10 - $20 \%$ Probenpuffer versetzt und in die Geltaschen pipettiert. Die Elektrophorese erfolgte mit einer Spannung von 3-4 V/cm. Das Ethidiumbromid interkaliert während der Elektrophorese in das DNA-Molekül. Die aufgetrennten DNA-Fragmente werden unter UV-Licht als Banden sichtbar. Auf dem UV-Transilluminator wurde das Gel analysiert und zur Dokumentation mit einem Video-System (Cybertech CS1) aufgenommen. 
$50 \times$ TAE-Puffer:

Proben-Ladepuffer:
2 M Tris/Essigsäure $\mathrm{pH} 8,0$

$100 \mathrm{mM}$ EDTA

$0,25 \%$ Bromphenolblau

$40 \%$ Sucrose

in $1 \times \mathrm{TAE}$

\begin{tabular}{ll}
\hline Agarose-Konzentration $(\%)$ & Trennbereich $(\mathrm{kb})$ \\
\hline 0,6 & $20-1$ \\
0,9 & $7-0,5$ \\
1,2 & $6-0,4$ \\
1,5 & $4-0,2$ \\
2,0 & $3-0,1$ \\
\hline
\end{tabular}

Tab. 3.4: Agarose-Konzentration und Trennbereich bei DNA-Agarose-Gelelektrophorese

\subsubsection{Isolierung von DNA aus Agarosegelen}

Zur Isolierung von DNA-Fragmenten aus Agarosegelen wurde das QIAquick ${ }^{\circledR}$ Gel Extraction Kit (Qiagen, Hilden) verwendet. Die DNA-Bande wurde unter UV-Licht (UV-Handlampe) mit einem Skalpell ausgeschnitten und gewogen. Anschließend erfolgte die DNA-Isolierung nach dem Herstellerprotokoll (QIAquick ${ }^{\circledR}$ Spin Handbook, 2006).

\subsubsection{Auftrennung von RNA in Agarosegelen}

Zur qualitativen Analyse von RNA und zur Northern Blot Analyse erfolgte eine Auftrennung der RNA durch Formaldehyd-Agarosegel-Elektrophorese. Alle verwendeten Materialien wurden vor Verwendung mindestens $30 \mathrm{~min}$ in $1 \mathrm{M} \mathrm{NaOH}$ eingelegt und anschließend mit $\mathrm{dH}_{2} \mathrm{O}$ gespült. Die RNA wurde mit Ladepuffer versetzt und bei $65^{\circ} \mathrm{C}$ 5 min erhitzt. Die Proben wurden auf das Formaldehyd-Agarosegel aufgetragen und bei 40 mA $6-7$ h aufgetrennt. Die aufgetrennte RNA wird unter UV-Licht sichtbar. Auf dem UV-Transilluminator wurde das Gel analysiert und zur Dokumentation mit einem VideoSystem (Cybertech CS1) aufgenommen. 


$\begin{array}{ll}\text { DEPC-Wasser: } & 0,1 \% \mathrm{DEPC} \text { (Diethylpyrocarbonat) } \\ & \text { in } \mathrm{ddH}_{2} \mathrm{O} \text {, über Nacht rühren, autoklavieren } \\ & 200 \mathrm{mM} \text { MOPS } \\ & 50 \mathrm{mM} \text { Natriumacetat } \\ & 10 \mathrm{mM} \text { EDTA } \\ & \text { einstellen von pH } 7,0 \text { mit NaOH } \\ & 16 \mu 1 \text { gesättigte Bromphenolblau-Lösung in } \mathrm{dH}_{2} \mathrm{O} \\ & 80 \mu 1800 \mathrm{mM} \text { EDTA } \\ & 720 \mu 137 \% \text { Formaldehyd } \\ & 2 \mathrm{ml} \text { Glycerin } \\ & 3084 \mu 1 \text { Formamid } \\ & 4 \mathrm{ml} 10 \times \text { MOPS-Laufpuffer } \\ & \text { mit DEPC-Wasser auf } 10 \mathrm{ml} \text { auffüllen } \\ & 9 \text { Teile DEPC-Wasser } \\ & 1 \mathrm{Teil} 10 \times \text { MOPS-Laufpuffer } \\ & 2 \% \text { Agarose } \\ \text { RNA-Gel: } & 1,6 \% \text { vafkochen, auf } 65^{\circ} \mathrm{C} \text { abkühlen lassen } 37 \% \text {-igen Formaldehyd-Lösung } \\ & 1 \mu \mathrm{g} / \mathrm{ml} \text { Ethidiumbromid }\end{array}$

\subsubsection{Ligation von DNA-Fragmenten}

Das Enzym Ligase katalysiert die Verknüpfung freier 3'-Hydroxy- und 5'-PhosphatEnden von Nukleinsäuren zu Phosphodiesterbindungen. Durch die Ligation können DNA-Fragmente in Vektoren integriert werden. Mit Restriktionsendonukleasen wurden der Klonierungsvektor und die zu integrierende cDNA gespalten. Die DNA-Fragmente wurden im Agarosegel aufgetrennt und aus dem Gel isoliert. Anschließend konnten die kohäsiven Enden von Vektor-DNA und cDNA durch Ligation verknüpft werden. Es wurden $100 \mathrm{ng}$ Vektor und ein 3- bis 5-molarer Überschuss an cDNA eingesetzt. Zur Ligation wurde die T4 DNA Ligase (NEB, Frankfurt/Main) verwendet. Die Ligation erfolgte über Nacht bei $16^{\circ} \mathrm{C}$ im Wasserbad. 
Ligationsansatz:

\author{
100 ng Vektor-DNA \\ x $\mu$ l DNA-Fragment (3-5 molarer Überschuss) \\ $1 \mu 110 \times$ T4-Ligase-Puffer \\ $1 \mu 1$ T4-DNA-Ligase (400 NEB-Einheiten/ $\mu \mathrm{l}$ ) \\ auf $10 \mu \mathrm{lmit} \mathrm{dH}_{2} \mathrm{O}$ auffüllen
}

\title{
3.2.1.13 Präparation chemisch kompetenter E. coli-Zellen
}

$1 \mathrm{ml}$ einer Über-Nacht-Kultur einer DH5 $\alpha$ E. coli Bakterienkultur wurden in $99 \mathrm{ml}$ Medium A bei $37^{\circ} \mathrm{C}$ im Schüttelinkubator inkubiert bis eine Dichte von OD 0,4 bis 0,6 erreicht war. Die Bakterienkultur wurde 10 min auf Eis abgekühlt und anschließend bei $5000 \mathrm{rpm} 15 \mathrm{~min}$ in der Kühlzentrifuge pelletiert. Das Bakterienpellet wurde vorsichtig mit $1 \mathrm{ml}$ kaltem Medium A und 2,5 ml Lösung B gemischt. Die Bakteriensuspension wurde dann in $200 \mu \mathrm{l}$ Volumina aliquotiert, in flüssigem Stickstoff eingefroren und bei $-80^{\circ} \mathrm{C}$ gelagert.

Medium A:

$0,2 \%$ Glucose

$10 \mathrm{mM} \mathrm{MgSO} 4$

in LB-Medium, steril filtrieren

Lösung B:

$$
\begin{aligned}
& \text { 36\% Glycerin, } \\
& 12 \% \text { PEG (MW 7500) } \\
& 12 \mathrm{mM} \mathrm{MgSO} 4 \\
& \text { in LB, pH 7,0 }
\end{aligned}
$$

\subsubsection{Transformation chemisch kompetenter E. coli-Zellen mit Plasmid-DNA}

Ein $200 \mu \mathrm{l}$ Aliquot transformationskompetenter DH5 $\alpha$ wurde auf Eis aufgetaut. $1 \mathrm{ng}$ ligierte Plasmid-DNA wurde mit der Bakteriensuspension vorsichtig vermischt. Nach 20 min Inkubation auf Eis erfolgte ein Hitzeschock für 2 min bei $65^{\circ} \mathrm{C}$. Dann folgte eine weitere 20 min Inkubation auf Eis. Der Bakteriensuspension wurde anschließend 0,5 ml LB-Medium zugesetzt und sie wurde $1 \mathrm{~h}$ bei $37^{\circ} \mathrm{C}$ auf dem Drehrad inkubiert. Danach wurden $50-100 \mu 1$ der transformierten Bakterien auf eine LB-Agarplatte mit 
Antibiotikum (Tab. 3.2) (entsprechend der Antibiotikumresistenz des Klonierungsvektors) ausgestrichen. Die Platten wurden über Nacht bei $37^{\circ} \mathrm{C}$ im Brutschrank inkubiert. Am nächsten Morgen wurden einige der gewachsenen Kolonien gepickt und in $20 \mu \mathrm{l} \mathrm{dH}_{2} \mathrm{O}$ resuspendiert. $10 \mu \mathrm{l}$ der Suspension wurden als Template zur PCR eingesetzt, um die Insertion in den ligierten Vektor zu überprüfen. Mit dem Rest der Suspension wurden $5 \mathrm{ml}$ Flüssigkultur (LB-Medium + Antibiotikum) angeimpft. Am folgenden Tag konnten $2 \mathrm{ml}$ der Flüssigkultur zur Plasmid-Präparation (siehe 3.2.1.15) eingesetzt werden. $700 \mu 1$ Flüssigkultur wurden mit $300 \mu 1$ sterilem Glycerin versetzt. Die Glycerinkultur wurde bei $-80^{\circ} \mathrm{C}$ gelagert und zum Animpfen neuer Kulturen verwendet.

\subsubsection{Mini-/Midi-Präparation von Plasmid-DNA}

Zur Isolierung von Plasmid-DNA aus $2 \mathrm{ml}$ Bakterienkultur transformierten E. coli wurde das QIAprep ${ }^{\circledR}$ Spin Miniprep Kit (Qiagen, Hilden) verwendet. Die Plasmid-Isolierung erfolgte nach dem Herstellerprotokoll (QIAprep ${ }^{\circledR}$ Miniprep Handbook, 2006). Zur Isolierung von Plasmid-DNA aus $100 \mathrm{ml}$ Kultur transformierten E. coli wurde das QIAGEN $^{\circledR}$ Plasmid Midi Kit (Qiagen, Hilden) verwendet. Die Plasmid-Isolierung erfolgte ebenfalls nach dem Herstellerprotokoll $\left(\right.$ QIAGEN $^{\circledR}$ Plasmid Purification Handbook, 2006).

\subsubsection{Klonieren mit dem Gateway System}

Die Gateway ${ }^{\circledR}$ Technology (Hartley et al. 2000) ist eine Klonierungsmethode, bei der die Insertion von cDNA in einen Vektor durch sequenzspefizische, homologe Rekombination der DNA erfolgt. Die Gateway ${ }^{\circledR}$ Technology nutzt das Rekombinationssystem des Bacteriophagen Lambda. Es basiert auf zwei Rekombinationsreaktionen. Die BP Reaktion katalysiert die Rekombination von DNA-Bereichen, die durch die attachment-Sequenz attB und attP flankiert sind. Die Reaktion erzeugt rekombinierte DNA-Bereiche die durch die attachment-Sequenzen attL und attR begrenzt sind. Die zweite Reaktion wird als LR Reaktion bezeichnet. Sie katalysiert die Rückreaktion von attL-flankierten DNA-Bereichen mit attR-flankierten Bereichen, wobei durch die Rekombination wiederum DNA-Bereiche erzeugt werden, die attB und attP flankiert 
sind. Die BP Reaktion des Gateway ${ }^{\circledR}$ Systems (Invitrogen, Karlsruhe) wird von dem Enzym BP Clonase ${ }^{\mathrm{TM}}$ katalysiert. Durch die BP Reaktion werden lineare doppelsträngige DNA-Sequenzen, die durch attB-Sequenzen flankiert sind in den attP-haltige Eingangsvektoren integriert. Dabei entsteht ein Eingangsvektor bei dem die inserierte cDNA von attL-Sequenzen flankiert wird. Anschließend wird das DNA-Fragment durch das Enzym LR Clonase ${ }^{\mathrm{TM}} \quad$ (Gateway $^{\circledR}$ System, Invitrogen, Karlsruhe) vom Eingangsvektor auf einen beliebigen attR-haltigen Zielvektor übertragen. Mit Hilfe des Gateway ${ }^{\circledR}$ Systems können somit cDNAs, die einmal in den Eingangsvektor rekombiniert wurden, durch eine einstufige Reaktion in viele verschiedene Zielvektoren übertragen werden.

\subsubsection{Insertion von cDNA durch BP-Rekombination}

Durch Add on-PCR wurden an die cDNAs der Kandidatenproteine attB-Sequenzen angefügt. Das PCR-Produkt wurde im Agarosegel analysiert und aus der Gel aufgereinigt. Dann erfolgte die Integration des attB-flankierten PCR-Produkts in den Eingangsvektor des Gateway ${ }^{\circledR}$ Systems.

BP-Rekombinationsansatz:

100 fmol attB-flankiertes PCR Produkt

$2 \mu \mathrm{pDONR} 221$ Vektor $(150 \mathrm{ng} / \mu \mathrm{l})$

$4 \mu 15 \times$ BP Clonase $^{\mathrm{TM}}$ Reaktionspuffer

auf $16 \mu 1$ auffüllen mit TE-Puffer

$4 \mu 1$ BP Clonase

Der Reaktionsansatz wurde $1 \mathrm{~h}$ bei $25^{\circ} \mathrm{C}$ inkubiert. Anschließend wurde der Reaktionsansatz zur Transformation in chemisch kompetente DH5 $\alpha$ eingesetzt (siehe 3.2.1.14). Der Vektor pDONR221 besitzt ein Kanamycin-Resistenzgen. Der Transformationsansatz wurde auf LB-Kanamycin-Platten ausplattiert. Bei erfolgreicher Rekombination des pDONR221 Vektors wird das attP-flankierte ChloramphinicolResistenzgen des Vektors durch das attB-flankierte PCR Produkt ersetzt. 100 Einzelklone wurden auf eine neue LB-Kanamycin-Platte, sowie auf eine Chloramphinicol-Platte ausgestrichen. Erfolgreich rekombinierte Bakterienklone wachsen nur auf Kanamycin 
und nicht auf Chloramphinicol. Die Integration des Inserts wurde weiter durch PCR und Sequenzierung des Inserts überprüft.

\subsubsection{DNA-Transfer mittels LR-Rekombination}

Aus dem Eingangsvektor pDONR221 wurden die cDNAs der Kandidatenproteine in den Vektor pcDNA-DEST40 übertragen.

LR-Rekombinationsansatz:

300 ng pDONR221 mit attL-flankiertem Insert

$2 \mu \mathrm{l}$ pcDNA-DEST40 (150 ng/ $\mu \mathrm{l})$

$4 \mu 15 \times$ LR Clonase $^{\mathrm{TM}}$ Reaktionspuffer

auf $16 \mu 1$ auffüllen mit TE-Puffer

$4 \mu 1$ LR Clonase

Der Reaktionsansatz wurde $1 \mathrm{~h}$ bei $25^{\circ} \mathrm{C}$ inkubiert. Anschließend wurde der Reaktionsansatz zur Transformation in chemisch kompetente DH5 $\alpha$ eingesetzt (siehe 3.2.1.14). Die Gateway ${ }^{\circledR}$ Zielvektoren besitzen ein Ampicillin-Resistenzgen. Der Transformationsansatz wurde auf LB-Ampicillin-Platten ausplattiert. Bei erfolgreicher Rekombination des pcDNA-DEST40-Vektors wird das attR-flankierte ChloramphinicolResistenzgen des Vektors durch das attL-flankierte Insert des pDONR221-Vektors ersetzt. 100 Einzelklone wurden auf eine neue LB-Kanamycin-Platte, sowie auf eine Chloramphinicol-Platte ausgestrichen. Erfolgreich rekombinierte Bakterienklone wachsen nur auf Ampicillin und nicht auf Chloramphinicol. Die Integration des Inserts wurde weiter durch PCR und Sequenzierung des Inserts überprüft.

\subsubsection{Southern Blot und Northern Blot}

Der Southern Blot (Alwine et al. 1977; Southern 1982) dient zum Nachweis von DNAAbschnitten in komplexen DNA-Proben (z. B. genomische DNA). Durch Verdau mit Restriktionsendonukleasen erfolgt eine spezifische Fragmentierung der DNA. Anschließend werden die DNA-Fragmente im Agarosegel aufgetrennt und auf eine Amersham Hybond ${ }^{\mathrm{TM}}-\mathrm{N}$ Membran (GE Healthcare, München) übertragen. Dort erfolgt 
der Nachweis des zu untersuchten DNA-Abschnitts durch Hybridisierung mit einer radioaktiv markierten Sonde.

Der Northern Blot dient der qualitativen und quantitativen Analyse von RNA. Im Formaldehyd-Agarosegel wird die isolierte Gesamt-RNA aufgetrennt und anschließend auf eine Amersham Hybond ${ }^{\mathrm{TM}}-\mathrm{N}$ Membran (GE Healthcare, München) geblottet. Durch Hybridisierung mit einer radioaktiv markierten cDNA-Sonde erfolgt der quantitative Nachweis der untersuchten mRNA.

\subsubsection{Transfer von DNA/RNA auf Hybond ${ }^{\mathrm{TM}}-\mathrm{N}$ Membranen}

Nach Auftrennung der DNA im Agarosegel wurde das Gel 20 min in Denaturierungspuffer geschwenkt. Nach Denaturierung der DNA wurde das Gel $20 \mathrm{~min}$ in Neutralisierungspuffer inkubiert und anschließend für $10 \mathrm{~min}$ in $20 \times \mathrm{SSC}$ äquilibriert. Anschließend wurde der Southern Blot wie in Abb. 3.1 dargestellt aufgebaut. Dazu wurde eine Glasscheibe über einem Pufferreservoir mit $20 \times$ SSC positioniert. Als Salzbrücke wurde auf die Glasscheibe ein in $20 \times$ SSC getränktes Whatman-Filterpapier aufgelegt, dessen Ränder seitlich in das Pufferreservoir reichten. Die Hybond ${ }^{\mathrm{TM}}-\mathrm{N}$ Membran wurde durch Schwenken in $\mathrm{dH}_{2} \mathrm{O}$ aktiviert und anschließend in $20 \times \mathrm{SSC}$ äquilibriert. Dann wurden das Gel, die Hybond ${ }^{\mathrm{TM}}-\mathrm{N}$ Membran, ein in $20 \times$ SSC getränktes WhatmanFilterpapier, 2 trockene Whatman-Filterpapiere und ein Stapel Papierhandtücher auf der Salzbrücke gestapelt. Der Stapel wurde mit einer Glasplatte abgedeckt und mit einem Gewicht beschwert. Der Transfer erfolgte über Nacht bei RT. Nach dem Transfer wurde die Membran getrocknet. Durch 15 Sekunden UV-Bestrahlung wurde die DNA fest mit der Membranoberfläche verbunden. Die Membran wurde kurz in $\mathrm{dH}_{2} \mathrm{O}$ geschwenkt und bei $60^{\circ} \mathrm{C}$ getrocknet.

Für einen Northern Blot wurde die zu untersuchende RNA im Formaldehyd-Agarosegel aufgetrennt. Das Gel wurde nach der Elektrophorese direkt in $20 \times$ SSC äquilibriert. Der Aufbau des Blots entspricht dem des Southern Blots. 


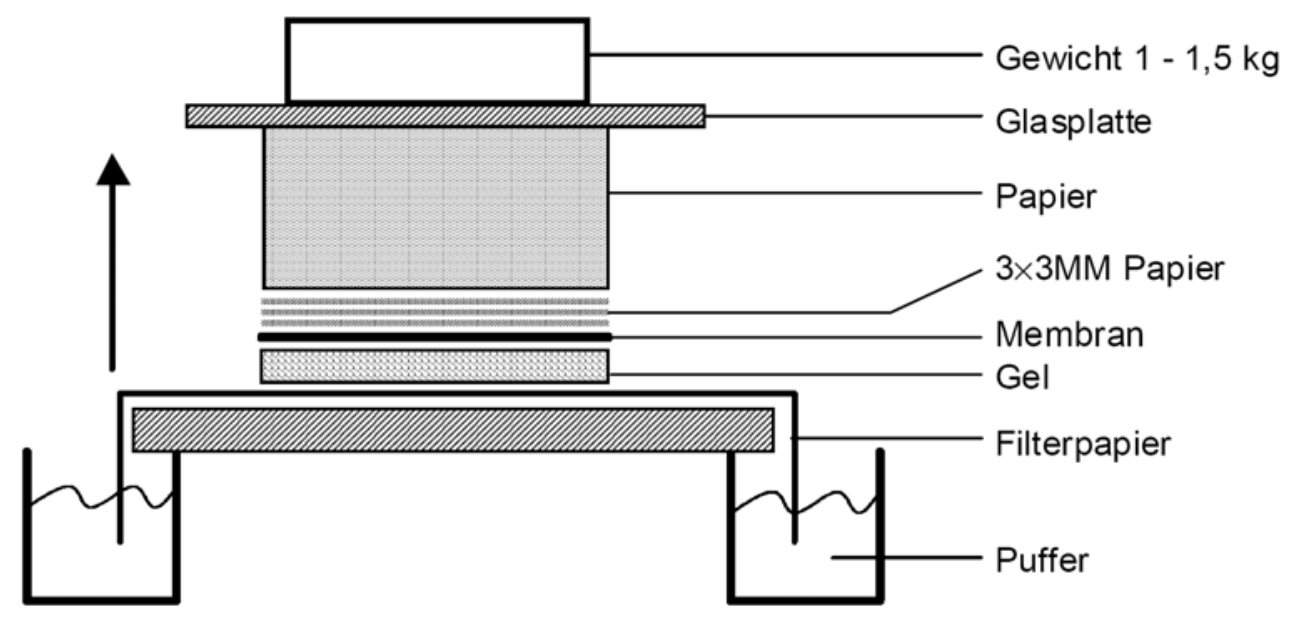

Abb. 3.1: Schematische Darstellung des Kapillartransfers von RNA bzw. DNA bei der Northern Blot bzw. Southern Blot Analyse

Die Kapillarkraft des Aufbaus erzeugt einen Flüssigkeitsstrom, der von einem Pufferreservoir ausgehend von unten durch das Gel, weiter durch die Membran zu einem Stapel saugfähigen Materials läuft. Dieser Strom zieht die DNA aus dem Gel mit und überträgt sie auf die Membran.

Denaturierungslösung:

Neutralisierungslösung:

$20 \times$ SSC:
$1,5 \mathrm{M} \mathrm{NaCl}$

$$
0,5 \mathrm{M} \mathrm{NaOH}
$$

$1,5 \mathrm{M} \mathrm{NaCl}$

$0,5 \mathrm{M}$ Tris/ $\mathrm{HCl} \mathrm{pH} 7,2$

1 mM EDTA

$3 \mathrm{M} \mathrm{NaCl}$

$300 \mathrm{mM}$ Natriumcitrat $\mathrm{pH} 7,0$

\subsubsection{Markierung von DNA-Sonden mit $\alpha-\left[{ }^{32} \mathrm{P}\right]$-dCTP}

$\mathrm{Zu}$ Markierung von mRNA- oder von DNA-Sequenzen wurden sie auf der Blotmembran mit radioaktiv markierten DNA-Sonden hybridisiert. Als Sonden für den Southern Blot dienten 400 - 1000 bp lange DNA-Fragmente, die durch PCR auf genomische DNA isoliert wurden. Als Northern Blot Sonden wurden 400 - 1000 bp lange cDNAAbschnitte verwendet. Zur radioaktiven Markierung der Sonden wurde das Amersham Rediprime II Random Prime Labelling System (GE Healthcare, München) genutzt. Zur Markierung wurden etwa $50 \mathrm{ng}$ eines entsprechenden PCR-Produkts verwendet. Die 
DNA wurde auf $45 \mu 1$ mit TE-Puffer aufgefüllt, bei $95^{\circ} \mathrm{C} 5$ min denaturiert und 5 min auf Eis abgekühlt. Der Ansatz und $50 \mu \mathrm{Ci} / 5 \mu 1^{32} \mathrm{P}$-dCTP (Hartmann Analytic, Braunschweig) wurden mit einem lyophilisierten Aliquot des Rediprime II Random Prime Labelling Kits vermischt. Nachdem sich das Lyophilisat gelöst hatte wurde der Ansatz 15 min bei $37^{\circ} \mathrm{C}$ inkubiert. Um die markierte Sonde von freien Nukleotiden zu befreien wurde der Ansatz anschließend nach dem QIAquick Nucleotide Removal Protokoll (QIAquick Spin Handbook 2006, QIAquick ${ }^{\circledR}$ Gel Extraction Kit, Qiagen, Hilden) entsprechend den Herstellerangaben aufgereinigt. Die radioaktiv markierte Sonde wurde nach der Aufreinigung mit $200 \mu 1$ Puffer EB von der QIAquick Spin Säule eluiert. $10 \mu 1$ des Eluats wurden in ein neues Gefäß überführt und zur Messung der Cerenkovstrahlung am Flüssigkeitsszintillationszähler 1900TR (Packard, Perkin Elmer, Überlingen) eingesetzt. Die eingebaute Radioaktivität der Sonde wurde daraufhin berechnet. Die spezifische Aktivität der ${ }^{32} \mathrm{P}$-markierten Sonden lag in der Regel bei etwa $10^{9} \mathrm{cpm} / \mu \mathrm{g}$ DNA.

\subsubsection{Hybridisierung der Blots mit radioaktiv markierten DNA-Sonden}

Nach dem Blotten wurde die getrocknete Hybond ${ }^{\mathrm{TM}}-\mathrm{N}$ Membran mit etwa $70 \mu 1 / \mathrm{cm}^{2}$ Amersham Rapid-hyb ${ }^{\text {TM }}$ Buffer (GE Healthcare, München) versetzt und 30 min bei $65^{\circ} \mathrm{C}$ vorinkubiert. Etwa $3 \times 10^{6} \mathrm{cpm}$ radioaktive Sonde pro ml Rapid-hyb ${ }^{\mathrm{TM}}$ Buffer wurden zur Hybridisierung eingesetzt. $100 \mu \mathrm{l}$ Hering-Sperma-DNA wurden mit der einzusetzenden Menge radioaktive Sonde gemischt und $5 \mathrm{~min}$ bei $95^{\circ} \mathrm{C}$ denaturiert. Der DNA-Mix wurde auf Eis abgekühlt und zur vorinkubierten Membran gegeben. Die Hybridisierung erfolgte über Nacht bei $65^{\circ} \mathrm{C}$ unter Rotation. Die Membran wurden dann $2 \times 15$ min mit Waschlösung 1 und $2 \times 15$ min mit Waschlösung 2 unter leichtem Schwenken bei RT gewaschen. Anschließend wurde sie noch $2 \times 10 \mathrm{~min}$ bei $65^{\circ} \mathrm{C}$ in Waschlösung 2 geschwenkt. Lag die gemessene Strahlung der Membran unter $50 \mathrm{cpm}$, wurde sie feucht in Folie eingeschweißt. Durch Exposition einer Phospho-Imaging Plate (Fujifilm, Düsseldorf) wurden die radioaktiven Sonden auf der Membran detektiert und mit dem Phosphoimager PMI (BioRad, München) analysiert.

Um eine radioaktive Sonde von einer Southern Blot oder Northern Blot Membran zu entfernen, wurde die Membran mit einer $95^{\circ} \mathrm{C}$ heißen 0,1\%-igen SDS Lösung übergossen. Unter Schwenken wurde die Membran 15 min mit der abkühlenden Lösung 
inkubiert und anschließend mit Waschlösung 2 gespült. Die Inkubation entfernt radioaktive Sonden von der Membran, ohne die Qualität und die Quantität der geblotteten DNA bzw. RNA zu verändern, und der Blot kann anschließend für die Hybridisierung mit einer weiteren Sonde eingesetzt werden.
Waschlösung 1:
$2 \times \mathrm{SSC}$
$0,1 \% \mathrm{SDS}$
Waschlösung 2:
$0,2 \times \mathrm{SSC}$
$0,1 \%$ SDS

\subsection{Zellbiologische Methoden}

\subsubsection{Kultivierung von eukaryontischen Zellen}

Die Zellen wurden in wassergesättigter Atmosphäre unter $5 \% \mathrm{CO}_{2}$ bei $37^{\circ} \mathrm{C}$ kultiviert. Medien und Lösungen wurden auf $37^{\circ} \mathrm{C}$ vorgewärmt. Im Allgemeinen erfolgte die Kultivierung der Zellen mit dem folgenden Medium.

Normalmedium:

DMEM

$10 \%$ FKS

$1 \%(\mathrm{v} / \mathrm{v})$ Penicillin/Streptomycin

$(100 \times$ Stocklösung $)$

$1 \%(\mathrm{v} / \mathrm{v})$ Glutamin $(200 \mathrm{mM}, 100 \times$ Stocklösung $)$

G418-Stocklösung:

$25 \mathrm{mg} / \mathrm{ml} \mathrm{G} 418$

$7,5 \%$ FKS

Medien für stabil pDNA3.1/Hygro transfizierte Zellen enthielten zusätzlich $500 \mathrm{U} / \mathrm{ml}$ Hygromycin B. Medien für stabil transfizierte pDNA-DEST40-transfizierte Zellen enthielten $400 \mu \mathrm{g} / \mathrm{ml} \mathrm{G} 418$. 


\subsubsection{Trypsinieren von Zellen}

Trypsinierung und Passage der Zellen erfolgte im Allgemeinen nach Erreichen der Konfluenz des Zellrasens. Das Medium wurde abgesaugt. Die Zellen wurden einmal mit PBS gespült. Nach Absaugen des PBS wurden die Zellen etwa 5 min mit 0,05\% (w/v) Trypsin-EDTA-Lösung (Gibco, Invitrogen, Karlsruhe) bei $37^{\circ} \mathrm{C}$ bis zur Abrundung der Zellen inkubiert. Die Trypsinierung wurde durch Zugabe von Normalmedium gestoppt. Die Zellen wurden durch mehrfaches Aufsaugen mit der Pipette vereinzelt und dann in der gewünschten Dichte ausgesät. Um die Zellen zur weiteren Verarbeitung zu pelletieren wurden sie in der Labofuge $5 \mathrm{~min}$ bei $1000 \mathrm{rpm}$ zentrifugiert. Das Zellpellet wurde mit PBS gewaschen und erneut abzentrifugiert. Zellpellets wurden bei $-20^{\circ} \mathrm{C}$ gelagert.

\subsubsection{Kryokonservierung von Zellen}

Die Zellen wurden trypsiniert, in Normalmedium aufgenommen und in der Labofuge (1000 rpm, 5 min) pelletiert. Nach Absaugen des Überstandes wurden die Zellen in $1 \mathrm{ml}$ kaltem Einfriermedium aufgenommen und in Kryoröhrchen überführt. Die Zellen wurden zunächst bei $-80^{\circ} \mathrm{C}$ eingefroren und nach $24 \mathrm{~h}$ in flüssigem Stickstoff überführt.

Einfriermedium:

$10 \%$ DMSO in Normalmedium

\subsubsection{Auftauen und Revitalisieren von Zellen}

Die Kryoröhrchen wurden aus dem Stickstoff genommen. Die Zellsuspension wurde bei $37^{\circ} \mathrm{C}$ aufgetaut und direkt nach dem Auftauen in $5 \mathrm{ml} 4^{\circ} \mathrm{C}$ kaltem Normalmedium aufgenommen. Die Zellen wurden in der Labofuge (1000 rpm, $5 \mathrm{~min}$ ) pelletiert. Der Überstand wurde abgesaugt. Die Zellen wurden in $10 \mathrm{ml}$ warmen Normalmedium resuspendiert und in eine Zellkulturflasche überführt. Nach $24 \mathrm{~h}$ wurde das Medium gewechselt. Falls erforderlich wurde dem Medium Selektionsantibiotikum zugesetzt. 


\subsubsection{Transfektion mit dem FuGENE ${ }^{\mathrm{TM}}$ 6-Transfektionsreagenz}

Zur Transfektion von adhärenten Zellen in Zellkultur wurde das FuGENE ${ }^{\mathrm{TM}} 6$ Transfektionsreagenz verwendet. Die Transfektion wurde auf $6 \mathrm{~cm}$-Zellkulturschalen nach Angaben des Herstellers durchgeführt (FuGENE ${ }^{\text {TM}} 6$ Transfektionsreagenz Handbuch 2004, Roche Applied Science, Indianapolis, USA). Die Zellen wurden $24 \mathrm{~h}$ vor der Transfektion mit $70 \%$ Konfluenz ausgesät. Für die Transfektion wurden $6 \mu 1$ FuGENE ${ }^{\mathrm{TM}} 6$ Transfektionsreagenz mit $200 \mu$ l serumfreiem DMEM vorsichtig vermischt. Der Ansatz wurde 5 min bei RT inkubiert. Dann wurden dem Transfektionsansatz 2 $4 \mu \mathrm{g}$ der $\mathrm{zu}$ transfizierenden Plasmid-DNA $(0,2-2 \mu \mathrm{g} / \mu \mathrm{l})$ zugefügt. Der komplette Ansatz wurde für 20 - 30 min bei RT inkubiert und anschließend tröpfchenweise in das Zellkulturmedium gegeben. Für die Transfektion in kleineren Zellkulturschalen wurde die Menge des Transfektionsansatzes angepasst.

\subsubsection{Isolierung von Zellklonen nach stabiler Transfektion}

Zur Herstellung stabil transfizierter Zellklone wurden die HT1080 Zellen mit dem FuGENE ${ }^{\mathrm{TM}} 6$ Transfektionsreagenz transfiziert (3.3.5). Zur Selektion von transfizierten Zellen wurde das Medium $48 \mathrm{~h}$ nach der Transfektion gewechselt. Die Zellen wurden mit Normalmedium mit $150 \mathrm{U} / \mathrm{ml}$ Hygromycin inkubiert. Als Sterbekontrolle wurden zusätzlich nicht transfizierte Zellen unter den gleichen Selektionsbedingungen kultiviert. Die Konzentration an Hygromycin B wurde alle $48 \mathrm{~h}$ bis $\mathrm{zu}$ einer Konzentration von $500 \mathrm{U} / \mathrm{ml}$ Normalmedium erhöht. Als auf der Kontrollplatte alle Zellen tot waren, wurden die selektionierten Zellen trypsiniert, die Zellzahl pro Milliliter wurde mit der NeubauerZählkammer bestimmt und die Zellen wurden mit einer Dichte von 20, 50, 100, 200, 500 und 1000 Zellen pro $14 \mathrm{~cm}$-Zellkulturschale in Selektionsmedium ausplattiert. Auf den $14 \mathrm{~cm}$-Schalen wuchsen innerhalb von 14 Tagen Zellklone heran. Zellklone, die sich durch starkes Wachstum im Selektionsmedium auszeichneten und sich gut von anderen Zellen abgrenzten, wurden mit Hilfe von Klonierungsringen von der Schale gepickt und in einer 24 well-Schale ausplattiert. Der Klonierungsring wurde am unteren Rand in Silikon getaucht und um den Zellklon auf der Kulturschale gesetzt. Anschließend wurden $20 \mu 1$ Trypsinlösung in den Ring pipettiert und bei $37^{\circ} \mathrm{C}$ inkubiert. Die Trypsinierung wurde durch Zugabe von Medium gestoppt und die abgelösten Zellen wurden in die 
24 well-Schale übertragen. Die Zellen eines Zellklons wurden vermehrt und kryokonserviert. Durch Western Blot Analyse wurde die Menge des sezernierten Proteins im Zellkulturmedium des Zellklons bestimmt. Dafür wurden die Zellen für $48 \mathrm{~h}$ mit DMEM/ 0,05 \% FKS inkubiert, der Zellüberstand wurde abgenommen, $50 \mu 1$ des Überstands wurde in Lämmli-Auftragspuffer aufgenommen und auf ein SDS-PAGE Gel aufgetragen.

\subsubsection{Inkubation von Fibroblasten mit M6P-markierten Proteinen}

M6P-markiertes Protein wurde nach der Expression in BHK-Zellen mittels Ni-NTA aufgereinigt (3.5.1.1). Das Eluat der Ni-NTA-Aufreinigung wurde 1:1 mit WaymouthMedium vermischt. Humane Fibroblasten wurden für 2 Stunden mit dem Gemisch inkubiert. Anschließend wurden die Zellen zweimal mit PBS gewaschen und zur Vorbereitung der Immunfärbung mit Methanol fixiert. Um zu untersuchen, ob die Endozytose der Proteine M6P-abhängig verläuft, wurde dem Gemisch aus Medium und Ni-NTA-gereinigtem Protein vor der Inkubation mit den Zellen $5 \mathrm{mM}$ M6P oder $5 \mathrm{mM}$ G6P (als Kontrolle) zugesetzt.

\subsubsection{Kultivierung von stabil transfizierten Zellen zur Ernte von rekombinanten Proteinen aus Zellmedium}

Stabil transfizierte Zellen, die lysosomale Matrixproteine exprimieren, sezernieren aufgrund der hohen Expressionsrate große Mengen des Proteins in das Zellkulturmedium. Zur Ernte des Proteins aus dem Zellkulturmedium wurden die stabil transfizierten Zellen auf $14 \mathrm{~cm}$-Zellkulturschalen ausplattiert. Der konfluente Zellrasen wurde zweimal mit PBS gespült und anschließend mit $20 \mathrm{ml}$ Erntemedium inkubiert. Nach $48 \mathrm{~h}$ wurde der Überstand von den Zellen abgesaugt und bei $9000 \times$ g zentrifugiert, um tote Zellen zu entfernen. Anschließend wurde das im Medium enthaltene Protein durch Fällung mit $0,5 \mathrm{~g} / \mathrm{ml}$ Ammoniumsulfat präzipitiert. Das gefällte Protein wurde bei $4^{\circ} \mathrm{C}$ in der Ammoniumsulfat-Lösung gelagert. Die Zellen wurden noch 2 weitere Male für $48 \mathrm{~h}$ mit Erntemedium inkubiert und dann verworfen. 
Erntemedium: DMEM

$$
\begin{aligned}
& 0,05 \% \text { FKS } \\
& 1 \%(\mathrm{v} / \mathrm{v}) \text { Penicillin/Streptomycin } \\
& (100 \times \text { Stocklösung }) \\
& 1 \%(\mathrm{v} / \mathrm{v}) \text { Glutamin }(200 \mathrm{mM}, 100 \times \text { Stocklösung })
\end{aligned}
$$

\subsubsection{Isolierung von mausembryonalen Fibroblasten (MEF)}

Zur Isolierung von mausembryonalen Fibroblasten (MEF) wurden die Mäuse terminiert verpaart. Am Tag 12.5 nach der Verpaarung wurde das trächtige Weibchen durch Genickbruch getötet. Der Uterus wurde herauspräpariert und in sterilem PBS aufgenommen. Unter der Sterilbank wurden die Embryonen mit ihrer Amnionhülle aus dem Uterus isoliert. Zur Genotypisierung des Embryos wurde aus der Amnionhülle des Embryos genomische DNA isoliert (3.2.1.1). Aus dem Embryonalgewebe wurden die roten Organe mit einer Pinzette entfernt, das restliche Gewebe wurde mehrfach zerschnitten und in einen sterilen $50 \mathrm{ml}$-Erlenmeyerkolben mit Glasperlen und $5 \mathrm{ml}$ $0,05 \%(\mathrm{w} / \mathrm{v})$ Trypsin-EDTA-Lösung (Gibco, Invitrogen, Karlsruhe) gegeben. Zur Vereinzeln der Zellen wurde der Kolben am Schüttelinkubator für 15 min bei $37^{\circ} \mathrm{C}$ inkubiert. Anschließend wurde die Trypsin-Reaktion durch Zugabe von $5 \mathrm{ml}$ Normalmedium gestoppt. Die Zellen wurden durch mehrfaches Aufsaugen mit der Pipette weiter vereinzelt und in ein Zentrifugenröhrchen überführt. Die Zellen wurden in der Labofuge (1100 rpm, 5 min) pelletiert, der Überstand wurde abgesaugt und die Zellen wurden in $5 \mathrm{ml}$ warmen Normalmedium resuspendiert und in eine $6 \mathrm{~cm}$-Zellkulturschale überführt. Nach 24 h wurde das Medium gewechselt. Die Passage der MEF gefolgte nach Erreichen der Konfluenz des Zellrasens. Nach der dritten Passage wurde jeweils ein Teil des MEF-Zellklons kryokonserviert (3.3.3).

\subsubsection{Kultivierung und mitotische Inaktivierung von Neomycin-resistenten Mausfibroblasten}

Neomycin-resistente Mausfibroblasten wurden kultiviert und vor der Benutzung als Feederzellen durch Behandlung mit Mitomycin-C mitotisch inaktiviert. Dazu wurden die 
konfluenten Zellen für 2,5 Stunden mit Mitomycin-C-haltigem Medium bei $37^{\circ} \mathrm{C}$ inkubiert. Anschließend wurden die Zelle dreimal mit PBS gewaschen, trypsiniert und in einer Dichte von. $2 \times 10^{6}$ Zellen pro $6 \mathrm{~cm}$ Platte ausplattiert. Nach Adhäsion der Fibroblasten konnten die embryonalen Stammzellen auf dem Feederrasen ausgesät werden.

Feedermedium:

$500 \mathrm{ml}$ KnockOut DMEM

$95 \mathrm{ml}$ Hyclone ES-Zell FKS

6 ml MEM nicht essenzielle Aminosäuren

6 ml Glutamin $(200$ mM, $100 \times$ Stocklösung $)$

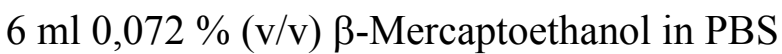

$3 \mathrm{ml}$ Penicillin/Streptomycin $(100 \times$ Stocklösung $)$

$50 \times$ Stocklösung Mitomycin-C: $\quad 0,5 \mathrm{mg} / \mathrm{ml}$ Mitomycin C

\subsubsection{Kultivierung embryonaler Mausstammzellen}

Embryonale Stammzellen (ES-Zellen) wurden auf mitotisch inaktivierten Mausfibroblasten kultiviert. Die Zellen wurden in ES-Zellmedium aufgetaut und auf eine Zellkulturschale mit Feederrasen ausplattiert. Die Zellen wuchsen in scharf abgerundeten Kolonien und wurden täglich mit frischem Medium versorgt. Bei 80 \%-iger Konfluenz wurden die ES-Zellen passagiert. Dazu wurden die Zellen mit 0,25 \% (w/v) Trypsin/ 1 mM EDTA-Lösung (Gibco, Invitrogen, Karlsruhe) inkubiert, die Trypsinierung wurde mit Medium abgestoppt und die Zellsuspension wurde für $10 \mathrm{~min}$ bei $37^{\circ} \mathrm{C}$ gelagert. Die Feederzellen sanken dabei auf den Gefäßboden ab, so dass die ES-Zell-Suspension anschließend abgenommen und auf einem frischen Feederrasen ausgesät werden konnte. Zur Kryokonservierung wurden die trypsinierten ES-Zellen pelletiert, in 0,5 ml eiskaltem Medium aufgenommen und in einem Einfrierröhrchen mit 0,5 ml Einfriermedium vermischt. Die Zellen wurden bei $-80^{\circ} \mathrm{C}$ eingefroren und nach $24 \mathrm{~h}$ in flüssigem Stickstoff überführt. 
Die Mikroinjektion der kultivierten ES-Zellen und der Transfer der Blastozysten in pseudoschwangere Mausweibchen erfolgten am Tierhaus des MPI für experimentelle Medizin durch Frau Monika Schindler.

ES-Zell-Medium:

Feedermedium

+ $67 \mu 1$ ESGRO (LIF, Leukemia Inhibitor Factor)

(LIF verhindert die Differenzierung der Zellen)

ES-Zell-Einfriermedium:

$60 \%$ DMEM

$20 \%$ FKS

$20 \%$ DMSO

\subsection{Histochemische Methoden}

\subsubsection{Einbetten von Mausgewebe in Paraffin und Anfertigen von Paraffinschnitten}

Zum Anfertigen von Paraffinschnitten aus Mausgewebe wurde die Maus durch Genickbruch getötet. Die zu untersuchenden Organe wurden entnommen und in einer $4 \%$ (v/v) Formaldehyd-Lösung in PBS über Nacht bei $4^{\circ} \mathrm{C}$ fixiert. Anschließend wurden die Organe $24 \mathrm{~h}$ in $70 \%$ igem Ethanol inkubiert. Die weiteren Inkubationsschritte erfolgten im Einbettautomaten Shandon Citadel ${ }^{\mathrm{TM}} 2000$ (Thermo Scientific, Waltham, USA) und sind in Tab. 3.5 aufgelistet.

Die Organe wurden anschließend aus dem Automaten entnommen und in ein $60^{\circ} \mathrm{C}$ warmes Paraffinbad überführt. Dann wurden die Organe an der Paraffineingießstation DDM-P-065 (Medim Schweiz GmbH, Baar, Schweiz) in Paraffinblöcke eingegossen. Die Schnitte wurden am Mikrotom HM 355 (Microm, Volketswil, Schweiz) mit einer Schnittdicke von $4 \mu \mathrm{m}$ angefertigt. Der Paraffinschnitt wurde mit einem Pinsel in ein $42^{\circ} \mathrm{C}$ warmes Wasserbad überführt. Nachdem sich der Schnitt auf der Wasseroberfläche eben gezogen hatte, wurde er mit einem Objektträger aufgenommen und auf der Glasoberfläche getrocknet. Anschließend wurde der Objektträger über Nacht im $37^{\circ} \mathrm{C}$ weiter getrocknet. 


\begin{tabular}{lll}
\hline Programmschritt & Inkubationslösung & Inkubationszeit \\
\hline 1 & $70 \%$ Ethanol & $3 \mathrm{~h}$ \\
2 & $80 \%$ Ethanol & $2 \mathrm{~h}$ \\
3 & $90 \%$ Ethanol & $2 \mathrm{~h}$ \\
4 & $96 \%$ Ethanol & $2 \mathrm{~h}$ \\
5 & $100 \%$ Ethanol & $2 \mathrm{~h}$ \\
6 & $100 \%$ Ethanol & $2 \mathrm{~h}$ \\
7 & Isopropanol & $30 \mathrm{~min}$ \\
8 & Xylol & $30 \mathrm{~min}$ \\
9 & Xylol & $45 \mathrm{~min}$ \\
10 & Xylol & $45 \mathrm{~min}$ \\
11 & Xylol/Paraplast $\left(60^{\circ} \mathrm{C}\right)$ & $90 \mathrm{~min}$ \\
12 & Paraplast $\left(60^{\circ} \mathrm{C}\right)$ & $7 \mathrm{~h}$ \\
\hline
\end{tabular}

Tab. 3.5: Inkubationsschritte beim Einbetten der Organe im Einbettautomaten

\subsubsection{Hämatoxylin-Eosin-Färbung von Gewebeschnitten}

Die Hämatoxylin-Eosinfärbung der Paraffinschnitte erfolgte im Färbeautomaten Shandon Varistain 24-4 (Thermo Scientific, Waltham, USA). Im Automat erfolgte zunächst eine Entparaffinierung durch eine absteigende Alkoholreihe gefolgt von einer Kernfärbung durch Mayers Hämalaun-Lösung (Merck, Darmstadt). Nach einem Waschschritt mit fließendem Wasser wurden die zytoplasmatischen Zellanteile durch Eosin gefärbt. Nach dem Entwässern in einer aufsteigenden Alkoholreihe wurden die Schnitte in Xylol abgestellt. Anschließend wurden sie mit dem Eindeckmedium DPX Mountant for histology (Sigma, Deisenhofen) eingedeckt.

Eosin-Lösung: $\quad 0,2 \%$ Eosin in $\mathrm{dH}_{2} 0$, angesäuert durch Essigsäure 


\begin{tabular}{|c|c|c|}
\hline Programmschritt & Inkubationslösung & Inkubationszeit \\
\hline 1 & Xylol & $2 \min$ \\
\hline 2 & Xylol & $5 \min$ \\
\hline 3 & $100 \%$ Ethanol & $2 \min$ \\
\hline 4 & $96 \%$ Ethanol & $2 \min$ \\
\hline 5 & $80 \%$ Ethanol & $2 \min$ \\
\hline 6 & $60 \%$ Ethanol & $2 \min$ \\
\hline 7 & $\mathrm{dH}_{2} \mathrm{O}$ & $2 \min$ \\
\hline 8 & Hämalaun & $4 \min$ \\
\hline 9 & $\mathrm{dH}_{2} \mathrm{O}$ & $1 \mathrm{~min}$ \\
\hline 10 & fließend $\mathrm{dH}_{2} \mathrm{O}$ & $15 \min$ \\
\hline 11 & Eosin & $7 \mathrm{~min}$ \\
\hline 12 & $\mathrm{dH}_{2} \mathrm{O}$ & $1 \mathrm{~min}$ \\
\hline 13 & $60 \%$ Ethanol & $1 \mathrm{~min}$ \\
\hline 14 & $80 \%$ Ethanol & $1 \mathrm{~min}$ \\
\hline 15 & $96 \%$ Ethanol & $1 \mathrm{~min}$ \\
\hline 16 & $100 \%$ Ethanol & $2 \min$ \\
\hline 17 & $100 \%$ Ethanol & $2 \min$ \\
\hline 18 & Xylol & $3 \min$ \\
\hline
\end{tabular}

Tab. 3.6: Inkubationsschritte der Hämatoxylin-Eosin-Färbung im Färbeautomaten

\subsubsection{Anfertigen von $\mathbf{4 0} \mu \mathrm{m}$-Gewebeschnitten}

Mit dem Mikrotom SM2000R (Leica, Heidelberg) wurden frei schwimmende Gewebeschnitte angefertigt. Durch transkardiale Perfusion mit PBS und mit einer 4 \%-igen PFA-Lösung wurden die Mausorgane fixiert. Die Organe wurden entnommen und $2 \mathrm{~h}$ in $4 \%$-iger PFA-Lösung nachfixiert. Anschließend wurden sie über Nacht in 30 \%-iger Sucrose-Lösung inkubiert. Das Mikrotom wurde mit Trockeneis gekühlt und das Organpräparat wurde auf einer Schicht 5 \%-iger Sucrose-Lösung festgefroren. Dann 
wurden Organschnitte mit einer Schnittdicke von $40 \mu \mathrm{m}$ angefertigt. Die Schnitte wurden mit einem Pinsel in einer 24 well-Schale mit PBS aufgenommen und konnten dort bis zur Färbung bei $4^{\circ} \mathrm{C}$ aufbewahrt werden.

$\begin{array}{ll}4 \% \text { PFA-Lösung: } & 4 \% \text { Paraformaldehyd in PBS } \\ 30 \text { \% Sucrose-Lösung: } & 30 \% \text { Sucrose } \\ & 0,1 \mathrm{M} \text { Natriumphosphat } \mathrm{pH} 7,4 \\ 5 \text { \% Sucrose-Lösung: } & 5 \% \text { Sucrose } \\ & 0,1 \mathrm{M} \text { Natriumphosphat } \mathrm{pH} 7,4\end{array}$

\subsubsection{X-Gal-Färbung an Mausorganen}

Zur Detektion der $\beta$-Gal-Reportergen-Aktivität in Gewebe von Gene Trap Mäusen wurden freischwimmende, $40 \mu \mathrm{m}$ Gewebeschnitte hergestellt. Die Gewebeschnitte wurden mit einer X-Gal-Färbelösung bei $30^{\circ} \mathrm{C}$ inkubiert. Nach Erreichen der gewünschten Färbeintensität wurde die Reaktion durch Waschen mit PBS gestoppt. Anschließend wurden die Schnitte 5 min mit Eosin-Lösung gefärbt, nochmals mit PBS gewaschen und anschließend mit Fluoromount Einbettmedium auf einem Objektträger eingedeckt. Um die Reportergen-Aktivität von der endogenen $\beta$-Galactosidase-Aktivität differenzieren zu können, wurden jeweils Gewebeschnitte von Gene Trap Mäusen und Schnitte von Kontrollmäusen parallel gefärbt.

Einige Organe (z. B. Hoden) und Mausembryonen sind nicht zum Herstellen von freischwimmenden Gewebeschnitten geeignet. Diese Präparate wurden nach der Entnahme in 4 \%-iger PFA-Lösung über Nacht fixiert, anschließend mit einem Skalpell halbiert und in der X-Gal-Färbelösung inkubiert. Die X-Gal-gefärbten Präparate wurden über Nacht in $70 \%$ Ethanol inkubiert und am folgenden Tag in Paraffin eingebettet (siehe 3.4.1). Es wurden Paraffinschnitte angefertigt. Diese wurden im Färbeautomaten mit Eosin gefärbt (siehe 3.4.2), wobei die Färbung mit Hämalaun im Färbeprogramm übersprungen wurde. Die X-Gal- und Eosin-gefärbten Schnitte wurden dann mit dem Eindeckmedium DPX Mountant for histology (Sigma, Deisenhofen) eingedeckt. 


$\begin{array}{ll}\text { Eosin-Lösung: } & 0,2 \% \text { Eosin in } \mathrm{dH}_{2} 0 \text {, angesäuert durch Eisessig } \\ \text { X-Gal-Färbelösung: } & 2 \mathrm{mM} \mathrm{MgCl}_{2} \\ & 5 \mathrm{mM} \mathrm{K}_{3} \mathrm{Fe}(\mathrm{CN})_{6} \\ & 5 \mathrm{mM} \mathrm{K}{ }_{4} \mathrm{Fe}(\mathrm{CN})_{6} \\ & 1 \mathrm{mg} / \mathrm{ml} \text { 5-Brom-4-chlor-3-indoxyl- } \\ & \beta \text {-D-galactopyranosid (X-Gal) }\end{array}$

\subsubsection{Indirekte Immunfluoreszenz}

Für die indirekte Immunfluoreszenz wurden Fibroblasten auf gelatinisierten Deckgläschen in 24-well-Zellkulturplatten ausplattiert. Sterile Deckgläschen wurden in 24-well-Zellkuturplatten mit einer $1 \%$-igen sterilen Gelatine-Lösung bedeckt und für $2 \mathrm{~h}$ bei $37^{\circ} \mathrm{C}$ inkubiert. Danach wurde die Lösung abgesaugt und die Deckgläschen wurden auf einer $37^{\circ} \mathrm{C}$-Heizplatte unter der Sterilbank getrocknet. Auf die Deckgläschen wurden die Zellen mit 50 - 70 \%-iger Konfluenz ausplattiert. Die adhärierten Zellen wurden am folgenden Tag einmal mit PBS bei RT gewaschen. Dann erfolgte die Fixierung der Zellen mit $-20^{\circ} \mathrm{C}$ kaltem Methanol für 5 min bei RT. Die Zellen wurden zweimal 5 min mit PBS gewaschen. Durch 15 min Inkubation der Zellen mit $1 \%$ BSA in PBS bei RT wurden unspezifische Antikörperbindungsstellen blockiert. Der erste Antikörper (3.1.7.1) wurde in 1\% BSA in PBS 1:25 bis 1:200 verdünnt. $20 \mu 1$ der Antikörperlösung wurden als Tropfen auf einen Streifen Parafilm pipettiert. Die Deckgläschen wurden mit der zellbewachsenen Seite nach unten auf den Tropfen gelegt und $1 \mathrm{~h}$ in einer feuchten Kammer bei RT inkubiert. Danach wurden die Zellen $3 \times 5$ min mit PBS gewaschen. Zur Blockierung von unspezifischen Bindungsstellen des Sekundärantikörpers wurden die Zellen anschließend für 30 min mit $10 \%$ Ziegen- oder Pferdeserum inkubiert. Die Fluorophor-gekoppelten Sekundärantikörper (3.1.7.2) wurden 1:400 in 1\% BSA in PBS verdünnt. Die Deckgläschen wurden wiederum auf Parafilm mit $20 \mu 1$ Sekundärantikörper-Lösung in der feuchten Kammer im Dunkeln bei RT inkubiert. Es folgten $5 \times 5$ min Waschschritte mit PBS und $3 \times 5$ min Waschschritte mit $\mathrm{dH}_{2} \mathrm{O}$. Die Deckgläschen wurden auf Objektträgern mit Fluoromount Medium eingebettet, um das schnelle Ausbleichen der Fluoreszenzfarben durch Oxidation zu verhindern. Nach dem 
Auspolymerisieren des Fluoromount Einbettmediums über Nacht wurden die Präparate mit Nagellack versiegelt und bei $4^{\circ} \mathrm{C}$ im Dunkeln gelagert. Die fluoreszenzmarkierten Zellen wurden am konfokalen Laser-Scan Mikroskop (Leica, Heidelberg) untersucht und aufgenommen.

\subsection{Proteinbiochemische Methoden}

\subsubsection{Aufreinigung von überexprimiertem Protein aus Zellkulturüberständen}

Zur Aufreinigung des rekombinanten Proteins wurden Zellkulturüberstände von stabil exprimierenden HT1080-Scpep1 Zellen gesammelt (3.3.7). Das Protein im Medium wurde mit Ammoniumsulfat gefällt und bei $4^{\circ} \mathrm{C}$ gelagert. Anschließend wurde das Protein über ein zweistufiges Aufreinigungsprotokoll isoliert. Im ersten Schritt erfolgte eine partielle Aufreinigung mittels Ni-NTA-Agarose. Im Anschluss daran wurde das Protein über Anionenaustauscher-Chromatografie vollständig von Proteinkontaminationen getrennt.

\subsubsection{Proteinaufreinigung mittels Ni-NTA-Agarose}

Zur partiellen Aufreinigung von RGS-His6-markiertem Protein wurde die Ni-NTAAgarose von Qiagen (The QIAexpressionist Handbook, 2003, Qiagen, Hilden) verwendet. Für einen Proteinaufreinigungsansatz wurde das gefällte Protein aus 5 Litern Zellkulturüberständen von stabil exprimierenden HT1080 eingesetzt. Das präzipitierte Protein wurde in der Kühlzentrifuge im JA-10 Rotor bei $10000 \mathrm{rpm}$ pelletiert. Das Proteinpellet wurde in $50 \mathrm{ml}$ PBS gelöst und gegen $3 \times 5$ Liter PBS über Nacht dialysiert. Anschließend wurden durch $30 \mathrm{~min}$ Zentrifugation bei $4500 \times \mathrm{g}$ in der Eppendorf Kühlzentrifuge nicht gelöste Anteile aus dem Dialysat entfernt. Der Überstand wurde in ein neues Gefäß überführt. Es wurden $4 \mathrm{ml}$ Ni-NTA-Suspension (50\%ige Suspension von Ni-NTA-Agarose in $30 \%$ igem Ethanol) zugesetzt und über Nacht bei $4^{\circ} \mathrm{C}$ auf dem Drehrad inkubiert. Die Ni-NTA-Agarose wurden bei $4500 \times \mathrm{g}$ pelletiert und in $50 \mathrm{ml}$ Waschpuffer ohne Imidazol resuspendiert. Zentrifugation und Resuspension wurden noch zweimal wiederholt. Dann wurde die Resuspension auf eine 5 ml-Mobitec-Säule aufgetragen. Die Ni-NTA-Agarose wurde auf der Säule mit Waschpuffer mit steigender 
Imidazolkonzentration gespült. Zuerst wurde die Agarose mit $150 \mathrm{ml}$ Waschpuffer mit $5 \mathrm{mM}$ Imidazol gewaschen. Es folgten Waschschritte mit $50 \mathrm{ml}$ Waschpuffer mit $10 \mathrm{mM}$ Imidazol, mit $50 \mathrm{ml}$ Waschpuffer mit $15 \mathrm{mM}$ Imidazol und mit $10 \mathrm{ml}$ Waschpuffer mit $20 \mathrm{mM}$ Imidazol. Dann wurde das Protein mit $7 \times 1 \mathrm{ml}$ Elutionspuffer mit $100 \mathrm{mM}$ Imidazol von der Säule eluiert. Die Elutionsfraktionen wurden gepoolt und über Nacht gegen 10 mM Tris/HCl pH 8,0 dialysiert. Zur Analyse der Aufreinigung wurden jeweils 0,1 \% der Aufreinigungsfraktionen im Western Blot und im SDS-Gel durch Silberfärbung analysiert.

Waschpuffer:

$$
\begin{aligned}
& 50 \mathrm{mM} \mathrm{NaH}_{2} \mathrm{PO}_{4} \\
& 300 \mathrm{mM} \mathrm{NaCl} \\
& 0-20 \mathrm{mM} \text { Imidazol } \\
& \text { pH mit NaOH auf pH 8,0 einstellen }
\end{aligned}
$$

Elutionspuffer:

$$
\begin{aligned}
& 50 \mathrm{mM} \mathrm{NaH}_{2} \mathrm{PO}_{4} \\
& 300 \mathrm{mM} \mathrm{NaCl} \\
& 100-250 \mathrm{mM} \text { Imidazol } \\
& \text { pH mit } \mathrm{NaOH} \text { auf pH 8,0 einstellen }
\end{aligned}
$$

Zur partiellen Aufreinigung von V5-His6-markiertem Protein nach transienter Transfektion von BHK-Zellen in $6 \mathrm{~cm}-$ Schalen wurde das folgende Protokoll verwendet. $12 \mathrm{~h}$ nach der Transfektion wurde das Normalmedium der Zellen gegen WaymouthMedium/ 2,5 \% FKS/ $20 \mathrm{mM} \mathrm{NH}_{4} \mathrm{Cl}$ ersetzt Durch die Anwesenheit von $20 \mathrm{mM} \mathrm{NH}{ }_{4} \mathrm{Cl}$ im Medium wird die Sekretion von M6P-markierten Proteinen induzieren, da der MPRabhängige Transport der M6P-markierten Proteine zum Lysosomen blockiert wird (Braulke et al. 1987). Nach $24 \mathrm{~h}$ Inkubation mit $20 \mathrm{mM} \mathrm{NH}{ }_{4} \mathrm{Cl}$ wurde das Medium geerntet und filtriert. Mittels 0,5 g/ml Ammoniumsulfat wurde das Protein aus dem Medium gefällt. Das Protein wurde in $700 \mu 1$ PBS aufgenommen und gegen PBS dialysiert. Dem Dialysat wurde $100 \mu \mathrm{l}$ Ni-NTA-Agarose zugesetzt und es folgte eine 1-stündige Inkubation am Drehrad bei $4^{\circ} \mathrm{C}$. Der Ansatz wurde 3 min bei $6000 \mathrm{rpm}$ zentrifugiert. Der Überstand wurde abgenommen. Das Pellet wurde $3 \times$ mit $500 \mu 1$ Waschpuffer mit $20 \mathrm{mM}$ Imidazol gewaschen. Dazu wurde das Pellet jeweils in 
Waschpuffer aufgenommen, geschwenkt und anschließend 3 min bei $6000 \mathrm{rpm}$ pelletiert. Zum Eluieren des V5-His6-markierten Proteins wurde das Pellet $2 \times$ mit $500 \mu 1$ Elutionspuffer mit $250 \mathrm{mM}$ Imidazol inkubiert. Zur Analyse der Aufreinigung wurden jeweils 5 Vol\% der Aufreinigungsfraktionen mit TCA gefällt. Die Probe wurde dazu mit $10 \mathrm{Vol} \%$ TCA versetzt und über Nacht auf Eis inkubiert. Am folgenden Tag wurde das präzipitierte Protein bei $13000 \mathrm{rpm}$ für $20 \mathrm{~min}$ pelletiert. Das Pellet wurde $2 \times$ mit eiskaltem Ethanol gewaschen und bei $37^{\circ} \mathrm{C}$ getrocknet. Anschließend wurde es in Lämmli-Auftragspuffer gelöst und zur Western Blot Analyse eingesetzt.

\subsubsection{Anionenaustauscher-Chromatografie}

Die Anionenaustauscher-Chromatografie erfolgte an der Vision HPLC Anlage (Applied Biosystems, Darmstadt). Es wurde eine Chromatografiesäule mit Poros $20 \mathrm{HQ} / \mathrm{M}$ Anionenaustauscher Matrix verwendet. Die Säule wurde mit $10 \mathrm{mM}$ Tris/ $\mathrm{HCl} \mathrm{pH} 8,0$ äquilibriert. Ein $4 \mathrm{ml}$ Aliquot der Proteinprobe wurde auf die Säule aufgetragen und durch einen Stufengradienten von 0 bis $1 \mathrm{M} \mathrm{NaCl}$ aufgetrennt. Das aufgetrennte Protein wurde in 2,5 ml Fraktionen gesammelt. Zur Analyse der Aufreinigung wurden 0,5\% der Fraktionen durch Western Blot und durch SDS-PAGE und Silberfärbung auf Menge und Reinheit des Proteins überprüft. Die Elutionsfraktionen der AnionenaustauscherChromatografie wurden bei $-80^{\circ} \mathrm{C}$ eingefroren. Die Fraktionen, die das aufgereinigte Protein enthielten, wurden in der Lyophile ankonzentriert, anschließend gegen PBS dialysiert und bei $-20^{\circ} \mathrm{C}$ aufbewahrt. 


\begin{tabular}{lccc}
\hline Programmschritt & Säulenvolumen & Puffer A & Puffer B \\
\hline Injektion der Probe & $4 \mathrm{ml}$ & $100 \%$ & $0 \%$ \\
Konstanter Fluss & 2 & $100 \%$ & $0 \%$ \\
Linearer Gradient & 5 & $85 \%$ & $15 \%$ \\
Konstanter Fluss & 3 & $85 \%$ & $15 \%$ \\
Linearer Gradient & 5 & $70 \%$ & $30 \%$ \\
Konstanter Fluss & 3 & $70 \%$ & $30 \%$ \\
Linearer Gradient & 5 & $50 \%$ & $50 \%$ \\
Konstanter Fluss & 3 & $50 \%$ & $50 \%$ \\
Linearer Gradient & 5 & $0 \%$ & $100 \%$ \\
Konstanter Fluss & 4 & $0 \%$ & $100 \%$ \\
\hline
\end{tabular}

Tab. 3.7: Programm zur Anionenaustauscher-Chromatografie mit Stufengradient

Die Anionenaustauscher-Chromatografie erfolgte an der Vision HPLC Anlage über eine 1,7 ml-Säule mit Poros HQ Matrix äquilibriert in $10 \mathrm{mM}$ Tris/ $\mathrm{HCl} \mathrm{pH} \mathrm{8.0.} \mathrm{Bei} \mathrm{einer} \mathrm{konstanten} \mathrm{Flußrate} \mathrm{von} 5 \mathrm{ml} / \mathrm{min}$ verlief ein Stufengradient von $0 \mathrm{M} \mathrm{NaCl}$ (Puffer A) zu $1 \mathrm{M} \mathrm{NaCl}$ (Puffer B) in $10 \mathrm{mM}$ Tris/HCl pH 8.0.

\subsubsection{MPR-Affinitätschromatografie}

Zellkulturüberstände von MEF-23-1SV Zellen wurden nach 48-stündiger Inkubation mit Waymouth-Medium/ 0,05 \% FKS von den Zellen abgenommen. Das geerntete Medium wurde abzentrifugiert, um kontaminierende Zellreste zu entfernen. Zur Bestimmung der Konzentration lysosomaler Proteine im Zellkulturüberstand wurden die Aktivitäten der Enzyme $\beta$-Hexosaminidase und Arylsulfatase A bestimmt (3.5.6). Das Protein im Medium wurde mit 0,5 g/ml Ammoniumsulfat gefällt und bei $10000 \mathrm{rpm}$ im JA-10 Rotor (Beckmann Kühlzentrifuge) 30 min pelletiert. Das Pellet wurde in $10 \mathrm{ml}$ Tris/ $\mathrm{HCl}$ pH 7,0 resuspendiert und zweimal gegen je $100 \mathrm{ml}$ Bindungspuffer dialysiert. Das Dialysat wurde in der Ultrazentrifuge bei $4^{\circ} \mathrm{C}$ (Ti60, $\left.45000 \mathrm{rpm}\right) 30 \mathrm{~min}$ zentrifugiert, und anschließend steril filtriert. Im Filtrat wurde die Aktivität der $\beta$-Hexosaminidase bestimmt. Dann wurden 1,5 U $\beta$-Hexosaminidase auf die in Bindungspuffer äquilibrierte MPR-Chromatografiesäule aufgetragen. Die verwendete MPR-Chromatografiesäule enthielt Affigel 10, gekoppelt mit einem 1:1-Gemisch der M6P-Rezeptoren MPR46 und MPR300. Die Säule wurde von Siva Kumar präpariert und für die Arbeit zur Verfügung herstellt. Nach dem Auftrag des Filtrats auf die Chromatografiesäule wurde diese auf dem 
Drehrad bei $4^{\circ} \mathrm{C}$ über Nacht inkubiert. Der Durchbruch wurde aufgefangen, die Säule wurde mit $4 \times 2 \mathrm{ml}$ Bindungspuffer und $3 \times 2 \mathrm{ml}$ Bindungspuffer mit $5 \mathrm{mM}$ G6P (Glucose-6-Phosphat) gewaschen und dann mit $11 \times 1 \mathrm{ml}$ Bindungspuffer mit $5 \mathrm{mM}$ M6P (Mannose-6-Phosphat) eluiert. Die Elutionsfraktionen wurden gepoolt, mit UH10 Ultrahülsen ankonzentriert und gegen Bindungspuffer dialysiert. In den Wasch- und Elutionsfraktionen wurde die spezifische $\beta$-Hexosaminidaseaktivität bestimmt, um die Qualität der Aufreinigung zu bilanzieren. Nach Verwendung der Säule wurde diese mit $5 \mathrm{ml}$ saurem Waschpuffer gereinigt und anschließend in Bindungspuffer/ $5 \mathrm{mM} \mathrm{M6P}$ abgestellt.

Bindungspuffer:

$50 \mathrm{mM}$ Imidazol/ $\mathrm{HCl} \mathrm{pH} 6,5$

$150 \mathrm{mM} \mathrm{NaCl}$

$5 \mathrm{mM} \mathrm{Na-} \beta$-glycerophosphat

2 mM EDTA

$10 \mathrm{mM} \mathrm{MgCl}_{2}$

$0,2 \% \mathrm{NaN}_{3}$

$0,05 \%$ Triton X-100

Bindungspuffer mit Proteinaseninhibitoren:

$0,5 \mu \mathrm{g} / \mathrm{ml}$ Pepstatin A

$0,5 \mu \mathrm{g} / \mathrm{ml}$ Aprotinin

$0,5 \mu \mathrm{g} / \mathrm{ml}$ Leupeptin

$0,5 \mu \mathrm{g} / \mathrm{ml}$ Chymostatin

Saurer Waschpuffer:

0,1 M Natriumacetat, $\mathrm{pH} 4,5$

$1 \mathrm{M} \mathrm{NaCl}$

$0,05 \%$ Triton $\mathrm{X}-100$

$0,02 \% \mathrm{NaN}_{3}$

Zur Analyse der M6P-Rezeptorbindung von partiell aufgereinigtem, überexprimiertem Protein wurde das Eluat der Ni-NTA-Aufreinigung mit $750 \mu 1$ Bindungspuffer mit Proteinaseninhibitoren versetzt und auf der in Bindungspuffer äquilibrierten MPR-Affinitätschromatografiesäule über Nacht inkubiert. Anschließend wurde die Säule 
mit $2 \times 1,5 \mathrm{ml}$ Bindungspuffer und mit $2 \times 1,5 \mathrm{ml}$ Bindungspuffer/ $5 \mathrm{mM} \mathrm{G6P}$ gewaschen. Es folgte die Elution mit $3 \times 1,5 \mathrm{ml}$ Bindungspuffer/ $5 \mathrm{mM} \mathrm{M6P.} \mathrm{Zur}$ Analyse der MPR-Bindung wurden die Fraktionen des Durchflusses, die Fraktionen der Waschschritte ohne und mit G6P und die Elutionsfraktionen mit TCA gefällt. Die Proben wurden dazu mit $10 \mathrm{Vol} \%$ TCA versetzt und über Nacht auf Eis inkubiert. Am folgenden Tag wurde das präzipitierte Protein bei $13000 \mathrm{rpm}$ für $20 \mathrm{~min}$ pelletiert. Die Pellets wurden zweimal mit eiskaltem Ethanol gewaschen und bei $37^{\circ} \mathrm{C}$ getrocknet. Anschließend wurden sie in Lämmli-Auftragspuffer gelöst und zur Western Blot Analyse eingesetzt. Die MPR-Affinitätschromatografiesäule wurde nach der Verwendung mit $5 \mathrm{ml}$ saurem Waschpuffer gereinigt und anschließend in Bindungspuffer/ $5 \mathrm{mM}$ M6P abgestellt.

\subsubsection{Gelfiltrationschromatografie lysosomaler Proteine}

Gelfiltrationsexperimente wurden mit dem SMART ${ }^{\text {TM }}$ System (Pharmacia, Uppsala, Schweden) mit den Gelfiltrationssäulen Superdex 200 und Superdex 75 durchgeführt. Die Gelfiltrationssäulen wurden zunächst mit $\mathrm{dH}_{2} \mathrm{O}$ gespült und anschließend im MES-Puffer äquilibriert. Eine $50 \mu \mathrm{l}$ Proteinprobe, äquilibriert in MES-Puffer wurde in eine Auftragsschleife injiziert. Anschließend erfolgte ein Gelfiltrationslauf mit einer Flussrate von $40 \mu \mathrm{l} / \mathrm{min}$, dabei wurde die Probe automatisch auf die Säule aufgetragen, die Elution der Säule wurde in $20 \mu \mathrm{l}$ Aliquots fraktioniert und im Western Blot analysiert. Als Größenstandard wurde anschließend ein Mix aus verschiedenen Standardproteinen unter gleichen Chromatografie- und Pufferbedingungen über die Säule aufgetrennt. Nach Verwendung der Säulen wurden diese mit $\mathrm{dH}_{2} \mathrm{O}$ gespült und anschließend in $20 \%$ Ethanol abgestellt.

MES-Puffer:

$20 \mathrm{mM}$ MES pH 4,5

$150 \mathrm{mM} \mathrm{NaCl}$ 


\subsubsection{Herstellung von Gewebe- und Zellhomogenaten}

Zur Herstellung von Gewebehomogenaten wurde die Maus mit Genickbruch getötet, die Organe wurden entnommen und auf Eis gelagert. Die Organe wurden gewogen, mit neun Volumen Lysispuffer zugesetzt, mit einer scharfen Schere grob zerkleinert und anschließend mit 20 Hüben im Teflon-Homogenisator (Braun, Melsungen) homogenisiert. Das Lysat wurde $3 \times 20 \mathrm{sec}$ sonifiziert und bei $4^{\circ} \mathrm{C}$ und $13000 \mathrm{rpm}$ abzentrifugiert. Der Überstand wurde in ein neues Gefäß überführt und die Proteinkonzentration wurde mittels DC Protein Assay (Biorad, München) bestimmt. Zur Herstellung von Homogenaten aus Zellen wurden die Zellen pelletiert. Das Pellet wurde mit PBS gewaschen und in $500 \mu$ Lysispuffer resuspendiert. Anschließend wurden die Zellen $3 \times 20 \mathrm{sec}$ sonifiziert und bei $4^{\circ} \mathrm{C}$ und $13000 \mathrm{rpm}$ abzentrifugiert. Bei Verwendung der Homogenate zur Western Blot Analyse wurde dem Lysispuffer zusätzlich $1 \%$ NP 40 zugesetzt.

$\begin{array}{ll}\text { Lysispuffer: } & 1 \times \text { TBS } \\ & 1 \mathrm{mM} \text { PMSF } \\ & 1 \mathrm{mM} \text { EDTA } \\ & 5 \mathrm{mM} \mathrm{JAA} \\ & 0,1 \% \text { Triton X-100 } \\ & 200 \mathrm{mM} \text { PMSF in DMSO }\left(-20^{\circ} \mathrm{C}\right) \\ \text { Proteaseinhibitoren: } & 500 \mathrm{mM} \mathrm{JAA} \text { in } \mathrm{dH}_{2} \mathrm{O}\left(-20^{\circ} \mathrm{C}\right) \\ & 200 \mathrm{mM} \text { EDTA in } \mathrm{dH}_{2} \mathrm{O}\end{array}$

\subsubsection{Proteinkonzentrationsbestimmung mittels Bio-Rad DC Protein Assay (Mikroansatz)}

Der Biorad DC Protein Assay ist eine colorimetrischer Methode zur Bestimmung von Proteinkonzentrationen, basierend auf der Methode nach Lowry (Lowry et al. 1951; Peterson 1979). Er toleriert die Anwesenheit von Detergenzien wie Triton X-100 und Tween 20 bis zu einer Konzentration von $1 \%$. In eine Mikrotiterplatte wurde eine Protein-Eichreihe mit $0-20 \mu \mathrm{g} / 100 \mu \mathrm{BSA}$ in Doppelwerten pipettiert. Jeweils $10 \mu \mathrm{l}$ 
einer Verdünnung der Proteinprobe wurden zur Proteinbestimmung eingesetzt und mit $\mathrm{dH}_{2} \mathrm{O}$ auf $100 \mu \mathrm{l}$ aufgefüllt. Anschließend wurde zu jeder Probe $25 \mu \mathrm{l}$ des Reagenz A' und dann $200 \mu 1$ des Reagenz B pipettiert. Nach 15 min Inkubation wurde die Extinktion der Proben bei $630 \mathrm{~nm}$ im Microplate Reader Model Spectra II (Tecan, SLT, Crailsheim) bestimmt. Mit Hilfe der Eichgeraden wurde die Proteinkonzentration der Proben bestimmt.

Reagenz A:

alkalische Kupfertartrat-Lösung

Reagenz B:

verdünntes Folin-Reagenz

Reagenz S:

keine Angaben vom Hersteller

Reagenz A':

$1 \mathrm{ml}$ Reagenz A

$20 \mu 1$ Reagenz $S$

\subsubsection{Aktivitätsbestimmungen lysosomaler Standardenzyme}

In Zell- und Gewebehomogenaten wurde die enzymatische Aktivität der lysosomalen Enzyme $\beta$-Hexosaminidase, $\beta$-Glucuronidase, $\alpha$-Mannosidase, $\alpha$-Galactosidase und $\alpha-\mathrm{N}$-Acetylgalactosaminidase mittels p-Nitrophenol-gekoppelter Substrate bestimmt. Bei der enzymatischen Reaktion wird als Produkt p-Nitrophenolat freigesetzt. Dies wurde durch eine Extinktionsbestimmung bei $405 \mathrm{~nm}$ bestimmt. Der molare Extinktionskoeffizient von p-Nitrophenolat bei $405 \mathrm{~nm}$ beträgt $18500 \mathrm{l} / \mathrm{mol} \cdot \mathrm{cm}$. Als Substrat für die Messung der enzymatischen Aktivität der Arylsulfatase A (ASA) wurde p-Nitrocatecholsulfat verwendet. Die Bildung von p-Nitrocatecholat im Reaktionsansatz wurde durch eine Extinktionsbestimmung bei $515 \mathrm{~nm}$ gemessen. Der molare Extinktionskoeffizient von p-Nitrocatecholat bei $515 \mathrm{~nm}$ beträgt $12400 \mathrm{l} / \mathrm{mol} \cdot \mathrm{cm}$.

In einem $200 \mu$ l-Reaktionsansatz (Tab. 3.8) wurde das Homogenat mit der entsprechenden Substratlösung inkubiert. Nach Inkubationszeiten zwischen $1-2 \mathrm{~h}$ im $37^{\circ} \mathrm{C}$-Wasserbad wurden die Reaktionen durch Zugabe von $1 \mathrm{ml}$ Stopp-Lösung beendet und die Extinktion bei $405 \mathrm{~nm}$ bzw. $515 \mathrm{~nm}$ wurde bestimmt. Die Aktivität der Homogenate wurde in doppelten Reaktionsansätzen bestimmt. Zusätzlich wurde zu jeder 
Probe ein Enzymleerwert (Reaktionsansatz ohne Substrat) und zu jeder Messreihe ein Substratleerwert (Reaktionsansatz ohne Homogenat) bestimmt.

Substratpuffer:

0,1 M Natriumcitrat, $\mathrm{pH}$ 4,6

$0,2 \%$ BSA

$0,04 \%$ Natriumazid

Stopp-Lösung:

0,4 M Glycin/ NaOH pH 10,4

\begin{tabular}{|c|c|c|}
\hline Enzym & Substrat & Reaktionsansatz/ Inkubationszeit \\
\hline \multirow[t]{4}{*}{$\beta$-Hexosaminidase } & 10 mM p-Nitrophenyl- & $100 \mu \mathrm{l}$ Substratlösung \\
\hline & $\beta$-D-glucopyranosid & $10 \mu \mathrm{l}$ Homogenat (1:10 Verd.) \\
\hline & & $90 \mu \mathrm{ld} \mathrm{H}_{2} \mathrm{O}$ \\
\hline & & $60 \mathrm{~min}, 37^{\circ} \mathrm{C}$ \\
\hline \multirow[t]{4}{*}{$\beta$-Glucuronidase } & 10 mM p-Nitrophenyl- & $100 \mu \mathrm{l}$ Substratlösung \\
\hline & $\beta$-D-glucuronid & $10 \mu \mathrm{l} \mathrm{Homogenat}$ \\
\hline & & $90 \mu \mathrm{ld} \mathrm{H}_{2} \mathrm{O}$ \\
\hline & & $90 \min 37^{\circ} \mathrm{C}$ \\
\hline \multirow[t]{5}{*}{$\alpha$-Mannosidase } & 10 mM p-Nitrophenyl- & $50 \mu \mathrm{l}$ Substratlösung \\
\hline & $\alpha$-D-mannopyranosid & $50 \mu \mathrm{l}$ Substratpuffer \\
\hline & & $90 \mu \mathrm{l} \mathrm{0,9 \%} \mathrm{NaCl}$ \\
\hline & & $10 \mu \mathrm{l}$ Homogenat \\
\hline & & $2 \mathrm{~h}, 37^{\circ} \mathrm{C}$ \\
\hline \multirow[t]{3}{*}{ Arylsulfatase A } & $10 \mathrm{mM}$ p-Nitrocatecholsulfat & $150 \mu \mathrm{l}$ Substratlösung \\
\hline & & $50 \mu \mathrm{l}$ Homogenat (1:10 Verd.) \\
\hline & & $2 \mathrm{~h}, 37^{\circ} \mathrm{C}$ \\
\hline
\end{tabular}

Tab. 3.8: Bestimmung der Aktivität lysosomaler Enzyme

Die enzymatische Aktivität der lysosomaler Enzyme $\beta$-Hexosaminidase, $\beta$-Glucuronidase, $\alpha$-Mannosidase, $\alpha$-Galactosidase und $\alpha$-N-Acetylgalactosaminidase wurde mit Hilfe von p-Nitrophenol-gekoppelten Substraten bestimmt. Zur Aktivitätsbestimmung der Arylsulfatase A wurde p-Nitrocatecholsulfat verwendet. In dieser Tabelle sind die verwendeten, spezifischen Substrate der Enzyme sowie die Reaktionsansätze und Inkubationszeiten aufgelistet. Die Reaktionen wurden durch Zugabe von $1 \mathrm{ml}$ StoppLösung abgestoppt und die Extinktion wurde bestimmt. 
Die enzymatische Aktivität wurde anschließend mit Hilfe der folgenden Formel berechnet.

Aktivität $\left[\frac{m U}{m l}\right]=\frac{\Delta E \cdot 10^{6}}{\varepsilon\left[\frac{\mathrm{l}}{\mathrm{mol} \cdot \mathrm{cm}}\right] \cdot d[\mathrm{~cm}] \cdot t[\mathrm{~min}]} \cdot \frac{V_{\text {Testvolumen }}[\mu \mathrm{l}]}{V_{\text {Probenvolumen }}[\mu \mathrm{l}]} \cdot F_{\text {Verd.Probe }}$

Formel 3.1: Bestimmung der enzymatischen Aktivität

$\Delta \mathrm{E}=\mathrm{E}_{\text {Probe }}-\mathrm{E}_{\text {Enzymleerwert }}-\mathrm{E}_{\text {Substratleerwert }}$; Testvolumen $=$ Reaktionsvolumen nach Abstoppen der Reaktion; $\mathrm{F}=$ Verdünnungsfaktor der Probe, $\varepsilon=$ Extinktionskoeffizient; Probenvolumen $=$ Volumen der eingesetzten Probe; $\mathrm{t}=$ Zeit, $\mathrm{d}=$ Dicke der Küvette $(1 \mathrm{~cm})$.

\subsubsection{Aktivitätsbestimmung der lysosomalen Serincarboxypeptidasen}

Die Bestimmung der Serincarboxypeptidase-Aktivität erfolgte durch die Methode nach Moore und Stein (Moore und Stein 1954), dabei wurden zunächst Aminosäuren durch die Inkubation von N-terminal blockierten Dipeptiden mit der Enzymprobe freigesetzt und anschließend durch eine Ninhydrin-Färbung nachgewiesen. $100 \mu \mathrm{l}$ eines $0,5 \mathrm{mM}$ N-terminal CBZ-blockierten Dipeptids in Substratpuffer wurden mit $10 \mu$ Enzymlösung versetzt und im Wasserbad bei $37^{\circ} \mathrm{C}$ für 30 min inkubiert. Die Reaktion wurde durch die Zugabe von $100 \mu \mathrm{l}$ Ninhydrin/ $\mathrm{ZnCl}_{2}$-Lösung und durch anschließendes 10-minütiges Erhitzen auf $104^{\circ} \mathrm{C}$ gestoppt. Nach Abkühlen wurde der Probe $1 \mathrm{ml} 50 \%$-ige 1-Propanol-Lösung zugesetzt und die Absorption bei $570 \mathrm{~nm}$ wurde bestimmt. Zur Bestimmung der Konzentration freigesetzter Aminosäuren wurde eine Eichreihe mit 0 - 0,8 mM L-Leucin in Substratpuffer angesetzt und parallel gemessen. Die Aktivität der Proben wurde in dreifachen Reaktionsansätzen bestimmt. Zusätzlich wurden zu jeder Probe doppelte Enzymleerwerte (Reaktionsansatz ohne Substrat) und zu jeder Messreihe doppelte Substratleerwerte (Reaktionsansatz ohne Homogenat) bestimmt.

Substratpuffer:

$50 \mathrm{mM}$ MES pH 4,5

2 mM EDTA

CBZ-blockiertes Dipeptid:

$25 \mathrm{mM}$ Stocklösung in Methanol

Ninhydrin-Lösung:

$4 \%(w / v)$ Ninhydrin in Methoxy-2-ethanol 
$\mathrm{ZnCl}_{2}$-Lösung:

Ninhydrin/ $\mathrm{ZnCl}_{2}$-Lösung:
$200 \mathrm{mM}$ Natriumcitrat $\mathrm{pH} 5,0$

$$
7,1 \mathrm{mM} \mathrm{ZnCl}_{2}
$$

1 Volumen Ninhydrin-Lösung

1 Volumen $\mathrm{ZnCl}_{2}$-Lösung

Ninhydrin- und $\mathrm{ZnCl}_{2}$-Lösungen täglich frisch ansetzen, Ninhydrin/ $\mathrm{ZnCl}_{2}$-Gebrauchslösung 15 min vor Benutzung ansetzen.

\subsubsection{Aktivitätsbestimmung der Succinatdehydrogenase}

Die Messung der enzymatischen Aktivität der Succinatdehydrogenase erfolgt durch eine gekoppelte Nachweisreaktion. Zunächst entsteht durch die enzymatische Dehydrierung von Succinat zu Fumarat SDH-gebundenes $\mathrm{FADH}_{2}$. In der zweiten Reaktion wird p-Iodonitrotetrazolium reduziert, wobei ein violetter Formazan-Farbstoff gebildet wird, dessen molarer Extinktionskoeffizient bei $490 \mathrm{~nm} 18300 \mathrm{l} / \mathrm{mol} \cdot \mathrm{cm}$ beträgt. $10 \mu 1$ Probenvolumen wurden in einem $200 \mu$ l-Reaktionsansatz mit $100 \mu 1$ Substratlösung und $90 \mu \mathrm{l} \mathrm{dH}_{2} \mathrm{O} 10 \mathrm{~min}$ im $37^{\circ} \mathrm{C}$-Wasserbad inkubiert. Dann wurde dem Reaktionsansatz $100 \mu \mathrm{l}$ Indikatorlösung zugesetzt und es folgten weitere 10 min Inkubation bei $37 \mathrm{C}$. Anschließend wurde die Reaktion durch Zugabe von $1 \mathrm{ml}$ Stopp-Lösung gestoppt. Die Proben wurden $5 \mathrm{~min}$ bei $13000 \mathrm{rpm}$ zentrifugiert und die Extinktion bei $490 \mathrm{~nm}$ wurde bestimmt. Die Aktivität der Homogenate wurde in doppelten Reaktionsansätzen gemessen. Zusätzlich wurde zu jeder Probe ein Enzymleerwert (Reaktionsansatz ohne Substrat) und $\mathrm{zu}$ jeder Messreihe ein Substratleerwert (Reaktionsansatz ohne Homogenat), sowie ein Indikatorleerwert bestimmt. Die enzymatische Aktivität wurde anschließend mit Formel 3.1 berechnet.

Substratpuffer:

Substratlösung:

Indikatorlösung:
$50 \mathrm{mM}$ Natriumphosphat $\mathrm{pH} 7,5$

$10 \mathrm{mM}$ Natriumsuccinat

50 mM Natriumphosphat $\mathrm{pH} 7,5$

$0,25 \%$ p-Iodonitrotetrazolium

50 mM Phosphatpuffer pH 7,5 
Stopp-Lösung

5 Volumen Ethylacetat

5 Volumen Ethanol

1 Vol TCA

\subsubsection{Aktivitätsbestimmung der 5'AMPase und der Glucose-6-Phosphatase}

Zur Bestimmung der 5'AMPase- und der Glucose-6-Phosphatase (G6Pase)-Aktivität wurde die Probe mit dem entsprechenden Substrat inkubiert und freigesetztes Phosphat wurde durch eine anschließende Ammoniummolybdatfärbung bestimmt. Für die G6PaseBestimmung wurden $50 \mu 1$ Probenvolumen, $300 \mu$ Puffer und $100 \mu 1$ Substrat für $1 \mathrm{~h}$ bei $37^{\circ} \mathrm{C}$ inkubiert. Anschließend wurde die Reaktion durch Zugabe von $1 \mathrm{ml}$ Stopp-Lösung gestoppt und bei $13000 \mathrm{rpm}$ für 10 min zentrifugiert. Anschließend wurden $300 \mu \mathrm{l}$ des Überstandes mit $700 \mu$ Phosphat-Nachweisreagenz bei $37^{\circ} \mathrm{C}$ für $1 \mathrm{~h}$ inkubiert und die $\mathrm{OD}_{820 \mathrm{~nm}}$ wurde gegen $\mathrm{H}_{2} \mathrm{O}$ gemessen. 0,01 mM Phosphat entsprechen einer $\mathrm{OD}_{820 \mathrm{~nm}}$ von 0,260. Die Aktivität der Proben wurde in doppelten Reaktionsansätzen gemessen. Ein dritter Reaktionsansatz wurde direkt mit Stopp-Lösung versetzt und diente als Leerwert.

Für die 5'AMPase-Aktivitätsbestimmung wurden $50 \mu \mathrm{l}$ Probenvolumen mit $250 \mu \mathrm{l}$ Substratlösung inkubiert. Der Reaktionsstopp und der Phosphatnachweis erfolgte anschließend wie für die G6Pase beschrieben.

\begin{tabular}{|c|c|}
\hline Reaktionspuffer G6Pase: & 0,2 M Maleinsäure $\mathrm{pH}$ 6,5 \\
\hline & $10 \mathrm{mM}$ Kaliumnatriumtartrat \\
\hline Substratlösung G6Pase: & 0,1 M Glucose-6-Phosphat in $\mathrm{dH}_{2} \mathrm{O}$ \\
\hline & pH 6,5 mit NaOH einstellen \\
\hline Reaktionspuffer AMPase: & $5 \mathrm{mM} \mathrm{MgCl}_{2}$ \\
\hline & $50 \mathrm{mM}$ Tris/ $\mathrm{HCl} \mathrm{pH}$ 7,5 \\
\hline & $10 \mathrm{mM}$ Kaliumnatriumtartrat \\
\hline Substratlösung AMPase: & $5 \mathrm{mM}$ cAMP in Reaktionspuffer \\
\hline Stopp-Lösung: & $8 \%$ TCA in $\mathrm{dH}_{2} \mathrm{O}$ \\
\hline Lösung A: & $10 \%$ Ascorbinsäure (frisch ansetzen) \\
\hline
\end{tabular}


Lösung B:

Phosphat-Nachweisreagenz:
3,4 mM Ammoniummolybdat-Tetrahydrat $2,86 \%(v / v)$ konz. Schwefelsäure

1 Volumen Lösung A + 6 Volumen Lösung B

(Lösung auf Eis kühlen)

\subsubsection{Deglykosylierung mit N-Glykosidase F}

Zur Untersuchung der N-Glykosylierung von Proteinen erfolgte eine Deglykosylierung mit dem Enzym N-Glykosidase F (Roche Applied Science, Indianapolis, USA) im Zellhomogenat und eine anschließende Western Blot Analyse. Das Zellhomogenat wurde mit TBS auf eine Proteinkonzentration von $5 \mu \mathrm{g} / \mu \mathrm{l}$ eingestellt. $50 \mu \mathrm{g}$ Zellhomogenat wurden im folgenden Reaktionsansatz eingesetzt.

Denaturierungsreaktion:

N-Glykosylierungsreaktion:
$10 \mu \mathrm{l}$ Zellhomogenat $(5 \mu \mathrm{g} / \mu \mathrm{l})$

$25 \mu 10,1 \mathrm{M} \beta-\mathrm{ME} / 1 \% \mathrm{SDS}$

5 min bei $100^{\circ} \mathrm{C}$, dann auf Eis abkühlen

Denaturierungsansatz

$30 \mu 1$ 0,5 M Tris/HCl pH 8,0/ 50 mM EDTA

$10 \mu 110 \%(\mathrm{v} / \mathrm{v})$ Triton X-100

$10 \mu \mathrm{l}$ 0,1 M 1,10-Phenanthroline/Methanol

$2 \mu 1 \mathrm{~N}-$ Glykosidase $\mathrm{F}$

Inkubation bei $37^{\circ} \mathrm{C}$

Die Reaktion wurde durch Zugabe von $20 \mu 1 \quad 6 \times$ Lämmli-Auftragspuffer und anschließender Inkubation für $5 \mathrm{~min}$ bei $98^{\circ} \mathrm{C}$ gestoppt. Die Proben wurden auf ein SDSGel aufgetragen und anschließend im Western Blot analysiert.

\subsubsection{Anreicherung von Lysosomen Tyloxapol-behandelter Mäuse durch subzelluläre Fraktionierung}

Intravenöse injiziertes Tyloxapol wird in den Lysosomen von Mäusen gespeichert und führt somit zur Verringerung der lysosomalen Dichte. Lysosomen aus Tyloxapol- 
behandelter Mausleber lassen sich durch differentielle Zentrifugation und anschließende Ultrazentrifugation im diskontinuierlichen Sucrosegradienten effizient von anderen Zellorganellen trennen (Wattiaux et al. 1963; Leighton et al. 1968).

Zur Isolierung der Tyloxapol-gefüllten Lysosomen wurden 4 Mäuse $5 \mu 1 / g$ Körpergewicht einer $17 \%$-igen (v/v)-Tyloxapol-Lösung (Triton WR-1339)/ 0,9\% NaCl intraperitoneal injiziert. 4 Tage nach der Injektion wurden die Mäuse narkotisiert, durch Dekaptieren getötet und ausgeblutet. 2,2 $\mathrm{g}$ Leber wurde mit $5 \mathrm{ml}$ eiskalter 0,25 M Sucrose-Lösung versetzt und im Teflonpotter homogenisiert. Das Homogenat wurde anschließend mit Sucrose-Lösung auf $12 \mathrm{ml}$ aufgefüllt, gemischt und $10 \mathrm{~min}$ bei $4^{\circ} \mathrm{C}$ mit $2300 \mathrm{rpm}$ in der Kühlzentrifuge 5804R (Eppendorf) zentrifugiert. Der Überstand (E1) wurde abgenommen, das Pellet wurde erneut in $5 \mathrm{ml}$ Sucrose-Lösung homogenisiert, auf $12 \mathrm{ml}$ aufgefüllt und abzentrifugiert. Das Pellet enthält die nukleäre Fraktion N. Die postnukleären Überstände wurden vereinigt und auf $22 \mathrm{ml}$ aufgefüllt. Je $10 \mathrm{ml}$ wurden auf zwei Ti75-Zentrifugen-Röhrchen aufgetragen und für 3 min bei $4^{\circ} \mathrm{C}$ mit $13000 \mathrm{rpm}$ in der Ultrazentrifuge im Rotor Ti75 zentrifugiert. Der Überstand wurde abgenommen. Die Pellets wurden in $10 \mathrm{ml}$ Sucrose-Lösung vereinigt und erneut für $3 \mathrm{~min}$ bei $4^{\circ} \mathrm{C}$ mit 13000 rpm zentrifugiert. Das Pellet enthält die mitochondriale Fraktion (M). Die beiden Überstände wurden vereinigt und anschließend auf die Ti75-Röhrchen verteilt. Er folgte eine 7 minütige Zentrifugation bei $4^{\circ} \mathrm{C}$ mit $25000 \mathrm{rpm}$ im Rotor Ti75. Der Überstand wurde quantitativ abgenommen. Die Pellets wurden mit $10 \mathrm{ml}$ Sucroselösung resuspendiert, vereint und erneut abzentrifugiert. Das Pellet enthält die light mitochondrial Fraktion (L). Der Überstand wurde d im Rotor Ti75 bei 35000 rpm 40 min zentrifugiert. Das Pellet wurde resuspendiert und erneut zentrifugiert. Das Pellet enthält mikrosomalen (Fraktion P) und der Überstand die zytosolischen Bestandteile (Fraktion S). Das Pellet L wurden in 1,21 $\rho$ Sucrose-Lösung resuspendiert, in einem Glaspotter vereinigt und homogenisiert. Anschließend wurde ein Sucrose-Dichte-Gradient geschichtet. Dazu wurde die L-Fraktion in ein SW40-Röhrchen gegeben und mit $3 \mathrm{ml}$

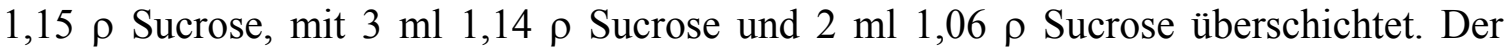
Gradient wurde für $150 \mathrm{~min}$ bei $4^{\circ} \mathrm{C}$ mit $25000 \mathrm{rpm}$ in der Ultrazentrifuge (Rotor SW40) zentrifugiert, wobei langsam beschleunigt und abgebremst wurde. Der Gradient besitzt nach der Zentrifugation drei Interphasen. Die Schicht über der Interphase 1 wurde 
als Fraktion F1 abgenommen, Die Interphase 1 (F2) enthält die Tyloxapol-gefüllten Lysosomen. Die Interphase 2 wird als F3 abgenommen und die Interphase 3, sowie das Pellet ergeben die Fraktion F4. Zur Analyse der subzellulären Fraktionierung wurden in den isolierten Fraktionen die enzymatische Aktivität der lysosomalen Enzyme $\beta$-Hexosaminidase und $\beta$-Glucuronidase, sowie die enzymatische Aktivität der mitochondrialen Succinatdehydrogenase, der plasmamembranständigen 5'AMPase und der G-6-Pase des ER, sowie die Proteinkonzentration bestimmt. Zusätzlich wurden jeweils $250 \mu \mathrm{g}$ der Fraktionen N bis S und $50 \mu \mathrm{g}$ der Fraktionen F1 bis F4 zur Western Blot Analyse eingesetzt.

\subsubsection{Untersuchung der Stabilität der lysosomalen Vesikel}

Um die Fragilität der Lysosomen $\mathrm{zu}$ untersuchen wurden die Lysosomen im postnukleären Überstand (PNS) von Gewebehomogenaten mit einer hypertonischen Glucose-Lösung inkubiert (Docherty et al. 1979). Die Glucose wird über GlucoseTransporter ins Lysosomen gepumpt. Aufgrund des steigenden osmotischen Drucks platzen die Lysosomen. Instabile Lysosomen werden dabei schneller zerstört als normale Lysosomen. Um die Anzahl zerstörter Lysosomen zu bestimmen werden intakte Lysosomen durch Ultrazentrifugation aus dem Überstand entfernt. Im Überstand wird dann die freigesetzte $\beta$-Hexosaminidase-Aktivität gemessen.

$250 \mathrm{mg}$ frisch entnommene Mausleber wurden mit $1 \mathrm{ml}$ Sucrose-Lösung versetzt und mit 20 Hüben im Teflon-Homogenisator homogenisiert. Das Homogenisat wurde $5 \mathrm{~min}$ bei $1000 \times \mathrm{g}$ bei $4^{\circ} \mathrm{C}$ zentrifugiert um die Zellkerne $\mathrm{zu}$ pelletieren. Der postnukleäre Überstand (PNS) wurde abgenommen. Das Kernpellet wurde in $1 \mathrm{ml}$ Puffer 1 resuspendiert, nochmals homogenisiert und zentrifugiert. Die PNS-Fraktionen wurden gepoolt. Anschließend wurden $50 \mu 1$ PNS mit $250 \mu$ l Sucrose-Lösung versetzt (Ansatz 1) und $50 \mu 1$ PNS mit $250 \mu 1$ Glucoselösung versetzt (Ansatz 2). Die Ansätze wurden bei $37^{\circ} \mathrm{C}$ inkubiert. Nach 0, 5, 10 und 20 min wurde jeweils eine $30 \mu 1$ Probe entnommen, mit $270 \mu 1$ Sucrose-Lösung versetzt und auf Eis gestellt. Zusätzlich wurde nach 0 min Inkubationszeit eine weitere $30 \mu \mathrm{l}$ Probe entnommen, mit $270 \mu 1$ SucroseLösung/ $1 \%$ Triton X-100 versetzt und auf Eis gestellt. Das Triton X-100 führte zur vollständigen Lyse der Lysosomen, so dass die Gesamtaktivität der $\beta$-Hexosaminidase 
einer Probe bestimmt werden konnte. Nach Abstoppen aller Proben wurden die intakten Lysosomen durch $10 \mathrm{~min}$ Zentrifugation bei $30000 \mathrm{rpm}$ und $4^{\circ} \mathrm{C}$ im TLA 45 Rotor abzentrifugiert. Vom Überstand wurden $50 \mu$ abgenommen und zur Bestimmung der $\beta$-Hexosaminidaseaktivität (3.5.6) eingesetzt.

$\begin{array}{ll}\text { Sucrose-Lösung: } & 250 \mathrm{mM} \text { Saccharose } \\ & 3 \mathrm{mM} \text { Imidazol } \mathrm{pH} 7,0 \\ & 250 \mathrm{mM} \text { Glucose } \\ \text { Glucose-Lösung: } & 3 \mathrm{mM} \text { Imidazol } \mathrm{pH} 7,0\end{array}$

\subsubsection{Untersuchung der Lysosomen durch Percoll ${ }^{\mathrm{TM}}$-Dichtegradienten}

Mit Hilfe der subzellulären Fraktionierung im 30\%igen Percoll ${ }^{\mathrm{TM}}$-Dichtegradienten ist es möglich die Dichte und Größe zellulärer Kompartimente zu untersuchen. Durch Zentrifugation einer Percoll ${ }^{\mathrm{TM}}$ Sucrose-Lösung bildet sich ein Dichtegradient aus. Zur Untersuchung von Dichte und Größe der Lysosomen im Mausgewebe wurde der postnukleäre Überstand (PNS) von Gewebehomogenaten auf einem Percoll ${ }^{\mathrm{TM}}$ Dichtegradienten aufgetrennt und die Fraktionen des Gradienten wurden anschließend auf die Anwesenheit von $\beta$-Hexosaminidaseaktivität untersucht.

$100 \mathrm{mg}$ frisch entnommene Mausleber bzw. Mausniere wurden mit $1 \mathrm{ml}$ Puffer 1 versetzt und mit 20 Hüben im Teflon-Homogenisator homogenisiert. Das Homogenisat wurde $5 \mathrm{~min}$ bei $1000 \times \mathrm{g}$ bei $4^{\circ} \mathrm{C}$ zentrifugiert um die Zellkerne zu pelletieren. Der postnukleäre Überstand (PNS) wurde abgenommen. Das Kernpellet wurde in $1 \mathrm{ml}$ Puffer 1 resuspendiert, nochmals homogenisiert und zentrifugiert. Die PNS-Fraktionen wurden gepoolt. Anschließend wurden 0,9 ml PNS mit $3 \mathrm{ml}$ Puffer P und $6 \mathrm{ml}$ Puffer 1 gemischt. Der Ansatz wurde in ein Ti75-Zentrifugenröhrchen überführt und in der Beckmann Ultrazentrifuge im Ti75 Rotor bei $4^{\circ} \mathrm{C}$ mit $30000 \times \mathrm{g}$ für 90 min zentrifugiert. Nach der Zentrifugation wurden von dem entstandenen Dichtegradienten 20 Fraktionen mit jeweils $0,5 \mathrm{ml}$ abgenommen. $30 \mu 1$ jeder Fraktion wurden $3 \times 20 \mathrm{sec}$ sonifiziert und zur Messung der $\beta$-Hexosaminidaseaktivität (3.5.6) eingesetzt. 
Puffer 1:

Puffer P:
$250 \mathrm{mM}$ Saccharose

3 mM Imidazol pH 7,4

$90 \%(\mathrm{v} / \mathrm{v})$ Percoll

$10 \%(\mathrm{v} / \mathrm{v}) 2,5 \mathrm{M}$ Saccharose

$30 \mathrm{mM}$ Imidazol pH 7,4

\subsubsection{Metabolische Markierung von Proteinen (Pulse Chase)}

Um die Prozessierung von Proteinen in der Zelle zu verfolgen wurden Pulse Chase Experimente durchgeführt. In der Zelle werden alle synthetisierten Proteine durch eine Inkubation mit ${ }^{35} \mathrm{~S}-$ Methionin metabolisch markiert. Anschließend wird die Prozessierung der Proteine zu verschiedenen Zeitpunkten nach der metabolischen Markierung gestoppt. Die zu analysierenden Proteine werden durch Immunpräzipitation aus dem Zellhomogenat isoliert, durch SDS-PAGE aufgetrennt und durch die inkorporierte Radioaktivität detektiert.

Die Zellen wurden auf $10 \mathrm{~cm}$-Schalen ausplattiert. Bei einer Konfluenz von $80 \%$ wurden die Zellen zweimal mit PBS gewaschen und anschließend für $1 \mathrm{~h}$ mit $4 \mathrm{ml}$ Hungermedium inkubiert. Dann wurde das Hungermedium gegen $5 \mathrm{ml}$ Markierungsmedium ersetzt und die Zellen wurden nochmals $1 \mathrm{~h}$ inkubiert („Pulse“). Zum Stoppen der metabolischen Markierung wurde das Markierungsmedium abgenommen, die Zellen wurden mit PBS gewaschen und anschließend mit $5 \mathrm{ml}$ Normalmedium inkubiert. Zu verschiedenen Zeitpunkten („Chase“-Zeiten) nach der metabolischen Markierung wurde die Inkubation gestoppt. Dazu wurde das Medium abgenommen und in der Kühlzentrifuge bei $4^{\circ} \mathrm{C}$ mit $5000 \mathrm{rpm}$ abzentrifugiert um kontaminierende Zellreste zu entfernen. Der Überstand wurde in ein neues Gefäß überführt und bei $-20^{\circ} \mathrm{C}$ eingefroren. Die Zellen wurden auf der $10 \mathrm{~cm}$-Schale einmal mit kaltem PBS gespült und anschließend mit $2 \times 500 \mu 1$ Lysispuffer mit einem Zellschaber von der Platte geschabt, in ein $1,5 \mathrm{ml}$-Gefäß überführt und bei $-20^{\circ} \mathrm{C}$ eingefroren. 
Hungermedium: $\quad$ DMEM ohne Methionin/Cystein/Glutamin $1 \mathrm{ml} / 100 \mathrm{ml}$ Glutamin

$5 \%$ hitzeinaktiviertes, dialysiertes FKS

Das FKS wurde durch 45 min Inkubation bei $56^{\circ} \mathrm{C}$ hitzeinaktiviert und anschließend bei $4^{\circ} \mathrm{C}$ gegen PBS dialysiert (Porengröße 12-14 kDa).

${ }^{35}$ S-Met/Cys-Markierungsmedium: Hungermedium $150 \mu \mathrm{Ci} / \mathrm{ml}^{35} \mathrm{~S}-$ Methionin/Cystein

Lysispuffer: $\quad 0,1 \%$ Triton X-100

$1 \mathrm{mM}$ EDTA, $1 \mathrm{mM}$ PMSF, 5 mM JAA

in TBS

\subsubsection{Immunpräzipitation}

Um die Prozessierung der Proteine nach der metabolische Markierung zu analysieren, erfolgte eine Immunpräzipitation der untersuchten Proteine. Zur Immunpräzipitation wurde ein Antiserum aus Ratte und die Protein G Sepharose $\mathrm{TM}^{\mathrm{TM}}$ Fast Flow (GE Healthcare, München) verwendet. Die Proben wurden auf Eis aufgetaut. Die Zelllysate wurden durch $3 \times 20 \mathrm{sec}$ Ultraschallbestrahlung homogenisiert, 5 min bei $13000 \mathrm{rpm}$ zentrifugiert und der Überstand wurde in ein neues Gefäß überführt. Zur Fällung der genomischen DNA wurde allen Proben 1 Vol\% einer $3 \%$ igen Protaminsulfat-Lösung zugesetzt. Die Proben wurden 15 min auf Eis inkubiert. Dann wurde die gefällte DNA $5 \mathrm{~min}$ bei $13000 \mathrm{rpm}$ abzentrifugiert und der Überstand wurde in UZ-stabile 1,5 ml-Gefäße überführt. Den Proben wurde dann 0,8 Volumen PIMM, $10 \mu 1$ Präimmunserum aus Ratte und $40 \mu 1$ Protein G-Suspension zugesetzt und sie wurden $1 \mathrm{~h}$ bei $4^{\circ} \mathrm{C}$ auf dem Drehrad inkubiert. Dann wurden die Proben $15 \mathrm{~min}$ in der Ultrazentrifuge bei $45000 \mathrm{rpm}$ im TLA45 Rotor zentrifugiert. Die Überstände wurden in neue Gefäße überführt, mit $10 \mu 1$ spezifischem Antiserum aus Ratte versetzt und über Nacht bei $4^{\circ} \mathrm{C}$ am Drehrad inkubiert. Am folgenden Tag wurde zu den Proben $40 \mu \mathrm{l}$ 
Protein G-Suspension gegeben und es wurde eine weitere Stunde bei $4^{\circ} \mathrm{C}$ am Drehrad inkubiert. Anschließend wurde die Protein G Sepharose bei $7000 \mathrm{rpm}$ und $4^{\circ} \mathrm{C}$ in der Tischzentrifuge pelletiert. Der Überstand wurde verworfen. Zum Waschen wurde das Pellet in $800 \mu \mathrm{l}$ Neufeldpuffer resuspendiert und bei $7000 \mathrm{rpm}$ abzentrifugiert. Der Waschschritt wurde nacheinander mit Immunomix, Immunomix mit $2 \mathrm{M} \mathrm{KCl}$ und 0,1 fach PBS wiederholt. Anschließend wurde der Waschpuffer vollständig abgenommen und das Pellet wurde in $80 \mu 11 \times$ Lämmli-Auftragspuffer resuspendiert. Die Proben wurden $8 \mathrm{~min}$ auf $98^{\circ} \mathrm{C}$ erhitzt, die Protein G Sepharose wurde mit $14000 \mathrm{rpm}$ abzentrifugiert und der Überstand wurde auf ein $15 \%$-iges SDS-Gel aufgetragen. Nach der Elektrophorese wurde das Gel im Geltrockner getrocknet und eine Phospho-Imaging Plate (Fujifilm, Düsseldorf) wurde aufgelegt. Nach 4 Tagen Exposition wurde der Film im Biorad PMI Phosphoimager ausgelesen.

Protaminsulfat-Lösung: $\quad 3 \%$ Protaminsulfat in $\quad \mathrm{dH}_{2} \mathrm{O}$

Präzipitationsimmunomix (PIMM): $1 \%$ Triton X-100

$0,5 \%$ Na-Deoxycholat

$0,2 \%$ SDS

$10 \%$ BSA

1 mM EDTA

$1 \mathrm{mM}$ PMSF

5 mM JAA

in PBS

Protein G-Suspension

$50 \%$ Protein G Sepharose

in PBS $/ 0,02 \%$ Natriumazid

Neufeldpuffer:

$10 \mathrm{mM}$ Tris/ $\mathrm{HCl} \mathrm{pH} 8,5$

$0,6 \mathrm{M} \mathrm{NaCl}$

$0,1 \%$ SDS

$0,05 \%$ Nonidet P-40

Immunomix (IMM): $\quad 0,5 \%$ Natriumdesoxycholat

$1 \%$ Triton X-100

in PBS 
2 M KCl-Immunomix:

$2 \mathrm{M} \mathrm{KCl}$

in IMM

\subsubsection{SDS-Polyacrylamid-Gelelektrophorese (SDS-PAGE)}

Die elektrophoretische Trennung von Proteinen erfolgte mittels diskontinuierlicher SDS-Polyacrylamid-Gelelektrophorese (Laemmli 1970). Das Polyacrylamidgel wurde zwischen zwei Glasplatten $(16 \mathrm{~cm} \times 18 \mathrm{~cm}$, Abstandshalter $1,5 \mathrm{~mm}$ dick $)$ gegossen. Es bestand aus einem Trenngel, das je nach gewünschtem Auftrennungsbereich der Proteine zwischen $10 \%$ und $15 \%$ Acrylamid enthielt, und einem $4 \%$-igen Sammelgel. Die Komponenten des Trenngels wurden entsprechend Tab. 3.9 gemischt, bis $4 \mathrm{~cm}$ unter den Rand zwischen die Glasplatten eingegossen und mit Isopropanol überschichtet. Nach etwa 30 min war das Gel polymerisiert. Das Isopropanol wurde abgegossen, die Trenngeloberfläche wurde mit $\mathrm{dH}_{2} \mathrm{O}$ gespült, das Sammelgel wurde auf das Trenngel gegossen und ein Probenkamm wurde eingesetzt. Nach $30 \mathrm{~min}$ war das Gel auspolymerisiert und konnte zur Elektrophorese verwendet werden. Das Gel wurde in die Elektrophoresekammer eingesetzt. Die Kammern wurde mit Anoden- und Kathodenpuffer gefüllt. Die Proteinproben wurden mit $3 \times$ Lämmli-Auftragspuffer versetzt und $5 \mathrm{~min}$ bei $96^{\circ} \mathrm{C}$ denaturiert. Die Proben wurden $1 \mathrm{~min}$ bei $14000 \mathrm{rpm}$ zentrifugiert und die Überstände wurden in die Geltaschen aufgetragen. Dann erfolgte die Elektrophorese für $2 \mathrm{~h}$ bei $20 \mathrm{~mA}$ und weiteren $2 \mathrm{~h}$ bei $40 \mathrm{~mA}$.

Anodenpuffer:

$50 \mathrm{mM}$ Tris/ $\mathrm{HCl} \mathrm{pH} 8,6$

$384 \mathrm{mM}$ Glycin

in $\mathrm{dH}_{2} \mathrm{O}$

Kathodenpuffer:

$0,1 \%$ SDS

0,001\% Bromphenolblau

in Anodenpuffer 
$3 \times$ Lämmli-Auftragspuffer:

$150 \mathrm{mM}$ Tris/ $\mathrm{HCl} \mathrm{pH}$ 6,8

$6 \% \operatorname{SDS}$

$30 \%$ Glycerin

0,3 \% Bromphenolblau

$3 \% \beta$-Mercaptoethanol (frisch zusetzen)

Trenngelpuffer:

1,5 M Tris/ $\mathrm{HCl} \mathrm{pH} 8,8$

$0,4 \%$ SDS

Sammelgelpuffer:

0,5 M Tris/ $\mathrm{HCl} \mathrm{pH} 6,8$

$0,4 \%$ SDS

Acrylamidlösung:

$30 \%$ Acrylamid/ 0,8\% Bisacrylamid in $\mathrm{dH}_{2} \mathrm{O}$

(Rotiphorese ${ }^{\circledR}$ Gel 30, Roth)

Ammoniumperoxodisulfat (APS): $\quad 10 \%$ Ammoniumperoxodisulfat in $\mathrm{dH}_{2} \mathrm{O}$

\begin{tabular}{lcccc}
\hline & $\begin{array}{l}\text { Trenngel 10\% } \\
(30 \mathrm{ml})\end{array}$ & $\begin{array}{l}\text { Trenngel 13\% } \\
(30 \mathrm{ml})\end{array}$ & $\begin{array}{l}\text { Trenngel 15\% } \\
(30 \mathrm{ml})\end{array}$ & $\begin{array}{l}\text { Sammelgel 4\% } \\
(10 \mathrm{ml})\end{array}$ \\
\hline Acrylamidlösung $(\mathrm{ml})$ & 9,8 & 12,7 & 14,7 & 1,3 \\
Trenngelpuffer $(\mathrm{ml})$ & 7,5 & 7,5 & 7,5 & --- \\
Sammelpuffer $(\mathrm{ml})$ & --- & --- & --- & 2,5 \\
$10 \%$ APS in $\mathrm{dH}_{2} \mathrm{O}(\mu \mathrm{l})$ & 250 & 250 & 250 & 100 \\
TEMED $(\mu \mathrm{l})$ & 25 & 25 & 25 & 10 \\
$\mathrm{dH}_{2} \mathrm{O}(\mathrm{ml})$ & 12,6 & 9,6 & 7,7 & 6,1 \\
\hline
\end{tabular}

Tab. 3.9: Zusammensetzung von Trenngelen verschiedener Polyacrylamidkonzentrationen und des Sammelgel

\subsubsection{D-Gelelektrophorese}

Bei der 2D-Gelelektrophorese erfolgt die Auftrennung von Proteinen in zwei Dimensionen. In der ersten Dimension erfolgt eine isoelektrische Fokussierung (IEF). In der zweiten Dimension werden die Proteine durch SDS-PAGE nach ihrem Molekulargewicht aufgetrennt. Affinitätschromatografisch aufgereinigte M6P-markierte Proteine wurden mit einer Endkonzentration von $80 \%$ Aceton gefällt. Nach einer 
Inkubation über Nacht bei $-20^{\circ} \mathrm{C}$ wurden die präzipitierten Proteine $10 \mathrm{~min}$ mit $16000 \times \mathrm{g}$ bei $4^{\circ} \mathrm{C}$ pelletiert, mit $80 \%$ Aceton gewaschen und erneut zentrifugiert. Das Proteinpellet wurde bei RT getrocknet und anschließend in IEF-Lysispuffer gelöst. Zur IEF wurden Röhrchengele vorbereitet. $15 \mathrm{~cm}$ lange Glasröhrchen mit $3 \mathrm{~mm}$ Durchmesser wurden mit Chromschwefelsäure gereinigt, mit $\mathrm{dH}_{2} \mathrm{O}$ und Aceton gespült und am unteren Ende mit Parafilm abgedichtet. Die Komponenten des IEF-Gel mit Ausnahme von APS und TEMED wurden gemischt und 15 min entgast. APS und TEMED wurden zugesetzt und das Röhrchen wurde $12,5 \mathrm{~cm}$ mit IEF-Gellösung und mit $100 \mu 1$ Gelüberschichtungspuffer gefüllt. Die Polymerisation erfolgt über Nacht bei $4^{\circ} \mathrm{C}$. Etwa 2 Stunden vor Gebrauch des Gels wurde der Gelüberschichtungspuffer gegen $100 \mu \mathrm{l}$ IEF-Lysispuffer ersetzt. Der Parafilm wurde entfernt und durch eine Dialysemembran getränkt in Anodenpuffer ersetzt. Das Röhrchen wurde in die Elektrophoresekammer gefüllt mit Anodenpuffer eingesetzt. Der IEF-Lysispuffer an der Kathode des Röhrchengels wurde gegen die Probe gelöst in IEF-Lysispuffer ersetzt und die Probe wurde mit $20 \mu \mathrm{l}$ Probenüberschichtungspuffer überschichtet. Das Röhrchen und die Elektrophoresekammer wurden mit Kathodenpuffer aufgefüllt. Die IEF erfolgte für $30 \mathrm{~min}$ bei $200 \mathrm{~V}$, für 18,2 Stunden bei $500 \mathrm{~V}$, für $1 \mathrm{~h}$ bei $800 \mathrm{~V}$ und $1 \mathrm{~h}$ bei $1000 \mathrm{~V}$. Nach der IEF wurde das Gel aus dem Röhrchen entfernt, 20 min in Äquilibierungspuffer I und 20 min in Äquilibierungspuffer II inkubiert und dann auf ein $15 \%$-iges SDS-PAGE-Gel (siehe 3.5.16) aufgetragen. Beim Gießen des Sammelgels wurde ein spezieller Kamm verwendet, sodass das äquilibrierte IEF-Gel auf die Sammelgeloberfläche aufgelegt werden konnte. Die SDS-PAGE erfolgte bei $10 \mathrm{~mA}$ für $45 \mathrm{~min}$, bei $15 \mathrm{~mA}$ für $30 \mathrm{~min}$, gefolgt von $30 \mathrm{~mA}$ für $3 \mathrm{~h}$.

IEF-Lysispuffer:

$$
\begin{aligned}
& 9 \text { M Harnstoff } \\
& 4 \% \text { CHAPS } \\
& 0,8 \% \text { Servalyt }^{\circledR} \text { carrier ampholytes } \mathrm{pH} 4-74 \text {. } \\
& 0,2 \% \text { Servalyt }^{\circledR} \text { carrier ampholytes } \mathrm{pH}_{3}-10 \\
& 10 \text { mM DTT }
\end{aligned}
$$


IEF-Gel:

Gelüberschichtungspuffer:

Anodenpuffer:

Kathodenpuffer:

Probenüberschichtungspuffer:

Äquilibrierungspuffer I:

Äquilibierungspuffer II:
5,2\% Acrylamid

$0,3 \%$ Bisacrylamid

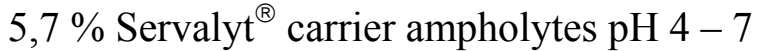

$1,4 \%$ Servalyt $^{\circledR}$ carrier ampholytes $\mathrm{pH} 3-10$

10,3 M Harnstoff

$3 \%$ CHAPS

$0,04 \%$ APS

$0,2 \%$ TEMED

6,5 M Harnstoff

$0,01 \mathrm{M} \mathrm{H}_{3} \mathrm{PO}_{4}$

$0,02 \mathrm{M} \mathrm{NaOH}$

7 M Harnstoff

$0,32 \%$ Servalyt $^{\circledR}$ carrier ampholytes $\mathrm{pH} 4-7$

$0,08 \%$ Servalyt $^{\circledR}$ carrier ampholytes $\mathrm{pH} 3-10$

0,05 M Tris/ $\mathrm{HCl} \mathrm{pH} 6,8$

$15 \%$ Glycerin

$4 \%$ SDS

$0,25 \%$ DTT

0,05 M Tris/ $\mathrm{HCl} \mathrm{pH} 6,8$

$30 \%$ Glycerin

6 M Harnstoff

$4 \%$ SDS

$25 \mathrm{mM}$ Jodacetamid

\subsubsection{Färbung von Polyacrylamid-Gelen mit kolloidaler Coomassie-Lösung}

Das SDS-Gel wurde nach der Elektrophorese für $1 \mathrm{~h}$ bei RT mit der Fixierlösung inkubiert. Dann wurde das Gel zweimal für $10 \mathrm{~min}$ mit $\mathrm{dH}_{2} \mathrm{O}$ gewaschen. Die Coomassie-Gebrauchslösung wurde vor der Verwendung frisch angesetzt (Neuhoff et al. 1988). Das Gel wurde mindestens 16 h gefärbt. Dann wurde es mit der Entfärbelösung bis zur gewünschten Farbintensität entfärbt. Zur Digitalisierung wurde das Gel mit der 
CCD-Kamera LAS-1000 (FuliFilm, Tokyo, Japan) aufgenommen oder eingescannt und im Geltrockner getrocknet.

Fixierlösung:

Coomassie-Stocklösung:

Coomassie-Gebrauchslösung:

Entfärbelösung:
$40 \%$ Ethanol

$10 \%$ Essigsäure

0,1 \% Coomassie Brilliant Blue G250

$2 \%(\mathrm{w} / \mathrm{v})$ Phosphorsäure

$10 \%$ Ammoniumsulfat

$80 \%$ Coomassie-Stocklösung

$20 \%$ Methanol

$1 \%$ Essigsäure

\subsubsection{Färbung von Polyacrylamid-Gelen mit Silberfärbung}

Die Silberfärbung erfolgte nach der Methode von Heukeshoven (Heukeshoven und Dernick 1988). Das SDS-Gel wurde nach der Elektrophorese $1,5 \mathrm{~h}$ bei RT in Fixierungslösung I inkubiert. Dann erfolgte eine weitere Fixierung in Fixierlösung II für $2 \mathrm{~h}$ bei RT. Anschließend wurde das Gel dreimal für je 20 min mit $\mathrm{dH}_{2} \mathrm{O}$ gespült und dann für $1 \mathrm{~h}$ mit der Silber-Färbelösung inkubiert. Es folgte die Entwicklung des Gels. Dazu wurde das Gel für 1 min in $\mathrm{dH}_{2} \mathrm{O}$ und 1 min mit der Entwicklerlösung gespült. Anschließend wurde das Gel mit Entwicklerlösung inkubiert bis die Proteinbanden gut sichtbar waren. Die Entwicklerlösung wurde abgegossen und die Reaktion wurde durch die Inkubation des Gels in Glycinlösung gestoppt. Nach 10 min konnte das Gel mit Wasser gespült werden. Zur Digitalisierung wurde das Gel mit dem LAS-1000 Gel Dokumentation System (Fujifilm, Düsseldorf) aufgenommen oder eingescannt und im Geltrockner getrocknet.

Fixierlösung I: $30 \%$ Ethanol $10 \%$ Essigsäure 


\begin{tabular}{|c|c|}
\hline \multirow{4}{*}{ Fixierlösung II: } & $0,5 \mathrm{M}$ Natriumacetat \\
\hline & $30 \%$ Ethanol \\
\hline & $0,5 \%$ Glutaraldehyd \\
\hline & $0,2 \%$ Natriumthiosulfat-Pentahydrat \\
\hline \multirow[t]{2}{*}{ Silber-Färbelösung: } & $0,1 \%$ Silbernitrat \\
\hline & $0,02 \%$ Formaldehyd \\
\hline \multirow[t]{2}{*}{ Entwicklerlösung: } & 2,5\% Natriumcarbonat \\
\hline & $0,01 \%$ Formaldehyd \\
\hline Glycinlösung: & 0,05 M Glycin \\
\hline
\end{tabular}

\subsubsection{Western Blot Analyse (Semidry-Methode)}

Zur Immundetektion von Proteinen wurden die Proben nach ihrer Auftrennung durch SDS-PAGE im Semidry-Western Blot Verfahren auf eine PVDF-Membran transferiert. Anschließend erfolgte die Immundetektion mittels Chemilumineszenz-Nachweis von HRP-konjugierten Sekundärantikörpern.

Nach Beendigung der SDS-PAGE wurde das SDS-Gel aus der Elektrophoresekammer genommen. Das Sammelgel wurde entfernt und das Trenngel wurde zum Äquilibrieren 10 min in Semidry-Kathodenpuffer inkubiert. Die PVDF-Membran wurde durch kurzes Schwenken in Methanol aktiviert und ebenfalls in Kathodenpuffer äquilibriert. Dann wurde der Blot in der Phegasus Blotkammer (Phase, Lübeck) aufgebaut. Der Aufbau ist in Abb. 32 schematisch dargestellt. Auf die untere Elektrodenplatte (Kathode) wurden drei in Kathodenpuffer getränkte Whatman-Filterpapiere gestapelt. Dann wurden das Gel, die Membran, drei in Anodenpuffer getränkte Whatman-Filterpapiere und anschließend die Anodenplatte aufgelegt. Der Elektrotransfer erfolgte bei einer Stromstärke von $1 \mathrm{~mA} / \mathrm{cm}^{2}$ für 70 Minuten.

Kathodenpuffer:

$40 \mathrm{mM} \varepsilon$-Aminocapronsäure

$20 \mathrm{mM}$ Tris/ $\mathrm{HCl} \mathrm{pH} 9,0$

$20 \%$ Methanol 
Anodenpuffer:

$75 \mathrm{mM}$ Tris/ $\mathrm{HCl} \mathrm{pH} 7,4$

$20 \%$ Methanol

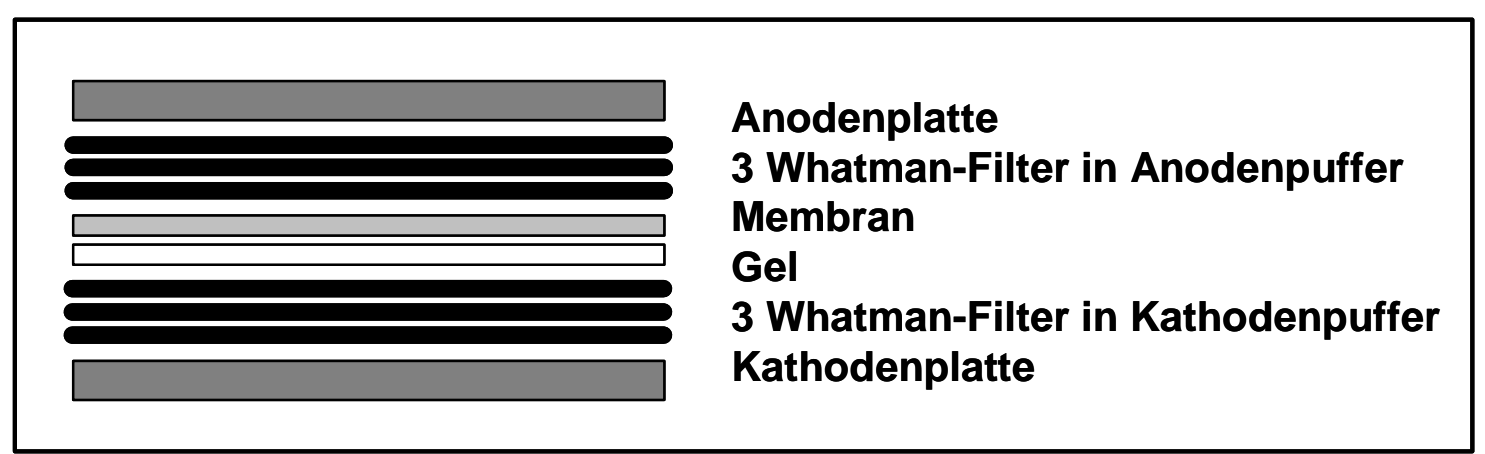

Abb. 3 2: $\quad$ Schematischer Aufbau eines Semidry-Western Blots

Nach Beendigung des Elektrotransfers wurde der Blot abgebaut und die PVDF-Membran wurde unter kontinuierlicher Bewegung auf einer Wippe inkubiert. Zunächst wurde die Membran, zum Blocken von Antigenbindungsstellen, $1 \mathrm{~h}$ in Blotto inkubiert. Dann folgte eine Inkubation mit Primärantikörper verdünnt in Blotto über Nacht bei $4^{\circ} \mathrm{C}$. Anschließend wurde die Membran $5 \times 10$ min mit PBST gespült. Es folgte eine 1stündige Inkubation mit HRP-konjugiertem (horseradish peroxidase) Sekundärantikörper und ein weiterer Waschschritt mit $5 \times 10$ min PBST. Die verwendeten Primärantikörper und ihre Verdünnung sind in Abschnitt 3.1.7.1 angegeben.

$\begin{array}{ll}\text { PBST: } & 1 \times \text { PBS } \\ & 0,1 \% \text { Tween- } 20 \\ \text { Blotto: } & 1 \times \text { PBS } \\ & 0,1 \% \text { Tween- } 20 \\ & 5 \% \text { Magermilchpulver }\end{array}$

Die Detektion der Proteine erfolgt mit Hilfe des Supersignal West Pico Chemiluminescent Detection Kits (Pierce, Rockford, USA). Die beiden Lösungen des Kits wurden 1:1 gemischt und auf der Membran verteilt. Unter gelegentlichem Schwenken wurde die Membran 5 min inkubiert. Anschließend wurde die Membran in 
Folie eingeschlagen. Die Detektion der Chemilumineszenz erfolgte durch die CCDKamera LAS-1000 (Fujifilm, Tokyo, Japan), wobei die Expositionszeit je nach Signalstärke variiert wurde.

Durch „Strippen“ der PVDF-Membran können die gebundenen Antikörperkomplexe von der Membran entfernt werden, ohne die Qualität und die Quantität der geblotteten Proteine zu verändern, und der Blot kann anschließend für die Immundetektion eines weiteren Proteins eingesetzt werden. Zum Strippen wurde die Membran $2 \times 5$ min mit $\mathrm{dH}_{2} \mathrm{O}$ gewaschen, dann $2 \times 5$ min mit $0,2 \mathrm{M} \mathrm{NaOH}$ inkubiert und anschließend nochmals $2 \times 5$ min mit $\mathrm{dH}_{2} \mathrm{O}$ gewaschen. Nach dieser Behandlung konnte die Membran beginnend mit der Blockierung mit Blotto zur weiteren Immundetektion eingesetzt werden.

\subsection{Tierexperimentelle Methoden}

\subsubsection{Immunisierung von Kaninchen und Ratten zur Generierung von Antiseren}

Zur Generierung von spezifischen Antiseren wurde Kaninchen und Ratten aufgereinigtes Protein und Stimune Adjuvant (Cedi Diagnostics, Lelystad, Niederlande) injiziert. Zur Immunisierung von Kaninchen wurde ein Injektionsvolumen von $600 \mu \mathrm{l}$ mit $300 \mu \mathrm{g}$ Protein (1.Injektion) bzw. $150 \mu \mathrm{g}$ Protein (folgende Injektionen) in $300 \mu \mathrm{l}$ PBS und $300 \mu 1$ Stimune Adjuvant angesetzt. Vor der ersten Injektion wurden dem Kaninchen zur Herstellung eines Präimmunserums aus einer Ohrvene $5 \mathrm{ml}$ Blut abgenommen. Zur Immunisierung wurde dem Kaninchen ein Injektionsvolumen von $600 \mu \mathrm{l}$ im Nackenbereich subkutan an zwei Stellen injiziert. Weitere Injektionen folgten in Zeitabständen von 28 Tagen. 14 Tage nach jeder Injektion wurden dem Kaninchen $2 \mathrm{ml}$ Blut aus der Ohrvene abgenommen, um die Immunreaktion des Kaninchens am Serum des Kaninchens zu testen. Zur Untersuchung der Immunspezifität des Serums wurden verschiedene Konzentrationen des injizierten Proteins im Western Blot mit verschiedenen Serumkonzentrationen nachgewiesen. Ein spezifisches Antiserum erkannte $10 \mathrm{ng}$ des Protein bei einer 1:1000 Verdünnung des Serum in Blotto. Nach vier Injektionen (100 Tage nach der ersten Injektion) wurde das Kaninchen getötet und ausgeblutet. Die Tötung und die Blutentnahme wurde von Tierarzt Dr. Schunk an der ZTE des Klinikums 
Göttingen durchgeführt. Das gewonnene Antiserum wurde aliquotiert und bei $-20^{\circ} \mathrm{C}$ gelagert.

Zur Immunisierung von Ratten wurde ein Injektionsvolumen von $250 \mu 1$ mit $125 \mu \mathrm{g}$ Protein in $125 \mu \mathrm{l}$ PBS und $125 \mu$ l Stimune Adjuvant angesetzt. Die Ratte wurde mit $\mathrm{CO}_{2}$ kurzzeitig narkotisiert, zur Bestimmung des Immunstatus wurden retrobulbär $500 \mu 1$ Blut entnommen und der Protein/Adjuvant-Mix wurde subkutan im Nackenbereich injiziert. Injektionen erfolgten in Zeitabständen von 21 Tagen. Die Immunspezifität des Serums wurde im Western Blot analysiert. Bei der fünften Immunisierung wurde das Protein ohne Adjuvant injiziert. 4 Tage später wurde die Ratte getötet und das Blut entnommen. Tötung und Blutentnahme erfolgte durch Stefan Wolf im Tierstall der Biochemie 2. Das Antiserum wurde gewonnen, aliquotiert und bei $-20^{\circ} \mathrm{C}$ gelagert.

\subsection{Sonstige Methoden}

\subsubsection{MALDI-TOF-MS Analyse zur Identifikation von Proteinen}

Zur Identifizierung von Proteinen aus SDS-Gelen erfolgte ein In-Gel-Verdau des Proteins und die anschließende Identifikation durch eine peptide mass fingerprint Analyse am MALDI-TOF Massenspektrometer. Aus dem Proteinspot des Coomassie-gefärbten Gels wurde ein $2 \mathrm{~mm}$ großes Gelstück ausgestanzt. Zum Waschen wurde das Gelstück bei $37^{\circ} \mathrm{C} 15 \mathrm{~min}$ mit $100 \mu \mathrm{l}$ Waschlösung 1, dann zweimal $30 \mathrm{~min}$ mit jeweils $100 \mu \mathrm{l}$ Waschlösung 2 und schließlich für 10 min mit $100 \mu$ Acetonitril behandelt. Das Gelstück wurde bei RT 5 min getrocknet. Zur reduktiven Carbamidomethylierung wurde die Probe mit $10 \mu \mathrm{l}$ DTT-Lösung für $1 \mathrm{~h}$ bei $56^{\circ} \mathrm{C}$ inkubiert, auf Eis abgekühlt, der Überstand wurde abgenommen und die Probe wurde im Dunkeln mit $10 \mu 1$ Iodacetamid-Lösung 30 min bei RT inkubiert. Der Überstand wurde entfernt und der Iodacetamid-Rückstand wurde mit $10 \mu \mathrm{l}$ DTT-Lösung für $10 \mathrm{~min}$ bei $37^{\circ} \mathrm{C}$ gequencht. Zum Waschen des Gelstücks wurde es bei $37^{\circ} \mathrm{C}$ für $30 \mathrm{~min}$ mit $100 \mu \mathrm{l}$ Waschlösung 2 und für $10 \mathrm{~min}$ mit $100 \%$ Acetonitril inkubiert. Dann wurde das Gelstück bei RT 5 min getrocknet. 2,5 $\mu 1$ Trypsin-Stocklösung wurden mit $60 \mu \mathrm{l}$ Waschlösung 1 gemischt. $6 \mu 1$ des Gemischs (120 ng Trypsin) wurden auf Eis auf das Gelstück pipettiert. Nachdem das Gelstück die Trypsinlösung aufgenommen hatte, wurde das Reaktionsgefäß mit Waschlösung 1 gefüllt 
bis das Gelstück vollständig bedeckt war. Es folgte eine Inkubation über Nacht bei $37^{\circ} \mathrm{C}$. Am folgenden Tag wurde der Überstand abgenommen und das Gel wurde zur vollständigen Extraktion der Peptide mit $20 \mu 11 \%$ TFA bei $37^{\circ} \mathrm{C}$ für 30 min inkubiert. Die Peptidlösungen wurden gepoolt, in der Vakuumzentrifuge getrocknet und in $10 \mu 1$ einer 0,1 \% TFA-Lösung aufgenommen. 0,5 $\mu 1$ der Peptidlösung und 0,5 $\mu 1$ DHB-Matrix (2,5-Dihydroxybenzoesäure) wurden zur Kokristallisation auf das MALDI-Target aufgetragen. Die Probe wurde im REFLEX III MALDI-TOF Massenspektrometer vermessen und mit Hilfe des MASCOT Suchalgorithmus (Perkins et al. 1999) wurden die Proteine anhand ihrer Peptidmassen in der NCBI nr (nonredundant) Protein Datenbank identifiziert. Alle massenspektrometrischen Analysen in dieser Dissertation wurden von Nicole Eiselt und Kudzai Mutenda durchgeführt.

Waschlösung 1:

Waschlösung 2:

DTT-Lösung:

Iodacetamid-Lösung:

Trypsin-Stocklösung:

DHB-Matrix:
$25 \mathrm{mM} \mathrm{NH}_{4} \mathrm{HCO}_{3}$

in $\mathrm{ddH}_{2} \mathrm{O}$

$50 \%$ Acetronitril

in Waschlösung 1

$10 \mathrm{mM}$ Dithiothreitol (DTT)

in Waschlösung 1

$25 \mathrm{mM}$ Iodacetamid

in Waschlösung 1

$0,5 \mu \mathrm{g} / \mu 1$ Trypsin

$0,01 \%$ Trifluoressigsäure (TFA)

5 mg 2,5-Dihydroxybenzoesäure (DHB)

$0,1 \%$ Trifluoressigsäure (TFA)

\subsubsection{MudPIT-Analyse}

Die MudPIT Analyse (Multidimensional Protein Identification technology) ist eine Proteomanalyse Methode, bei der ein komplexes Peptidgemisch durch multidimensionale Chromatografieschritte aufgetrennt wird. Die aufgetrennten Peptide werden anschließend durch Tandem-Massenspektrometrie (MS/MS) und Datenbankanalyse identifiziert. Die 
MudPIT Analyse in dieser Dissertation aufgereinigten Proteine erfolgte methodisch entsprechend der MudPIT-Analyse von Washburn (Washburn et al. 2001). Das zu identifizierende Proteingemisch wurde tryptisch verdaut. Die tryptischen Peptide wurden durch sequenzielle Chromatografie an Kationenaustauscher- und Reverse Phase-Säulen aufgetrennt und durch ESI-Tandem-Massenspektrometrie (ESI-MS/MS) identifiziert.

Die ankonzentrierten, dialysierten Eluate der MPR-Affinitätschromatografie (siehe 3.5.2) wurden lyophilisiert und anschließend in $45 \mu 18 \mathrm{M}$ Harnstoff/ $0,4 \mathrm{M} \mathrm{NH}_{4} \mathrm{HCO}_{3} \mathrm{pH} 8,5$ gelöst. Zur Reduktion der Proteine wurde $5 \mu 100 \mathrm{mM}$ DTT zugegeben und $1 \mathrm{~h}$ bei $56^{\circ} \mathrm{C}$ inkubiert. Die Cysteine der reduzierten Proteine wurden mit $5 \mu 1300 \mathrm{mM}$ Iodacetamid $30 \mathrm{C}$ bei RT in Dunkelheit carbamidomethyliert. Überschüssiges Iodacetamid wurde durch Zugabe von 2,5 $\mu 1100$ mM DTT gequencht. Die Proteinlösung wurde mit Wasser auf eine Konzentration von $2 \mathrm{M}$ Harnstoff verdünnt und mit $4 \mu \mathrm{g}$ Trypsin $16 \mathrm{~h}$ bei $37^{\circ} \mathrm{C}$ verdaut. Nach $8 \mathrm{~h}$ Inkubation wurde frisches Trypsin zugesetzt. Das Peptidgemisch wurde zum Entsalzen an eine ZipTipC18 Säule (Millipore, Schwalbach) gebunden, mit $200 \mu 170 \%$ Acetonitril und $0,1 \%$ TFA eluiert und anschließend getrocknet. Die Peptide wurden anschließend, äquilibriert in $5 \%$ Acetonitril/ 0,1 \% TFA, auf eine Poros 10 S-Kationaustauschersäule $(1 \times 150 \mathrm{~mm}$, LC Packings, Amsterdam, Niederlande) aufgetragen. Die Elution der Peptide erfolgte in einem linearen, 60-Minuten Gradienten von 0 bis $50 \% 250 \mathrm{mM}$ Ammoniumacetat. Bei einer Flussrate von $40 \mu \mathrm{l} / \mathrm{min}$ wurden jeweils $25 \mu \mathrm{l}$ Fraktionen gesammelt. $2 \mu 1$ jeder Fraktion wurden auf eine C18 Reverse-Phase Nano-Säule (PepMap C18, $0.075 \times$ $150 \mathrm{~mm}$, LC Packings) am Nanoflow HPLC System (Ultimate, LC Packings) aufgetragen. In einem linearen 30-Minuten-Gradient von $2 \%$ bis $50 \%$ Puffer B (90\% Acetonitril/ 0,1\% Ameisensäure) wurden die Peptide mit einer Flussrate von $200 \mu \mathrm{l} / \mathrm{min}$ von der Säule eluiert. Die eluierte Probe wurde 1:1000 gesplittet und mit einer Flussrate von $200 \mathrm{nl} / \mathrm{min}$ online der Messung am ESI-MS-Massenspektrometer (Esquire 3000+, Bruker Daltonik) zugeführt. Automatisch wurden MS und MS/MS Analysen durchgeführt. Die Identifizierung der Proteine erfolgte durch dem MASCOT Algorithmus (Perkins et al. 1999). Eine signifikante Identifizierung des Proteins erfolgte bei einem MASCOT Score von mindestens 50, ermittelt anhand von Peptiden mit mindestens 6 
Aminosäuren. Alle MudPIT-Analysen zu dieser Dissertation wurden von Kudzai Mutenda durchgeführt.

\subsubsection{Edman Analyse}

Zur Identifizierung der N-terminalen Aminosäuresequenz von Proteinen erfolgte eine Edman Analyse. Aufgereinigte Proteine oder Proteinfragmente wurden über SDS-PAGE aufgetrennt, auf eine PVDF-Membran übertragen. Die Membran wurde $3 \mathrm{~min}$ in Coomassie-Färbelösung und anschließend in Entfärbelösung inkubiert bis distinkte Proteinbanden zu erkennen waren. Die Banden wurden aus der PVDF-Membran ausgeschnitten und der automatischen N-terminalen Sequenzierung im Procise cLC sequenator (Applied Biosystems) zugeführt. Die Sequenzierung der vorbereiteten Proben wurde von Klaus Neifert durchgeführt.

Commassie-Färbelösung:

$0,25 \%(w / v)$ Coomassie Serva-Blue R-250

$10 \%(\mathrm{v} / \mathrm{v})$ Essigsäure

$50 \%(\mathrm{v} / \mathrm{v})$ Methanol

Entfärbelösung:

$10 \%(\mathrm{v} / \mathrm{v})$ Essigsäure

$50 \%(\mathrm{v} / \mathrm{v})$ Methanol 


\section{$4 \quad$ Ergebnisse}

\subsection{Proteomanalyse M6P-markierter Proteine}

\subsubsection{Aufreinigung M6P-markierter Proteine}

Lysosomale Matrixproteine werden durch die Bildung von M6P-Resten modifiziert und nach Bindung an einen der beiden MPR zum Lysosom transportiert. Zur Aufreinigung lysosomaler Matrixproteine kann man sich diese Modifikation und die Bindung der Proteine an die MPR zu Nutze machen. M6P-markierte Proteine wurden aus Zellkulturüberständen der MPR-defizienten Mausfibroblasten MEF-23-1SV (Kasper et al. 1996; Dittmer et al. 1998; Dittmer et al. 1999) gewonnen. Aufgrund des gezielten Ausschaltens der Gene für den MPR300 und MPR46 werden M6P-markierte Proteine von MEF-23-1SV konstitutiv sezerniert. Zellkulturüberstände der MEF-23-1SV wurden gesammelt und zur quantitativen Fällung der Proteine mit 0,5 g/ml Ammoniumsulfat versetzt. Das Präzipitat wurde gegen Bindungspuffer dialysiert und mit Hilfe immobilisierter MPR affinitätschromatografisch aufgereinigt (3.5.2). Nach intensiver Dialyse gegen Bindungspuffer erfolgte eine Rechromatografie unter gleichen Bedingungen. Die Fraktionen der Aufreinigung wurden durch Bestimmung der spezifischen Aktivität der lysosomalen Proteine $\beta$-Hexosaminidase und Arylsulfatase A auf den Gehalt an lysosomalen Proteinen untersucht. Durch die affinitätschromatografische Aufreinigung konnte die spezifische Aktivität der $\beta$-Hexosaminidase auf 27 U/mg Protein angereichert werden. Die Isolierung der M6P-markierten Proteine erfolgte durch Martina Balleiniger.

\subsubsection{Identifizierung von M6P-markierten Proteinen durch 2D-Gelelektrophorese und Massenspektrometrie}

Zur Identifizierung der M6P-haltigen Proteine erfolgte zunächst eine Untersuchung der MPR-affinitätsgereinigten Proteine durch 2D-Gelelektrophorese mit anschließender Analyse der Proteine durch MALDI-TOF-MS. In der ersten Dimension wurden die 
Proteine durch isoelektrische Fokussierung mit einem $\mathrm{pH}$-Gradienten von $\mathrm{pH} 4-8$ aufgetrennt, in der zweiten Dimension erfolgte eine Trennung der Proteine durch SDS-PAGE mit einem 15 \%-igen Acrylamidgel (3.5.17). Die Proteine im 2D-Gel wurden mit kolloidalem Coomassie angefärbt und durch einen In-Gel-Verdau mit Trypsin und anschließender MALDI-TOF-MS Analyse identifiziert (3.7.1). Bei Proteinen, die durch MALDI-TOF-MS nicht identifiziert werden konnten, erfolgte zusätzlich eine offline nano ESI-MS Analyse (3.7.2). Die 2D-Gelelektrophorese wurde von Martina Balleiniger durchgeführt. Alle MALDI-TOF- und ESI-MS-Analysen wurden von Kudzai Mutenda und Nicole Eiselt unter Anleitung von Bernhard Schmidt durchgeführt.

Abb. 4.1 zeigt die Auftrennung von M6P-markierten Proteinen im 2D-Gel. Von 201 ausgestanzten Spots konnten in 198 Spots Proteine durch MALDI-TOF-MS oder ESI-MS Analyse identifiziert werden. Die identifizierten Proteine mit ihren korrespondierenden Proteinspots im 2D-Gel sind in der Tab. 4.2 aufgelistet. In drei Spots (Nr. 31, 187, 188) konnten die Proteine nicht identifiziert werden. In einem Spot (Nr. 192) wurde ein eindeutig nicht lysosomales Protein, das Dynamin 2 (gi: 6681207) identifiziert. In 180 Spots wurden insgesamt 28 bekannte lysosomale Matrixproteine identifiziert. Die lysosomalen Proteine $\alpha$-L-Fucosidase, die Arylsulfatase A, das CLN Protein 5 (ceroidlipofuscinosis neuronal protein 5), die Ribonuklease 6 und die Tripeptidylpeptidase I wurden jeweils durch einen einzelnen Spot im Gel identifiziert, während die übrigen Proteine in bis zu 34 Spots ( $\beta$-Hexosaminidase) detektiert wurden. Durchschnittlich wurde ein Protein durch sieben verschiedene Spots nachgewiesen. Die Heterogenität der Proteine in Ladung und Größe lässt sich auf die Glykosylierung und Phosphorylierung, sowie auf eine limitierte Proteolyse der Proteine zurückführen. 


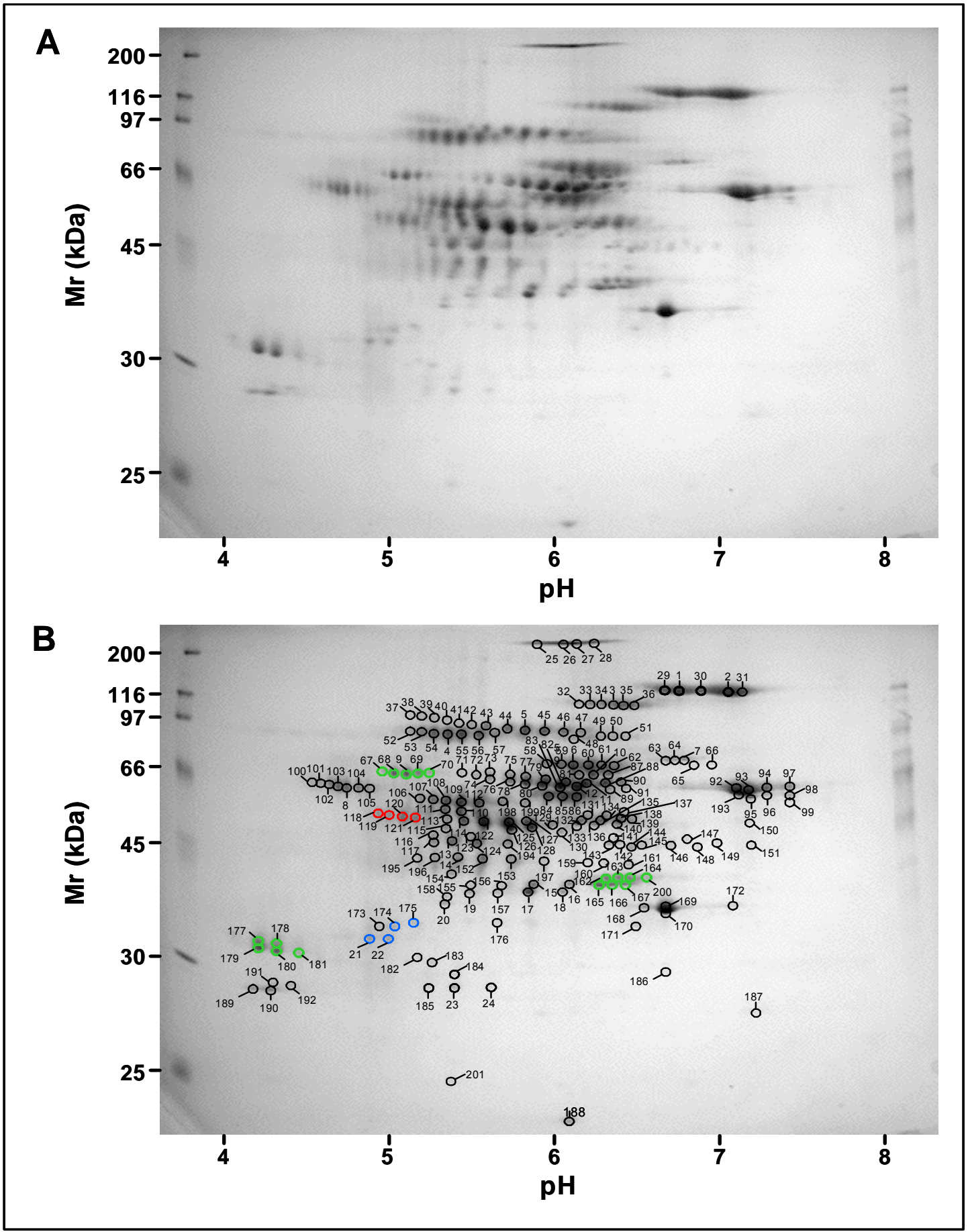

\section{Abb. 4.1: 2D-Gel von M6P-haltigen Proteinen aus MPR-defizienten mausembryonalen Fibroblasten}

(A) M6P-haltige Proteine wurden aus Zellkulturüberstand der MPR-defizienten Mausfibroblasten MEF-23-1SV gewonnen. Durch die Bindung an immobilisierte MPR wurden die Proteine affinitätschromatografisch aufgereinigt und anschließend durch 2D-GE separiert (IEF im Bereich von pH 4 - pH 8 gefolgt von SDS-PAGE mit einem 15\%-igen Gel, Coomassie-Färbung). Die in (B) markierten Spots wurden durch MALDI-TOF analysiert. Die Nummerierung der Proteinspots entspricht den Spotnummern in Tab. 4.2, in der die identifizierten Proteine aufgelistet sind. Farblich markiert sind Proteinspots in denen Kandidaten für neue lysosomale Proteine identifiziert wurden: Scpep1 (rot), 66.3 kDa-Protein (grün), MERP-2 (blau). 
Zusätzlich zu den 28 bekannten lysosomalen Matrixproteinen und dem nicht lysosomalen Protein wurden drei weitere Proteine im 2D-Gel identifiziert. Dabei handelt es sich zum einen um das hypothetical $66.3 \mathrm{kDa}$ protein (66.3 kDa-Protein). Dieses Protein wurde in 17 Spots identifiziert, was auf eine starke Heterogenität in Ladung und Größe des Proteins hinweist. Fünf Spots zeigten ein Molekulargewicht von $66 \mathrm{kDa}$ und lagen im $\mathrm{pH}-$ Bereich zwischen $\mathrm{pH}$ 5-5,5. Eine Gruppe von sieben Spots wurde mit einem Molekulargewicht von $40 \mathrm{kDa}$ im pH-Bereich von pH 6,2 - 6,6 detektiert und fünf Spots mit einem Molekulargewicht von $30 \mathrm{kDa}$ lagen bei $\mathrm{pH} 4,2-4,5$. Das zweite, neu identifizierte Protein, das mammalian ependymin related protein 2 (MERP-2), wurde in vier Spots des 2D-Gels identifiziert. Es zeigte ein Molekulargewicht von $32 \mathrm{kDa}$. Die Spots lagen im pH-Bereich von pH 4,8 - 5,2. Das dritte, neu identifizierte Protein war die Serincarboxypeptidase 1 (Scpep1). Dieses Protein wurde in vier Spots mit einem Molekulargewicht von $55 \mathrm{kDa}$ und einem pI zwischen $\mathrm{pH}$ 5,0 und 5,3 detektiert. Das aufgrund der Aminosäuresequenz berechnete Molekulargewicht von MERP-2 beträgt $22 \mathrm{kDa}$, das der Scpep1 beträgt $51 \mathrm{kDa}$.

\subsubsection{Identifizierung von M6P-haltigen Proteinen durch MudPIT-Analyse}

In einem zweiten Ansatz wurden die affinitätsgereinigten, M6P-markierten Proteine

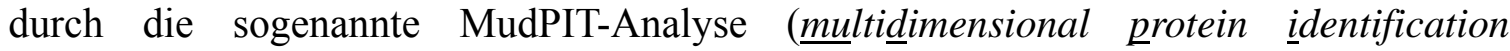
technology) untersucht. Die M6P-markierten Proteine wurden tryptisch verdaut, als tryptische Peptide durch sequenzielle Kationenaustauscher- und Reverse PhaseChromatografie separiert und durch ESI-Tandem-Massenspektrometrie (MS/MS) analysiert. Mit Hilfe der erhaltenen Peptidsequenzen wurden die M6P-markierten Proteine durch den MASCOT Suchalgorithmus in der NCBI nr Protein Datenbank identifiziert (3.7.2). Dabei wurden nur Peptide mit einer Sequenzlänge von mindestens sechs Aminosäuren zugelassen. Die MudPIT-Analyse wurde von Kudzai Mutenda durchgeführt.

Mit Hilfe der MudPIT-Analyse wurden insgesamt 149 Peptide mit einer Länge von sechs bis 18 Aminosäuren bestimmt. Dabei wurden insgesamt 28 bekannte lysosomale, sechs putativ lysosomale Proteine, sowie ein bekanntes nicht lysosomales Protein, das Keratin Complex 2, identifiziert. In Tab. 4.2 sind die identifizierten Proteine aufgelistet. Für jedes 
Protein wurden durchschnittlich vier Peptide gefunden, was einer durchschnittlichen Sequenzabdeckung von $10 \%$ entspricht. Bei den identifizierten, putativ lysosomalen Proteinen handelt es sich zum einen um die Proteine unnamed protein product (gi: 26354020), RIKEN cDNA entry (gi: 38081771) und Progranulin/Epithelin (gi: 26384542). Zum anderen wurden die drei putativ lysosomalen Proteine MERP-2 (gi: 13562142), 66.3 kDa-Protein (gi: 12004583) und Scpep1 (gi: 12852682) die ebenfalls durch 2D-PAGE identifiziert wurden, nachgewiesen. Das $66.3 \mathrm{kDa}$-Protein wurde durch sechs Peptide mit einer Länge von 7, 8, 9, 12, 12 und 13 Aminosäuren identifiziert. Das entspricht einer Sequenzabdeckung von $11 \%$. MERP-2 wurde durch drei Peptide mit einer Länge von 11, 11 und 18 Aminosäuren identifiziert (18 \% Sequenzabdeckung). Das Protein Scpep1 wurde mit sechs Peptiden identifiziert (7, 7, 9, 10, 13 und 15 Aminosäuren), was einer Sequenzabdeckung von $14 \%$ entspricht. Das Protein Progranulin/Epithelin wurde durch fünf Peptide mit einer Länge von 7, 10, 13, 13 und 14 Aminosäuren (10\% Sequenzabdeckung) als weiteres putativ lysosomales Protein identifiziert. Die Proteine unnamed protein product (gi: 26354020) und RIKEN cDNA entry (gi: 38081771) wurden mit zwei Peptiden (7, 15 Aminosäuren) und einem Peptid (8 Aminosäuren) nachgewiesen.

Die Proteinsequenzen der putativ lysosomalen Proteine wurden auf Eigenschaften lysosomaler Proteine untersucht. Zum Transport neu synthetisierter Proteine in das ER besitzen lysosomale Matrixproteine ein N-terminales Signalpeptid. Des Weiteren benötigen lysosomale Proteine N-Glykosylierungssequenzen zur kotranslationalen N-Glykosylierung (Kornfeld und Kornfeld 1985; Helenius und Aebi 2001), um im Golgi eine M6P-Modifikation zu erhalten (Lazzarino und Gabel 1988), die als lysosomales Transportsignal dient (Kornfeld 1986; von Figura und Hasilik 1986). Als zusätzliches Auswahlkriterium sollten die Kandidatenproteine als lösliche lysosomale Matrixproteine keine Transmembrandomänen besitzen. Mit Hilfe der bioinformatischen Analyse konnte gezeigt werden, dass die Proteine MERP-2, Scpep1, $66.3 \mathrm{kDa}$-Protein und Progranulin/Epithelin Eigenschaften putativ lysosomaler Proteine besitzen (Tab. 4.1). Die Sequenzen dieser Proteine enthalten N-terminale Signalpeptide und Konsensussequenzen für N-Glykosylierungen (N-X-S/T) (Kornfeld und Kornfeld 1985), jedoch keine Transmembrandomänen. Die Sequenzen der Proteine unnamed protein product 
(gi: 26354020) und RIKEN cDNA entry (gi: 38081771) enthalten keine N-terminalen Signalpeptide. Sie wurden deshalb in Tab. 4.2 den kontaminierenden und nicht den lysosomalen Proteinen zugeordnet.

\begin{tabular}{|c|c|c|c|}
\hline Protein & gi Nummer & Position von Signalpeptid & $\begin{array}{l}\text { Putative } \\
\text { N-Glykosylierungs- } \\
\text { sequenzen }\end{array}$ \\
\hline \multirow{2}{*}{$\begin{array}{l}\text { mammalian ependymin } \\
\text { related protein } 2 \text { (MERP-2) }\end{array}$} & \multirow[t]{2}{*}{13562142} & \multirow[t]{2}{*}{ SP AS 1-37 } & ${ }^{129} \mathrm{QNSTFE}^{134}$ \\
\hline & & & ${ }^{181} \mathrm{RNYTVV}^{186}$ \\
\hline \multirow[t]{5}{*}{ Scpep1 } & \multirow[t]{5}{*}{12852682} & \multirow[t]{5}{*}{ SP AS 1-28 } & ${ }^{63} \mathrm{KNFSEL}^{68}$ \\
\hline & & & ${ }^{101} \mathrm{RNTTWL}{ }^{106}$ \\
\hline & & & ${ }^{125}$ VNTTDA $^{130}$ \\
\hline & & & ${ }^{191} \mathrm{CNFSGV}^{196}$ \\
\hline & & & ${ }^{361} \mathrm{VNVTVY} \mathrm{Y}^{366}$ \\
\hline \multirow[t]{5}{*}{ hypothetical $66.3 \mathrm{kDa}$ protein } & \multirow[t]{5}{*}{12004583} & \multirow[t]{5}{*}{ SP AS 1-46 } & ${ }^{92} \mathrm{ANLTNA}{ }^{97}$ \\
\hline & & & ${ }^{114} Y N D S L Q^{119}$ \\
\hline & & & ${ }^{235} \mathrm{LNKTNT^{240 }}$ \\
\hline & & & ${ }^{440} \mathrm{FNASGL}^{445}$ \\
\hline & & & ${ }^{519}$ ANGSYP ${ }^{524}$ \\
\hline \multirow[t]{4}{*}{ Progranulin/ Epithelin } & \multirow[t]{4}{*}{26384542} & \multirow[t]{4}{*}{ SP AS 1-30 } & ${ }^{50} \mathrm{ANYSCC}{ }^{55}$ \\
\hline & & & ${ }^{275} \mathrm{KNYTTD}^{280}$ \\
\hline & & & ${ }^{385}$ TNNTCC $^{390}$ \\
\hline & & & ${ }^{538} \mathrm{DNQTCC} \mathrm{CH}^{543}$ \\
\hline
\end{tabular}

Tab. 4.1: Signalpeptid und putative N-Glykosylierungssequenzen der putativ lysosomalen Proteine MERP-2, Scpep1, 66.3 kDa Protein und Progranulin/ Epithelien

Mit Hilfe der Bioinformatik-Server SignalP 3.0 (http://www.cbs.dtu.dk/services/SignalP/), TMHMM v 2.0 (http://www.cbs.dtu.dk/services/TMHMM/) und ELM (http://elm.eu.org/) wurden die Proteinsequenzen der Kandidatenproteine auf die Anwesenheit von Signalpeptid und N-Glykosylierungssequenzen und die Abwesenheit von Transmembrandomänen untersucht. 


\begin{tabular}{|c|c|c|c|c|c|}
\hline Protein & $\begin{array}{l}\text { gi } \\
\text { Nummer }\end{array}$ & $\begin{array}{l}\text { Theoretische } \\
\text { Masse } \\
\mathrm{M}_{\mathrm{r}}\left(\times 10^{3}\right) \\
\end{array}$ & $\begin{array}{l}\text { 2D-GE } \\
\text { Anzahl der Spots (Spot } \\
\text { Nr.) }\end{array}$ & $\begin{array}{l}\text { MudPIT: Anzahl der } \\
\text { Peptide (Länge der } \\
\text { Peptide in AS) }\end{array}$ & $\begin{array}{l}\text { Sequenze- } \\
\text { abdeckung } \\
\text { in MudPIT }\end{array}$ \\
\hline \multicolumn{6}{|l|}{ Bekannte lysosomale Enzyme } \\
\hline$\alpha$-Glucosidase & 20913867 & 106 & $4(37-40)$ & $3(11,12,13)$ & $3 \%$ \\
\hline$\alpha$-L-Fucosidase & 12832063 & 52 & $1(140)$ & -- & -- \\
\hline$\alpha-\mathrm{N}$-Acetylgalactosaminidase & 3327016 & 47 & $5(13,116,117,124,194)$ & $4(9,10,11,17)$ & $11 \%$ \\
\hline$\alpha-\mathrm{N}$-Acetylglucosaminidase & 3329361 & 83 & $4(48-51)$ & $7(8,8,8,11,13,13,13)$ & $10 \%$ \\
\hline Arylsulfatase A & 1703420 & 54 & $1(198)$ & $6(6,6,8,9,11,16)$ & $11 \%$ \\
\hline Arylsulfatase B & 33302601 & 43 & $8(6,10,58-62,87)$ & $3(7,11,13)$ & $8 \%$ \\
\hline$\beta$-Galactosidase & 192185 & 73 & $\begin{array}{c}12(5,41-47,106 \\
150,159,171)\end{array}$ & $2(12,13)$ & $4 \%$ \\
\hline$\beta$-Glucuronidase & 309257 & 74 & $9(7,25-28,63-66)$ & $4(6,11,13,15)$ & $7 \%$ \\
\hline$\beta$-Hexosaminidase alpha & 232255 & 61 & $\begin{array}{c}34(11,12,71-83, \\
88-91,106-113, \\
130,154,174,195 \\
196,198,199)\end{array}$ & $3(7,8,13)$ & $5 \%$ \\
\hline$\beta$-Hexosaminidase beta & 1346280 & 61 & $10(92-99,151,193)$ & $4(8,10,11,16)$ & $8 \%$ \\
\hline$\beta$-Mannosidase & 13310141 & 101 & $6(3,32-36)$ & $1(12)$ & $2 \%$ \\
\hline Cathepsin A & 6679437 & 54 & $\begin{array}{c}19(14,111-114,122 \\
125-129,152,153 \\
173-175,189-191\end{array}$ & $5(7,8,11,13,18)$ & $12 \%$ \\
\hline Cathepsin B & 6681079 & 37 & $4(14,152,195197)$ & $5(8,10,11,13,14)$ & $17 \%$ \\
\hline Cathepsin C / DPP-I & 31560607 & 52 & $10(131-140)$ & $\begin{array}{c}10(6,7,7,8,8,10 \\
12,12,14,14)\end{array}$ & $21 \%$ \\
\hline Cathepsin D & 115718 & 45 & $10(141-149,151)$ & $5(8,10,10,10,18)$ & $14 \%$ \\
\hline Cathepsin F & 4826565 & 52 & --- & $1(15)$ & $3 \%$ \\
\hline Cathepsin L & 200501 & 38 & $\begin{array}{c}6(168-170 \\
172,183,186)\end{array}$ & $3(10,16,20)$ & $13 \%$ \\
\hline Cathepsin Z & 11066226 & 34 & $9(15,16,18-20,15-158)$ & $5(9,10,11,12,17)$ & $19 \%$ \\
\hline Ceroid-lipofusc.neur.prot. 5 & 20881345 & 39 & $1(141)$ & -- & -- \\
\hline Deoxyribonuklease II & 6753654 & 39 & $2(160,161)$ & $1(9)$ & $3 \%$ \\
\hline Dipeptidylpeptidase II & 13626390 & 56 & $7(8,100-105)$ & $3(11,12,14)$ & $7 \%$ \\
\hline Galactocerebrosidase & 2459856 & 76 & -- & $1(16)$ & $2 \%$ \\
\hline Legumain & 7242187 & 49 & $3(84-86)$ & $1(12)$ & $3 \%$ \\
\hline $\mathrm{N}$-Acetylglucosamine-6-sulfatase & 29789239 & 61 & $7(4,52-57)$ & $\begin{array}{l}13(6,7,8,9,9,1012 \\
12,12,13,13,16,17)\end{array}$ & $27 \%$ \\
\hline Neuraminidase 1 & 24496770 & 45 & $2(115,123)$ & --- & -- \\
\hline Niemann Pick Typ C2 prot. & 12963667 & 16 & --- & $4(7,11,12,16)$ & $31 \%$ \\
\hline
\end{tabular}




\begin{tabular}{|c|c|c|c|c|c|}
\hline Prosaposin & 1381582 & 61 & --- & $\begin{array}{c}12(7,9,10,10,10,11 \\
11,11,11,12,14,15)\end{array}$ & $24 \%$ \\
\hline Ribonuklease 6 & 12858578 & 30 & $1(176)$ & --- & --- \\
\hline Saure $\alpha$-D-Mannosidase & 1914843 & 112 & $4(1,2,29,30)$ & $4(9,14,14,14)$ & $5 \%$ \\
\hline Saure Ceramidase & 9790019 & 45 & --- & $5(10,11,11,14,17)$ & $16 \%$ \\
\hline Saure Lipase I, Iysosomal & 11496259 & 46 & --- & $2(10,11)$ & $5 \%$ \\
\hline Tripeptidylpeptidase I & 12644085 & 61 & $1(77)$ & --- & --- \\
\hline $\begin{array}{l}\text { cellular repressor of } \\
\text { E1A-stimulated genes (CREG) }\end{array}$ & 6753520 & 25 & $4(23,24,184,185)$ & --- & --- \\
\hline $\begin{array}{l}\text { secreted } \alpha \text {-Mannosidase class } \\
2 B(\mathrm{M} 2 \mathrm{~B} 2)\end{array}$ & 6678792 & 116 & $4(1,2,29,30)$ & $3(11,12,13)$ & $4 \%$ \\
\hline \multicolumn{6}{|l|}{ Putative lysosomale Matrixproteine } \\
\hline $\begin{array}{l}\text { mammalian ependymin related } \\
\text { protein } 2 \text { (MERP-2) }\end{array}$ & 13562142 & 26 & $4(21,22,174,175)$ & $3(11,11,18)$ & $18 \%$ \\
\hline $\begin{array}{l}\text { Scpep1 (or retinoid-inducible } \\
\text { serine carboxypeptidase) }\end{array}$ & 12852682 & 51 & $4(118-121)$ & $6(7,8,9,10,13,15)$ & $14 \%$ \\
\hline hypothetical 66.3 kDa protein & 12004583 & 66 & $\begin{array}{c}17(9,67-70,162-167 \\
177-181,200\end{array}$ & $6(7,8,9,12,12,13)$ & $11 \%$ \\
\hline Progranulin/ Epithelin & 26384542 & 65 & --- & $5(7,10,13,13,14)$ & $10 \%$ \\
\hline \multicolumn{6}{|l|}{ Non-Iysosomal contaminants } \\
\hline Dynamin 2 & 6681207 & 98 & $1(192)$ & --- & --- \\
\hline unnamed protein product & 26354020 & 20 & --- & $2(7,15)$ & $12 \%$ \\
\hline $\begin{array}{l}\text { similar to RIKEN cDNA } \\
9030227 \mathrm{G} 01\end{array}$ & 38081771 & 62 & --- & $1(8)$ & $2 \%$ \\
\hline Keratin complex 2, gene 17 & 38077188 & 121 & --- & $2(12,12)$ & $2 \%$ \\
\hline
\end{tabular}

Tab. 4.2: $\quad$ 2D-PAGE/MALDI-TOF und MudPIT-Analyse identifizierter Proteine

Liste der durch 2D-PAGE/MALDI-TOF und MudPIT identifizierten Proteine. In der Tabelle sind die Anzahl und Nummern der Proteinspots angegeben, durch die Proteine bei der 2D-PAGE identifiziert wurden. Zudem sind Anzahl und Länge der Peptide angegeben, mit denen die Proteine durch MudPIT-Analyse identifiziert wurden. Eine ausführliche Tabelle der durch MudPIT analysierten Peptidsequenzen befindet sich im Anhang (Tab. 8.1).

\subsubsection{Generierung von cDNA der neu identifizierten Proteine}

Zur weiteren Untersuchung der Kandidatenproteine Progranulin/Epithelin, MERP-2, Scpep1 und 66.3 kDa-Protein wurden die entsprechenden cDNAs durch RT-PCR aus muriner RNA generiert und in Vektoren des Gateway Systems (Invitrogen, Karlsruhe) kloniert. Als Kontrollen für die folgenden Experimente wurden zudem die cDNAs der 
Proteine M2B2 und CREG kloniert, da M2B2 und CREG bereits als MPR-bindende Proteine beschrieben worden waren (Belmonte et al. 1998; Journet et al. 2000; Di Bacco und Gill 2003).

Die RT-PCR der Kandidatenproteine Progranulin/Epithelin und Scpep1 erfolgte mit RNA aus der Niere. Die RNA zur Generierung der MERP-2 cDNA stammte aus Herz, die der Kandidaten 66.3 kDa-Protein, sowie von CREG und M2B2 aus Leber. Nach der RT-Reaktion erfolgte eine zweistufige, nested PCR (Abb. 4.2). Die generierten cDNAs wurden in den Vektor pDONR221 integriert und anschließend sequenziert. Die cDNAs konnten den NCBI Nucleotide Datenbankeinträgen der Proteine MERP-2 (gi:14009839), 66.3 kDa-Protein (gi:24047307), Progranulin (gi:142357784), Scpep1 (gi:13436037), CREG (gi:31542419) und M2B2 (gi:42542424) zugeordnet werden.

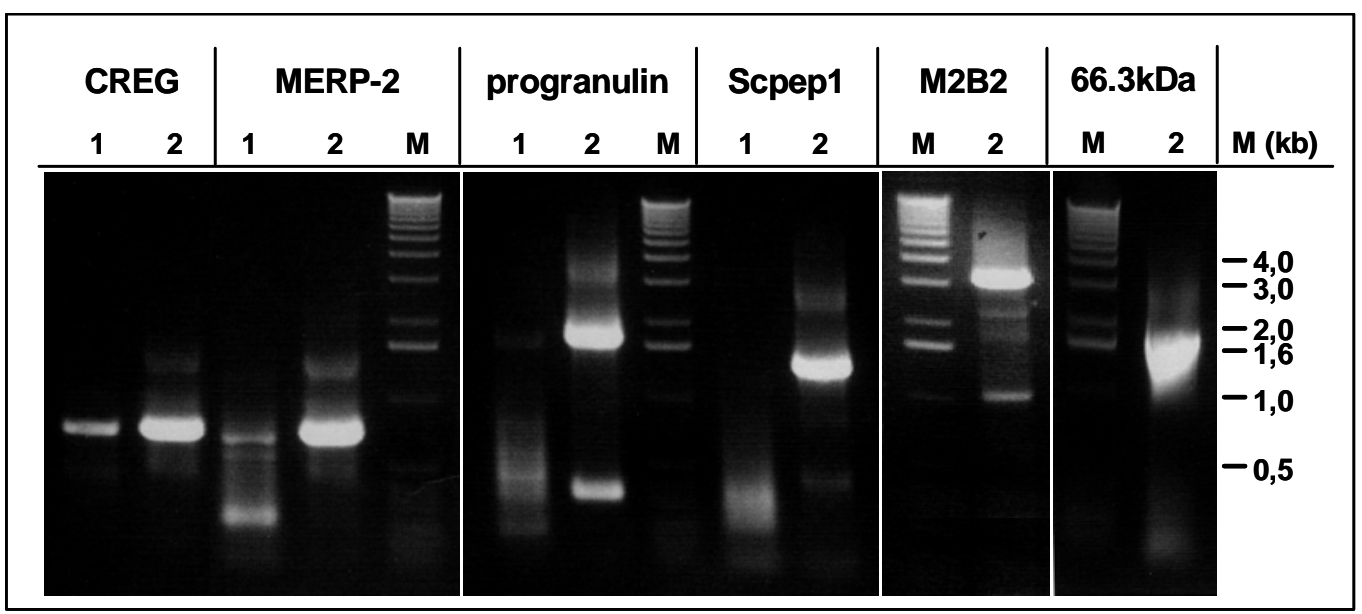

Abb. 4.2: Generierung der cDNA der Kandidatenproteine durch reverse Transkription und nested PCR

Durch reverse Transkription gefolgt von einer nested PCR wurden die cDNAs der Kandidatenproteine aus RNA amplifiziert. Die PCR 1 und die PCR 2 der nested PCR wurden im Agarosegel aufgetragen. Die PCRProdukte der PCR 2 wurden aus dem Gel isoliert und in den Vektor pDONR221 rekombiniert. Durch Sequenzierung wurden die integrierten cDNA-Sequenzen kontrolliert. Verwendeten Primer sind im Anhang (8.3.1) aufgelistet. M: Marker (kb).

\subsubsection{Expression der identifizierten Proteine in BKH Zellen und Analyse der M6P-Rezeptorbindung der exprimierten Proteine}

Die cDNAs der Kandidatenproteine wurden in den Vektor pcDNA-DEST40 transferiert, der die Expression der Proteine mit C-terminalem V5-His6-Tag ermöglicht. BHK Zellen 
(baby hamster kidney cells) wurden transient mit den generierten Vektoren transfiziert. Die Expression der C-terminal V5-His6-markierten Proteine in den transfizierten Zellen wurde durch Western Blot Analyse mit einem $\alpha$-V5-Antikörper nachgewiesen (nicht abgebildet). Um die exprimierten Proteine aus dem Medium der transfizierten Zellen isolieren zu können, wurden die transfizierten BHK Zellen mit $20 \mathrm{mM} \mathrm{NH}_{4} \mathrm{Cl}$ behandelt. $\mathrm{NH}_{4} \mathrm{Cl}$ verhindert den MPR-abhängigen Transport $\mathrm{zu}$ den Lysosomen, so dass M6P-markierte Proteine ins Medium sezerniert werden. Mittels Ni-NTA-Agarose wurde das V5-His6-getaggte Protein partiell aus dem Medium aufgereinigt und anschließend mit immobilisiertem MPR inkubiert. Nicht gebundenes Material wurde im Durchfluss (FT) aufgefangen. Die MPR-Säule wurde ausgiebig mit Bindungspuffer (W1) und mit G6P-haltigem Bindungspuffer (W2) gewaschen und anschließend mit einem M6P-haltigen Bindungspuffer eluiert (E). Die Fraktionen der MPR-Affinitätschromatografie wurden im Western Blot mit einem $\alpha$-V5-Antikörper analysiert (Abb. 4.3).

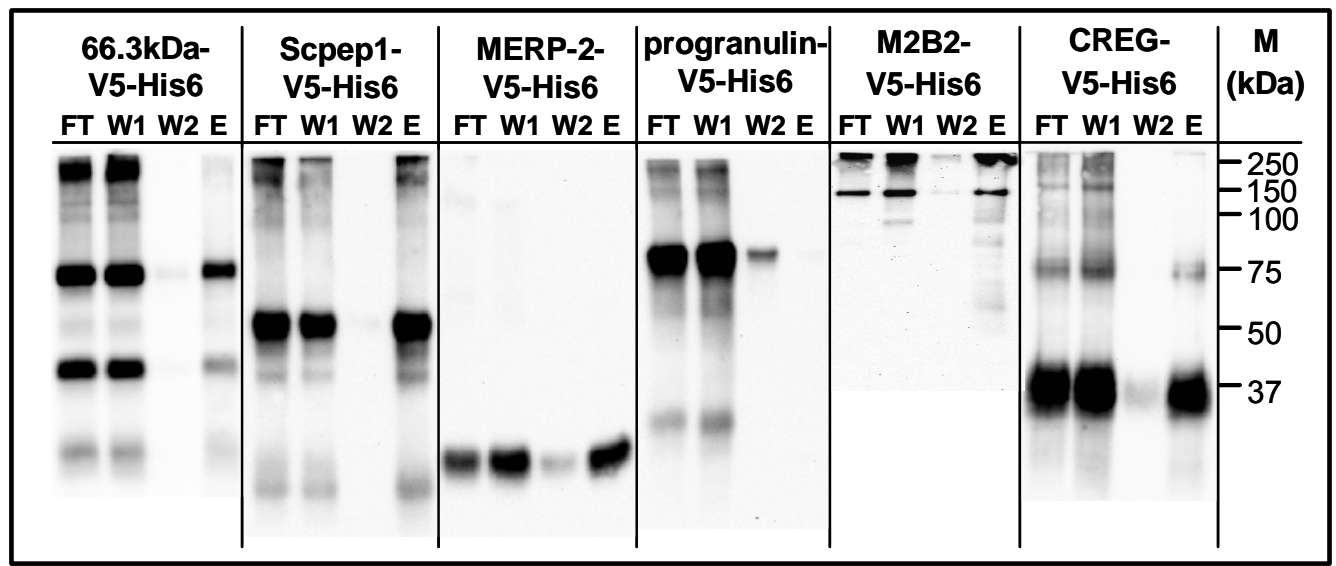

Abb. 4.3: Western Blot Analyse der neu identifizierten, putativ lysosomalen Proteine

Die V5-His6-getaggten Proteine wurden in BHK21 Zellen exprimiert und mit Ni-NTA-Agarose aus den Zellkulturüberständen der Zellen aufgereinigt. Das gereinigte Protein wurde mit immobilisiertem MPR inkubiert. Die Säule wurde mit Bindungspuffer (W1) und mit Bindungspuffer mit Glucose-6-Phosphat (W2) gewaschen. Die Eution des Proteins erfolgte durch Bindungspuffer mit Mannose-6-Phosphat. Mittels Western Blot Analyse mit einem monoklonalen $\alpha$-V5-Antikörper wurde das Protein in den Fraktionen Durchfluß (FT), Waschfraktion 1 und 2 (W1, W2) und Eluat (E) nachgewiesen.

Eine densitometrische Analyse des Western Blots ergab, dass bei $66.3 \mathrm{kDa}$-Protein, Scpep1, MERP-2, M2B2 und CREG zwischen 20 und $35 \%$ des aufgetragenen Gesamtproteins an die MPR-Affinitätschromatografiesäule gebunden und spezifisch mit 
M6P eluiert wurde (E). Der Rest des detektierten Proteins befand sich im Durchfluss (FT) und in der Waschfraktion 1 (W1). Die relativ geringe Bindungseffizienz der Proteine ist wahrscheinlich auf eine unvollständige M6P-Markierung aufgrund der hohen Expressionsrate zurückzuführen. Die spezifische M6P-Rezeptorbindung identifiziert die Kandidatenproteine Scpep1, 66.3 kDa-Protein und MERP-2 als M6P-markierte Proteine, womit sie eine essenzielle Eigenschaft lysosomaler Matrixproteine besitzen. Das V5-His6-markierte Progranulin/Epithelin wurde nicht an die MPR-Chromatografiesäule gebunden. Das Protein besitzt entweder keine M6P-Modifizierung oder die Bindung einer vorhandenen M6P-Markierung wurde durch den V5-His6-Tag behindert.

\subsubsection{Internalisation der putativ lysosomalen Kandidatenproteine in Fibroblasten}

Um die subzelluläre Lokalisation der Kandidatenproteine zu untersuchen, wurden die C-terminal V5-His6-markierten Kandidatenproteine in verschiedenen eukaryontischen Zelllinien (BHK, HT1080, HeLa) exprimiert. Bei der Immunfärbung der transient transfizierten Zellen mit einem polyklonalen $\alpha$-V5-Antikörper wurde bei allen Kandidatenproteinen eine Färbung des ER (endoplasmatisches Reticulum) und teilweise eine zusätzliche Färbung des Golgi Apparats detektiert. Eine lysosomale Lokalisation konnte jedoch nicht nachgewiesen werden. Möglicherweise wird der 40 AS-lange V5-His6-Tag des rekombinanten Proteins aufgrund der hohen proteolytischen Aktivität im Lysosomen degradiert, was eine Detektion in den Lysosomen verhindert.

Alternativ wurde humanen Fibroblasten partiell Ni-NTA-aufgereinigtes Kandidatenprotein zur Endozytose angeboten. Die Fibroblasten wurden anschließend fixiert und mittels indirekter Immunfluoreszenz analysiert. Die internalisierten V5-His6markierten Proteine CREG, 66.3 kDa-Protein, Scpep1 und MERP-2 waren nach der Endozytose durch schwache Signale in den Lysosomen der Fibroblasten nachweisbar. Die Signalstärke konnte durch die Vorinkubation der Fibroblasten mit den Proteaseinhibitoren Leupeptin und Pepstatin A oder durch die Verwendung von I-cell-Fibroblasten, deren proteolytische Aktivität in den Lysosomen signifikant reduziert ist (Raas-Rothschild et al. 2000; Tiede et al. 2005), erhöht werden. Die Inhibierung der proteolytischen Aktivität steigert offensichtlich die Stabilität des C-terminalen Protein-Tags in den Lysosomen, so dass diese besser nachweisbar sind. Durch indirekte Immunfluoreszenz mit einem $\alpha$-V5- 
Antikörper wurde das internalisierte V5-His6-markierte Protein in den I-cell-Fibroblasten detektiert (Abb. 4.4). Zusätzlich wurde das lysosomale, integrale Membranprotein LAMP-1 angefärbt. Die lysosomalen Membranen werden bei den konfokalen Aufnahmen als rote Ringe detektiert. Das internalisierte Protein ist als grüne Signale in den lysosomalen Ringen dargestellt. Bei dem Protein Progranulin/Epithelin konnte keine Internalisierung detektiert werden. Die Endozytose des Proteins konnte auch bei I-cellFibroblasten und bei mit Proteaseinhibitoren behandelten Fibroblasten nicht nachgewiesen werden.

In Abb. 4.5 sind die I-cell-Fibroblasten nach Internalisation in Anwesenheit von $5 \mathrm{mM}$ M6P und in Anwesenheit von G6P dargestellt. In Anwesenheit von 5 mM M6P nahmen die Zellen deutlich weniger Protein auf als in Anwesenheit von G6P. Demnach konnte die Internalisation der Kandidatenproteine mittels M6P im Medium inhibiert werden. Dies bestätigt, dass es sich bei den Proteinen Scpep1, MERP-2, und 66.3 kDa-Protein um M6P-markierte Proteine handelt und dass die Proteine MPR-vermittelt in die Lysosomen der Zellen gelangen. Das V5-His6-getaggte Progranulin/Epithelin hingegen wird von den M6P-Rezeptoren nicht als spezifischer Ligand erkannt und konnte somit auch nicht durch MPR-spezifische Endozytose in die Zellen aufgenommen werden. 


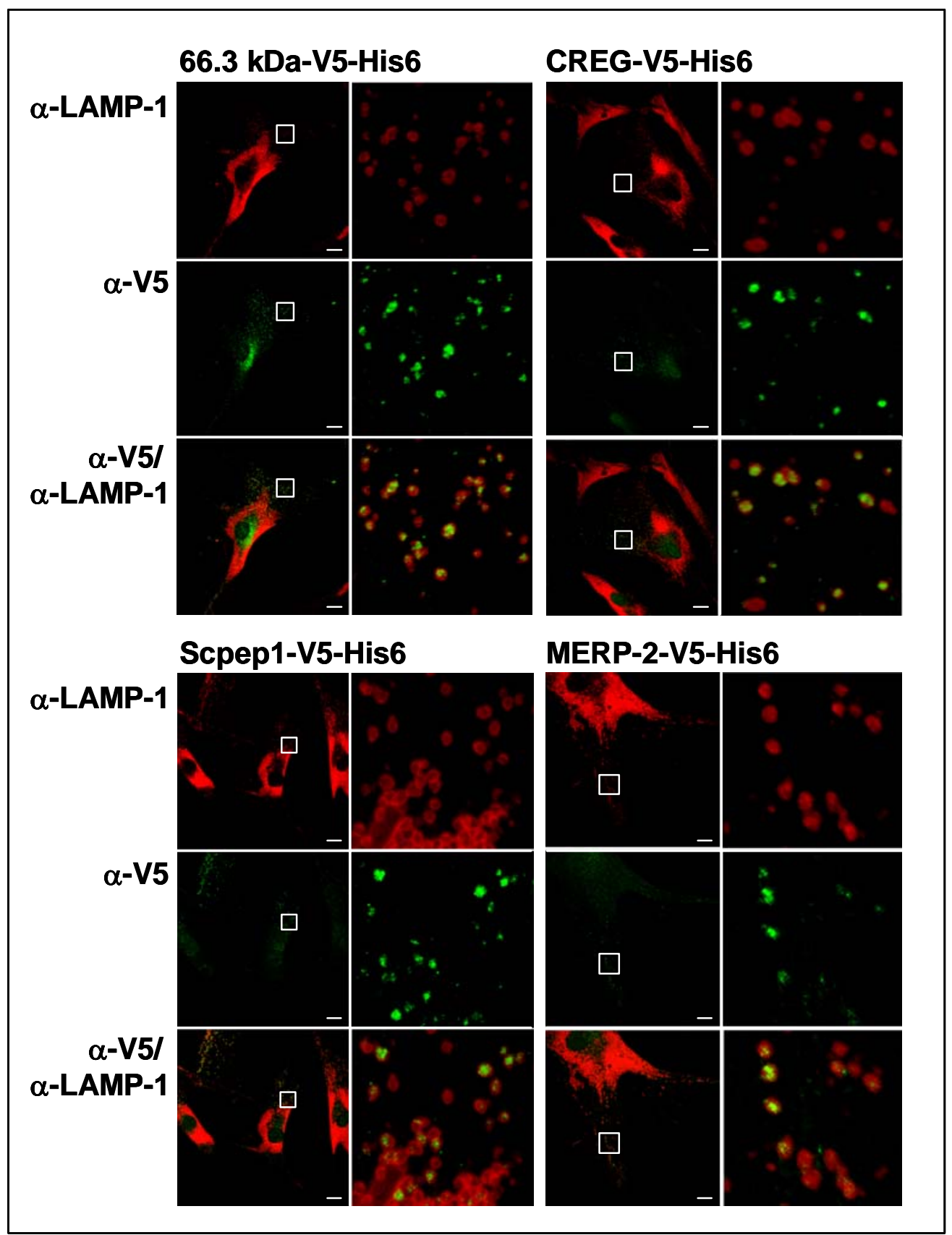

Abb. 4.4: Internalisation von putativ lysosomalen Proteinen in I-cell-Fibroblasten

I-cell-Firoblasten wurden mit Ni-NTA-aufgereinigtem, V5-His6-getaggtem Protein $2 \mathrm{~h}$ inkubiert. Bei MERP-2 wurden die Fibroblasten vor der Inkubation mit Leupeptin und Pepstatin A behandelt. Die lysosomale Lokalisation nach der Internalisation wurde durch indirekte Immunfluoreszenz mit Antkörpern gegen den V5-Tag und gegen das lysosomale Markerprotein LAMP-1 detektiert. Balken $20 \mu \mathrm{m}$ 


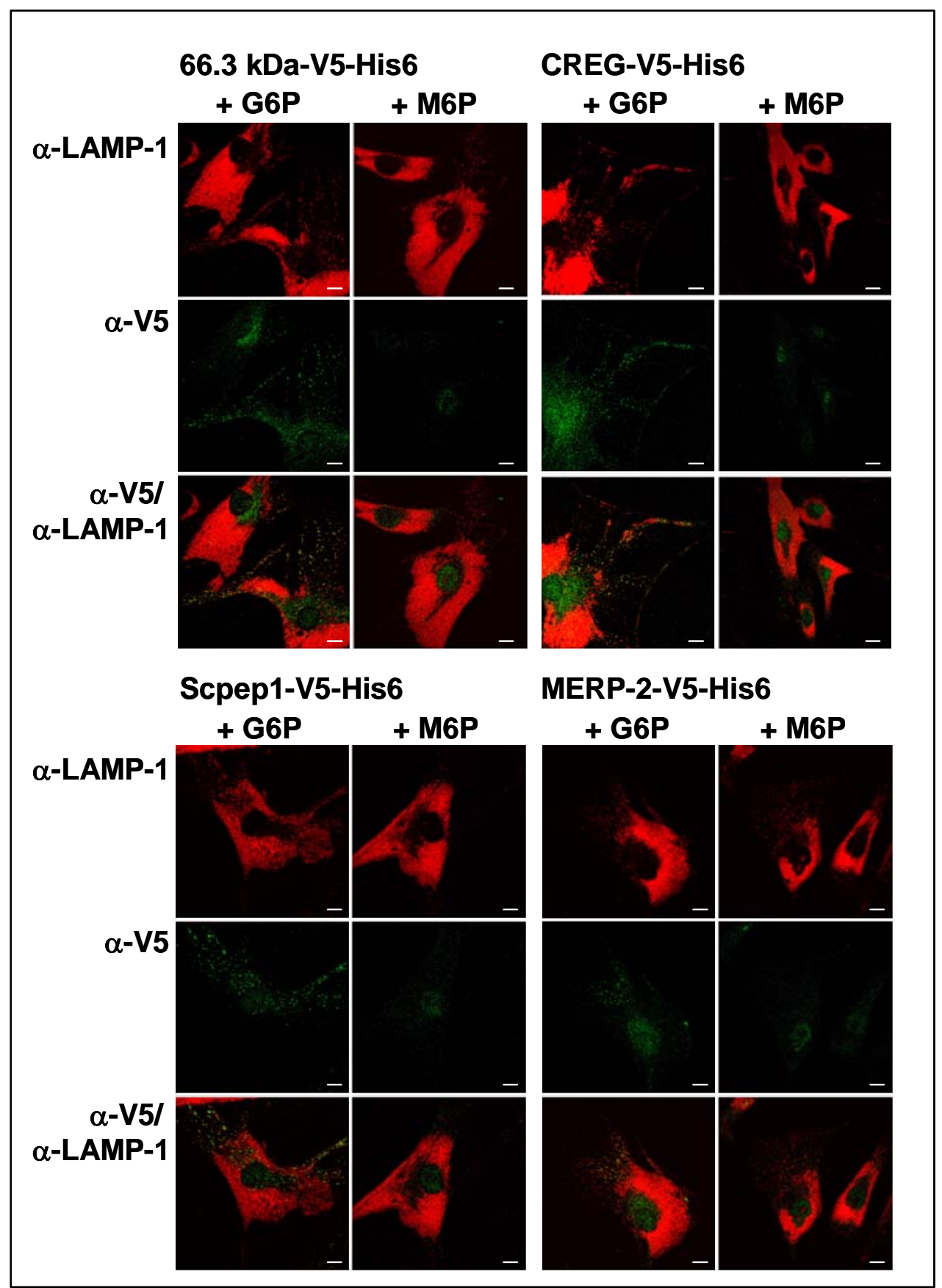

Abb. 4.5: Inhibierung der Internalisation von putativ lysosomalen Proteinen in I-cellFibroblasten durch Mannose-6-phosphat

I-cell-Firoblasten wurden mit Ni-NTA-aufgereinigtem, V5-His6-markiertem Protein in Anwesenheit von $5 \mathrm{mM}$ Glucose-6-phosphat oder Mannose-6-Phosphat 2h inkubiert. Bei MERP2 wurden die Fibroblasten vor der Inkubation mit Leupeptin und Pepstatin A behandelt. Die intrazelluläre Lokalisation nach der Internalisation wurde durch indirekte Immunfluoreszenz gegen den V5-Tag und gegen das lysosomale Markerprotein LAMP-1 detektiert. Balken $20 \mu \mathrm{m}$ 


\subsection{Bioinformatische Analyse der Scpep1}

Die Scpep1 ist durch die Proteomanalyse M6P-markierter Proteine als putativ lysosomales Protein identifiziert worden. Als Serincarboxypeptidase ist sie ein interessanter Kandidat für eine lysosomale Hydrolase, so dass die Scpep1 in weiterführenden Analysen untersucht wurde.

\subsubsection{Das Scpep1-Gen aus Maus und seine Transkripte}

Das Gen der Scpep1 (Abb. 4.6) ist in Maus auf dem Chromosom 11 in Position 88.740.110 - 88.771.522 in Abschnitt C lokalisiert (Gene ID: 74617). Das Scpep1-Gen besitzt 13 Exons, die für ein 452 Aminosäuren langes Protein codieren.

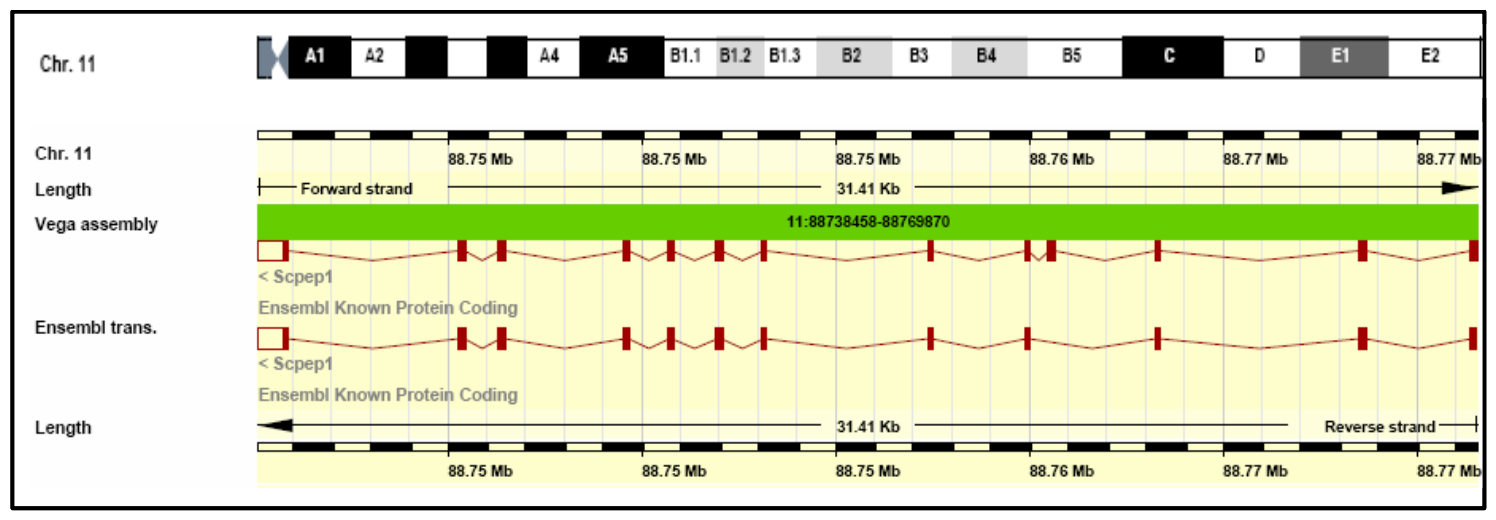

Abb. 4.6: Scpep1-Gen auf Chromosom 11 des Mausgenoms

Grafische Darstellung des Scpep1-Gens im Mausgenom. Die Abbildung wurde durch die Ensemble Mouse Contig View Datenbank erstellt und zeigt Chromosom 11: bp88740110-88771522, (http://www.ensembl.org/Mus_musculus/contigview?l=11:88740110-88771522).

Durch eine Blast Analyse (http://www.ncbi.nlm.nih.gov/blast/Blast.cgi) wurden in der Datenbank $\mathrm{nr}$ (non-redundant protein sequences database) vier Proteinvarianten der murinen Scpep1 identifiziert (Tab. 4.3). Dabei handelt es sich um drei Proteinvarianten bei denen einzelne Aminosäuren ausgetauscht sind (V1 - V3). Diese Varianten wurden in verschiedenen cDNA Datenbanken als exprimierte Proteine identifiziert und haben ihren Ursprung im Nukleotid Polymorphismen des murinen Scpep1-Gens (http://www.ncbi. nlm.nih.gov/sites/entrez $? \mathrm{db}=$ snp\&cmd $=$ search\&term $=)$. Bei der vierten Proteinvariante der Scpep1 handelt es sich um eine Proteinspleißvariante (V4) bei der die Aminosäuren L106 bis T157 deletiert sind (http://www.ncbi.nlm.nih.gov/entrez/ 
viewer.fcgi?db=protein\&id=74151992). Diese Proteinvariante wurde in einer Makrophagen-spezifischen cDNA-Datenbank identifiziert. Bei der Klonierung der Kandidaten-cDNA (4.1.4) wurde für die Scpep1 eine cDNA aus Niere generiert, die die Scpep1-Proteinvariante V1 (gi:13436038) der Tab. 4.3 kodiert. Diese Scpep1-Variante wurde in allen weiteren molekularbiologischen Untersuchungen verwendet. Die Expression der anderen Proteinvarianten, insbesondere der Scpep1-Spleißvariante V3, wurde nicht weiter untersucht.

\begin{tabular}{lcc}
\hline $\begin{array}{l}\text { Scpep1- } \\
\text { Proteinvarianten }\end{array}$ & Protein GI & $\begin{array}{c}\text { Protein } \\
\text { Sequenzvarianten }\end{array}$ \\
\hline Scpep1 V1 & 13436038 & Q11, H30, E229 \\
Scpep1 V2 & 12852682 & Q11 $\rightarrow$ R11 \\
& & H30 $\rightarrow$ D30 \\
Scpep1 V3 & Q11 $\rightarrow$ R11 \\
& & H30 $\rightarrow$ D30 \\
& & $\Delta 106-157$ \\
Scpep1 V4 & 15146429 & Q11 $\rightarrow$ R11 \\
& & $\mathrm{H} 30 \rightarrow$ D30 \\
& & E229 $\rightarrow$ M229 \\
\hline
\end{tabular}

Tab. 4.3: Proteinvarianten der Scpep1 in Maus

Nukleotid Polymorphismen des Scpep1-Gens im Mausgenom und alternatives Splicing des Scpep1Transkripts führen zu Varianten der Scpep1. Die Tabelle zeigt die verschiedenen Scpep1 Einträge der NCBI Datenbank nr für das murine Scpep1-Protein.

\subsubsection{Die Scpep1, eine Serincarboxypeptidase der Familie S10}

Mit Hilfe der NCBI Conserved Domains Datenbank (http://www.ncbi.nlm.nih.gov/ sites/entrez? $d b=c d d$ ) und der MEROPS Peptidasen Datenbank (http://merops. sanger.ac.uk/) wurde die Scpep1-Proteinsequenz untersucht. Die Scpep1 ist eine Peptidase der Familie S10, die dem Serinpeptidase Clan C angehört. Andere Namen für die Scpep1 sind retinoid-inducible serine carboxypeptidase oder RISC Peptidase (MEROPS Name, ID: S10.013).

Proteolytische Enzyme, deren katalytische Aktivität von einem Serinrest im aktiven Zentrum des Enzyms abhängig sind, nennt man Serinpeptidasen (Rawlings und Barrett 
1993). Serinpeptidasen findet man in Eukaryonten, Bakterien und Viren. Sie können Exopeptidasen, Endopeptidasen, Oligopeptidasen oder Omega-Peptidasen sein. Serinpeptidasen werden in Clans und Familien unterteilt. Das katalytische Zentrum der Serinpeptidasen der Clans A, B und C wird von den Aminosäuren Serin (S), Aspartat (D) und Histidin $(\mathrm{H})$ gebildet. Das Serin dient bei der Hydrolysereaktion als Nukleophil, das Aspartat als Elektrophil und das Histidin als Base. Im Serinpeptidase Clan C sind die Aminosäuren der katalytischen Triade in der Reihenfolge S-D-H angeordnet (Rawlings und Barrett 1994).

Carboxypeptidasen bilden zwei Hauptgruppen, die Metallocarboxypeptidasen und die Serincarboxypeptidasen. Alle bekannten Serincarboxypeptidasen sind Mitglieder der Serinpeptidase Familie S10 im Clan C. Die Serincarboxypeptidasen besitzen proteolytische Aktivität im sauren $\mathrm{pH}$-Bereich und bilden damit eine Ausnahme unter den Serinpeptidasen (Remington und Breddam 1994). Sie werden aufgrund ihrer Substratspezifität in zwei Gruppen klassifiziert, den Carboxypeptidasen C und D. Die Carboxypeptidasen $\mathrm{C}$ zeigen eine starke Affinität $\mathrm{zu}$ hydrophoben C-terminalen Aminosäuren. Die Carboxypeptidasen der Gruppe D können am effizientesten basische Aminosäuren vom C-Terminus eines Peptids abspalten. Die Serincarboxypeptidasen sind in Pflanzen und in Fungi in den Vakuolen zu finden. In Tieren sind sie lysosomal lokalisiert. Sie besitzen ein N-terminales Signalpeptid und werden als Präproenzym synthetisiert. Strukturell gehören die Serincarboxypeptidasen der $\alpha / \beta$-Hydrolase Familie an (Remington und Breddam 1994).

\subsubsection{Scpep1-Phylogenetik}

Zur Untersuchung der phylogenetischen Entwicklung der Scpep1 wurde in Eukaryonten nach homologen Genen und Proteinen gesucht. In Abb. 4.7 ist ein phylogenetischer Stammbaum dargestellt. Die verwendeten Sequenzen sind in Tab. 4.4 zusammengefasst. Bei den Tieren findet man ab der Stufe der Bilateria orthologe Scpep1-Sequenzen (MEROPS ID: S10.013). Die anderen Serincarboxypeptidasen der Familie S10 weisen gegenüber der murinen Scpep1 eine geringere Homologie auf. Zwei Mitglieder der Serincarboxypeptidase Familie S10 findet man als paraloge Gene bei den Tieren. Dabei 
handelt es sich um das protective protein/Cathepsin A (PPCA) und die vitellogenic like carboxypeptidase (CPVL).

\begin{tabular}{|c|c|c|c|c|}
\hline Spezies & $\begin{array}{l}\text { Entrez Gen } \\
\text { Symbol/ ID }\end{array}$ & mRNA ID & Protein ID & $\begin{array}{l}\text { Identität \% } \\
\text { Gen /Protein }\end{array}$ \\
\hline \multirow[t]{3}{*}{ Mus musculus } & $\begin{array}{l}\text { Scpep1/ } \\
\text { ID:74617 }\end{array}$ & NM_029023.2 & NP_083299.2 & $-/-$ \\
\hline & $\begin{array}{l}\text { CPVL/ } \\
\text { ID:71287 }\end{array}$ & XM_984554.1 & XP_989648.1 & $35,9 \% / 22,7 \%$ \\
\hline & $\begin{array}{l}\text { PPCA/ } \\
\text { ID:19025 }\end{array}$ & NM_001038492.1 & NP_001033581.1 & $28,2 \% / 22,9 \%$ \\
\hline $\begin{array}{c}\text { Rattus } \\
\text { norvegicus }\end{array}$ & $\begin{array}{l}\text { Scpep1/ } \\
\text { ID:114861 }\end{array}$ & NM_133383.1 & NP_596874.1 & $92,0 \% / 92,9 \%$ \\
\hline Homo sapiens & $\begin{array}{l}\text { SCPEP1/ } \\
\text { ID:59342 }\end{array}$ & NM_021626.1 & NP_067639.1 & $82,1 \% / 82,4 \%$ \\
\hline Bos taurus & $\begin{array}{l}\text { SCPEP1/ } \\
\text { ID:505054 }\end{array}$ & NM_001045909.1 & NP_001039374.1 & $67,5 \% / 75,4 \%$ \\
\hline Gallus gallus & $\begin{array}{l}\text { SCPEP1/ } \\
\text { ID:417403 }\end{array}$ & NM_001012803.1 & NP_001012821.1 & $66,7 \% / 67,4 \%$ \\
\hline Danio rerio & $\begin{array}{l}\text { Scpep1/ } \\
\text { ID:393161 }\end{array}$ & NM_200192.1 & NP_956486.1 & $63,8 \% / 64,4 \%$ \\
\hline $\begin{array}{l}\text { Arabidopsis } \\
\text { thaliana }\end{array}$ & $\begin{array}{l}\text { SCPL51/ } \\
\text { ID:817336 }\end{array}$ & NM_128351.3 & NP_565663.1 & $46,2 \% / 52,6 \%$ \\
\hline Oryza sativa & $\begin{array}{l}\text { Os03g0392600/ } \\
\text { ID:4333028 }\end{array}$ & NM_001056820.1 & NP_001050285.1 & $44,3 \% / 50,7 \%$ \\
\hline $\begin{array}{c}\text { Caenorhabditis } \\
\text { elegans }\end{array}$ & $\begin{array}{l}\text { Y32F6A.5/ } \\
\text { ID:179459 }\end{array}$ & NM_182330.2 & NP_872130.1 & $45,0 \% / 50 \%$ \\
\hline $\begin{array}{c}\text { Trypanosoma } \\
\text { cruzei }\end{array}$ & $\begin{array}{c}\text { CBP1/ } \\
\text { ID:3532510 }\end{array}$ & XM_797910.1 & XP_803003.1 & $37,6 \% / 19,6 \%$ \\
\hline $\begin{array}{c}\text { Saccharomyces } \\
\text { cerevisiae }\end{array}$ & $\begin{array}{c}\text { PRC1/ } \\
\text { ID:855343 }\end{array}$ & - & NP_014026.1 & $38,9 \% / 19,3 \%$ \\
\hline
\end{tabular}

Tab. 4.4: Analyse der Sequenzhomologie der murinen Scpep1 zu anderen Serincarboxypeptidasen der Familie S10

In der Tabelle sind die Identifikationsnummern der untersuchten Serincarboxypetidase Gene, mRNAs und Proteine aufgelistet. Die Homologie der untersuchten Gene und Proteine zum murinen Scpep1-Gen bzw. Protein ist durch Angabe der prozentualen Identität dargestellt.

Bei den Vertebraten ist die Scpep1-Sequenz stark konserviert. Die Aminosäuresequenz von Maus und Mensch sind zu 82,4\% identisch. Die Sequenzen von Zebrafisch und Maus sind noch zu 64,4 \% identisch. Die homologen Serincarboxypeptidasen der Pflanze (z.B. SCPL51 in A. thaliana), die Carboxypeptidase Y (CPY) aus Hefe und die 
Serincarboxypeptidase (SCP) aus T. cruzei, sowie die paralogen Serincarboxypeptidasen CPVL und PPCA gehören anderen Serincarboxypeptidase-Gruppen an und weisen eine geringere Homologie zur Scpep1 der Vertebraten auf. Innerhalb der Serincarboxypeptidasen der S10 Familie zeigt das Protein SCPL51 aus Arabidopsis thaliana mit 46 \% Identität die stärkste Homologie zur Scpep1-Sequenz. Die Funktion und Aktivität der SCPL51 ist unbekannt.

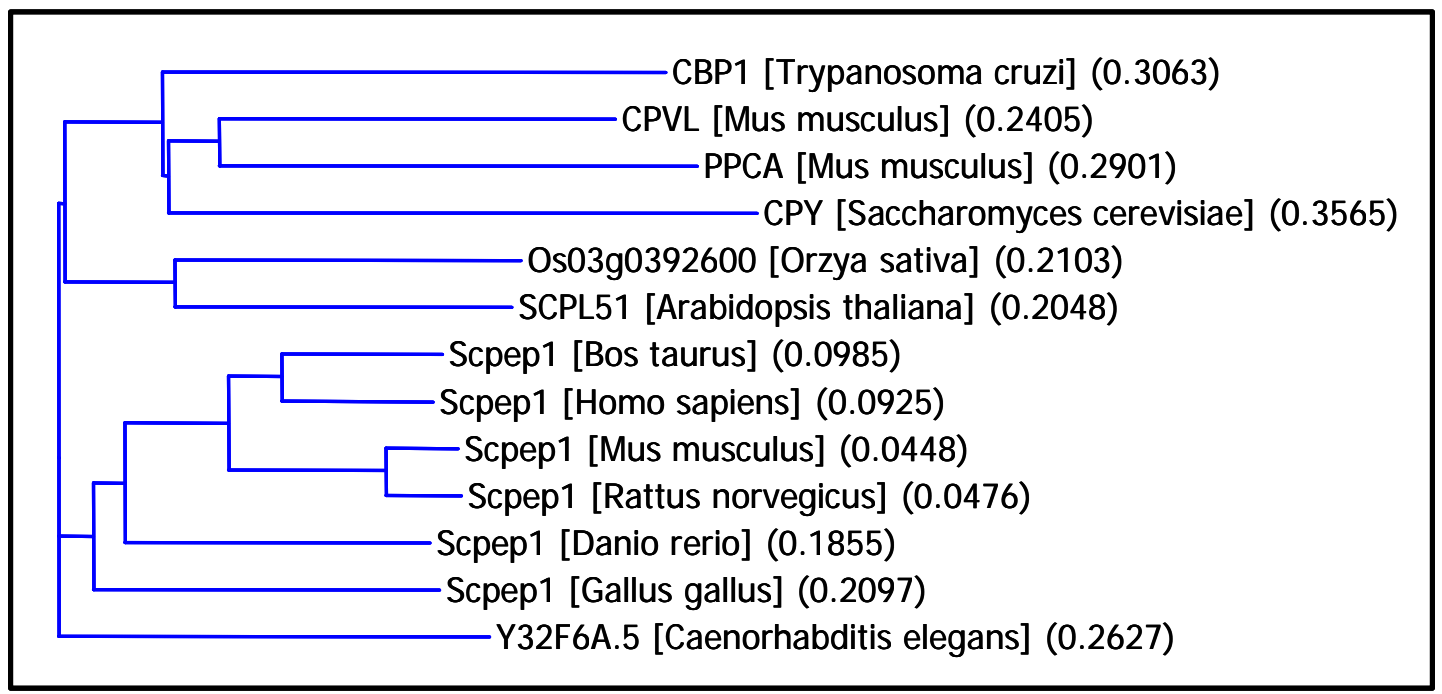

Abb. 4.7: Phylogenetischer Stammbaum der Scpep1

Der phylogenetische Stammbaum wurde im Programm Vector NTI Advance-AlignX erstellt. Das Alignment wurde mit Hilfe des ClustalW Algorithmus (Nucleic Acid Research, 22 (22): 4673-4680, 1994) berechnet. Der phylogenetische Baum wurde durch die Neighbor Joining (NJ) Methode (Saitou und Nei 1987) erzeugt. Die Distanz zwischen den Sequenzen entspricht dem Grad ihrer Divergenz. In Klammern sind die Distanzwerte der einzelnen Sequenzen im Bezug auf die Alignment-Gruppe angegeben.

\subsubsection{Sequenzvergleich von Scpep1 mit anderen Serincarboxypeptidasen}

Die Aminosäuresequenz der murinen Scpep1 wurde durch ein CLUSTALW-Alignment im Programm Vector NTI AlignX mit den Sequenzen anderer Serincarboxypeptidasen verglichen. In Abb. 4.8 ist das Sequenz-Alignment der Serincarboxypeptidasen CPY (Merops ID: S10.001), des murinen PPCA (ID: S10.002), der murinen CPVL (ID: S10.003) und der murinen Scpep1 (ID: S10.013) dargestellt. 


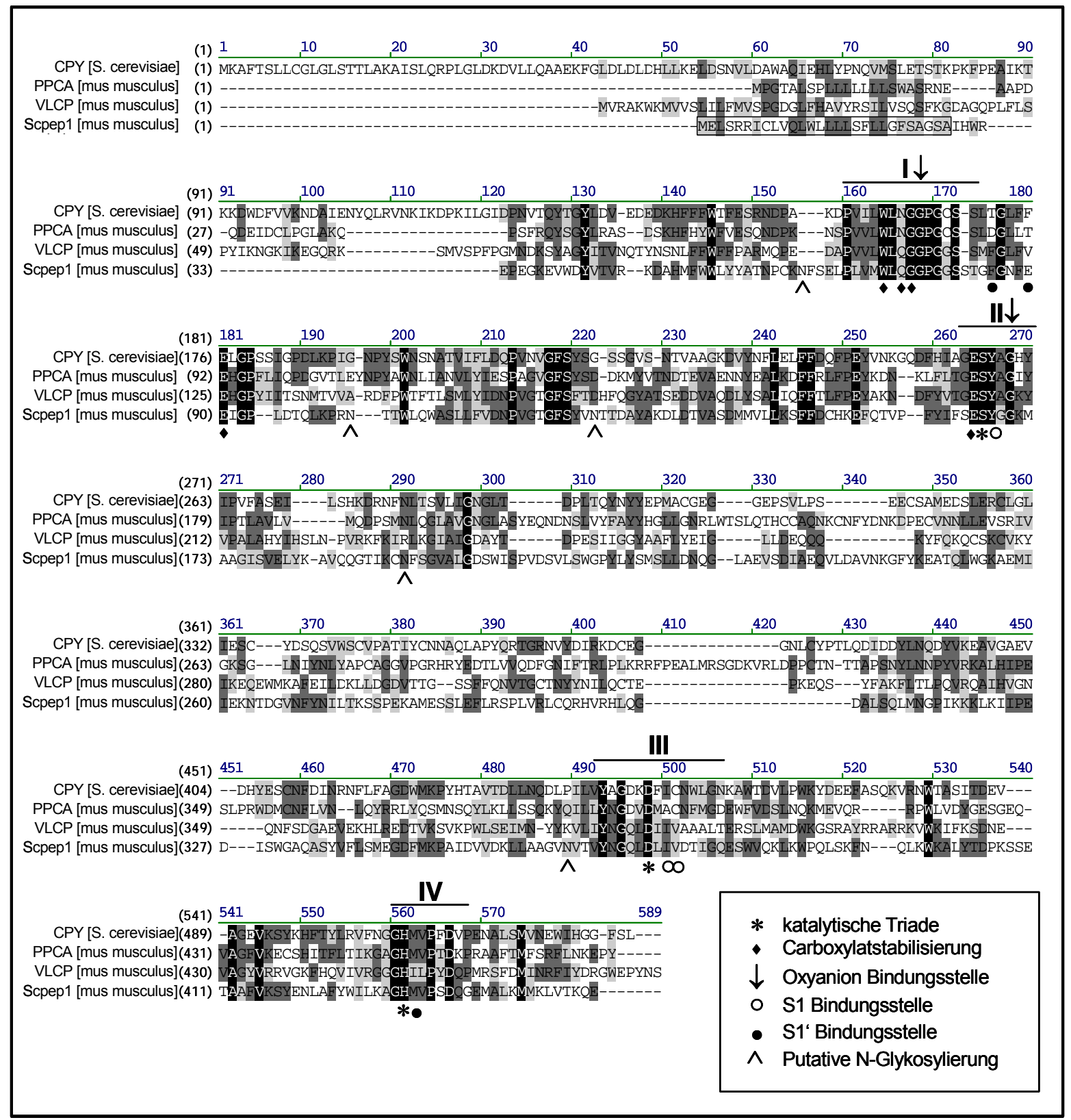

\section{Abb. 4.8: Aminosäuresequenz Alignment der murinen Scpep1 mit anderen Mitgliedern der Peptidase Familie S10}

Die Sequenzen wurden mit dem Clustal W Algorithmus (Nucleic Acid Research, 22 (22): 4673-4680, 1994) verglichen. Nach BLOSUM62 Matrix homologe AS sind durch verschiedene Hintergrundfarben markiert, dabei entspricht identischen, stark homologe, _ weniger homologen Aminosäuren. Die für die Katalyse essenziellen Aminosäuren sind mit (*) markiert. Die putative Substratbindungsstellen (I) und katalytische Bereiche (II-IV) sind mit Linien gekennzeichnet. AS die bei CPY und PPCA an der S1 Bindungsstelle beteiligt sind, sind mit (o) markiert. AS die an der S1' Bindung beteiligt sind, sind mit (•) markiert. Außerdem sind AS gekennzeichnet, die die Oxyanion Bindungsstelle $(\downarrow)$ und die Carboxylatbindungsstelle $(\diamond)$ stabilisieren. Putative N-Glykosylierungssequenzen der Scpep1 sind mit $(\wedge)$ markiert. Die Scpep Sequenzen die zum Vergleich verwendet wurden waren S. cerevisiae CPY (GI:115901), Mus musculus PPCA (GI:84042523), Mus musculus CPVL (GI:82901491) und Mus musculus Scpep1 (GI:13436038). 
Die CPVL weist in der Gruppe die stärkste Homologie zur Scpep1 auf $(36,5 \%$ Homologie/ 22,7 \% Identität). PPCA (33,7 \% Homologie/ 22,9 \% Identität) und die CPY (31,2 \% Homologie/ 19,3 \% Identität) sind etwas weniger homolog. Im Alignment kann man erkennen, dass die Serincarboxypeptidasesequenzen im Bereich der Substratbindungsstelle (I), sowie in Bereichen, die das aktive Zentrum des Enzyms bilden (II-IV) stark konserviert sind. Das putative katalytische Zentrum der murinen Scpep1 bilden die Aminosäuren S167, D371 und H431. Zusätzlich sind Aminosäuren, die an der Bindung und Stabilisierung des Carboxylats beteiligt sind und die Aminosäuren der Substratbindungsstellen konserviert. Im mittleren Bereich der Scpep1-Sequenz zwischen Aminosäure 200 und 350 zeigen die Sequenzen hingegen nur wenig Homologie. In der Abb. 4.8 sind zusätzlich der Sequenzbereich des putativen, N-terminalen Signalpeptids von M1 bis A28 und fünf putative N-Glykosylierungssequenzen (N64, N102, N126, N192 und N362) der Scpep1 markiert. In der Scpep1-Sequenz gibt es fünf Cysteine, von denen ein Cystein im Signalpeptid lokalisiert ist. Bei der Position von Argininen und Cysteinen, die N-Glykosylierungen bzw. Disulfidbrücken bilden könnten, ist keine Sequenzhomologie im Vergleich zu den anderen Serincarboxypeptidasen zu erkennen.

Mit den Programmen des Swiss-Model Servers (http://swissmodel.expasy.org) erfolgte für das Scpep1-Protein ein Automated Comparative Protein Modelling (Kopp und Schwede 2004; Arnold et al. 2006). In der Swiss-Model Template Library wurden die Kristallstrukturen des humanen PPCA (PDB code: 1ivyA, (Rudenko et al. 1995)) und der CPY (PDB code: 1cpy_, (Mortensen et al. 1994)) als passende Vorlagen für die Berechnung von putativen, dreidimensionalen Strukturen für das Scpep1-Protein identifiziert. In Abb. 4.9 ist die Kristallstruktur des PPCA und die daraus berechnete Struktur des Scpep1-Proteins (B), sowie die Kristallstruktur der CPY (C) und die daraus vorhergesagte Struktur des Scpep1 (D) dargestellt. In der dreidimensionalen Struktur von PPCA und CPY ist der typische Aufbau einer Serincarboxypeptidase zu erkennen. Die Proteine bestehen aus zwei Proteindomänen. Die erste Domäne zeigt eine typische $\alpha / \beta$ Faltung. Sie besteht aus einem achtsträngigen $\beta$-Faltblatt, das durch $\alpha$-Helices verbunden ist. Das katalytische Zentrum der Serincarboxypeptidasen ist in dieser Domäne lokalisiert, die bei den Serincarboxypeptidasen stark konserviert ist. 
A PPCA (1ivyA)

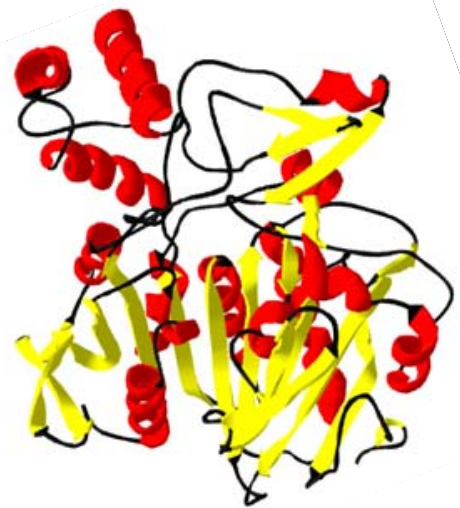

C CPY (1cpy_)

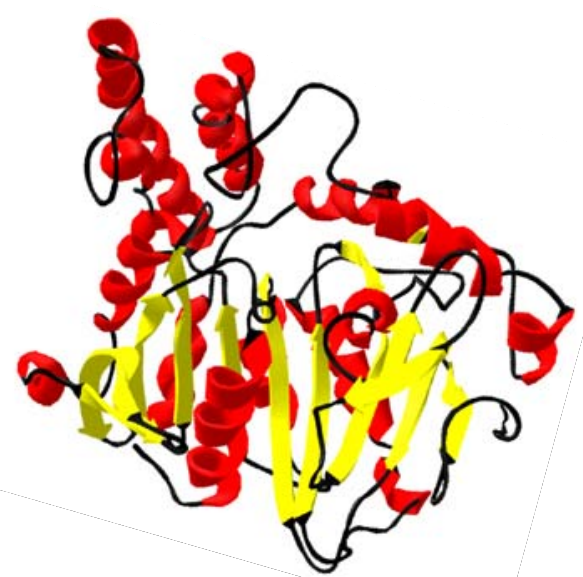

B Scpep1 (Model: 1ivyA)

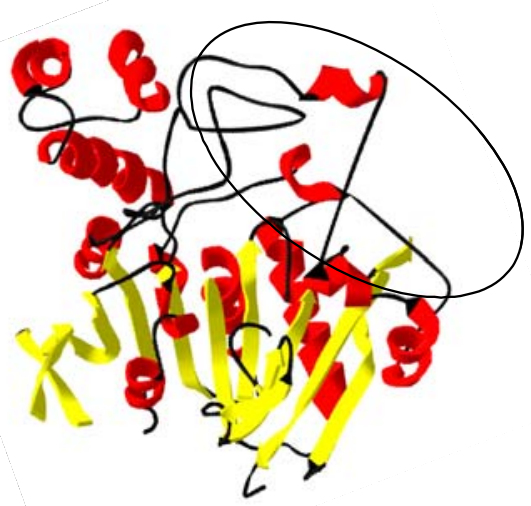

D Scpep1 (Model: 1cpy_)

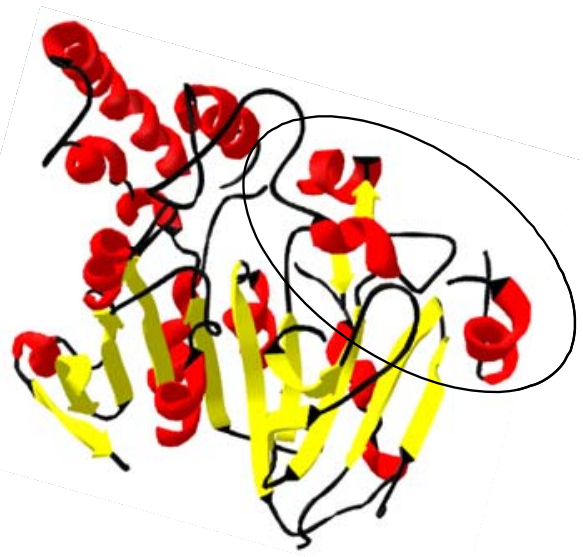

Abb. 4.9: Dreidimensionale Struktur der Serincarboxypeptidasen Cathepsin A und CPY, sowie die daraus berechneten, putativen Strukturen der Scpep1

Schematische Darstellung der humanen PPCA Struktur (A) und der daraus berechneten putativen Scpep1Struktur (B), sowie der Kristallstruktur der CPY (C) und der berechneten Scpep1-Struktur (D). Mit Hilfe des Automated Comparative Protein Modelling (Swiss-Model Server, http://swissmodel.expasy.org) wurden für das Scpep1-Protein putative, dreidimensionale Strukturen berechnet. Der Berechnung wurde die Kristallstruktur der homologen Serincarboxypeptidase PPCA (PDB: 1ivy), sowie der CPY (PDB: 1cpy_) zugrunde gelegt. In der Abbildung ist die Sekundärstruktur der Proteine farblich markiert: $\alpha$-Helices rot, $\beta$-Faltblätter gelb. In der berechneten Scpep1-Struktur ist jeweils der schwach konservierte Proteinbereich umkreist. 
In Abb. 4.9 ist zu erkennen, dass sich die berechneten Scpep1-Strukturen der PPCA und der CPY Struktur im Bereich der Kerndomäne stark ähneln. Das $\beta$-Faltblatt und die $\alpha$-Helices der Kerndomäne sind konserviert. Im Gegensatz zur ersten Domäne variiert die zweite Domäne in der Gruppe der Serincarboxypeptidasen stark in ihrer Struktur und Funktion (Rudenko et al. 1995; Hiraiwa 1999). In der Abb. 4.9 ist diese zweite Domäne über der ersten Domäne dargestellt. Es ist $\mathrm{zu}$ erkennen, dass die vorhergesagten Strukturen im Bereich der zweiten Scpep1-Domäne stark variieren, wobei der markierte Bereich dem schwach homologen mittleren Teil des Aminosäuresequenz-Alignments entspricht (siehe Abb. 4.8). Die dreidimensionale Struktur dieser Scpep1-Domäne ist aufgrund der starken Sequenzunterschiede nicht eindeutig vorhersagbar. Es ist wahrscheinlich, dass sich dieser Teil des Proteins bei Scpep1, PPCA und CPY deshalb auch funktionell stark unterscheidet. 


\subsection{Etablierung des Scpep1-Gene Trap Mausmodell RST426}

Die Scpep1 ist eine putativ lysosomale Serincarboxypeptidase und weist eine ausgeprägte Homologie zum PPCA auf (siehe 4.2.3). Im Lysosom bildet das PPCA Komplexe mit den Glykosidasen Neuraminidase und $\alpha$-Galactosidase (Galjart et al. 1988). Der Multienzymkomplex stabilisiert diese Enzyme und schützt sie so vor einer schnellen Degradation im Lysosom. Die lysosomale Speichererkrankung Galactosialidosis, eine kombinierten Galactosidose/Sialidose, wird durch Mutationen der PPCA verursacht, die zu einer Destabilisierung des Enzymkomplexes und somit zur vorzeitigen Degradation der Glykosidasen Neuraminidase und $\alpha$-Galactosidase führt (d'Azzo A. 1995; Vinogradova et al. 1998). Zudem ist die Galactosialidosis durch den Verlust der PPCA-Aktivität charakterisiert. Zur molekularen und funktionellen Untersuchung der Scpep1 in vivo wurde ein Scpep1-Gene Trap Mausmodell generiert. Durch die Inaktivierung der Scpep1 im Mausmodell sollte die enzymatische Aktivität des Enzyms identifiziert werden und untersucht werden, ob die Scpep1-Defizienz zu einem pathologischen Phänotyp führt.

\subsubsection{Die Gene Trap ES-Zelllinie RST426}

Das BayGenomics Konsortium (http://www.genetrap.org/) stellt murine embryonale Stammzellklone zur Verfügung, bei denen durch zufällige Gene Trap Insertion Gene ausgeschaltet wurden. Durch eine 5'-RACE-PCR und durch Sequenzierung des PCR-Produkts war eine Gene Trap Insertion im Gen Scpep1 des ES-Zellklon RST426 identifiziert und in der BayGenomics Gene Trap Resource Datenbank veröffentlicht worden (http://baygenomics.ucsf.edu/cgi-bin/BayDbAccess.py). 
Chr. 11 C (88740110..88771522)

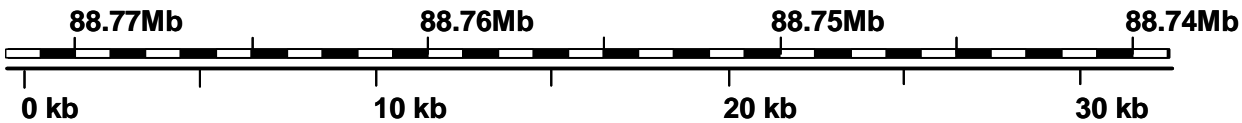

Scpep1-Gen (Gene ID:74617)

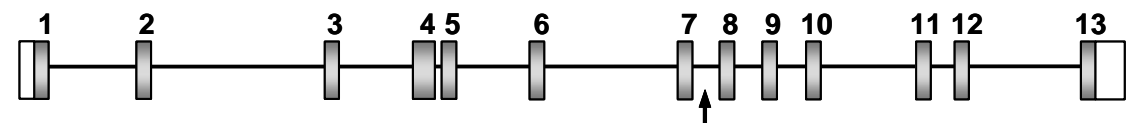

Gene Trap Insertion

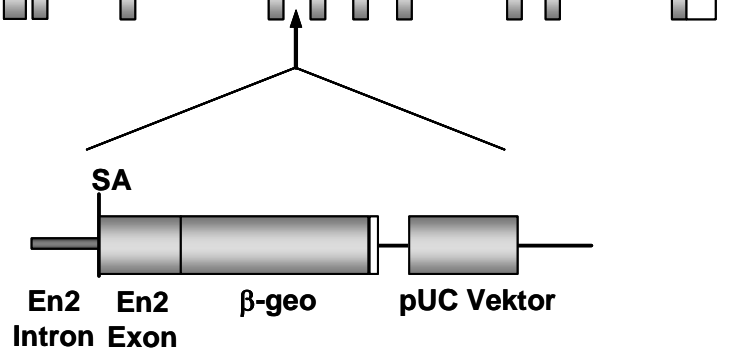

Scpep1-Gene Trap mRNA

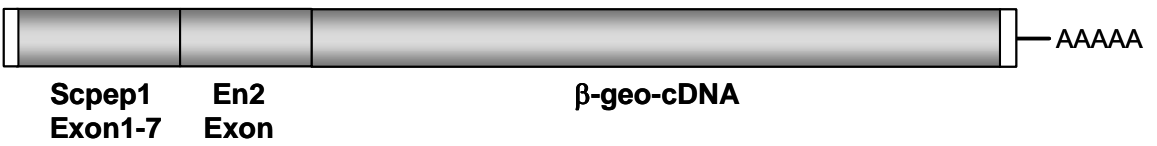

Scpep1-Gene Trap Fusionprotein (200 kDa)

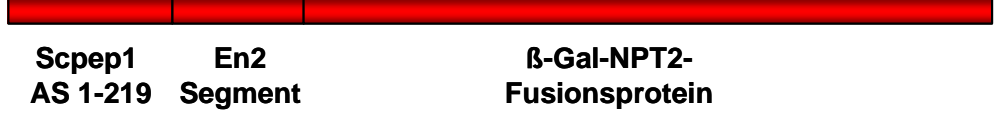

Abb. 4.10: Darstellung des Scpep1-Gene Trap

Die Abbildung zeigt das Scpep1-Gen auf Chromosom 11 (Gene ID: 74617) mit seiner Intron-Exon Struktur und der Gene Trap Insertionsstelle in ES Zellklon RST426. Durch eine 5' RACE PCR mit nachfolgender Sequenzierung werden die Baygenomics ES Zellklone auf die Insertionsstelle des Gene Trap Vektors untersucht. Die Sequenzierung zeigte für den ES Zellklon RST426 eine Insertion des Gene Trap Vektors in Intron 7 des Scpep1-Gens.

Der ES-Zellklon RTS426 wurde durch Insertion des Gene Trap Vektor pGT0TMpfs (http://baygenomics.ucsf.edu/cgi-bin/BayVector.py?KEY=pGT0TMPFS) in ES-Zellen des Mausstamms 129/Ola generiert. Der Gene Trap Vektor besitzt eine En2-Spleißakzeptorsequenz (SA), die 5' von einem En2-Intronanteil (engrailed-2 gene intron 1) und 3' von einem En2 Exonanteil (engrailed-2 gene exon 1) flankiert wird. Nach der En2-Exonsequenz folgt in 3' Richtung die fusionierte Sequenz des Reportergens $\beta$-Galactosidase und des Neomycin-Resistenzgens ( $\beta$-geo), ein SV40Polyadenylierungssignal (SV40pA) und die pUC Vektor Sequenz. Die Insertion des 
Gene Trap Vektors erfolgte laut BayGenomics Datenbankeintrag in Intron 7 des murinen Scpep1-Gens (Abb. 4.10). Beim Spleißen der Scpep1-Gene Trap mRNA wird das En2/ $\beta$ geo Exon des Vektors an das Exon 7 der Scpep1 angefügt. Durch Translation der Scpep1Gene Trap mRNA entsteht ein 200 kDa großes Fusionsprotein mit einem N-terminalen Scpep1-Anteil aus Aminosäure M1 bis M219 und einem C-terminalen Fusionsproteinanteil ( $\beta$-geo) aus $\beta$-Galactosidase ( $\beta$-Gal) und Neomycinphosphotransferase 2 (NPT2), wobei das Scpep1-Fragment und das Reportergen durch ein En2 Exon Segment (en2 coding leader sequence) verbunden sind (Abb. 4.10). Im Folgenden wird für das Scpep1-Gene Trap Allel die Bezeichnung Scpep1-(-)-Allel verwendet. Es ist dabei zu beachten, dass der Gene Trap nicht zur völligen Deletion des Scpep1-Proteins führt, sondern zur Bildung des 200 kDa-Fusionsproteins. Ob der Scpep1-Gene Trap eine funktionelle Inaktivierung der Scpep1 erzeugt, war zu überprüfen.

\subsubsection{Generierung von Chimären durch Retransfer der transgenen ES-Zellen und Verpaarung der Nachkommen zur Etablierung des RST426 Mausstamms}

Der ES-Zellklon RST426 wird von dem MMRRC (Mutant Mouse Regional Resource Center, Davis, CA, USA) für die Herstellung eines Scpep1-Gene Trap Mausstamms zur Verfügung gestellt. Zur Überprüfung des Scpep1-Gene Trap wurden von den ES-Zellen mRNA und genomische DNA isoliert. Zudem wurden ES-Zellen zur Mikroinjektion in C57BL/6 Blastozysten vorbereitet. Die Blastozysteninjektion und der Transfer der Blastozysten in pseudoschwangere Weibchen erfolgten am Tierhaus des MPI für experimentelle Medizin durch Frau Monika Schindler. Durch die Blastozysteninjektion wurden 5 chimäre Männchen und ein chimäres Weibchen erzeugt. Der Chimärimus der Tiere konnte anhand der Fellfarbe der Tiere beurteilt werden. Er lag zwischen 50 und $70 \%$. Ein $70 \%$ und ein $50 \%$ chimäres Männchen wurden mit C57BL/6 Weibchen verpaart und erzeugten schwarze sowie agoutifarbene Nachkommen. Die Vererbung des Agouti-Fellmarkers des 129/Ola-Mausstamms zeigt eine Keimbahnbeteiligung der mikroinjizierten ES-Zellen an. Die Genotypisierung der Nachkommen zeigte, dass wie erwartet $50 \%$ der agoutifarbenen Tiere heterozygot für das Scpep1-Gene Trap Allel waren. Für die weitere Zucht wurden heterozygote Nachkommen untereinander verpaart, 
so dass bei dem RST426 Mausstamm ein genetischer Mischhintergrund 129/Ola/C57BL/6 erhalten blieb.

\subsubsection{Verifizierung des Scpep1-Gene Trap durch RT-PCR}

Um sicherzustellen, dass es sich bei dem ES-Zellklon RST426 um den beschriebenen Scpep1-Gene Trap handelt, wurde vor der Blastozysteninjektion das Ergebnis der BayGenomics 5'RACE-PCR überprüft. Dazu wurde aus den ES-Zellen mRNA isoliert und zur reversen Transkription mit Oligo-dT-Primer eingesetzt. Anschließend erfolgte eine PCR auf dem Produkt der reversen Transkription mit dem Primer Scpep1-Ex7-FW auf Exon 7 der Scpep1 und dem Primer Bay- $\beta$-Gal-RV auf der $\beta$-Gal-Sequenz des inserierten Gene Trap Vektors, wobei ein 966 bp PCR-Produkt erzeugt wurde. Die Spezifität des PCR-Produkts wurde durch Sequenzierung abgesichert. Das erzeugte RT-PCR Produkt weist die Generierung der Scpep1-Gene Trap mRNA mit einem Übergang von der Exon 7-Sequenz zur Vektor-Exonsequenz und damit die Insertion des Gene Trap Vektors in Intron 7 des Scpep1-Gens nach.

\subsubsection{Nachweis der Gene Trap Insertionsstelle durch PCR auf genomischer DNA}

Um die Insertionsstelle des Gene Trap Vektors pGT0TMpfs im Intron 7 des Scpep1-Gens zu identifizieren, wurde genomische DNA aus den ES-Zellen RST426 isoliert. Zur Identifizierung der Vektorinsertionsstelle erfolgte eine PCR mit dem Primer Scpep1-Ex7FW auf Exon 7 der Scpep1 und dem Primer Scpep1-KO-RV auf der Intron Sequenz En2 des Gene Trap Vektors (siehe Abb. 4.11). Zur Kontrolle wurde mit den Primern Scpep1Ex7-FW und Scpep1-Ex8-RV zusätzlich eine PCR auf das nicht veränderte Allel der Scpep1 durchgeführt. Beide PCR-Ansätze waren erfolgreich. Die Gene Trap PCR erzeugte ein 600 bp großes Produkt (Abb. 4.11). Dieses PCR Produkt wurde sequenziert, um die Insertionsstelle des Vektors zu ermittelt. Der Übergang von der Scpep1Gensequenz in die inserierte Vektorsequenz erfolgt nach bp 18955 der genomischen Sequenz (Gene ID:74617). Dies entspricht 536 bp 5' des Exon 7. Die inserierte $\begin{array}{lllllll}\text { Vektorsequenz beginnt mit bp } 114 \text { der } & \text { pGT0TMpfs } & \text { Sequenz }\end{array}$ (http://baygenomics.ucsf.edu/cgi-bin/BayVector.py?KEY=pGT0TMPFS). 
A

Scpep1-Gen (Gene ID:74617)

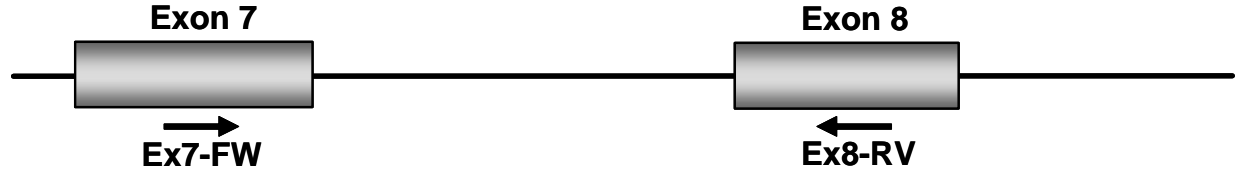

Scpep1-Gene Trap Allel

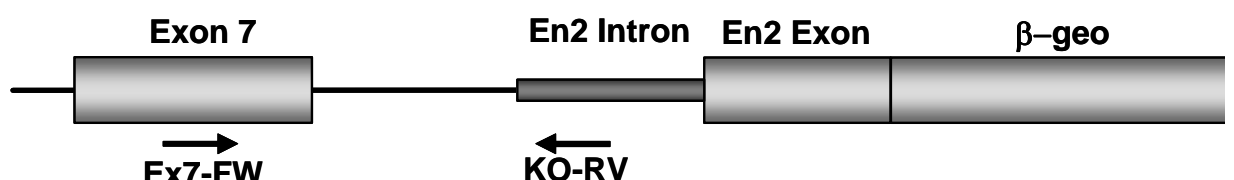

B

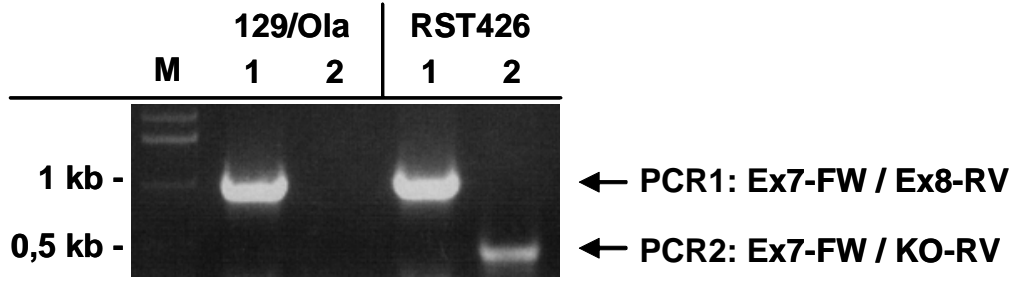

C

Sequenzierung von KO-RV

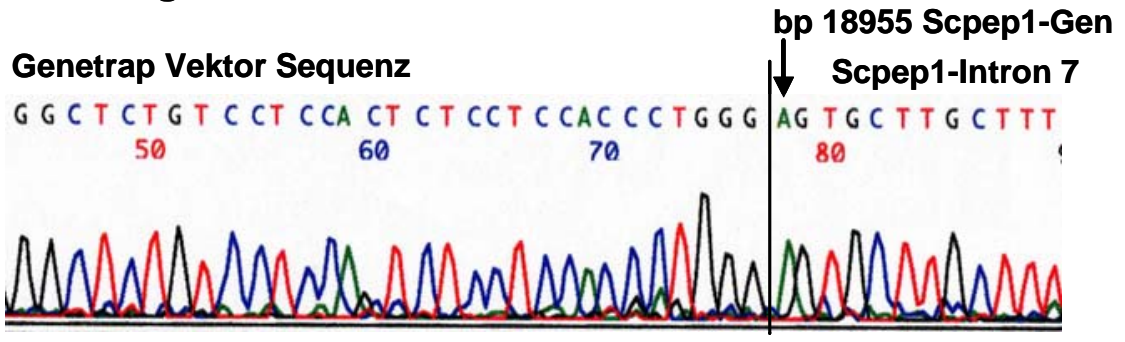

Abb. 4.11: Identifizierung der Gene Trap Insertionsstelle durch PCR und Sequenzierung

Zur Identifizierung der Scpep1-Gene Trap Insertionsstelle im ES-Zellklon RST426 wurde genomische DNA isoliert. Anschließend wurde durch PCR der Übergangsbereich von Scpep1-Gen zur inserierten Vektorsequenz amplifiziert (A,B). Durch Sequenzierung des PCR Produktes wurde dann die genaue Insertionsstelle identifiziert (C).

\subsubsection{Genotypisierung des RST426 Mausmodells durch Southern Blot Analyse und Multiplex-PCR}

Die Genotypisierung der RST426 Mäuse erfolgte durch Southern Blot Analyse und durch eine Multiplex-PCR, die zuvor an RST426 ES-Zell-DNA etabliert wurde. Bei der Southern Blot Analyse wurden $10 \mu \mathrm{g}$ der genomischen DNA mit dem Restriktionsenzym Bgl II verdaut. In der Scpep1-Gensequenz befinden sich in Intron 6 und in Intron 9 Bgl II-Schnittstellen. Ein Bgl II-Verdau der genomischen DNA führt zu einem 5,2 kb 
großen DNA-Fragment. Durch die Insertion des Gene Trap Vektors in das Intron 7 des Scpep1-Gens wird in das Gene Trap Allel eine weitere Bgl II Schnittstelle eingefügt. Die Bgl II-Schnittstelle befindet sich in der En2-Exonsequenz des Vektors. Ein Bgl II Verdau führt im Scpep1-(-)- Allel zu einem 4 kb großen DNA-Fragment. Die Identifizierung der Scpep1-Allele erfolgte im Southern Blot durch Hybridisierung der DNA Fragmente mit einer Sonde gegen den 5' Bereich des Scpep1-Exons 7. Die 600 bp lange Sonde wurde zuvor durch PCR auf genomischer DNA mit Hilfe der Primer Scpep1-Sonde-5'-FW und Scpep1-Sonde-5'-RV generiert (8.3.3).

\section{A}

\section{Scpep1-(+)-Allel}

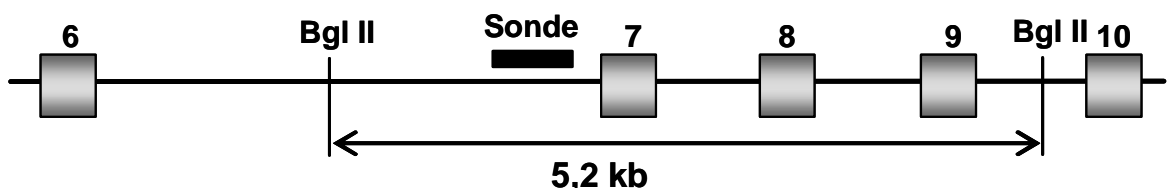

Scpep1-Gene Trap (-)-Allel,

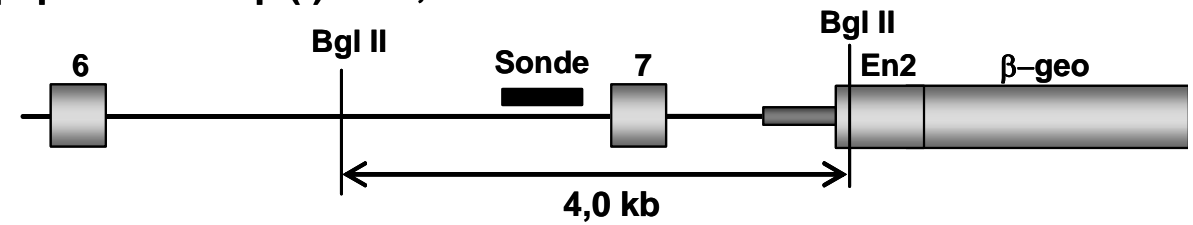

B

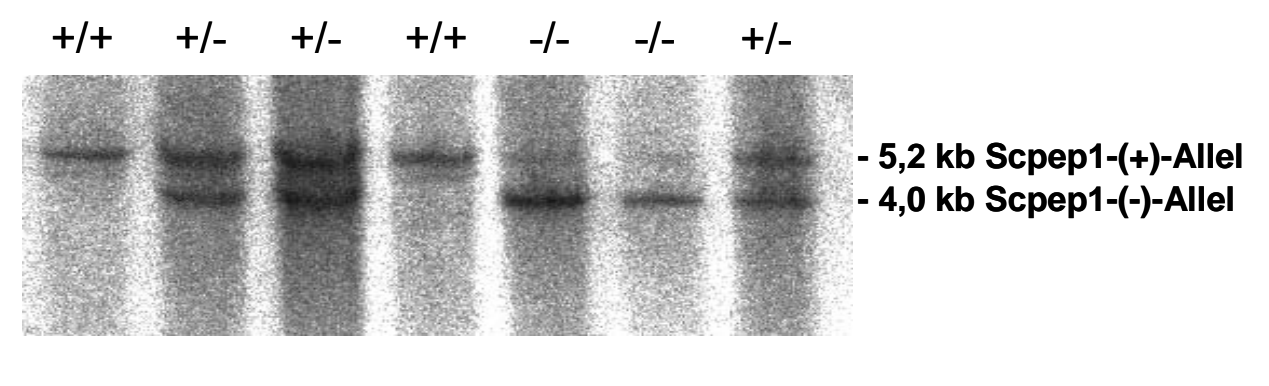

Abb. 4.12: Southern Blot Analyse des Scpep1-Gene Trap

Zur Genotypisierung der RST426 Mäuse erfolgte eine Southern Blot Analyse auf Bgl II verdaute Mausschwanz-DNA. Nach dem Transfer der DNA auf eine Hybond N-Membran erfolgte die Hybridisierung der DNA-Fragmente mit einer 600 bp-Sonde gegen den 5'-Bereich des Scpep1-Exons 7. Das Scpep1-(+)-Allel wurde durch eine 5,2 kb-Bande, das Scpep1-Gene Trap Allel durch eine 4,0 kbBande identifiziert.

Abb. 4.12 A zeigt eine grafische Darstellung des normalen Scpep1-(+)-Allels und des Scpep1-(-)-Allels, sowie die Bgl II Schnittstellen auf beiden Allelen. Bei der Southern Blot Analyse erzeugt das Scpep1-(+)-Allel eine 5,2 kb Bande und das Scpep1-(-)-Allel eine 4,0 kb Bande (Abb. 4.12 B). 


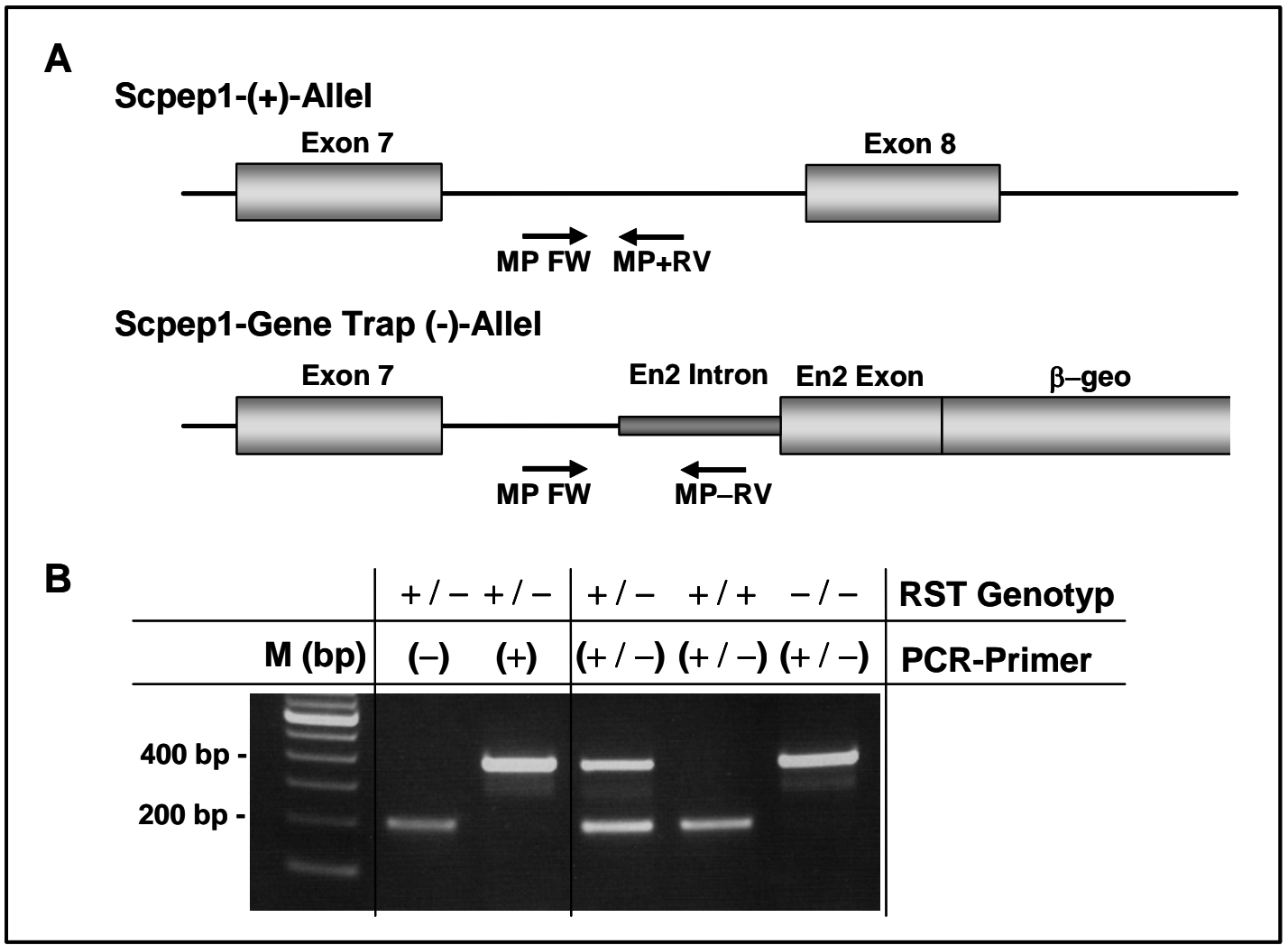

Abb. 4.13: Multiplex-PCR zur Genotypisierung der RST426 Mäuse

Zur Genotypisierung der RST 426 Mäuse wurde neben der Southern Blot Analyse eine Multiplex-PCR etabliert. Auf die isolierte Mausschwanz-DNA erfolgte eine Multiplex-PCR mit dem Forward-Primer (MP FW) und mit einem 1:1-Mix der Reverse-Primer MP+RV und MP-RV. Das Scpep1-(+)-Allel erzeugt ein PCR-Produkt von 200 bp Länge. Das PCR-Produkt des Scpep1-(-)-Allels ist 390 bp lang.

Zum schnellen Genotypisieren wurde zusätzlich eine Multiplex-PCR mit einem Forwardund zwei Reverse-Primern etabliert. Als Multiplex Forward-Primer (Scpep1 MP FW) wurde eine Sequenz in Intron 7 des Scpep1-Gens im 5' Bereich direkt vor der Vektorinsertionsstelle gewählt. Als Multiplex Reverse-Primer wurde für das Scpep1-(+)Allel der Primer Scpep1 MP+RV in Intron 7 3' der Vektorinsertionsstelle generiert. Für die PCR des Scpep1-(-)-Allels wurde der Multiplex Primer Scpep1 MP-RV 390 bp vom 5' Ende der pGT0TMpfs Vektorsequenz ausgewählt. Bei einer Multiplex PCR auf DNA einer heterozygoten RST426 Maus entstehen bei einer Annealing-Temperatur von $52^{\circ} \mathrm{C}$ beide PCR-Produkte zu gleichen Anteilen. Bei homozygoten RST426 Mäusen wird hingegen nur das spezifische (+)- oder (-)-PCR-Produkt erzeugt (Abb. 4.13). 


\subsection{Lokalisation und Expression der Scpep1}

\subsubsection{Aufreinigung des Scpep1-Proteins zu Herstellung von $\alpha$-Scpep1-Antiseren}

Zur Generierung von spezifischen Antiseren gegen das Scpep1-Protein wurde das Scpep1-Protein mit einem C-terminalen RGS-His6-Tag exprimiert, aufgereinigt und zur Immunisierung von Kaninchen eingesetzt.

In vergleichenden Expressionsstudien in BHK und HT1080 Zellen mit verschiedenen Vektorkonstrukten wurde der Zellklon HT1080-Scpep1 generiert. Dieser Zellklon zeigte nach stabiler Transfektion mit dem Vektorkonstrukt pcDNA3.1/Hygro-Scpep1 (8.3.5) eine starke Expression des C-terminal RGS-His6-markierten Scpep1-Proteins. Die HT1080-Scpep1 Zellen sezernierten aufgrund der hohen Expressionsrate in $48 \mathrm{~h}$ etwa $2 \mathrm{mg} / \mathrm{l}$ Scpep1 in das Zellkulturmedium. Das sezernierte Protein wurde mit Ammoniumsulfat präzipitiert und zur Scpep1-Aufreinigung eingesetzt.

\subsubsection{Zweistufige Aufreinigung des Scpep1-Proteins mittels Ni-NTA- und Ionenaustauscherchromatografie}

Als Ausgangsmaterial für eine Scpep1-Aufreinigung wurden fünf Liter Zellkulturüberstand von HT1080-Scpep1 Zellen eingesetzt (3.3.8). Das RGS-His6-markierte Scpep1-Protein wurde zunächst mit Ni-NTA-Agarose affinitätschromatografisch aufgereinigt (3.5.1.1). Zur Analyse der Ni-NTA-Aufreinigung wurden jeweils 0,5 Vol\% der Fraktionen im Silbergel, sowie im Western Blot untersucht (Abb. 4.14). Das RGS-His6-markierte, $55 \mathrm{kDa}$ große Scpep1-Protein bindet vollständig an die Ni-NTA-Agarose. Im Durchbruch ist kein Scpep1 nachweisbar. Beim Waschen der Säule mit $10 \mathrm{mM}, 15 \mathrm{mM}$ und $20 \mathrm{mM}$ Imidazol werden bereits $30 \%$ des gebundenen Scpep1Proteins von der Säule gewaschen. Bei der anschließenden Elution wird $70 \%$ des RGS-His6-markierten Proteins von der Säule eluiert. Die Elutionsfraktionen enthalten zusätzlich zur eluierten Scpep1 eine Reihe kontaminierender Proteine. Zur weiteren Reinigung der Scpep1 mussten die Proteine der Ni-NTA-Elutionsfraktion durch Ionenaustauscherchromatografie weiter aufgetrennt werden. 


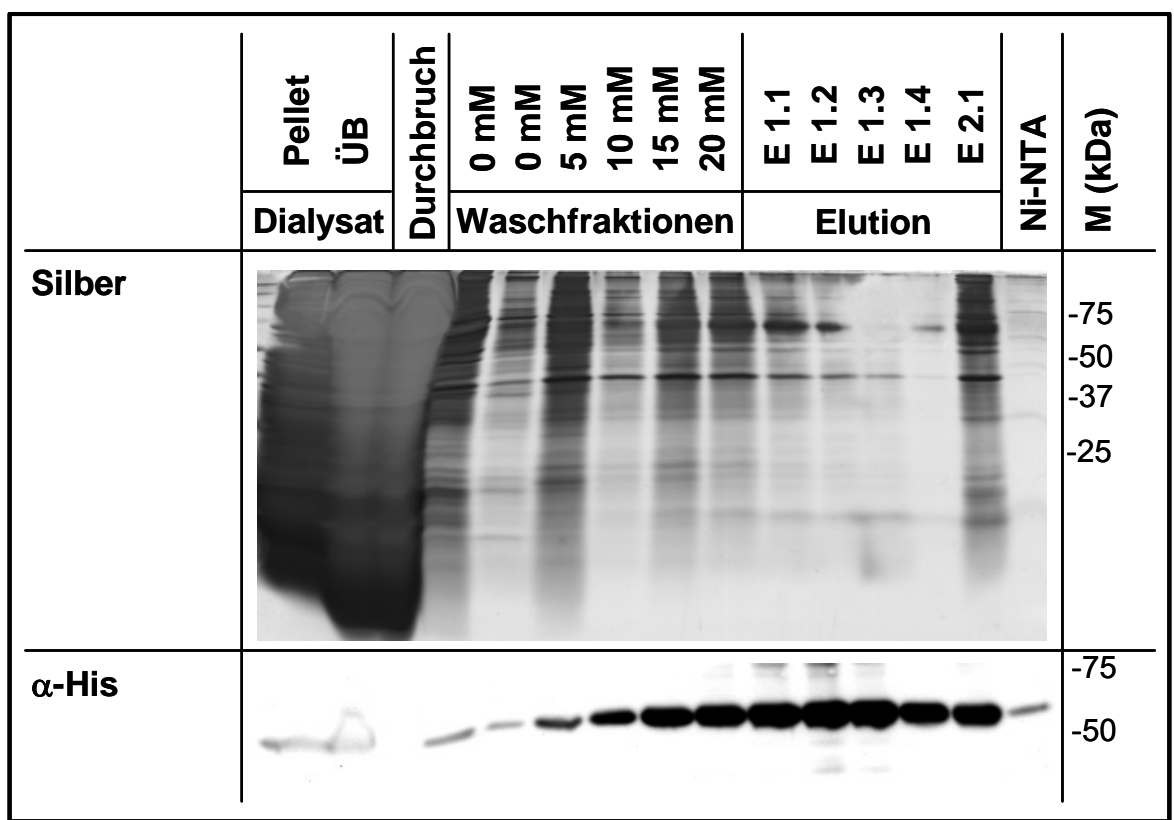

Abb. 4.14: Affinitätschromatgrafische Ni-NTA-Aufreinigung von RGS-His6-markiertem Scpep1

Das RGS-His6-markierte Scpep1-Protein, aus Zellkulturüberständen überexprimierender HT1080 wurde gesammelt, präzipitiert und gegen PBS dialysiert (Dialysat). Der lösliche Anteil des Dialysats (ÜB) wurde mit Ni-NTA-Agarose inkubiert, die Agarose wurde auf eine Säule aufgetragen (Durchbruch), mit steigender Imidazolkonzentration gewaschen (Waschfraktionen) und mit $100 \mathrm{mM}$ Imidazol (E1) und $200 \mathrm{mM}$ Imidazol (E2) eluiert. 0,5\% der Aufreinigungsfraktionen wurden im Silbergel und im Western Blot mit $\alpha$-His-Antikörper analysiert.

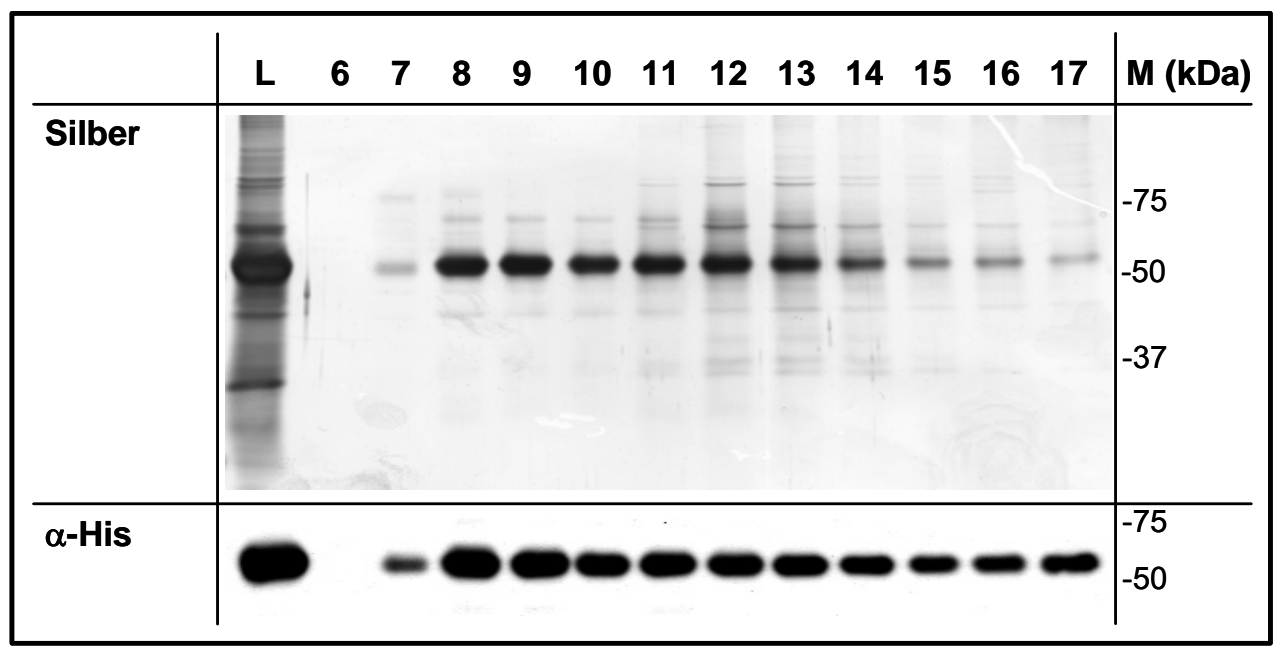

Abb. 4.15: Ionenaustauscherchromatograpie der RGS-His6-markierten Scpep1 nach partieller Aufreinigung mit Ni-NTA-Agarose

Das RGS-His6-markierte Scpep1-Protein im Eluat der Ni-NTA-Aufreinigung wurde auf eine Poros HQ Anionenaustauscherchromatografiesäule aufgetragen (L) und mit einem NaCl-Stufengradienten von der Säule eluiert. Fraktionen 6 bis 17 des Chromatografielaufs wurden im Silbergel und im Western Blot mit $\alpha$-His-Antikörper auf Reinheit und Menge des Scpep1-Proteins untersucht. 
Das Eluat der Ni-NTA-Aufreinigung wurde dialysiert und auf eine Poros HQ Anionenaustauscher Säule aufgetragen. Die Elution der Proteine erfolgte dabei durch einen diskontinuierlichen $\mathrm{NaCl}-G r a d i e n t e n$ (3.5.1.2). Zur Analyse der Aufreinigung wurden jeweils 0,5 Vol\% der Fraktionen im Silbergel sowie im Western Blot untersucht. Das Scpep1-Protein eluiert zu Beginn des Gradienten bei einer Konzentration von 50 $150 \mathrm{mM} \mathrm{NaCl}$ von der Säule. 75 \% der Scpep1 eluiert in den Fraktionen 8 bis 13 von der Säule, wobei das Protein in den Fraktionen 8 und 11 sehr sauber ist. Die Fraktionen 8 - 11 wurden lyophilisiert, in PBS aufgenommen und gegen PBS dialysiert. Aus fünf Litern Zellkulturüberstand wurden mit dieser Methode etwa $1 \mathrm{mg}$ sauberes Protein isoliert. Das aufgereinigte Scpep1-Protein hat ein Molekulargewicht von 55 kDa. Durch EdmanAnalyse wurde die Aminosäure Ile29 als N-terminale Aminosäure des aufgereinigten Proteins identifiziert. Zudem ist das Protein über seinen C-terminalen RGS-His6-Tag nachweisbar.

Das aufgereinigte Protein wurde zur Immunisierung von Kaninchen und Ratten eingesetzt (3.6.1). Mit einer 1:1000 Verdünnung der generierten Seren konnten 10 ng des Scpep1-Protein im Western Blot nachgewiesen werden. Ein RGS-His6-markiertes Kontrollprotein (80 ng) wurden hingegen unter diesen Bedingungen nicht detektiert. Die generierten Antiseren aus Kaninchen werden im Folgenden als $\alpha$-Scpep1-D2 und $\alpha$-Scpep1-C6 bezeichnet, das Ratten-Antiserum als $\alpha$-Scpep1-Ratte.

\subsubsection{Lysosomale Lokalisation des Scpep1-Proteins}

\subsubsection{Immundetektion endogener Scpep1 in Fibroblasten}

Die Lokalisation des endogenen Scpep1 wurde durch indirekte Immunfluoreszenz untersucht. Embryonale Mausfibroblasten (MEF) wurden fixiert und mit den $\alpha$-Scpep1Antiseren, sowie mit einem Antikörper gegen das lysosomale Membranprotein LAMP-1 ( $\alpha$-mLAMP-1, 1D4B) inkubiert. Das endogene Scpep1-Protein ist in der lysosomalen Matrix lokalisiert. Die lysosomalen Membranen sind durch die Detektion des integralen Membranproteins LAMP-1 grün gefärbt. Die roten Signale der $\alpha$-Scpep1-Färbung sind von den grün gefärbten lysosomalen Membranen umgeben (Abb. 4.16). Gleiche Ergebnisse wurden mit den Antiseren $\alpha$-Scpep1-C6 und $\alpha$-Scpep1-Ratte erzielt. 


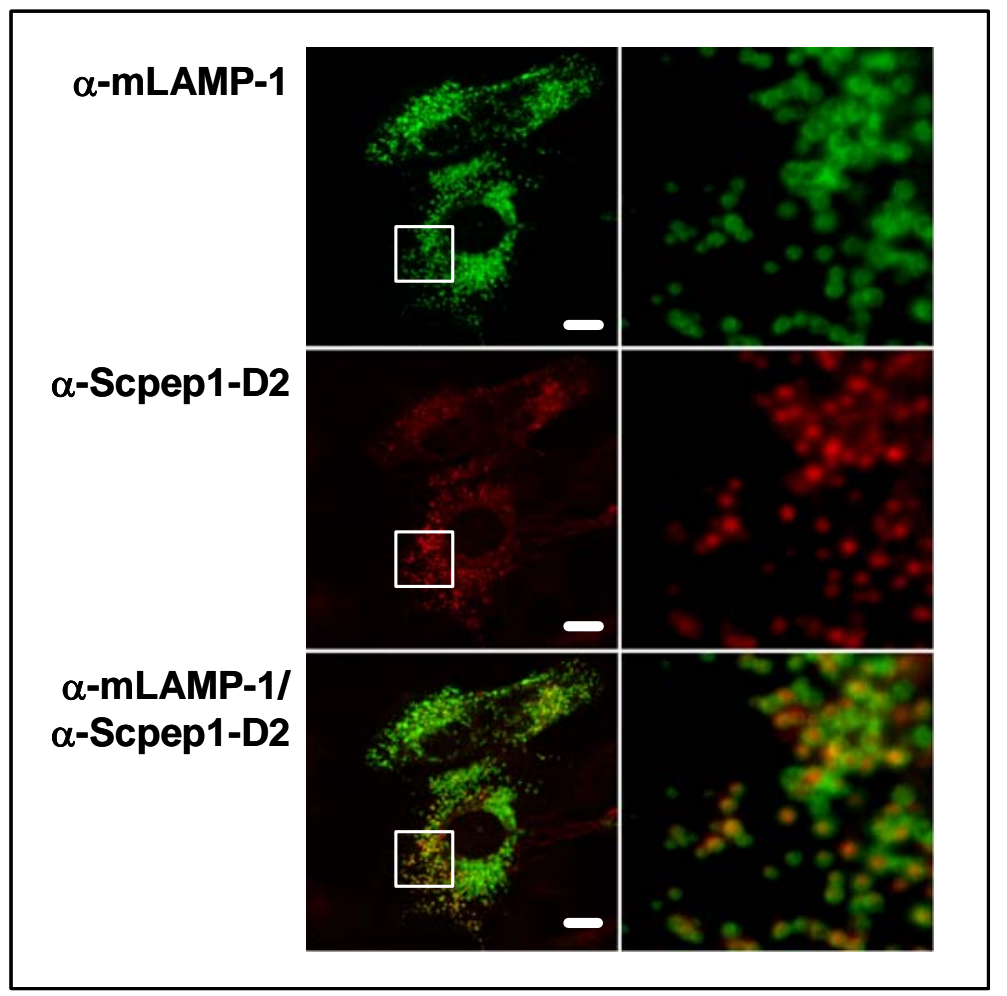

Abb. 4.16: Endogene Anfärbung von Scpep1 in MEF durch $\alpha$-Scpep1-D2-Serum

MEF wurden mit Methanol fixiert und Scpep1 wurde endogen durch indirekte Immunfluoreszenz mit dem aScpep1-D2-Antiserum detektiert. Lysosomale Membranen wurden mit einen Antikörper gegen das lysosomale Markerprotein LAMP-1 dargestellt. Balken $20 \mu \mathrm{m}$.

\subsubsection{Nachweis der endogenen Scpep1 nach subzellulärer Fraktionierung}

Die Behandlung von Zellen mit Tyloxapol (Triton WR1339) führt zur Verringerung der lysosomalen Dichte, so dass Lysosomen aus Tyloxapol-behandelten Mauslebern durch differentielle Zentrifugation (Fraktionen $\mathrm{N}$ bis $\mathrm{S}$ ) und anschließende Ultrazentrifugation im diskontinuierlichen Sucrosedichtegradienten (F1 bis F4) von anderen Zellorganellen effizient getrennt werden können (Leighton et al. 1968).

Tab. 4.5 zeigt die prozentuale Aufteilung der Gesamtaktivität der lysosomalen Markerenzyme $\beta$-Hexosaminidase ( $\beta$-Hex) und $\beta$-Glucuronidase ( $\beta$-Gluc). Zusätzlich ist die prozentuale Verteilung der Enzymaktivität der mitochondrialen Succinatdehydrogenase (SDH), der 5'AMPase, die auf der Plasmamembran lokalisiert ist und der G-6-Pase, die im ER aktiv ist, angegeben, sowie die prozentuale Proteinverteilung in den Fraktionen der subzellulären Fraktionierung. 


\begin{tabular}{l|ccccc|cccc}
\hline & $\mathrm{N}$ & $\mathrm{M}$ & $\mathrm{L}$ & $\mathrm{P}$ & $\mathrm{S}$ & $\mathrm{F} 1$ & $\mathrm{~F} 2$ & $\mathrm{~F} 3$ & $\mathrm{~F} 4$ \\
\hline B-Hex & 9,0 & 14,0 & 49,4 & 20,7 & 6,9 & 1,8 & 65,0 & 6,1 & 27,1 \\
$\beta$-Gluc & 4,9 & 6,4 & 37,8 & 31,9 & 19,0 & 2,1 & 50,5 & 7,1 & 40,3 \\
SDH & 8,4 & 49,3 & 35,8 & 4,8 & 1,7 & 0,0 & 0,2 & 0,3 & 99,5 \\
5'-AMPase & 44,7 & 1,3 & 10,0 & 37,4 & 6,6 & 0,0 & 9,7 & 0,0 & 90,3 \\
G-6-Pase & 7,2 & 1,5 & 16,0 & 74,2 & 1,1 & 0,05 & 0,2 & 1,15 & 98,6 \\
Protein & 13,9 & 11,5 & 15,4 & 20,3 & 38,9 & 0,1 & 3,4 & 1,6 & 94,9 \\
\hline
\end{tabular}

Tab. 4.5: Analyse einer subzellulären Fraktionierung von Mausleberhomogenat nach TyloxapolBehandlung

Das Leberhomogenat von Tyloxapol-behandelten Mäusen wurde durch differentielle Zentrifugation fraktioniert. Zuerst wurde die nukleäre Fraktion $\mathrm{N}$ vom postnukleären Überstand getrennt (E). Der Überstand wurde weiter in die Fraktionen M (mitochondrial), L (light mitochondrial), P (microsomal) und S (supernatant) aufgetrennt. Die Fraktion L wurde anschließend auf einem diskontinuierlichen Sucrosedichtegradienten in vier Fraktionen weiter separiert. Die Tabelle zeigt die prozentuale Aufteilung der Gesamtaktivität der lysosomalen Enzyme $\beta$-Hexosaminidase $(\beta$-Hex) und $\beta$-Glucuronidase $(\beta$-Gluc) bei der differentiellen Zentrifugation $(\Sigma=100 \%)$ und anschließend bei der Sucrosedichtegradientenzentrifugation $(\Sigma=100 \%)$. Zusätzlich ist die prozentuale Verteilung der Enzymaktivität der mitochondrialen Succinatdehxdrogenase (SDH), der 5'AMPase (Plasmamembran) und der G-6-Pase (ER), sowie die prozentuale Proteinverteilung in den Fraktionen der subzellulären Fraktionierung angegeben.

Bei der subzellulären Fraktionierung erfolgt zuerst eine Trennung von nukleären Bestandteilen (N) und postnukleärem Überstand (E). Der Überstand wird durch differentielle Zentrifugation weiter in die mitochondriale (M), leichte mitochondriale (L), die mikrosomale (Golgi/ER) (P) und die zytoplasmatische Fraktion (S) aufgeteilt. In der analysierten Präparation sind 49,3\% der SDH-Gesamtaktivität in der Fraktion (M) enthalten und 35,8 \% in der leichten, mitochondrialen Fraktion (L), in der auch 49,4\% der $\beta$-Hex-Gesamtaktivität angereicht ist. Die Fraktion L wurde durch einen Sucrosedichtegradienten weiter in vier Fraktionen (F1 bis F4) separiert. 65 \% der auf den Dichtegradienten aufgetragenen $\beta$-Hexosaminidase-Aktivität und $50,5 \%$ der $\beta$-Glucuronidase-Aktivität wird in der Fraktion F2 angereichert. Die mitochondriale Aktivität wird hingegen zu über $99 \%$ in der Fraktion F4 nachgewiesen. Nur 0,2 \% der SDH-Aktivität ist in Fraktion F2 enthalten. In der Fraktion F2 ist nach der subzellulären Fraktionierung 32,1\% der $\beta$-Hexosaminidase-Aktivität und $0,5 \%$ der Gesamtproteinmenge des Ausgangshomogenats enthalten. Dies entspricht einer 68-fachen Anreicherung des lysosomalen Markerenzyms in der Fraktion F2 der analysierten Präparation. 
A Subzelluläre Fraktionierung von Scpep1 ${ }^{+++}$-Leberhomogenaten

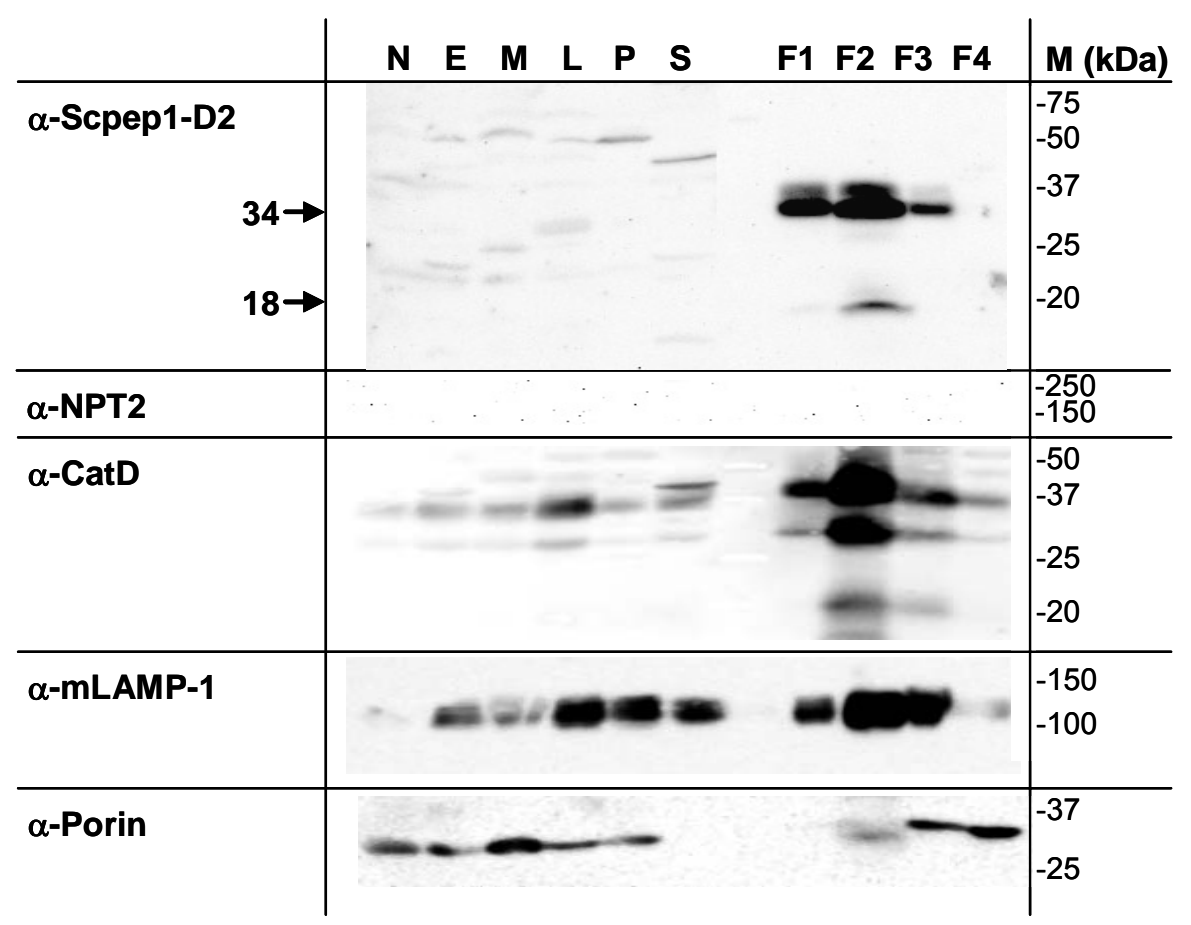

B Subzelluläre Fraktionierung von Scpep1 ${ }^{- \text {-Leberhomogenaten }}$

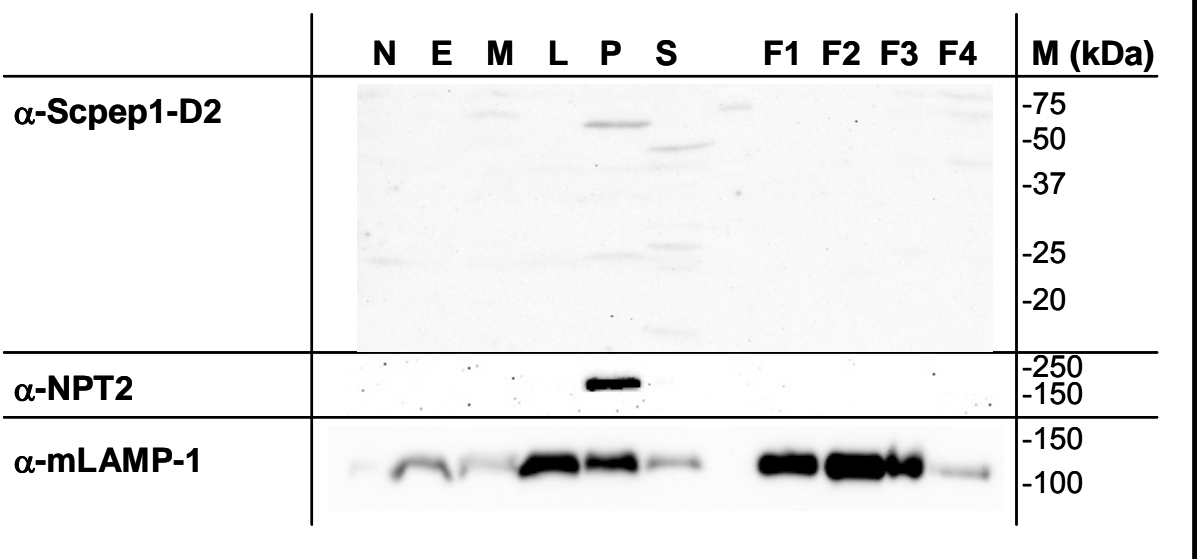

Abb. 4.17: Analyse einer subzellulären Fraktionierung von Mausleberhomogenat nach TyloxapolBehandlung

Das Leberhomogenat von Tyloxapol-behandelten Mäusen wurde durch differentielle Zentrifugation fraktioniert. Zuerst wurde die nukleäre Fraktion N vom postnukleären Überstand getrennt (E). Die Fraktion E wurde weiter in die Fraktionen M (mitochondrial), L (light mitochondrial), P (peroxisomal) und S (supernatant) aufgetrennt. Die Fraktion L wurde anschließend auf einem diskontinuierlichen Sucrosedichtegradienten in 4 Fraktionen weiter separiert. Anschließend folge die Western Blot Analyse von jeweils $250 \mu \mathrm{g}$ Protein der Fraktionen N bis S der subzellulären Fraktionierung und je $50 \mu \mathrm{g}$ der Fraktionen F1 bis F4. (A) Fraktionierung von Scpep1 ${ }^{+/+}$-Mausleberhomogenaten (B) Fraktionierung von Scpep $1^{-/-}$ Mausleberhomogenat. Detektiert wurden die Proteine lysosomalen Markerproteine Cathepsin D ( $\alpha$-CatD) und LAMP-1 ( $\alpha$-mLAMP-1), das mitochondriale Protein Porin ( $\alpha$-Porin), sowie die Scpep1 ( $\alpha$-Scpep1D2) und die Neomycinphosphotransferase-Domäne des Gene Trap Fusionsprotein ( $\alpha-\mathrm{NPT} 2)$. 
Die subzellulären Fraktionierungen aus Scpep1 ${ }^{+/+}$und aus Scpep $1^{-/-}$-Leberhomogenaten wurden im Western Blot untersucht (Abb. 4.17). Jeweils $250 \mu$ g Protein der Fraktionen N bis $\mathrm{S}$ und $50 \mu \mathrm{g}$ der Fraktionen F1 bis F4 wurden über SDS-PAGE unter reduzierenden Bedingungen aufgetrennt und geblottet. Der Blot wurde mit Antikörpern gegen die lysosomalen Proteine Cathepsin D (CatD) und LAMP-1, mit einem Antikörper gegen das mitochondriale Protein Porin und mit dem $\alpha$-Scpep1-D2-Antiserum, sowie mit einem Antiserum gegen die Neomycin-Phosphotransferase-Domäne (NPT2) des Gene Trap Fusionsproteins inkubiert. Im Western Blot ist die Anreicherung der lysosomalen Proteine LAMP-1 und Cathepsin D in der Fraktion L und F2 der Fraktionierung zu erkennen. Das mitochondriale Protein Porin wird hingegen hauptsächlich in Fraktion M detektiert und ist nach der Dichtegradientenzentrifugation in Fraktionen F3 und F4 zu finden. Das Scpep1-Protein kofraktioniert mit den lysosomalen Proteinen. In Fraktion F2 detektiert das $\alpha$-Scpep1-Antiserum ein starkes $34 \mathrm{kDa}$-Signal und ein weiteres schwaches Signal bei 18 kDa, jedoch kein 55 kDa großes Scpep1-Protein, wie bei der Scpep1-Aufreinigung (siehe Abb. 4.15) detektiert wurde. Das endogene Scpep1-Protein liegt im Lysosom in einer prozessierten Form vor.

Die subzelluläre Fraktionierung aus Scpep $1^{-/}$-Mausleberhomogenaten zeigte bei der Analyse der Fraktionen die gleiche prozentuale Verteilung der Markerenzymaktivitäten wie bei der Scpep $1^{+/+}$-Fraktionierung (Daten nicht angegeben), wobei in der Fraktion F2 eine 58-fache Anreicherung der $\beta$-Hexosaminidaseaktivität detektiert wurde. Im Western Blot zeigten alle nachgewiesenen Markerproteine die gleiche Signalverteilung wie bei einer Scpep $1^{+/+}$-Präparation. In den Fraktionen $\mathrm{L}$ und den Fraktionen des Dichtegradienten ist trotz Anreicherung der lysosomalen Proteine um den Faktor 58 in Fraktion F2 kein spezifisches Scpep1-Signal detektierbar. Mit Hilfe eines Antikörpers gegen die Neomycinphosphotransferasedomäne wurde die Lokalisation des Gene Trap Fusionsproteins untersucht. Das Fusionsprotein ist bei der Scpep $1^{-/-}$-Fraktionierung als $200 \mathrm{kDa}$ Signal in der mikrosomalen Fraktion P (Golgi/ER) nachweisbar, jedoch nicht in der lysosomalen Fraktion. 


\subsubsection{Untersuchung der Scpep1-Expression in Mausgewebe}

\subsubsection{Northern Blot Analyse}

Zur Analyse der gewebespezifischen Expression der Scpep1 in der Maus wurden Northern Blot Analysen an verschiedenen Geweben von RST426 Mäusen durchgeführt. Je $10 \mu \mathrm{g}$ RNA wurde im Agarose/Formaldehyd-Gel aufgetrennt, auf eine Hybond N Membran transferiert und mit einer cDNA Sonde gegen den 3'-Bereich der Scpep1mRNA hybridisiert (3'-Scpep1-Sonde, 8.3.6). Zur Normalisierung wurde der Northern Blot zusätzlich mit einer GAPDH Sonde hybridisiert (8.3.6).

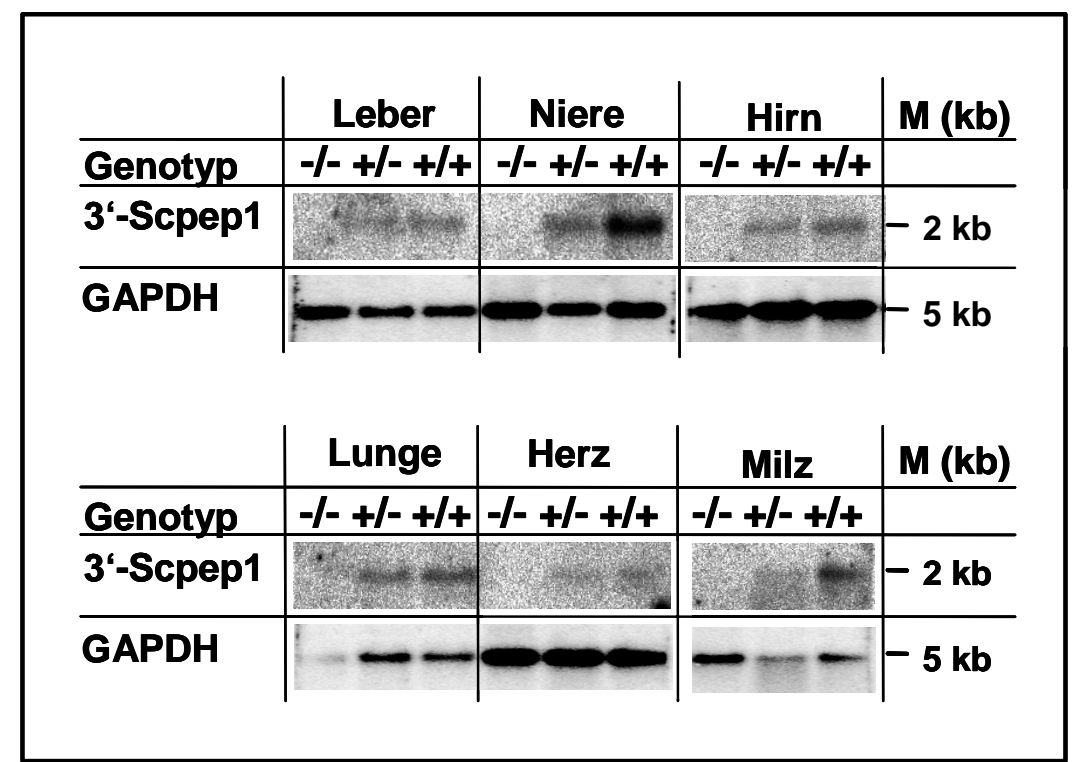

Abb. 4.18: Differentielle Northern Blot Analyse der Scpep1-Expression im RST426 Mausmodell

Differentielle Northern Blot Analyse an RNA von Scpep1 ${ }^{+/+}$, Scpep $^{+/-}$und Scpep $1^{-/-}$Mäusen der RST426. Zur Hybridisierung der Scpep1-mRNA wurde eine Northern Sonde verwendet die aus dem 3' Bereich der Scpep1-cDNA generiert wurde.

Im Northern Blot ist die Scpep1-mRNA als 2 kb-Bande nachweisbar. Die Scpep1-mRNA ist in der Niere am stärksten exprimiert. Bei der differentiellen Analyse der Scpep1 ${ }^{+/+}$, Scpep $1^{+/-}$- und Scpep $1^{-/-}$-mRNA im Northern Blot ist bei den heterozygoten Tieren eine Reduzierung der Signalintensität $\mathrm{zu}$ beobachten und bei der Scpep1 ${ }^{-/-}$-Mäusen ist erwartungsgemäß kein Scpep1-mRNA detektierbar, was auf eine effiziente Nutzung der Spleißakzeptorsequenz des Gene Trap Vektors schließen lässt. 


\subsubsection{Western Blot Analyse der Scpep1-Proteinexpression in Gewebe}

Zur Analyse der gewebespezifischen Expression des Scpep1-Proteins in der Maus wurde eine differentielle Western Blot Analyse durchgeführt. Dazu wurden je $200 \mu \mathrm{g}$ Gesamtprotein verschiedener Gewebe von Kontroll- und Scpep1 ${ }^{-/-}$-Mäusen über SDSPAGE aufgetrennt und auf eine PVDF-Membran übertragen. Zur Kontrolle wurden zudem Zellhomogenate von HT1080-Scpep1 und HT1080 analysiert. Der Western Blot wurde mit dem $\alpha$-Scpep1-Ratten-Antiserum, sowie mit einem Antiserum gegen die Neomycin-Phosphotransferase-Domäne ( $(\alpha-N P T 2)$ des Gene Trap Fusionsproteins analysiert. Als Ladekontrolle und zur Normalisierung des Scpep1-Signals wurde der Western Blot zusätzlich mit einem $\alpha$-GAPDH Antikörper inkubiert. Mit dem $\alpha$-Scpep1Ratten-Antiserum wurde in Scpep $1^{+/+}$-Geweben ein spezifisches $34 \mathrm{kDa}$ Scpep1-Signal detektiert (Abb. 4.19). Dieses 34 kDa-Fragment der Scpep1 war bereits bei der subzellulären Fraktionierung in der angereicherten lysosomalen Fraktion nachweisbar (siehe Abb. 4.17). In den HT1080-Scpep1 und den Scpep1 ${ }^{+/+}$-MEF wurde neben dem 34 kDa-Scpep1-Signal das 55 kDa-Scpep1-Protein detektiert. In Geweben konnte diese Scpep1-Proteinform hingegen nicht detektiert werden. Neben den spezifischen Scpep1-Signalen wird mit dem $\alpha$-Scpep1-Ratten-Antiserum in Scpep ${ }^{-/-}$-Geweben und im $\mathrm{MEF}^{+/+}$-Homogenat eine schwache 53 kDa-Bande detektiert die keinem Scpep1Signal zugeordnet werden kann und als unspezifisch eingestuft wird. 


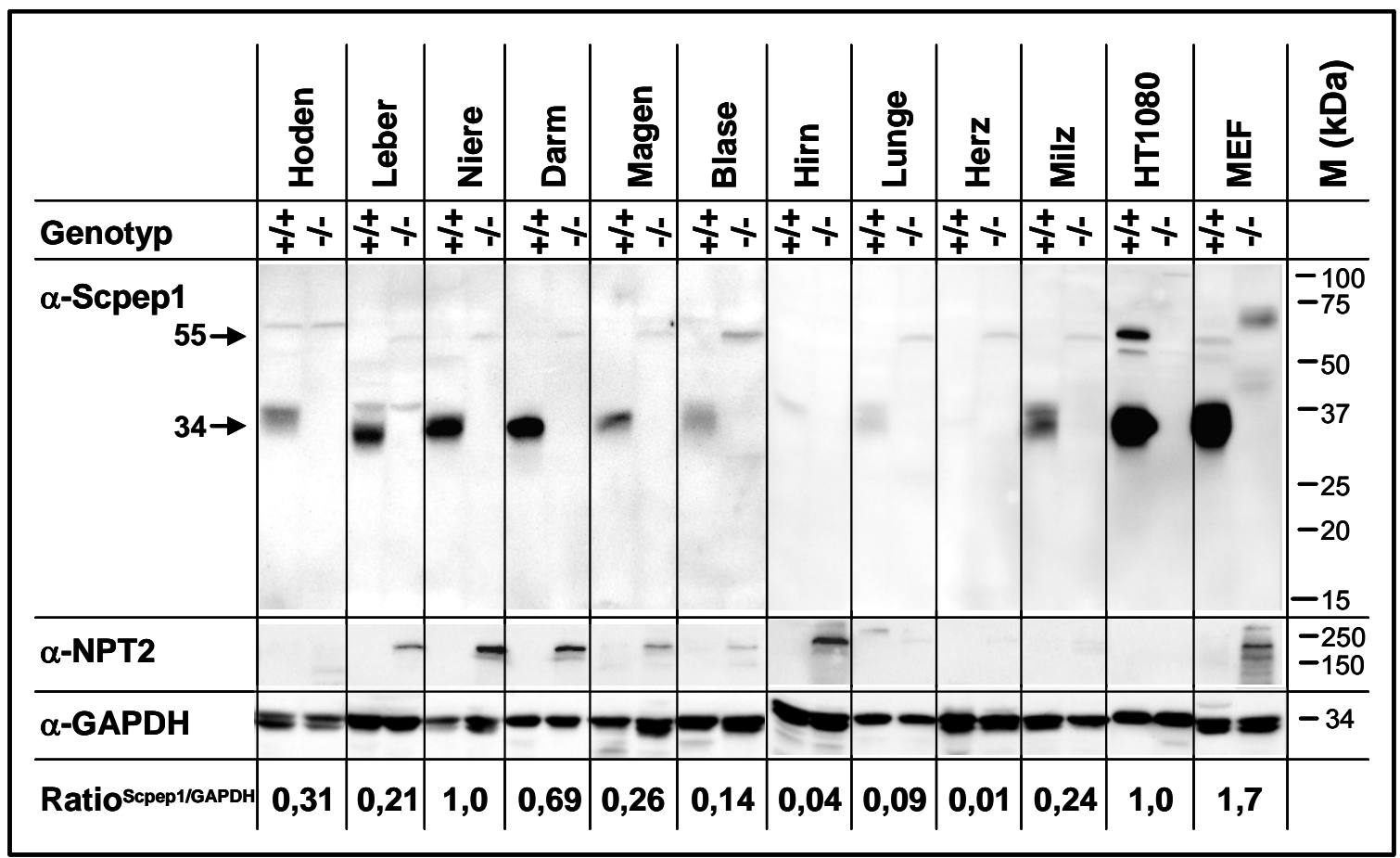

Abb. 4.19: Differentielle Western Blot Analyse der Scpep1-Expression im RST426 Mausmodell

Gewebe von Scpep1 $1^{+/+}$und Scpep1 ${ }^{-/}$Mäusen der RST426 Zucht wurden in TBS/1\%NP40/PI homogenisiert, $200 \mu \mathrm{g}$ der Gewebehomogenate und $50 \mu \mathrm{g}$ Zellhomogenat von HT1080 und stabil exprimierenden HT1080-Scpep1, sowie von embryonalen Mausfibroblasten wurden durch SDS-PAGE unter reduzierenden Bedingungen aufgetrennt und geblottet. Die Analyse der Western Blots erfolgte mit Scpep1-Antiseren aus Kaninchen (D2) und Ratte (1:500) und mit $\alpha$ NPT2- (1:1000) und $\alpha$-GAPDH (1:300) Antikörpern.

Die Scpep1 wird in MEF, Niere und Darm besonders stark exprimiert, während Leber, Milz, Hoden und Magen ein niedriges Expressionsniveau aufweisen. In den Gewebehomogenaten der Scpep1 $1^{-/}$-Mäuse konnte kein 34 kDa-Signal detektiert werden. Bei der Analyse mit dem $\alpha$-NPT2-Antiserum konnte im Gegenzug ein 200 kDa-Signal in den Geweben detektiert werden, in denen im Wildtyp eine erhöhte Scpep1-Expression detektiert wurde. Die Hirnhomogenate stellen dabei eine Ausnahme dar. Trotz einer geringen Expression des Scpep1-Proteins im Scpep1 ${ }^{+/+}$-Hirnhomogenat wurde im Scpep $1^{-/}$-Hirnhomogenat ein starkes Signal für das $200 \mathrm{kDa}-F u s i o n s p r o t e i n ~ d e t e k t i e r t$. Möglicherweise ist dies auf eine höhere Stabilität des Fusionsproteins im Gehirn zurückzuführen. 


\subsubsection{Darstellung der Scpep1-Expression durch LacZ-Reportergenfärbung in}

\section{Embryonen}

Zur Darstellung der Scpep1-Expression im Mausembryo wurden Scpep1 $1^{-/-}$Embryonen mit PFA fixiert und anschließend in einer X-Gal-Färbelösung inkubiert. Durch die $\beta$-GalReportergenaktivität des Gene Trap Fusionsproteins konnten Bereiche in denen das Scpep1-Protein exprimiert wird im embryonalen Gewebe blau angefärbt werden. Die gefärbten Embryonen wurden in Paraffin eingebettet. Anschließend wurden sagitale Schnitte angefertigt, die mit Eosin nachgefärbt wurden. In Abb. 4.20 sind Schnitte eines Scpep $^{-/}$-Embryos von Tag E12.5 dargestellt. Die Abbildung zeigt Teile des Gehirns (A) und das sich entwickelnde Innenohr (B). Im Anschnitt des Thorax sind Teile des Herzens (D) und der Lunge (E) zu sehen. Im abdominalen Bereich erkennt man den Magen und das Pankreas (F), sowie Teile des Mitteldarms (C). Retroperitoneal lassen sich die endgültige Nierenanlage (Metanephros) und die cranial davon gelegene Nebenniere (G) darstellen. Im Bereich des embryonalen Gehirns (A) sind Anschnitte eines lateralen, sowie des vierten Ventrikels zu sehen. In den Ventrikeln sind die Plexus choroidei zu erkennen, in deren Epithel eine starke Scpep1-Expression nachweisbar ist. Zudem findet man im Cortex cerebri und im Mesencephalon eine starke Scpep1-Expression. Bei der Anlage des Innenohres (B) sind die Epithelien der Cochlea und des Sacculus, sowie die Nervenzellen des Ganglion Vestibulocochleare (VIII) gefärbt. Im Herzen des Embryos (D) ist keine blaue Färbung zu erkennen. In der embryonalen Lunge (E) ist die Reportergenaktivität hauptsächlich in den Epithelien des Bronchialsystems detektierbar. In den Organen des Gastrointestinaltrakts, wie im Mitteldarm (D), im Eosophagus (G) und im Magen $(G)$ findet man in den Epithelien eine starke Scpep1-Expression. Zudem ist eine Färbung des Pankreas $(\mathrm{G})$ zu erkennen. In der Niere $(\mathrm{H})$ ist eine starke Färbung des sich ausbildenden Tubulussystems zu erkennen. Zudem ist in der Anlage der Nebenniere eine starke Reportergenaktivität nachweisbar, wobei die Aktivität im Nebennierenmark größer zu sein scheint als in der Nebennierenrinde. Insgesamt wird die Scpep1 im Embryo in vielen Organen exprimiert, wobei man eine erhöhte Expression in den Epithelien der Gewebe zu erkennen ist. 


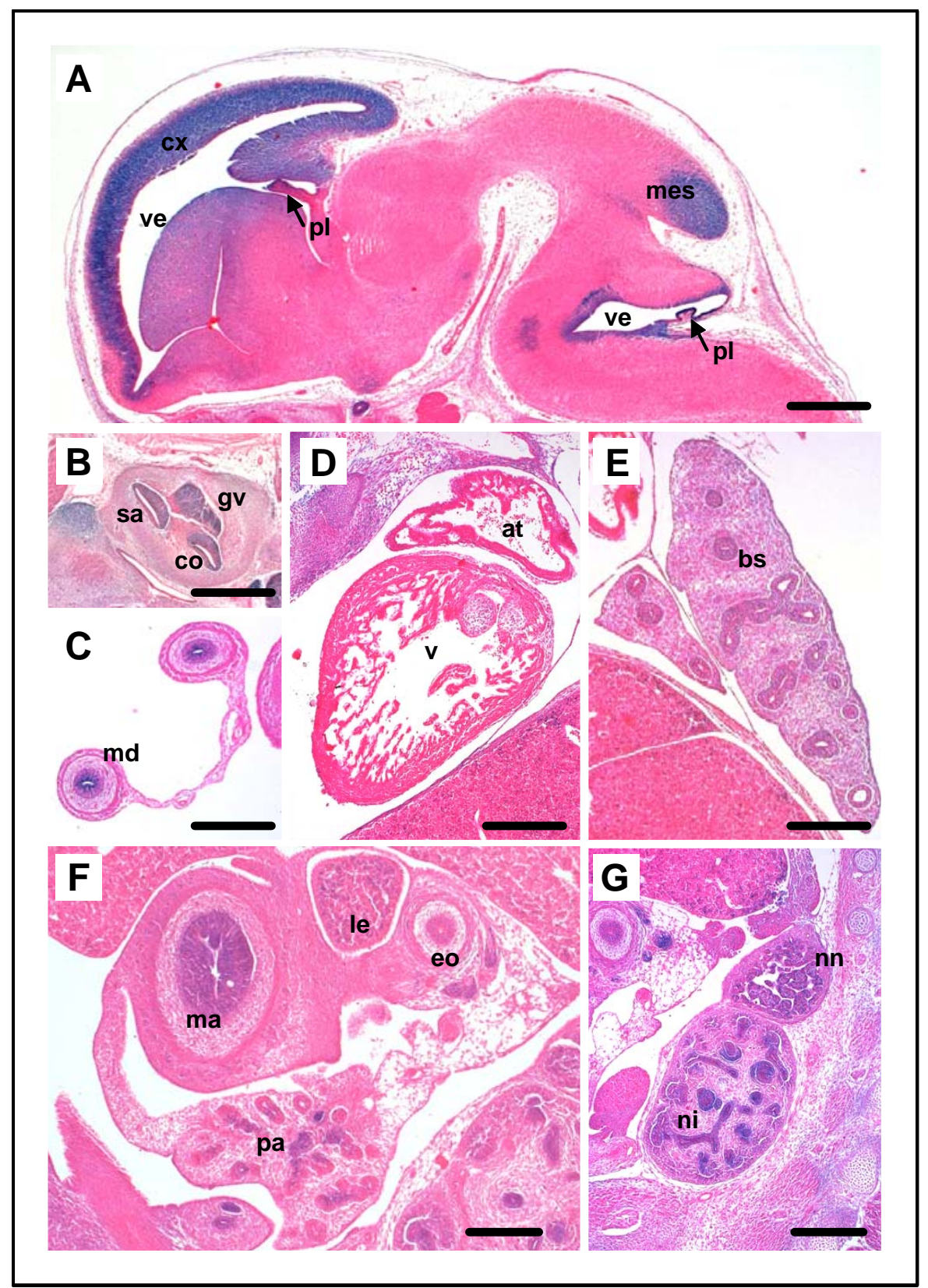

\section{Abb. 4.20: Gene Trap Reportergen-Färbung zur Darstellung der Scpep1-Expression in Embryonen e12,5}

Nach terminierter Verpaarung von RST426 Scpep ${ }^{-/-}$-Mäusen wurden die Scpep1 ${ }^{-/}$-Embryonen am Tag e12,5 entnommen, mit 4 \% PFA in PBS fixiert, anschließend mit einem Skalpell halbiert und in der X-GalFärbelösung inkubiert. Die X-Gal-gefärbten Präparate wurden über Nacht in $70 \%$ Ethanol inkubiert und am folgenden Tag in Paraffin eingebettet. Die Paraffinschnitte wurden zusätzlich mit Eosin gefärbt und eingebettet. Dargestellt sind sagitale Schnitte eines Scpep $1^{-/-}$-Embryonen e12.5. Abgebildet sind Schnitte des Gehirn (A), des entwickelnden Innenohrs (B), des Mitteldarms (C), des Herzens (D), der entwickelnden Lunge (E), des Magens und des Pankreas (F) sowie der entwickelnden Niere (G). at: Atrium ; bs: Bronchialsystem ; co: Cochlea ; cx: Cortex cerebri ; eo: Eosophagus ; gv: Ganglion Vestibulocochleare (VIII) ; le: Leber ; ma: Magen ; md: Mitteldarm ; mes: Mesencephalon ; ni: Niere ; nn: Nebenniere ; pa: Pankreas ; pl: Plexus choroidie ; sa: Saccule ; ve: Ventrikel ; Maßstab: $120 \mu \mathrm{m}$. 


\subsubsection{Darstellung der Scpep1-Expression durch Reportergenfärbung in adultem}

\section{Gewebe}

Zur Untersuchung der Scpep1-Expression in adultem Mausgewebe erfolgte eine X-GalReportergenfärbung auf $30 \mu \mathrm{m}$-Gewebeschnitten. Dazu wurden die PFA-fixierte Gewebe von 5 Monate alten Scpep1 $1^{-/-}$-Mäusen mit X-Gal-Färbelösung inkubiert. Die Schnitte wurden mit Eosin gegengefärbt und eingebettet. Um die Spezifität der Blaufärbung zu überprüfen, wurden zusätzlich Scpep1 ${ }^{+/+}$-Gewebe mit der X-Gal-Färbelösung inkubiert. In Abb. 4.21 ist die Gene Trap Reportergenfärbung in Nierengewebe dargestellt. In Scpep $^{-/-}$-Nieren-Schnitten (Abb. 4.21. A und B) ist nach Inkubation mit X-GalFärbelösung eine Blaufärbung der proximalen Tubuli zu erkennen. Die distalen Tubuli sowie die Glomeruli zeigen hingegen keine Reportergenfärbung. Die Zellen der proximalen Tubuli besitzen eine große Anzahl von Lysosomen, da im proximalen Tubulus Proteine aus dem Primärharn endozytiert und degradiert werden. Die starke Expression der Scpep1 in diesem Segment des Nephrons lässt vermuten, dass die Scpep1 an Degradationsprozessen in den Lysosomen der proximalen Tubuli beteiligt ist.

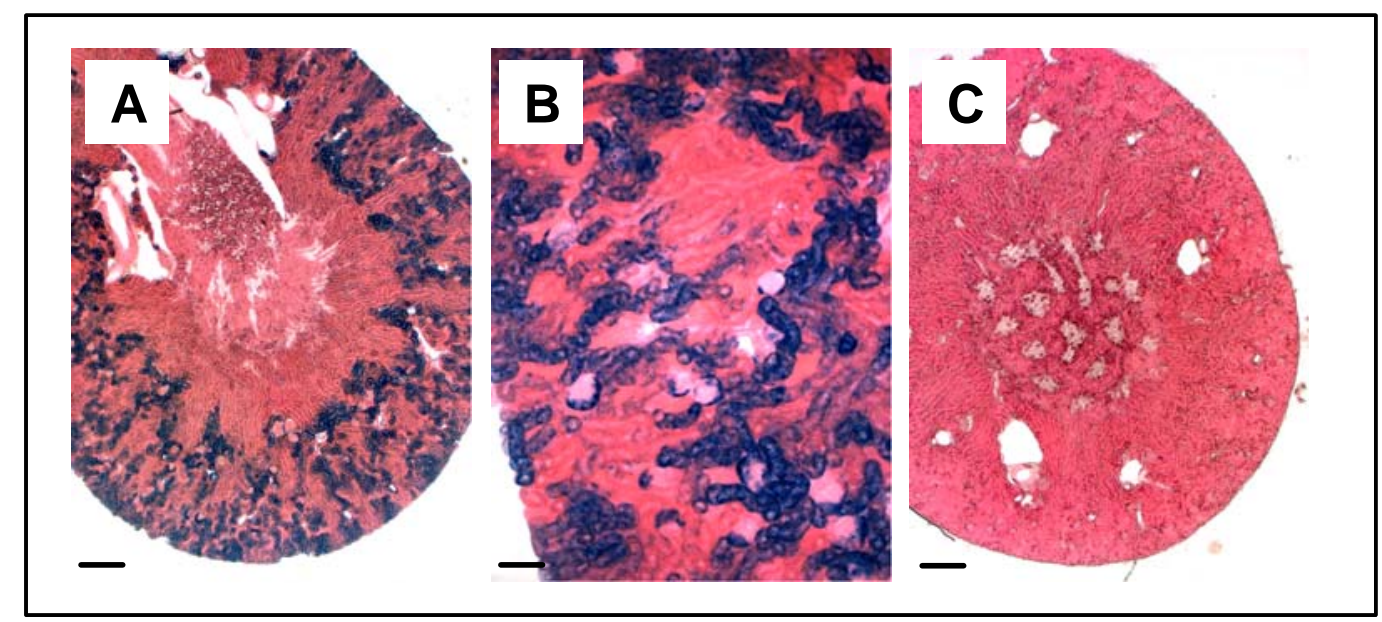

Abb. 4.21: Gene Trap Reportergenfärbung zur Darstellung der Scpep1-Expression in muriner Nieren

Zur Analyse der Scpep1-Expression in muriner Niere wurden $30 \mu \mathrm{m}$-Gewebeschnitte von PFA-fixierten

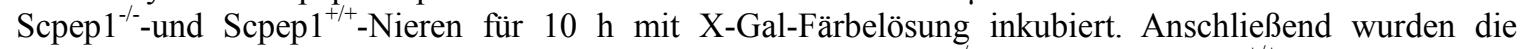
Schnitte mit Eosin gegengefärbt und eingebettet. (A), (B) Scpep $1^{-/-}$-Niere, (C) Scpep1 ${ }^{+/+}$-Niere. Maßstab: A,C $200 \mu \mathrm{m}$, B $50 \mu \mathrm{m}$. 
Im Oesophagus zeigen epitheliale Zellen eine spezifische, starke Reportergenfärbung (Abb. 4.22). Auf Schnitten von Magen- und Darmgewebe konnte die Gene Trap Reportergenfärbung hingegen nicht angewendet werden, da auch Scpep $1^{+/+}$Gewebeschnitte durch die Expression von endogener $\alpha$-Galactosidase stark unspezifisch angefärbt wurden.

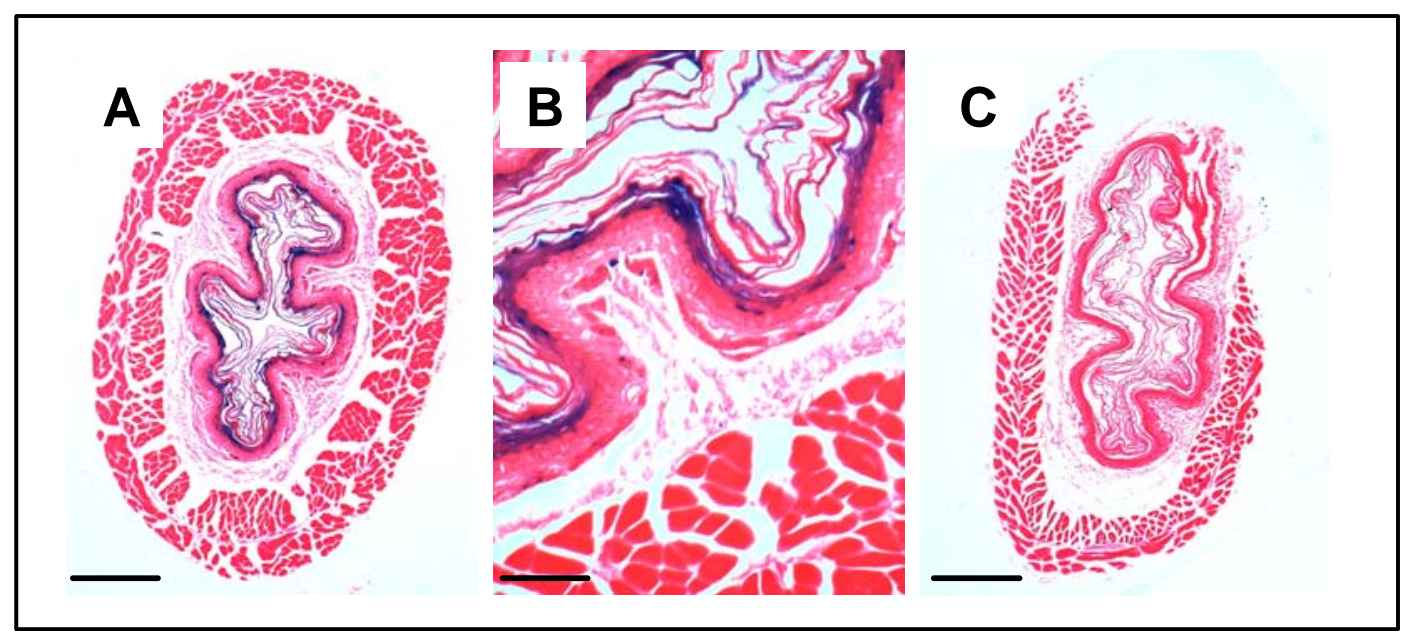

Abb. 4.22: Gene Trap Reportergenfärbung zur Darstellung der Scpep1-Expression im murinen Oesophagus

Zur Analyse der Scpep1-Expression im murinen Oesophagus wurden die PFA-fixierten Scpep ${ }^{-/}$-und Scpep $1^{+/+}$-Gewebe für $10 \mathrm{~h}$ mit X-Gal-Färbelösung inkubiert. Anschließend wurden sie in Paraffin eingebettet, geschnitten und mit Eosin gegengefärbt. (A), (B) Scpep $1^{-/}$-Oesophagus, (C) Scpep1 $1^{+/+}$ Oesophagus. Maßstab: A,C $200 \mu \mathrm{m}, \mathrm{B} 20 \mu \mathrm{m}$.

Im gesamten Gehirn konnte eine starke, spezifische Reportergenaktivität detektiert werden, wobei Nervenzellen im Hippocampus und im Cerebellum eine besonders starke Anfärbung zeigten (Abb. 4.23). Bei Schnitten von Leber, Milz, Herz und Lunge konnte auch nach 12 h Inkubation mit X-Gal-Färbelösung keine Blaufärbung detektiert werden. Möglicherweise ist dies auf eine $\mathrm{zu}$ geringe Scpep1-Expression in den Geweben zurückzuführen oder das Gene Trap Fusionsprotein wird in diesen Geweben nicht stabil exprimiert und schnell degradiert, so dass keine Reportergenaktivität detektiert werden kann. 

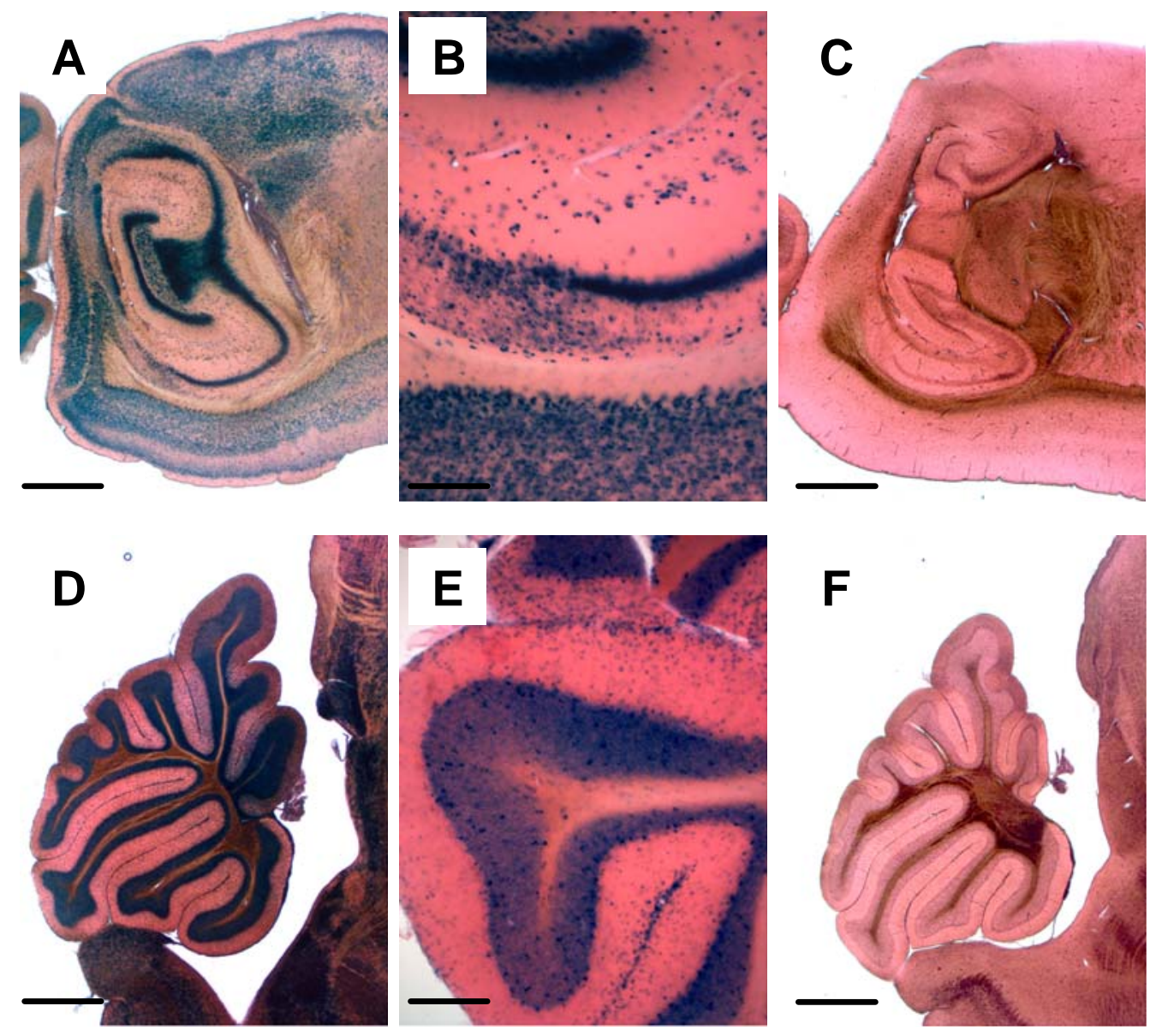

Abb. 4.23: Gene Trap Reportergenfärbung zur Darstellung der Scpep1-Expression im murinen Gehirn

Zur Analyse der Scpep1-Expression im murinen Gehirn wurden $30 \mu \mathrm{m}$-Gewebeschnitte von PFA-fixierten

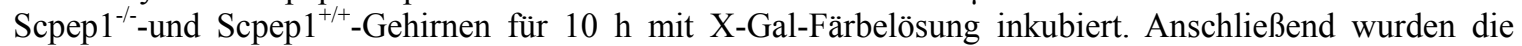
Schnitte mit Eosin gegengefärbt und eingebettet. (A), (B) Scpep1 ${ }^{-/-}$-Hippocampus, (C) Scpep1 $1^{+/+}$Hippocampus, (D), (E) Scpep1 $1^{-/-}$-Cerrebellum, (F) Scpep $1^{+/+}$-Cerrebellum. Maßstab: A,C $200 \mu$ m, B,E 20 $\mu \mathrm{m}, \mathrm{D}, \mathrm{F} 150 \mu \mathrm{m}$.

Immunhistologische Analysen zur Untersuchung der Scpep1-Expression in Gewebe wurden von Lee et al. (Lee et al. 2006) veröffentlicht. Lee beschreibt eine starke Expression von Scpep1 in den proximalen Tubuli der Niere, in den Bezegzellen des Magens und in den Lieberkuhn'schen Krypten und Zotten des Darm. Eine moderate Scpep1-Expression ist in Hepatozyten und in den Langerhans'schen Inseln des Pankreas nachweisbar. Zudem wurden in Lunge, Milz und Lymphknoten makrophagenartige Zellen mit einer starken Scpep1-Expression detektiert. Im Herz, sowie im Cerebellum und im Hippocampus des Gehirns konnte keine Scpep1 nachgewiesen werden. Mit Hilfe 
der Gene Trap Reportergenfärbung konnten die Ergebnisse der immunhistologischen Untersuchung von Lee zum Teil bestätigt werden. Die starke Scpep1-Expression in Niere und Oesophagus wurde durch beide Methoden detektiert. Die Expression in Leber, Milz und Lunge war durch die Reportergenfärbung nicht nachweisbar. Die Expression im Gehirn wurde hingegen nur durch die Reportergenfärbung detektiert.

\subsection{Molekulare Charakterisierung der Scpep1}

\subsubsection{Nachweis der Scpep1-Proteinfragmente exprimiert in HT1080}

Die Scpep1 wird als 55 kDa-Vorläuferprotein synthetisiert und später in eine 34 kDa-und eine $18 \mathrm{kDa}$-Form prozessiert. Um herauszufinden, aus welchem Bereich des Scpep1Vorläufers die detektierten Scpep1-Proteinfragmente entstehen, wurden zunächst Zellhomogenate und Medium von HT1080-Scpep1 und normaler HT1080, sowie eine Fraktion angereichert mit lysosomalen Proteinen (F2, 4.4.2.2) im Western Blot analysiert (Abb. 4.24). Im Western Blot wurde mit dem $\alpha$-His-Antikörper im Medium und in den Zellen der HT1080-Scpep1 das 55 kDa-Scpep1-Vorläuferprotein detektiert. Zusätzlich wurde ausschließlich in den HT1080-Scpep1 Zellen ein $18 \mathrm{kDa}$-Proteinfragment nachgewiesen, das somit das C-terminale Fragment des 55 kDa-Proteins darstellt. Untransfizierte HT1080 wiesen mit dem $\alpha$-His-Antikörper kein Signal auf. Bei der Auftrennung der Proteine unter nicht reduzierenden Bedingungen war keine Verschiebung der spezifischen Scpep1-Signale nachweisbar. Die 34 kDa- und 18 kDaScpep1-Fragmente sind offensichtlich nicht durch Disulfidbrücken miteinander verbunden. Mit dem $\alpha$-Scpep1-D2-Antiserum wurde in den Homogenaten der HT1080Scpep1 ein schwaches 55 kDa-Signal und ein starkes 34 kDa-Signal detektiert, zudem wurde im Medium der Zellen ein starkes 55 kDa-Signal detektiert. Das Scpep1-D2Antiserum erzeugte bei den Homogenaten untransfizierter HT1080 zusätzlich ein unspezifisches $60 \mathrm{kDa}$-Signal, zudem wurden im Medium bei etwa $50 \mathrm{kDa}$ und im hochmolekularen Bereich unspezifische Signale mit dem $\alpha$-Scpep1-D2-Antiserum detektiert. In der Fraktion angereicherter lysosomaler Proteine aus Mausleber (F2, siehe 4.4.2.2) wurde mit dem $\alpha$-Scpep1-D2-Antiserum ein starkes $34 \mathrm{kDa}$-Signal, ein schwaches $18 \mathrm{kDa}$-Signal und darüber hinaus ein $5 \mathrm{kDa}$-Signal detektiert. Ob es sich bei 
dem 5 kDa-Siganl un ein spezifisches Signal handelt konnte nicht geklärt werden. Das $\alpha$-Scpep1-Antiserum aus Ratte zeigte keine Immunreaktivität gegenüber den untransfizierten HT1080 Zellen und deren Medium. Im Zellhomogenat von HT1080Scpep1 wurden hingegen ein $55 \mathrm{kDa}$ - und ein $34 \mathrm{kDa}$-Signal, sowie ein schwaches $18 \mathrm{kDa}$-Signal nachgewiesen. Das Medium der HT1080-Scpep1 zeigte ein starkes $55 \mathrm{kDa}$ - und ein schwaches 34 kDa-Signal. Bei der Analyse der Lysosomenfraktion (F2, siehe 4.4.2.2) wurden ein schwaches $55 \mathrm{kDa}$-Signal, ein starkes $34 \mathrm{kDa}$-Signal und ein schwaches $18 \mathrm{kDa}$-Signal identifiziert.

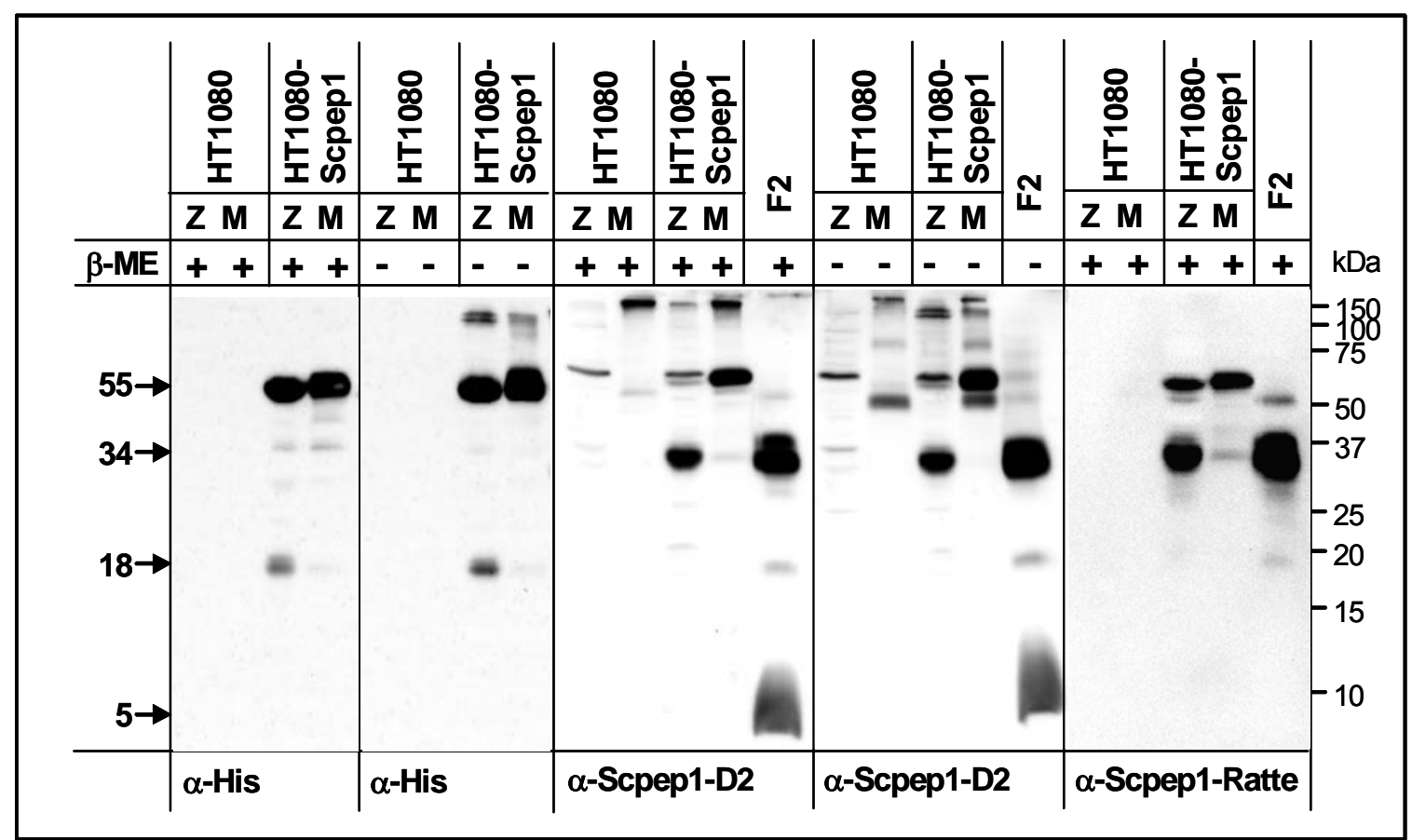

Abb. 4.24: Western Blot Analyse der Scpep1-Formen in überexprimierenden HT1080 und in der Fraktion F2 nach subzellulärer Fraktionierung

Protein aus $100 \mu \mathrm{g}$ Zellhomogenat und $50 \mu \mathrm{l}$ Medium Scpep1-RGS-His6 überexprimierender HT1080 wurde durch SDS-PAGE unter reduzierenden und nicht reduzierenden Bedingungen aufgetrennt und anschließend im Western Blot mit $\alpha$-Scpep1-Antiseren und $\alpha$-His-Antikörper analysiert.

\subsubsection{N-Glykosylierung der Scpep1 exprimiert in HT1080}

Die Scpep1-Aminosäuresequenz enthält fünf putative N-Glykosylierungssequenzen, von denen vier im N-terminalen und eine im C-terminalen Sequenzbereich lokalisiert sind. 
Zur Untersuchung der Glykosylierung der Scpep1 wurden Zellhomogenate von HT1080Scpep1 bis zu sechs Stunden mit N-Glykosidase F inkubiert, durch SDS-PAGE aufgetrennt und im Western Blot mit einem $\alpha$-His-Antikörper und dem $\alpha$-Scpep1-RattenAntiserum analysiert (Abb. 4.25).

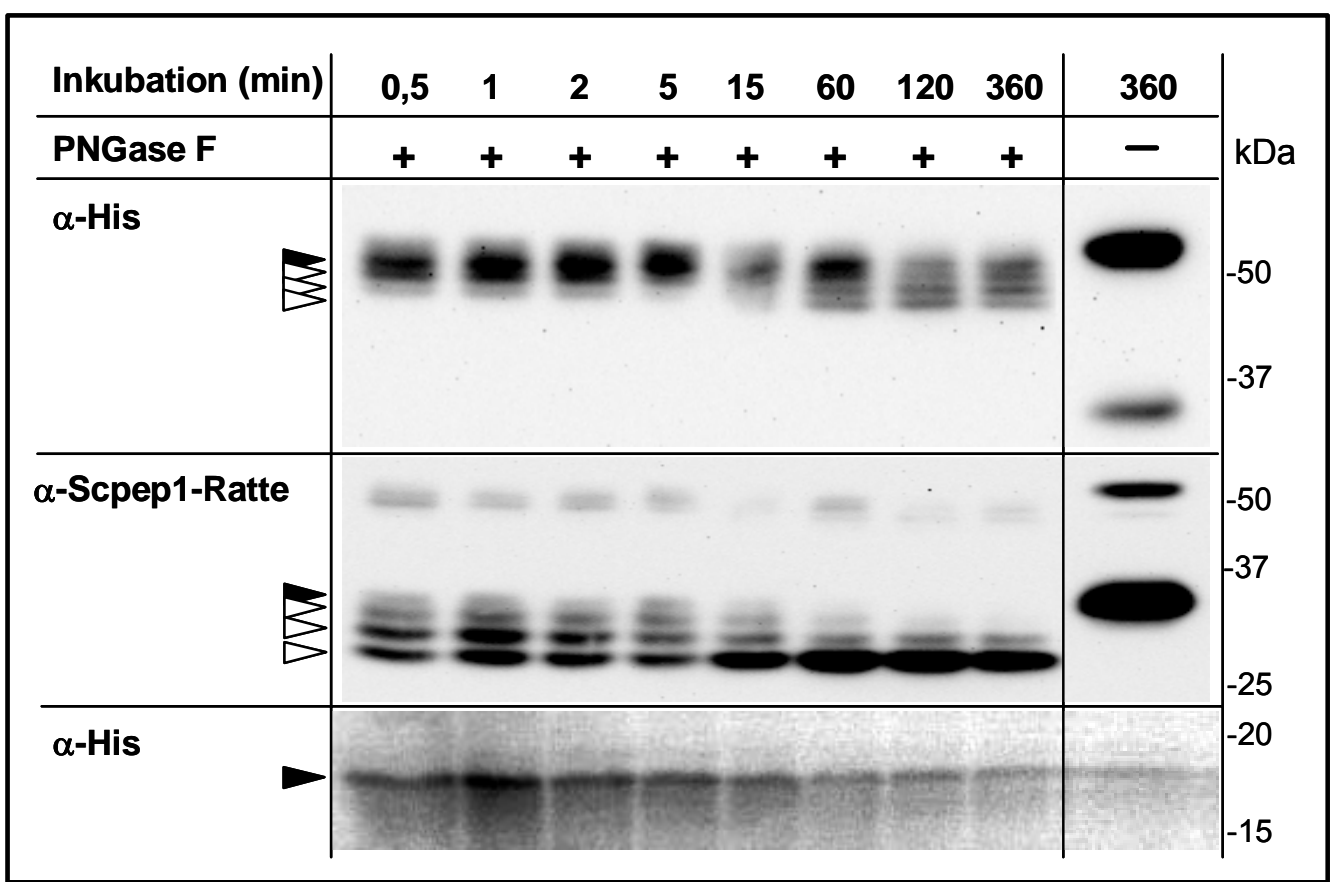

\section{Abb. 4.25: Deglykosylierung der Scpep1 mit N-Glykosidase F}

Jeweils $25 \mu$ g Protein aus Zellhomogenaten von Scpep1-RGS-His6 überexprimierenden HT1080 wurden bis zu 6 h mit N-Glykosidase F (PNGaseF) inkubiert. Anschließend wurden die Proteine durch SDS-PAGE separiert und im Western Blot mit $\alpha$-Scpep1-Ratten-Antiserum und $\alpha$-His-Antikörper analysiert. Die schwarzen Pfeile weisen auf die glykosylierte Form der Scpep1. Die weißen Pfeile zeigen auf die deglykosylierten der Scpep1.

Mit dem $\alpha$-His-Antikörper wurde das $55 \mathrm{kDa}$ - und das $18 \mathrm{kDa}$-Fragment der Scpep1 nachgewiesen. Dabei konnte für das $18 \mathrm{kDa}$-Signal keine Größenverschiebung beobachtet werden, was gegen eine Glykosylierung des Fragments spricht. Die $55 \mathrm{kDa}$-Form wurde innerhalb von sechs Stunden über zwei intermediäre Proteinformen nur unvollständig $\mathrm{zu}$ einer $48 \mathrm{kDa}$-Proteinform deglykosyliert, während das $34 \mathrm{kDa}$-Scpep1-Fragment zeitgleich fast vollständig über zwei Zwischenformen zu einem 28 kDa-Proteinfragment deglykosyliert wurde. Diese Befunde weisen auf eine dreifache N-Glykosylierung der Scpep1 in den HT1080 Zellen hin, wobei die 3 N-Glykosylierungsstellen im Sequenzbereich des 34 kDa-Fragments lokalisiert sind. 


\subsubsection{Biosynthese und Prozessierung der Scpep1}

In Western Blot Analysen konnte neben der $55 \mathrm{kDa}$-Vorläuferform der Scpep1 eine $34 \mathrm{kDa}$ - und eine $18 \mathrm{kDa}$-Form des Proteins identifiziert werden. Zur Untersuchung der Prozessierungskinetik und der Halbwertszeit der Scpep1-Proteinformen wurden Scpep $^{+/+}$-MEF für $1 \mathrm{~h}$ mit ${ }^{35} \mathrm{~S}$-Methionin metabolisch markiert. Nach verschiedenen Inkubationszeiten (Chase) wurde das Scpep1-Protein in den Zellen und im Medium mit dem $\alpha$-Scpep1-Ratten-Antiserum immunopräzipitiert, durch SDS-PAGE aufgetrennt und durch Autoradiografie analysiert. Zur Identifizierung von spezifischen und unspezifischen Signalen wurde das Experiment parallel mit Scpep1 ${ }^{-/-}$-MEF durchgeführt (nicht abgebildet).

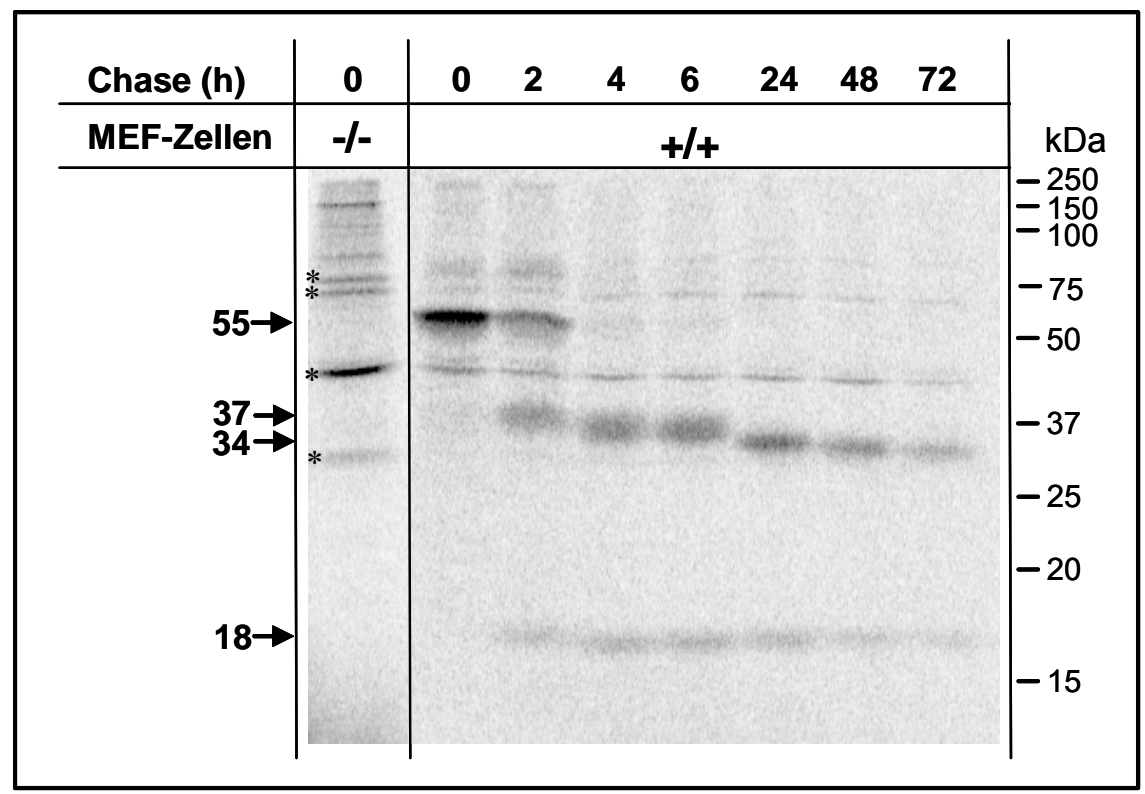

Abb. 4.26: Prozessierung der Scpep1 in Mausembryonalen Fibroblasten

Scpep ${ }^{+/+}$- und Scpep ${ }^{1--}$-MEF wurden $1 \mathrm{~h}$ mit ${ }^{35}$ S-Methionin markiert und anschließend zwischen $0 \mathrm{~h}$ und $72 \mathrm{~h}$ inkubiert. Die Scpep1 wurde mit $\alpha$-Scpep1-Ratten-Antiserum aus Zelllysaten und Medium immunpräzipitiert, durch SDS-PAGE separiert und audioradiografisch detektiert. Unspezifische Signale sind durch * gekennzeichnet.

Nach metabolischer Markierung konnte das $55 \mathrm{kDa}-$ Scpep1-Vorläuferprotein in den MEF-Zellen detektiert werden (Abb. 4.26). Nach zwei Stunden Inkubation konnten noch etwa $50 \%$ des $55 \mathrm{kDa}$-Signals und zusätzlich ein intermediäres $37 \mathrm{kDa}$-Fragment und das 18 kDa-Fragment detektiert werden. Nach vier bis sechs Stunden war das 55 kDa- 
Signal nicht mehr nachzuweisen, während die Signalstärken des 37 kDa- und des 18 kDaSignals konstant blieben. 24 Stunden nach der Markierung war das komplett prozessierte $34 \mathrm{kDa}$-Fragment und das $18 \mathrm{kDa}$-Fragment nachweisbar. Nach 48 Stunden reduzierte sich die Signalintensität der Fragmente und nach 72 Stunden wurde nur noch etwa $5 \%$ des Ausgangssignals detektierbar. Im Medium konnten zu keinem Zeitpunkt spezifische Scpep1-Signale detektiert werden (nicht abgebildet).

\subsubsection{Inhibierung der Scpep1-Prozessierung durch $\mathrm{NH}_{4} \mathrm{Cl}$}

Die Behandlung von Zellen mit Ammuniumchlorid $\left(\mathrm{NH}_{4} \mathrm{Cl}\right)$ führt zur Erhöhung des endosomalen/lysosomalen $\mathrm{pH}-$ Werts auf $\mathrm{pH}$ 6,0 bis $\mathrm{pH}$ 6,3, wodurch die Dissoziation M6P-markierter Proteine von den M6P-Rezeptoren im späten Endosomen blockiert wird (Braulke et al. 1987). Dies führt wiederum dazu, dass alle MPR besetzt bleiben und neu synthetisierte M6P-markierte Proteine sezerniert werden. Es ist jedoch zu beachten, dass der Transport einiger lysosomaler Proteine MPR-unabhängig erfolgt (z. B. Glucocerebrosidase) (Dittmer et al. 1999). HT1080 und HT1080-Scpep1 wurden in An- und Abwesenheit von $20 \mathrm{mM}$ Ammoniumchlorid metabolisch markiert und $0 \mathrm{~h}$ bis $24 \mathrm{~h}$ weiter kultiviert. Anschließend erfolgte die Immunpräzipitation der Scpep1 mit dem $\alpha$-Scpep1-Ratten-Antiserum. In untransfizierten HT1080 und in ihrem Medium wurde kein Scpep1-spezifisches Signal detektiert (Abb. 4.27). In HT1080-Scpep1 wurde zunächst die $55 \mathrm{kDa}$-Vorläuferform der Scpep1 detektiert. In den nicht $\mathrm{NH}_{4} \mathrm{Cl}$ behandelten HT1080-Scpep1 wurde die Scpep1 intrazellulär über eine intermediäre $37 \mathrm{kDa}$-Form zu einem 34 kDa-Scpep1-Fragment prozessiert. Zudem wurde die $55 \mathrm{kDa}$ Form der Scpep1 ins Medium der HT1080-Scpep1 sezerniert. In $\mathrm{NH}_{4} \mathrm{Cl}$-behandelten HT1080-Scpep1 wurde hingegen kein $37 \mathrm{kDa}$ - und kein 34 kDa-Signal nachgewiesen. Zudem wies die $55 \mathrm{kDa}$-Vorläuferform in $\mathrm{NH}_{4} \mathrm{Cl}$-behandelten HT1080-Scpep1 eine längere Halbwertszeit als in unbehandelten Zellen auf. Nach sechs Stunden ist in behandelten HT1080-Scpep1 noch $15 \%$ des $55 \mathrm{kDa}$-Signals detektierbar. In unbehandelten HT1080-Scpep1 ist das 55 kDa-Signal hingegen nach sechs Stunden auf $<5 \%$ reduziert. Das Scpep1-Protein wird vollständig sezerniert und sammelt sich im

Medium an. Das $18 \mathrm{kDa}$-Fragment ist in HT1080-Scpep1 nach einer Stunde 
metabolischer Markierung nicht nachweisbar. Das 18 kDa-Fragment kann erst nach längerer metabolischer Markierung (6 - 8 h) in HT1080-Scpep1 detektiert werden.

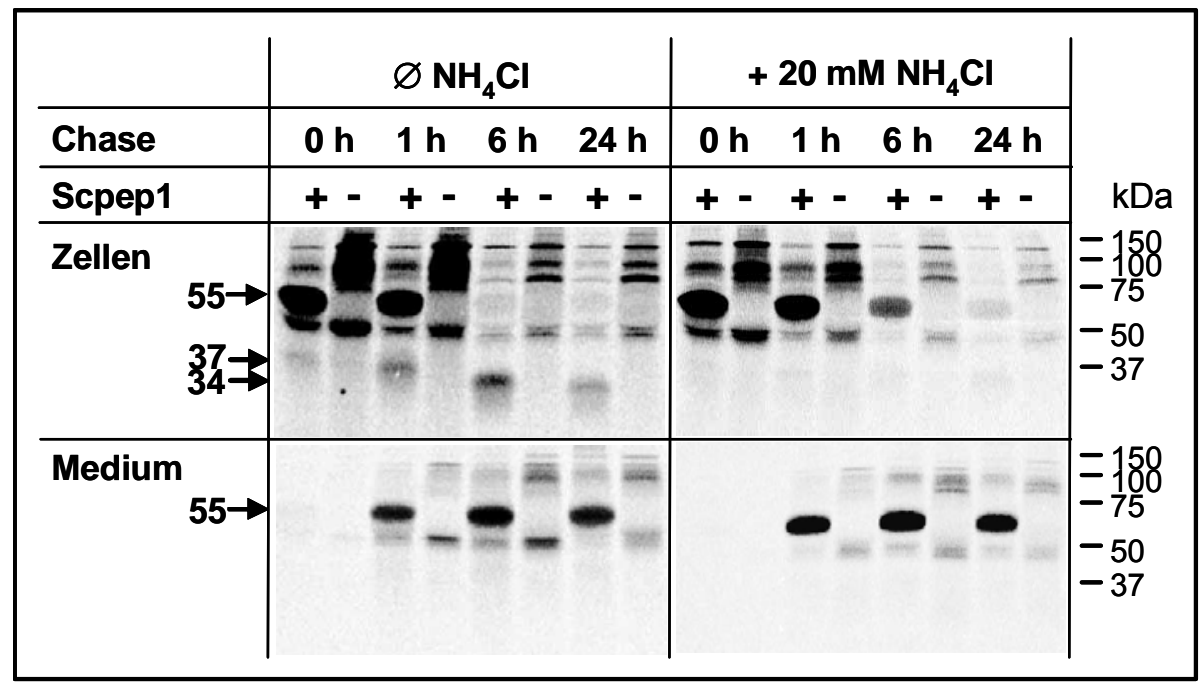

Abb. 4.27: Prozessierung der Scpep1 in überexprimierenden HT1080 nach Inkubation der Zellen mit Ammoniumchlorid

Untransfizierte (-) HT1080 und HT1080-Scpep1 (+) wurden mit $20 \mathrm{mM} \mathrm{NH4Cl}$ inkubiert. Nach $24 \mathrm{~h}$ wurden die $\mathrm{NH}_{4} \mathrm{Cl}$ behandelten und unbehandelte Zellen für $1 \mathrm{~h}$ mit ${ }^{35} \mathrm{~S}$-Methionin markiert und anschließend $0 \mathrm{~h}$ bis $24 \mathrm{~h}$ weiter kultiviert. Das Scpep1-Protein wurde mit $\alpha$-Scpep1-Ratten-Antiserum aus Zelllysaten und Medium immunpräzipitiert, durch SDS-PAGE separiert und autoradiografisch detektiert. Unspezifische Signale sind dadurch erkennbar, dass sie in HT1080 (+) und (-) enthalten sind.

\subsubsection{Modell zur Prozessierung der Scpep1}

Die Scpep1-Protein kodiert für ein 452 Aminosäuren langes Polypeptid. Die Untersuchung des exprimierten Scpep1-Proteins zeigte, dass das Scpep1-Protein mehrfach prozessiert wird. Aus den Überständen von HT1080-Scpep1 Zellen konnte ein $55 \mathrm{kDa}$-Vorläuferprotein der Scpep1 aufgereinigt werden, dass im Western Blot durch das C-terminale RGS-His6-Peptid detektiert wurde (4.4.1.1). Die N-terminale Sequenzierung des 55 kDa-Vorläuferproteins identifizierte Ile29 als N-terminale Aminosäure (4.4.1.1). In Western Blot Analysen mit HT1080-Scpep1 Zellhomogenaten und Medien konnte mit einem RGS-His6-spezifischen Antikörper neben dem 55 kDa-Vorläuferprotein ein Cterminales $18 \mathrm{kDa}$-Scpep1-Fragment in den Zellen identifiziert werden. Zudem detektierte ein Scpep1-spezifisches Antiserum ein $34 \mathrm{kDa}-S c p e p 1-F r a g m e n t$ in den Zellen (4.5.1). Metabolische Markierung mit anschließender Immunpräzipitation des 
Scpep1-Proteins bestätigten, dass das $55 \mathrm{kDa}$ große Scpep1-Vorläuferprotein in MEF zu einem $34 \mathrm{kDa}$-Fragment und einem $18 \mathrm{kDa}$-Fragment prozessiert wird, wobei bei der Prozessierung des $34 \mathrm{kDa}$-Peptids zunächst eine intermediäre $37 \mathrm{kDa}-F o r m$ entsteht (4.5.3). Eine limitierte Deglykosylierung des Scpep1-Vorläuferproteins und der Scpep1Proteinfragmente zeigte, dass drei der fünf $\mathrm{N}$-Glykosylierungssequenzen genutzt werden und diese ausschließlich auf dem 34 kDa-Fragment des Proteins lokalisiert sind (4.5.2). Vier der fünf putativen N-Glykosylierungsstellen sind im N-terminalen Scpep1Sequenzbereich lokalisiert. Dies bestätigt wiederum, dass das $34 \mathrm{kDa}-F r a g m e n t$ aus dem N-terminalen Sequenzbereich der Scpep1 stammt. Mittels N-terminaler Sequenzierung nach einer in vitro-Prozessierung des $55 \mathrm{kDa}$-Proteins mit katalytischen Mengen lysosomaler Proteine konnte Ile29 als N-terminale Aminosäure des 37 kDa-Fragments identifiziert werden (Daten nicht gezeigt). Die N-Termini des 34 kDa- und des 18 kDaFragments konnte hingegen nicht identifiziert werden.

Bei der Prozessierung des $55 \mathrm{kDa}$ - Vorläuferproteins erfolgt zunächst eine proteolytische Spaltung, wobei ein $18 \mathrm{kDa}$-Fragment und eine intermediäre $37 \mathrm{kDa}$-Proteinform entstehen. Bei der anschließenden Prozessierung des $37 \mathrm{kDa}$-Intermediats zur $34 \mathrm{kDa}-$ Form des Scpep1-Porteins kann es sich hingegen um einen weiteren Proteolyseschritt oder um eine Prozessierung des Kohlenhydratanteils handeln. 


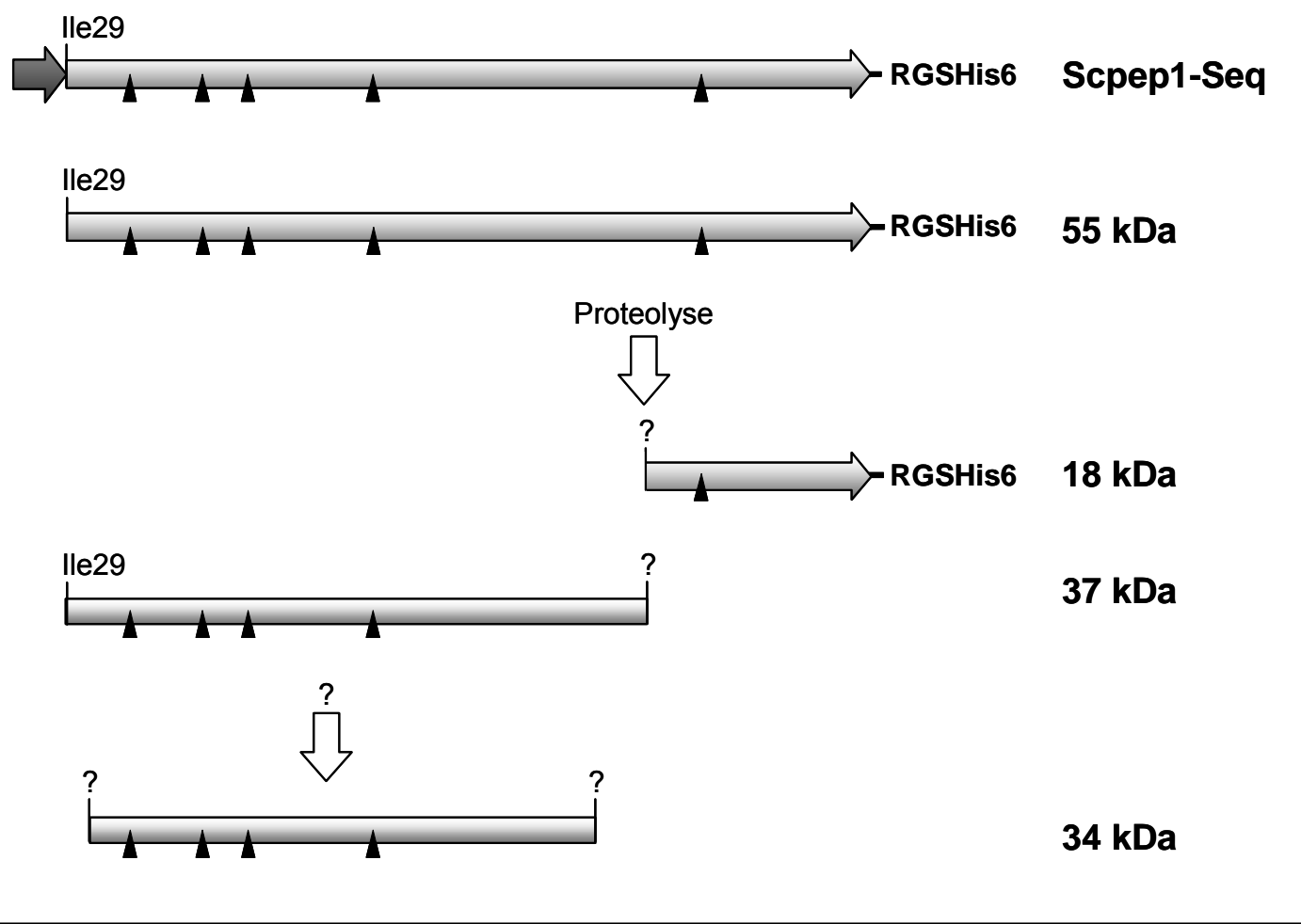

Abb. 4.28: Schematische Darstellung der Scpep1-Prozessierung

Im Western Blot von HT1080-Scpep1 und durch Immunpräzipitation des Scpep1-Proteins nach metabolischer Markierung können vier spezifische Proteinformen der Scpep1 mit einer Größe von 55 kDa, $37 \mathrm{kDa}, 18 \mathrm{kDa}$ und $34 \mathrm{kDa}$ detektiert werden. Durch N-terminale Sequenzierung, Deglykosylierung und mit Hilfe des C-terminalen RGS-His6-Peptidtags können die detektierten Proteinfragmente teilweise der Scpep1-Sequenz zugeordnet werden. $\boldsymbol{\Delta}$ putative N-Glykosylierungsstelle, dunkelgrauer Pfeil: N-terminales Signalpeptid.

\subsubsection{Analyse der endogenen Scpep1 durch Gelfiltration-Chromatografie}

$50 \mu \mathrm{g}$ einer Fraktion angereicherter lysosomaler Proteine (F2, siehe 4.4.2.2) wurde auf einer Superdex 75 sowie auf einer Superdex 200 Gelfiltrationssäule aufgetrennt und fraktionsweise im Western Blot analysiert. Bei der Gelfiltration eluieren das $34 \mathrm{kDa}$ - und das $18 \mathrm{kDa}$-Fragment der Scpep1 gemeinsam. Die Elution erfolgt dabei analog zu dem 67 kDa großen Standardprotein Albumin. Die lässt darauf schließen, dass die Scpep1Fragmente nach der Prozessierung weiter interagieren und einen etwa $70 \mathrm{kDa}$ großen Komplex bilden. Zudem kann die Bindung eines weiteren Bindungspartners an die heterodimere Scpep1-Form aufgrund des apparenten Laufverhaltens der Scpep1Fragmente nicht ausgeschlossen werden. 


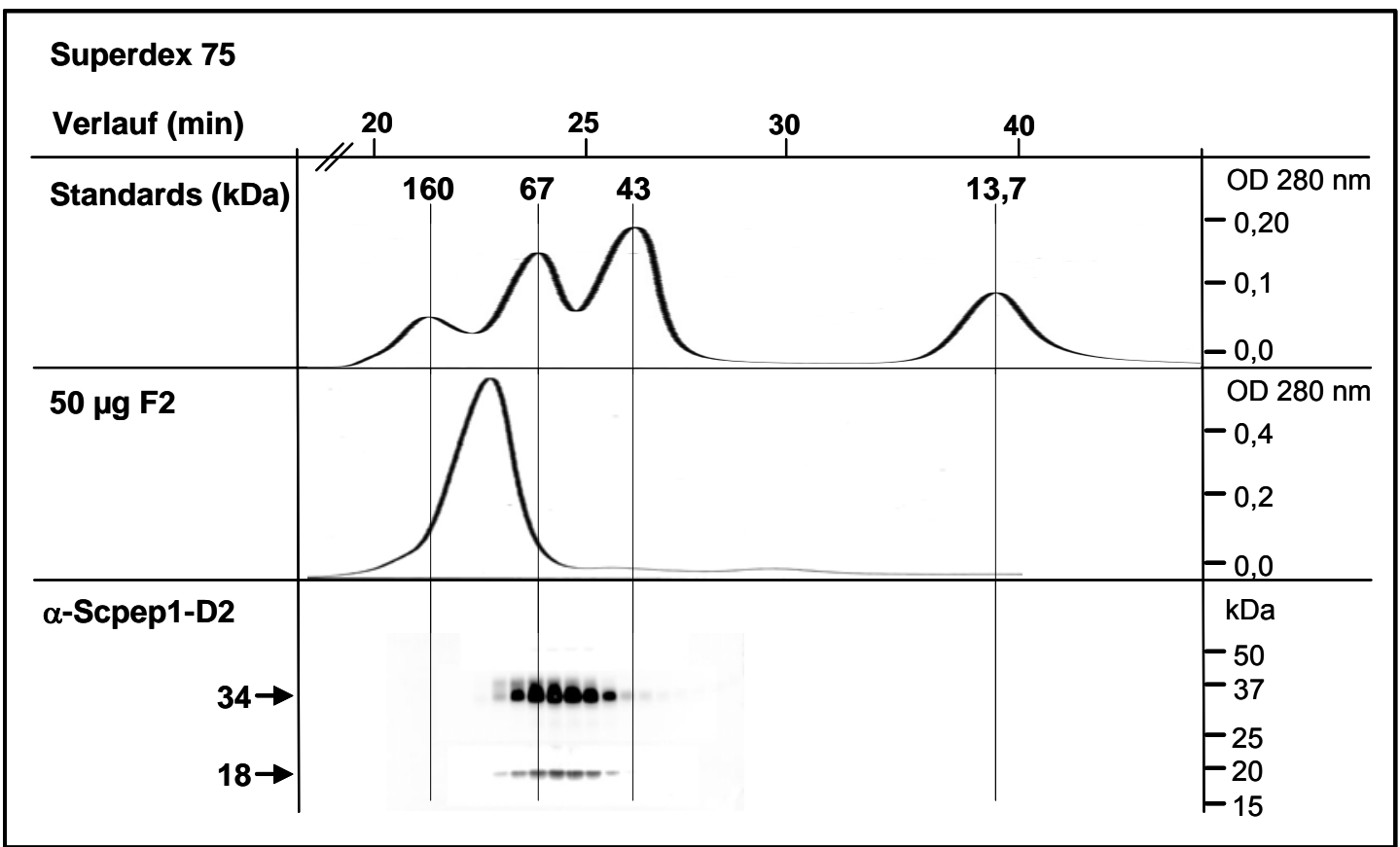

Abb. 4.29: Superdex 75-Gelfiltration von angereichertem, lysosomalem Protein

$50 \mu \mathrm{g}$ Protein einer Fraktion angereicherter lysosomaler Proteine (F2, siehe 4.4.2.2) wurden in AcetatPuffer pH 4,5 aufgenommen und bei einer Flußrate von $40 \mu \mathrm{l} / \mathrm{min}$ auf einer Superdex 75 Gelfiltrationssäule aufgetrennt. Anschließend wurden die Fraktionen der Gelfiltration im Western Blot mit dem $\alpha$-Scpep1-D2 Serum untersucht. Zur Bestimmung der molekularen Größe der Proteine in den Gelfiltrationsfraktionen erfolgte unter gleichen Bedingungen ein Gelfiltrationslauf mit den Standardproteinen Immunglobulin $G$ (160 kDa), Albumin (67 kDa), Ovalbumin (43 kDa) und Ribonuklease A (13,7 kDa).

\subsection{Enzymatische Aktivität der Scpep1}

\subsubsection{Untersuchung des rekombinanten Scpep1-Proteins auf Carboxypeptidase} Aktivität

Die Scpep1 wird der Familie S10 der SC zugeordnet, deren bekanntesten Vertreter die CPY aus S. cerevisiae und das PPCA sind. Beide Serincarboxypeptidasen besitzen ein pH-Optimum im sauren Bereich und zeigen hohe Affinität gegenüber Peptiden mit hydrophoben C-terminalen Peptiden. Die Serincarboxypeptidaseaktivität der Scpep1 wurde in vitro mittels artifizieller N-blockierter Dipeptide anhand der Freisetzung der Cterminalen Aminosäure bestimmt (3.5.7). Bei der Inkubation von $0,5 \mathrm{mM}$ CBZ-Phe-Leu-OH mit steigenden Konzentrationen rekombinanter CPY konnte eine $\mathrm{pH}$-, zeit- und dosis-abhängige proteolytische Aktivität bestimmt werden. Bei der Inkubation 
des Substrats mit steigenden Konzentrationen des aufgereinigten Scpep1-55kDaVorläuferproteins war hingegen keine proteolytische Aktivität nachweisbar. Das Scpep1Vorläuferprotein besitzt offensichtlich keine enzymatische Aktivität.

Im nächsten Schritt wurde die proteolytische Aktivität in Zellhomogenaten von normalen HT1080 und HT1080-Scpep1 untersucht. Dazu wurde 0,5 mM CBZ-Phe-Leu-OH mit $20 \mu \mathrm{g}$ Zellhomogenat in MES/EDTA-Puffer $\mathrm{pH}$ 4,5 inkubiert. Das EDTA im Puffer inhibiert Metalloproteasen im Homogenat, so dass ausschließlich die proteolytische Aktivität der sauren Serincarboxypeptidasen gemessen wird. Trotz der nachweislich hohen Expressionsrate der Scpep1 in stabil transfizierten HT1080 konnte in den Zellhomogenaten der HT1080-Scpep1 keine Erhöhung der Serincarboxypeptidaseaktivität bestimmt werden (Abb. 4.30).

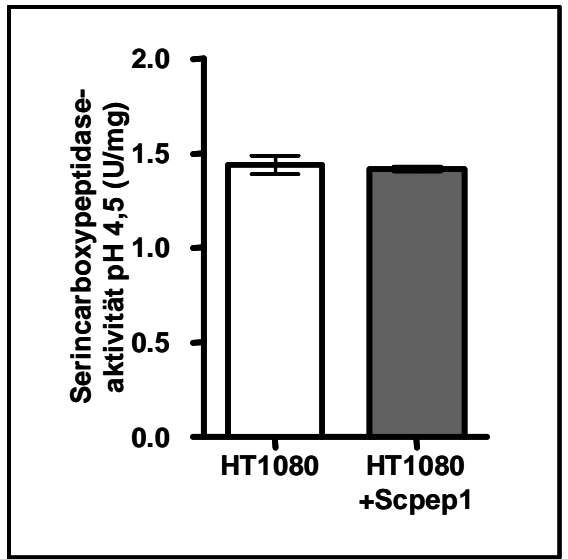

Abb. 4.30: Bestimmung der Serincarboxypeptidase-Aktivität in Scpep1-RGS-His6 exprimierenden HT1080

Zur Bestimmung der Serincarboxypeptidase-Aktivität in Zellhomogenaten von HT1080 und HT1080-Scpep1 wurden jeweils $20 \mu \mathrm{g}$ Zellhomogenat mit $0,5 \mathrm{mM}$ CBZ-Phe-Leu-OH in 100 mM MES/2 mM EDTA pH 4,5 inkubiert. Anschließend wurde die Konzentration freier Aminosäuren durch Ninhydrinfärbung photometrisch bestimmt. ( $\mathrm{n}=1$ Zellklon; je 4 technische Replikate)

\subsubsection{Bestimmung der Serincarboxypeptidaseaktivität in Homogenaten von embryonalen Mausfibroblasten und Geweben Scpep1-defizienter Mäuse}

Die Scpep1-Aktivität wurde in verschiedenen Geweben von Scpep1 ${ }^{+/+}$- und Scpep1 $1^{-/}$Mäusen mit N-blockierten CBZ-Phe-Leu-OH als Serincarboxypeptidase-Substrat bestimmt. In Darmhomogenaten der Scpep1 ${ }^{+/+}$-Mäuse wurde eine spezifische Serincarboxypeptidase-Aktivität von etwa 2 U/mg Protein gemessen (Abb. 4.31 A), während die spezifische Aktivität in Nierenhomogenaten durchschnittlich 1,4 U/mg 
Protein und in Leberhomogenaten $0,8 \mathrm{U} / \mathrm{mg}$ Protein betrug. Die SerincarboxypeptidaseAktivität war in der Leber der Scpep1-defizienten Mäuse um $20 \%$ und in den Nieren um $10 \%$ reduziert, wohingegen im Darm eine signifikante Reduzierung der Carboxypeptidase-Aktivität um etwa $30 \%$ nachgewiesen werden konnte (Abb. $4.31 \mathrm{~A}$ ). Zur Messungen der Serincarboxypeptidaseaktivität an einem definierten Zelltypen wurden aus Mausembryonen der RST 426 Zucht sieben Scpep1 $1^{-/}$- und fünf Scpep1 $1^{+/+}$ MEF Zelllinien etabliert. Scpep $1^{+/+}$-MEFs, die in Western Blot Analysen eine hohe Scpep1-Expression zeigten, wiesen eine spezifische Serincarboxypeptidaseaktivität von $1,4 \mathrm{U} / \mathrm{mg}$ Protein auf. In Scpep $1^{-/-}$-MEF konnte eine signifikante Reduzierung der spezifischen Aktivität um 50 \% nachgewiesen werden (Abb. 4.31 B).

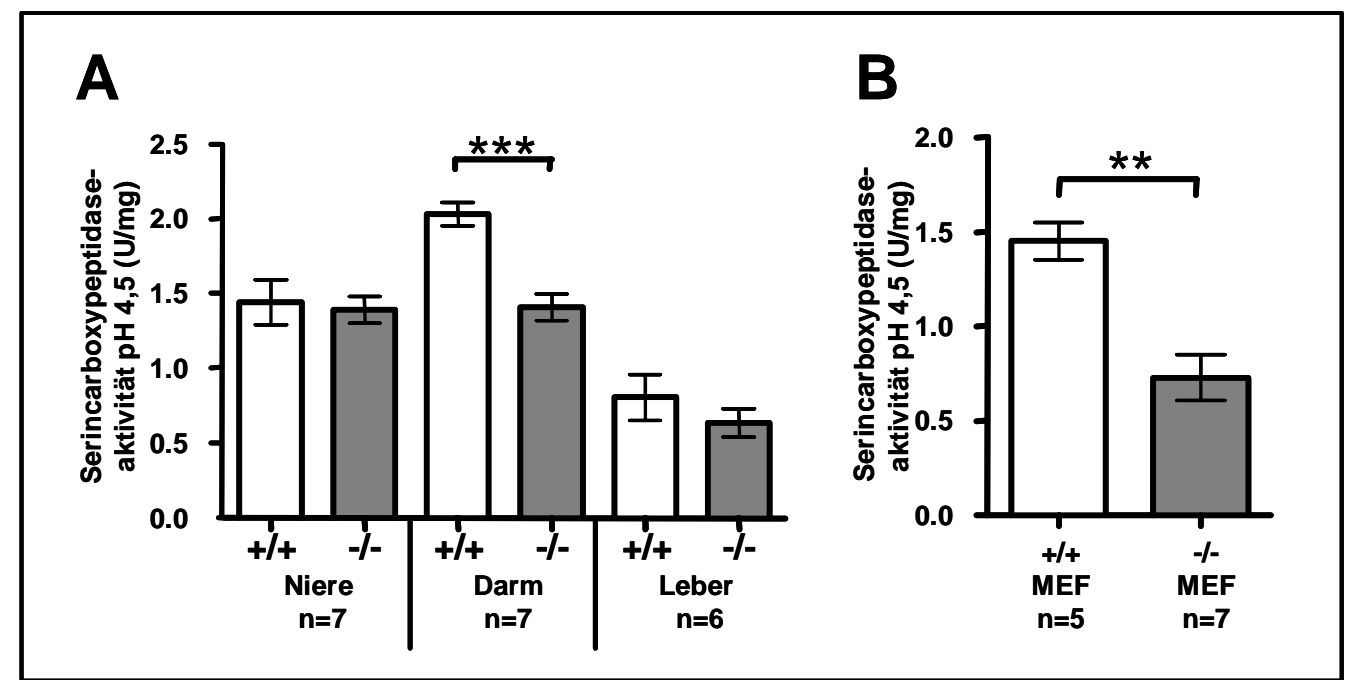

Abb. 4.31: Analyse der Serincarboxypeptidaseaktivität bei pH 4,5 in RST426 Mausgewebe und RST426 embryonalen Mausfibroblasten

Zur Bestimmung der Serincarboxypeptidase-Aktivität in Gewebehomogenaten (A) und Zellhomogenaten embryonaler Mausfibroblasten (B) von Scpep1 ${ }^{+/+}$-Mäusen und Scpep1 $1^{-/}$-Mäusen wurden jeweils $20 \mu \mathrm{g}$ Homogenat mit 0,5 mM CBZ-Phe-Leu-OH in $100 \mathrm{mM}$ MES/2 mM EDTA pH 4,5 inkubiert. Anschließend wurde die Konzentration freier Aminosäuren durch Ninhydrinfärbung photometrisch bestimmt. $(\mathrm{n}=$ Anzahl biologischer Replikate; je 4 technische Replikate; **: P $\leq 0,005 ; * * *: \mathrm{P} \leq 0,0005)$.

Zusätzlich wurden weitere artifizielle Dipeptide (CBZ-Phe-Phe, CBZ-Phe-Leu, CBZPhe-Ala, CBZ-Leu-Phe, CBZ-Ala-Phe, CBZ-Gly-Leu, CBZ-Gly-Gly und CBZ-Arg-Lys) zur Bestimmung der Carboxypeptidaseaktivität eingesetzt. Dabei erwiesen sich insbesondere im Darmgewebe alle Dipeptide mit einer hydrophoben Aminosäure am C-Terminus (P') als verwendbare Serincarboxypeptidase-Substrate, während mit den 
Dipeptiden CBZ-Gly-Gly und CBZ-Ala-Lys keinerlei Aktivität unter den gegebenen Bedingungen bei pH 5 und unter Verwendung von EDTA als Inhibitor von Metalloproteasen messbar war. CBZ-Ala-Lys ist ein spezifisches Substrat für Serincarboxypeptidasen der Gruppe S10 D, die eine starke Substrataffinität gegenüber Peptiden mit basischen, C-terminalen Aminosäuren aufweisen. Durch die differentielle Messung der Serincarboxypeptidaseaktivität konnte gezeigt werden, dass die Scpep1 eine Substrataffinität gegenüber hydrophoben Dipeptiden und keine messbare Substrataffinität gegenüber dem basischen Dipeptid zeigt, und somit der Gruppe C der Serincarboxypeptidasen zugeordnet werden kann.

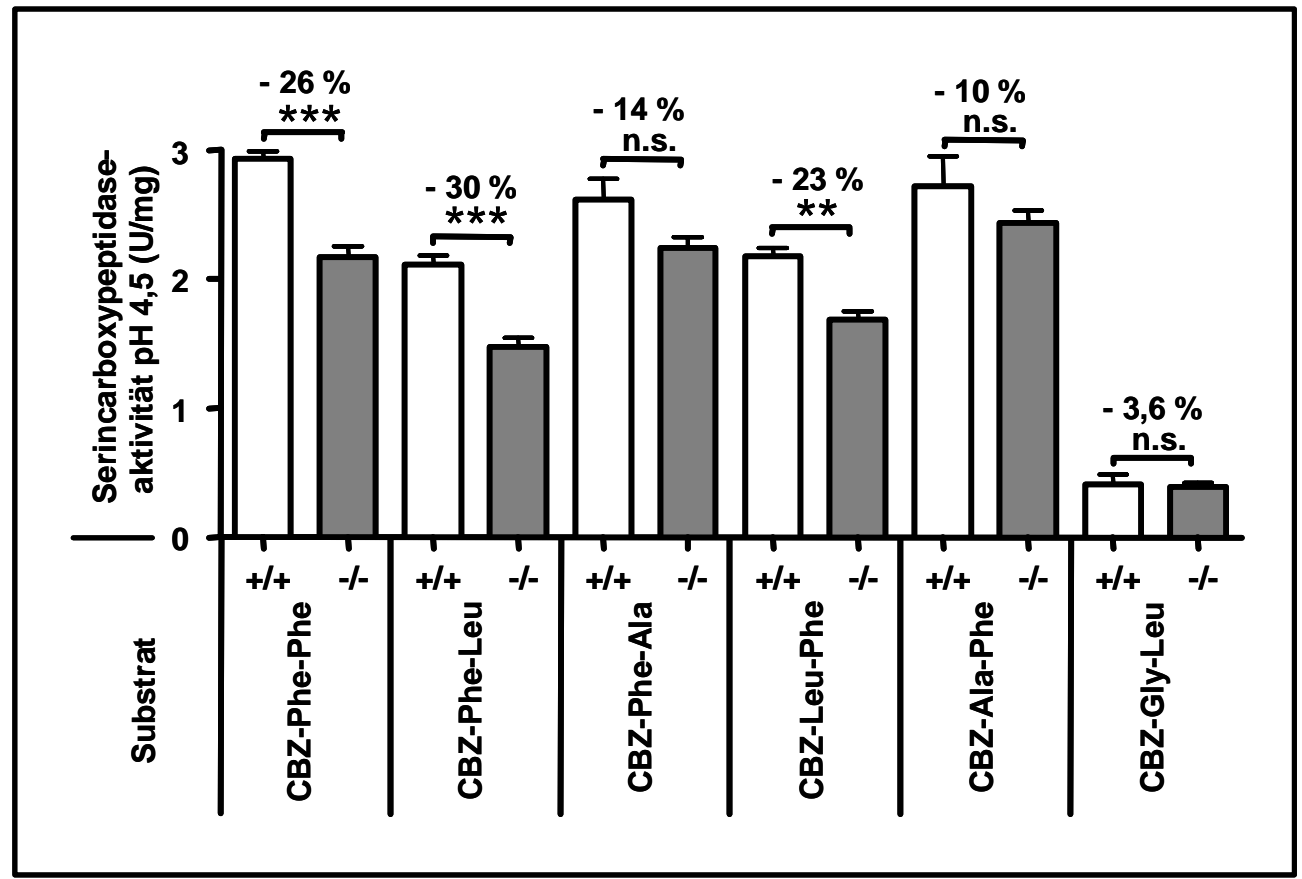

Abb. 4.32: Analyse der Serincarboxypeptidaseaktivität bei pH 4,5 in RST426 Darmhomogenaten unter Verwendung verschiedener Substrate

Zur Bestimmung der Serincarboxypeptidase-Aktivität in Gewebehomogenaten aus Scpep1 $1^{+/+}$-Darm und Scpep $1^{-/}$-Darm wurden jeweils $20 \mu \mathrm{g}$ Homogenat mit 0,5 mM N-terminal, CBZ-blockierter Dipeptide in $100 \mathrm{mM}$ MES/2 mM EDTA pH 4,5 inkubiert. Anschließend wurde die Konzentration freier Aminosäuren durch Ninhydrinfärbung photometrisch bestimmt (4 biologische Replikate; je 4 technische Replikate; $* *: \mathrm{P} \leq 0,005 ; * * *: \mathrm{P} \leq 0,0005 ;$ n.s.: nicht signifikant). 


\subsection{Phänotypische Untersuchung Scpep1-defizienter (-/-) Mäuse}

\subsubsection{Makroskopisches Erscheinungsbild der Scpep1-defizienten Mäuse}

Bei der Verpaarung heterozygoter Nachkommen des RST426 Stamms (129/Ola/C57BL/6 50/50-Hybriden) wurden insgesamt etwa 350 Nachkommen analysiert. Bei der Genotypisierung der Mäuse konnte eine Verteilung nach den Mendel'schen Regeln festgestellt werden, wobei der Anteil der Scpep $1^{-/-}$-Mäuse bei 23,6 \% lag. Zudem waren Scpep1-defiziente Mäuse beider Geschlechter fertil. Die Entwicklung der defizienten Mäuse ins adulte Alter vollzieht sich unauffällig. Scpep1-defiziente Tiere wiesen makroskopisch keine offensichtlichen Veränderungen gegenüber den Geschwistertieren auf. Auch Sektionen mit Beurteilung der inneren Organe erbrachten keine vom Wildtyp abweichenden Befunde.Die Gewichtsentwicklung und die Sterblichkeitsrate der Tiere mit unterschiedlichen Scpep1-Genotypen war vergleichbar.

\subsubsection{Verhalten von Scpep1-defizienten Mäusen}

Das Verhalten von 16 weiblichen Scpep1-defizienten Mäusen und 14 weiblichen Kontrollmäusen wurde von Rudi D'Hooge und Leen Van Aerschot im Laboratory of Biological Psychology, Department of Psychology an der Universität Leuven in Belgien untersucht (Caeyenberghs et al. 2006). Die neuromotorische Koordination (rotarod performance) und die Griffstärke der Scpep1-defizienten Tiere war normal. Bei der Aufnahme der 24-Stunden-Käfig-Aktivität waren die Scpep1-defizienten Tiere gegenüber den normalen Geschwistertieren marginal hypoaktiv $(\mathrm{P}=0,07)$. Im Open Field-Test war ihre Aktivität hingegen völlig normal, zudem waren Weglängen, Latenzzeiten und die im Zentrum des Feldes verbrachten Zeiten der Scpep1-defizienten Mäuse vergleichbar mit denen der Kontrolltiere. Im Erkundungsverhalten (social exploration, elevated plus maze activity) waren keine Unterschiede zweischen Scpep1-defizienten und Kontrollmäuse zu erkennen. In Lernexperimenten (step-through box, hidden-platform Morris water maze task) zeigten die Scpep1-defizienten Mäuse ein normales Orientierungs- und Erinnerungsvermögen. 


\subsubsection{Lichtmikroskopische Untersuchung von Scpep1-defizienten Mausgeweben}

Zur histologischen Untersuchung wurden verschiedene innere Organe von drei Scpep1defizienten Mäusen und zwei Scpep1 ${ }^{+/+}$-Mäusen im Alter von 5 Monaten in Formalin fixiert und in Paraffin eingebettet. Anschließend erfolgte die Untersuchung der Organe durch Hämatoxylin-Eosin-Färbung der Paraffinschnitte. Es wurden Schnitte der Organe Gehirn, Lunge, Leber, Niere, Milz, Oesophagus, Magen, Doudenum, Harnblase, der Hoden und der Ovarien untersucht. In lichtmikroskopischen Analysen der Gewebeschnitte konnten keine Auffälligkeiten an den Organen Scpep1-defizienter Mäuse festgestellt werden.

Für weitere Untersuchungen wurden Scpep1 $1^{-/}$-Mäuse im Alter von 9 und 12 Monaten, sowie gleichaltrige Kontrolltiere durch Perfusion mit $6 \%$ Glutaraldehyd fixiert. Die histologische Untersuchung der Tiere wurde anschließend von Prof. Dr. R. LüllmannRauch am Anatonischen Institut der Universität Kiel durchgeführt. Anhand von Semidünnschnitten wurden Niere, Leber, Lunge, Pankreas und Nebenniere lichtmikroskopisch untersucht. Alle analysierten Gewebe erwiesen sich als morphologisch unauffällig. Es wurden keine Anzeichen einer Vergrößerung der Lysosomen oder einer lysosomalen Speicherung gefunden. In Gewebeschnitten Scpep1defizienter Organe waren zudem weder Anzahl noch Größe der Lysosomen verändert, so dass eine massive lysosomale Speicherung ausgeschlossen werden konnte. Anhand elektronenmikroskopischer Untersuchungen der Lysosomen in den genannten Organen sollen auch leichte Speicherungen in Lysosomen ausgeschlossen werden.

\subsubsection{Biochemische Analyse der Scpep1-defizienten Mausgewebe}

Da weder makroskopisch, noch lichtmikroskopisch ein durch die Scpep1-Defizienz hervorgerufener spezifischer Phänotyp feststellbar war, wurden Scpep1-defiziente Gewebe biochemisch analysiert. 


\subsubsection{Untersuchung der Lysosomenmorphologie aus Scpep1-defizientem}

\section{Mausgewebe}

Die Lysosomen Scpep1-defizienter Mäuse wurden hinsichtlich ihrer Dichte und Integrität analysiert. Dazu wurden Leber- und Nierenhomogenate auf einem Percoll-Dichtegradienten subzellulär fraktioniert. Der postnukleäre Überstand (PNS) von Gewebehomogenaten wurde auf einem $30 \%$ igen Percolldichtegradienten aufgetrennt (3.5.13).

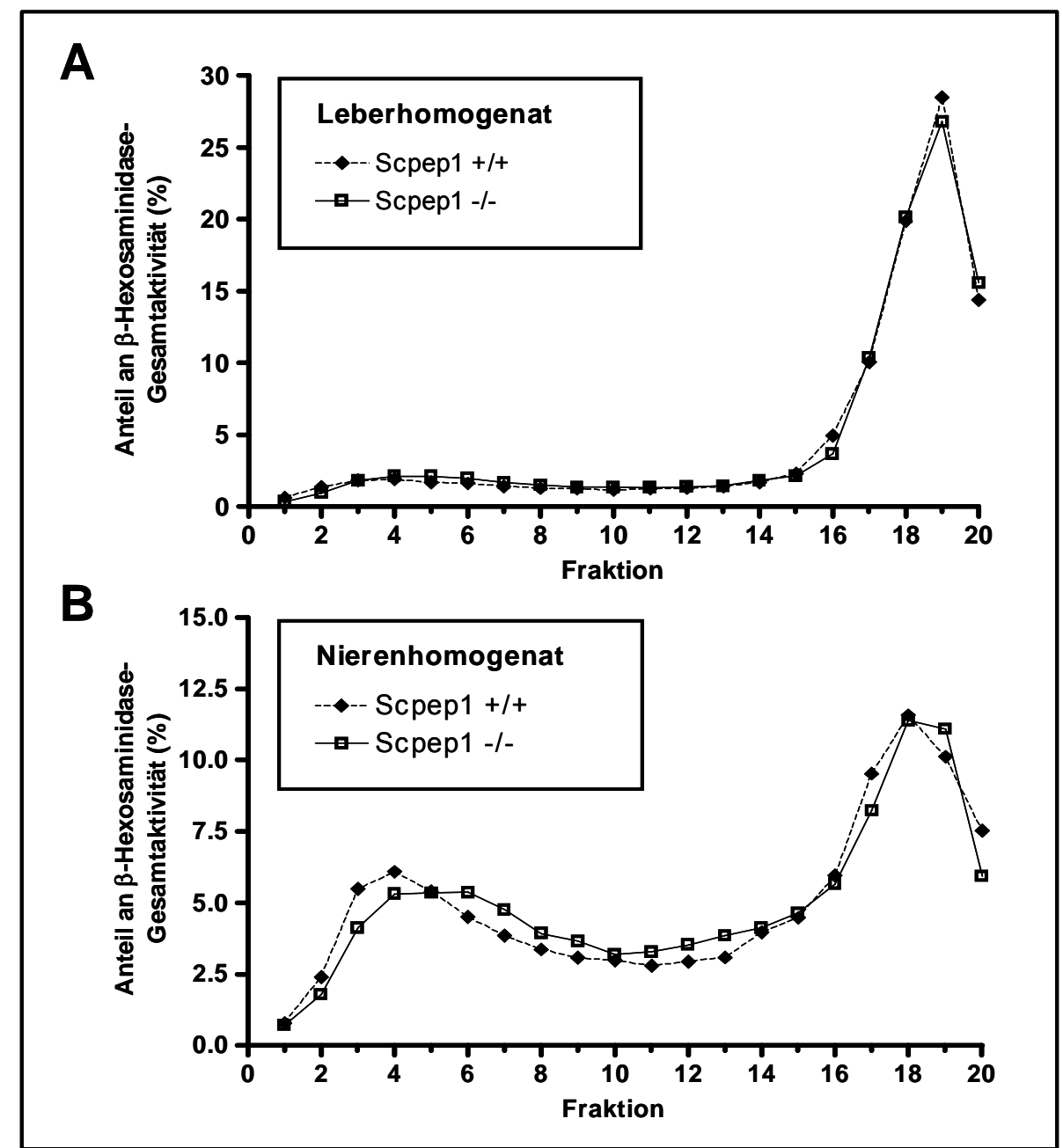

Abb. 4.33: Subzelluläre Fraktionierung von Scpep1 ${ }^{-/-}$-Gewebehomogenaten auf einem Percolldichtegradienten

Perinukleäre Überstande von Scpep $1^{+/+}$- und Scpep $1^{-/-}$-Leberhomogenaten (A) und Nierenhomogenaten (B) wurden auf einem 30 \%igen Percolldichtegradienten fraktioniert. Die 20 Fraktionen des Gradienten wurden hinsichtlich ihrer die $\beta$-Hexosaminidaseaktivität analysiert. Die prozentualen Anteile der einzelnen Fraktionen an der $\beta$-Hexosaminidase-Gesamtaktivität im Gradienten sind grafisch dargestellt. 
Die Verteilung der Lysosomen innerhalb des Gradienten wurde durch die Messung der $\beta$-Hexosaminidaseaktivität bestimmt. Leber- und Nierenhomogenate von Scpep1defizienten und Kontrollmäusen weisen keine Unterschiede in der Verteilung der Lysosomen nach der subzellulären Fraktionierung im Percollgradienten auf (Abb. 4.33).

Zur Untersuchung der osmotischen Stabilität der Lysosomen Scpep1-defizienter Mäuse wurde der perinukleäre Überstand von Scpep1 $1^{-/}$- und Scpep1 ${ }^{+/+}$-Leberhomogenaten in einer osmotisch wirksamen 0,25 M Glucoselösung und zur Kontrolle in einer osmotisch nicht wirksamen 0,25 M Sucroselösung inkubiert (3.5.12). Die Lysosomenmembranen enthalten Glucose-Transporter, die die Glucose aktiv in die lysosomalen Vesikel transportieren und somit die Osmolarität des Lysosomeninhalts erhöhen. Dies führt zu Wasseraufnahme und zur allmählichen Ruptur der Lysosomen. Bei der Inkubation des perinukleären Überstands (PNS) aus Scpep $1^{+/+}$- und Scpep1 $1^{-/-}$-Leber mit isotonischer 0,25 M Sucrose erfolgte erwartungsgemäß keine zeitabhängige Lyse der Lysosomen. Die $\beta$-Hexosaminidaseaktivität im Überstand blieb über 20 min konstant. Dagegen war bei der Inkubation des PNS mit 0,25 M Glucoselösung schon innerhalb der ersten 5 min ein starker Anstieg der freigesetzten $\beta$-Hexosaminidase im Überstand des Reaktionsansätze messbar. Nach 10 min waren $66 \%$ der Lysosomen im Scpep ${ }^{+/+}$-Ansatz ruptiert. Im

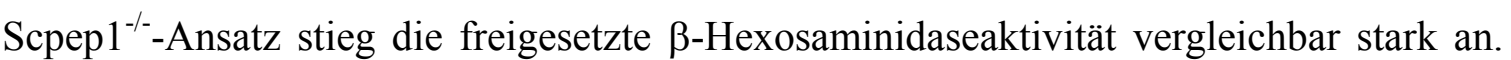
Nach 10 min waren $62 \%$ der Lysosomen ruptiert.

Stabilitätstest und subzellulärer Fraktionierung mittels Percoll-Gradienten lassen keine Unterschiede zwischen Lysosomen aus Gewebe von Scpep1-defizienten und Kontrolltieren erkennen. Dies bestätigt die Ergebnisse der histologischen Untersuchung, bei der ebenfalls keine Veränderungen in Form und Anzahl der Lysosomen nachgewiesen werden konnte (4.7.3). 


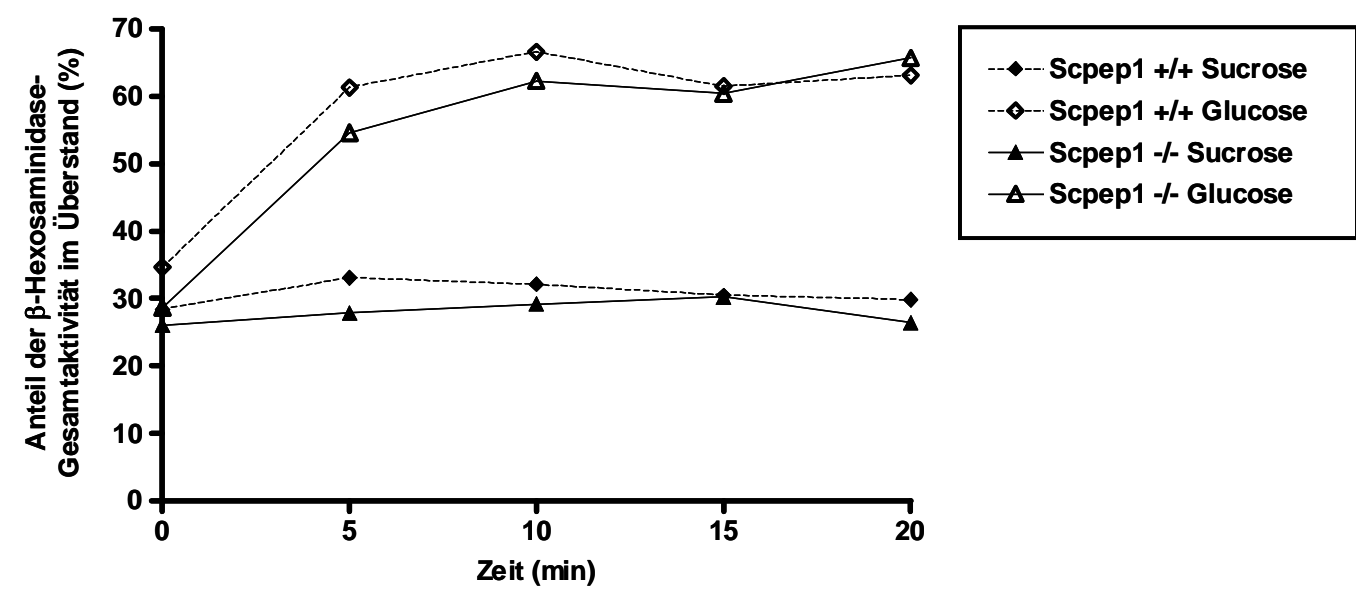

Abb. 4.34: Osmotische Stabilität der Scpep1-defizienten Leberlysosomen in Glucoselösung

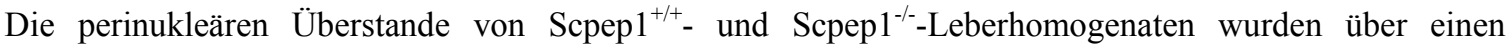
Zeitraum von 20 Minuten in 0,25 M Sucrose bzw. 0,25 M Glucoselösung inkubiert. Während der Inkubation wurden Aliquots abgenommen und mit 0,25 M Sucroselösung abgestoppt. Durch Ultrazentrifugation wurden intakte Lysosomen pelletiert. Im Überstand wurde die $\beta$-HexosaminidaseAktivität der ruptierten Lysosomen gemessen. Durch Zugabe von 1\% Triton wurde die Gesamtaktivität im Ansatz detektiert. Anschließend konnte der prozentuale Anteil der lysierten Lysosomen im Ansatz bestimmt werden.

\subsubsection{Bestimmung der Aktivität lysosomaler Enzyme in Geweben von Scpep1- defizienten Mäusen}

Um zu überprüfen, ob die Scpep1-Defizienz zur Veränderung der Aktivität anderer lysosomaler Enzyme führt, wurde die spezifische Aktivität der Enzyme $\beta$-Hexosaminidase, $\beta$-Glucuronidase, $\alpha$-Mannosidase und $\alpha$-Galactosidase in Gewebehomogenaten von Scpep1-defizienten Mäusen und Kontrollmäusen bestimmt. Dazu wurden die Gewebehomogenate aus Gehirn, Lunge, Herz, Leber, Milz, Niere und Hoden von jeweils drei viermonatigen Scpep $1^{+/+}$- und Scpep $1^{-/}$-Mäusen analysiert (Abb. 4.35). Ein statistisch signifikanter Unterschied in den spezifischen Aktivitäten der Enzyme konnte nur in einzelnen Geweben für eines der analysierten Enzyme detektiert werden. Die $\beta$-Hexosaminidase-Aktivität war nur in Hoden Scpep1-defizienter Mäuse erhöht ( $+50 \%, \mathrm{P}<0,05)$, während die $\alpha$-Mannosidase-Aktivitäten in Hirn bzw. Herz Scpep1-defizienter Mäuse signifikant erhöht waren $(+80 \%, \mathrm{P}<0,005$ bzw $+58 \%$, $\mathrm{P}<0,05)$. Die $\beta$-Glucuronidase-Aktivität war hingegen in der Niere Scpep1-defizienter Mäuse leicht verringert $(-24 \%, \mathrm{P}<0,5)$. 


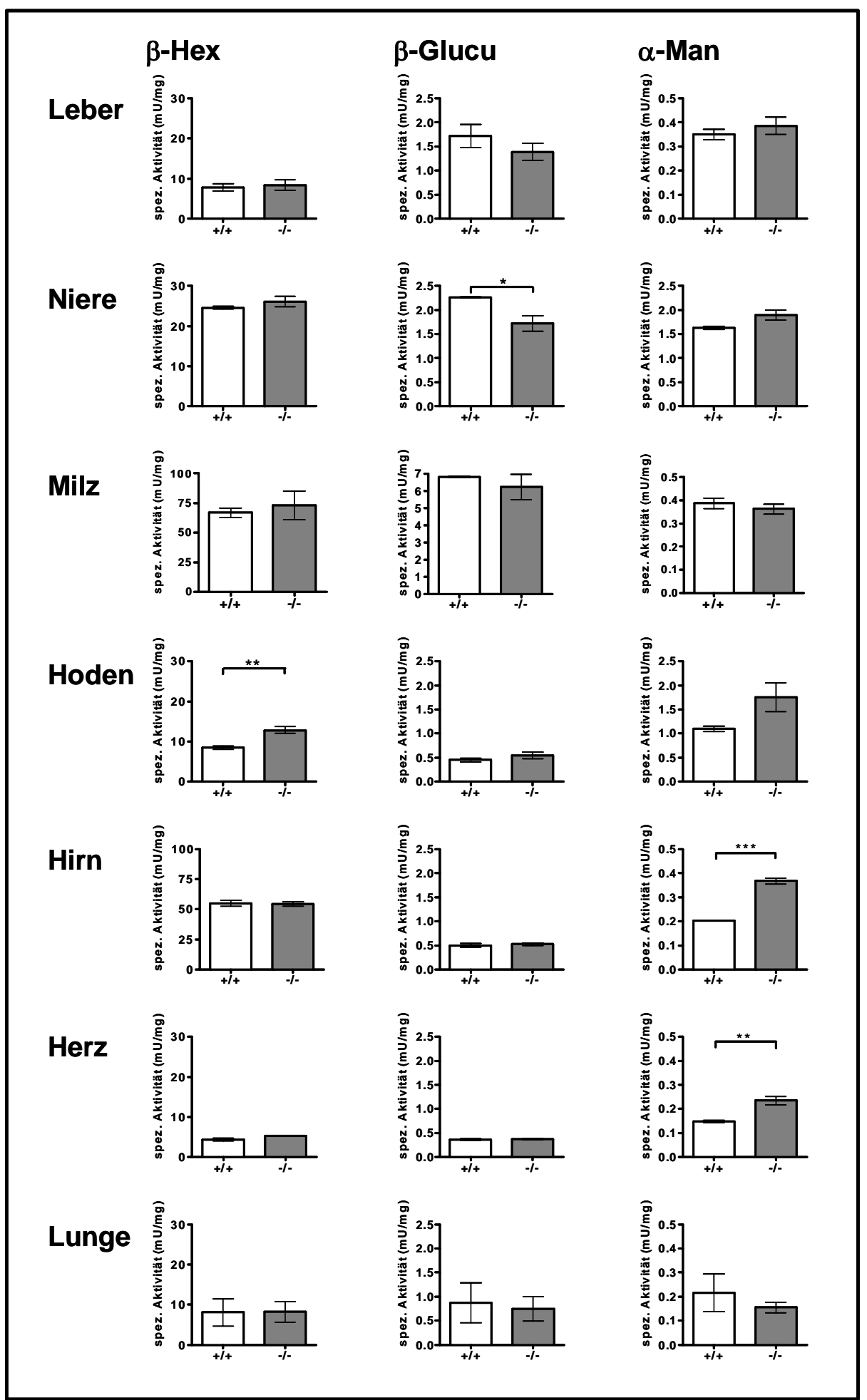

Abb. 4.35: Spezifische Aktivität lysosomaler Enzyme in verschiedenen Organen Scpep1-defizienter Mäuse

Aus den Organen Leber, Niere, Milz, Hoden, Hirn, Herz und Lunge Scpep1-defizienter Mäuse und Kontrollmäuse wurden Gewebehomogenate hergestellt, in denen die spezifische Aktivität der lysosomalen Enzyme $\beta$-Hexosaminidase, $\beta$-Glucuronidase, $\alpha$-Mannosidase und $\alpha$-Galactosidase bestimmt wurden. $(n=$ 3 biologische Replikate; *: $\mathrm{P} \leq 0,05 ; * *: \mathrm{P} \leq 0,005$; ***: $\mathrm{P} \leq 0,0005)$. 


\subsubsection{Untersuchungen am Blut Scpep1-defizienter Mäuse}

Zur Untersuchung des Bluts wurde Scpep1-defizienten Mäusen und Kontrollmäusen retrobulbär Blut entnommen. Zur Untersuchung des Blutbilds wurde das Blut mit EDTA versetzt. Die Blutproben wurden zur Analyse an das Tierärztliche Institut, Abteilung Hygiene der Nutztiere der Universität Göttingen gegeben. In Tab. 4.6 sind die Ergebnisse der Blutzellanalyse zusammengefasst. Es ist kein Unterschied zwischen dem Blutbild von Kontrollen und Scpep1-defizienten Mäusen zu erkennen. Die ermittelten Werte liegen dabei im normalen Standardmessbereich.

\begin{tabular}{|c|c|c|c|c|}
\hline \multirow[b]{2}{*}{ WBC $\left(10^{3} / \mu \mathrm{l}\right)$} & \multicolumn{2}{|c|}{ Kontrolle $(n=4)$} & \multicolumn{2}{|c|}{ Scpep $1^{-/-}(n=4)$} \\
\hline & 5,48 & $\pm 1,12$ & 4,53 & $\pm 0,98$ \\
\hline $\operatorname{RBC}\left(10^{6} / \mu \mathrm{l}\right)$ & 9,30 & $\pm 0,55$ & 9,70 & $\pm 0,29$ \\
\hline HGB (g/dl) & 15,03 & $\pm 0,41$ & 14,98 & $\pm 0,70$ \\
\hline $\mathrm{HCT}(\%)$ & 43,53 & $\pm 2,60$ & 45,60 & $\pm 1,93$ \\
\hline $\operatorname{MCV}(\mathrm{fl})$ & 46,78 & $\pm 0,62$ & 47,16 & $\pm 0,57$ \\
\hline $\mathrm{MCH}(\mathrm{pg})$ & 16,33 & $\pm 1,00$ & 15,45 & $\pm 0,27$ \\
\hline $\mathrm{MCHC}(\mathrm{g} / \mathrm{dl})$ & 34,85 & $\pm 1,90$ & 32,85 & $\pm 0,43$ \\
\hline RDW (\%) & 17,20 & $\pm 0,27$ & 18,04 & $\pm 0,80$ \\
\hline $\operatorname{PLT}\left(10^{3} / \mu \mathrm{l}\right)$ & 1116 & \pm 163 & 1084 & \pm 115 \\
\hline MPV (fl) & 6,30 & $\pm 0,36$ & 6,15 & $\pm 0,30$ \\
\hline
\end{tabular}

Tab. 4.6: Blutbild von Scpep1-defizienten Mäusen und Kontrollmäusen

Zur Analyse der Blutbilds wurde je vier weiblichen Scpep1-defizienten Mäusen und Kontrollmäusen im Alter zwischen neun und zwöf Monaten Blut entnommen. WBC (weiße Blutzellen), RBC (rote Blutzellen), HGB (Hämoglobin), HCT (Hämatokrit), MCV (mean cellular volume of RBC), $\mathrm{MCH}$ (mean cellular heamoglobine of RBC), MCHC (mean cellular heamoglobine concentration), RDW (red cell distribution width), PLT (Thrombozyten), MPV (mean volume of PLT). Angegeben ist der berechnete Mittelwert der Untersuchungsergebnisse und die Standardabweichung (SEM), $\mathrm{n}=4$.

In Serumproben der gleichen Tiere wurden spezifische Marker pathologischer Veränderungen der inneren Organe analysiert (Tab. 4.7). Mögliche Leberschäden wurden durch die Messung der AST (Aspartat-Aminotransferase) und der GGT (GammaGlutamyl-Transferase), sowie durch die Eisenbestimmung untersucht. Durch die Messung von Eisen, Gesamtprotein und Albumin wurde auf eine nephrotische 
Veränderung hin untersucht. Alle analysierten Parameter waren in Scpep1-defizienten Mäusen und Kontrolltieren vergleichbar.

\begin{tabular}{l|cc|cc}
\hline & \multicolumn{2}{|c|}{ Kontrolle $(\mathrm{n}=4)$} & \multicolumn{2}{|c}{$\operatorname{Scpep}^{-/-}(\mathrm{n}=4)$} \\
\hline AST $(\mathrm{U} / \mathrm{l})$ & 86,00 & $\pm 12,62$ & 94,17 & $\pm 2,77$ \\
GGT $(\mathrm{U} / \mathrm{l})$ & 8,00 & $\pm 0,0$ & 8,00 & $\pm 0,0$ \\
Eisen $(\mu \mathrm{g} / \mathrm{dl})$ & 34,70 & $\pm 2,65$ & 34,28 & $\pm 5,99$ \\
Protein $(\mathrm{g} / \mathrm{dl})$ & 5,988 & $\pm 0,26$ & 6,046 & $\pm 0,1871$ \\
Albumin $(\mathrm{g} / \mathrm{dl})$ & 2,905 & $\pm 0,08$ & 2,783 & $\pm 0,17$ \\
\hline
\end{tabular}

Tab. 4.7: Analysierte Serumparameter von Scpep1-defizienten Mäusen und Kontrollmäusen

Zur Analyse der Serumparameter wurde je 4 weiblichen Scpep1-defizienten Mäusen und Kontrollmäusen im Alter zwischen 9 und 12 Monaten retrobulbär Blut entnommen, aus dem das Serum gewonnen wurde. Die Analyse des Serums erfolgte an Tierärztlichen Institut, Abteilung Hygiene der Nutztiere der Universität Göttingen. Gemessen wurde AST (Aspartat-Aminotransferase), GGT (Gamma-Glutamyl-Transferase), Eisen, Gesamtprotein und Albumin. Angegeben ist der berechnete Mittelwert der Untersuchungsergebnisse und die Standardabweichung (SEM), $n=4$.

\subsubsection{Untersuchungen am Urin Scpep1-defizienter Mäuse}

In Mausgewebe wurde in der Niere eine hohe Scpep1-Expression im Western Blot nachgewiesen (4.4.3.2). Zudem konnte durch die X-Gal-Reportergenfärbung eine starke Scpep1-Expression in den proximalen Tubuli der Niere bestimmt werden (4.4.3.4). Um die Nierenfunktion der Scpep1-Mäuse zu untersuchen wurde der Urin der RST426 Tiere durch reduzierende SDS-PAGE und Silberfärbung der Gele analysiert (Abb. 4.36). In normalem Urin findet man nur wenig hochmolekulare Proteine ( $\geq 60 \mathrm{kDa})$, da diese bei der Filtration des Bluts an der Basalmembran der Glomeruli zurückgehalten werden. Bei einer glomerulären Schädigung hingegen werden überdurchschnittlich viele hochmolekulare Proteine im Urin ausgeschieden. Auch eine Schädigung des tubulären Systems kann durch die Analyse des Proteinmusters nachgewiesen werden, da eine eingeschränkte Rückresorptionsrate infolge eines Tubulusschadens $\mathrm{zu}$ einer mikroglobulären Proteinurie führt, bei der vermehrt Proteine mit einem Molekulargewicht $\leq 60 \mathrm{kDa}$ mit dem Urin ausgeschieden werden. 


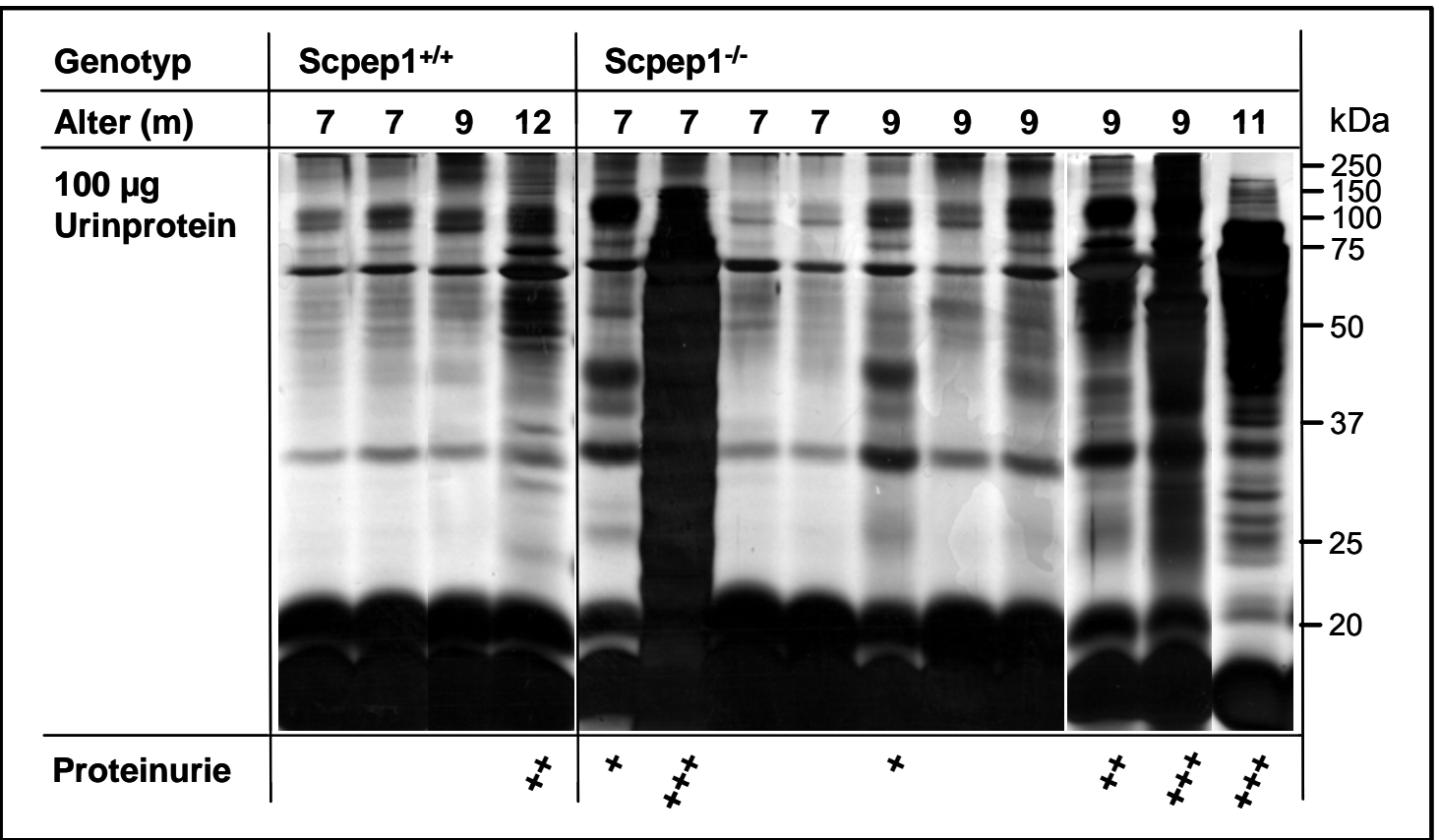

Abb. 4.36: Proteinmuster im Urin von Scpep1 $1^{-/-}$-Mäusen und Kontrollmäusen

Der Urin der RST426 Mäuse wurde in einem Eppendorfgefäß aufgefangen. Die Proteinkonzentration im Urin wurde bestimmt und $100 \mu \mathrm{g}$ des Gesamtproteins wurde durch SDS-PAGE unter reduzierenden Bedingungen aufgetrennt. Nach Silberfärbung des Gels wurde das Proteinmuster im Urin beurteilt. (+: leicht erhöhte Proteinmenge; ++: mittlere Proteinurie; +++: starke Proteinurie)

Im Urin von sieben Monate alten Scpep $1^{+/+}$-Mäusen war nur wenig Protein $>20 \mathrm{kDa}$ enthalten, während im Urin von älteren Scpep1 ${ }^{+/+}$-Mäusen ein Anstieg der Proteinmenge nachweisbar war. Bei einige Scpep1 $1^{-/}$-Mäusen im gleichen Alter wurde hingegen eine moderate Erhöhung von Proteinen mit einem Molekulargewicht von 30 bis 150 kDa im Urin detektiert und vereinzelt war eine starke Proteinurie nachweisbar. Insgesamt wurde

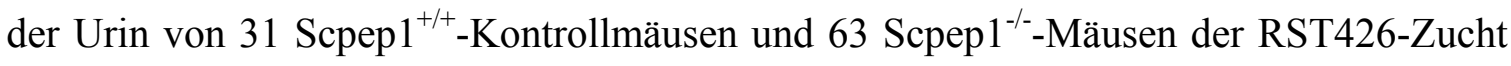
untersucht. Dabei zeigten vier Scpep $1^{--}$-Mäuse $(6 \%)$ eine starke Proteinurie. Neun weitere Scpep $1^{-/}$-Mäuse $(14 \%)$ zeigten eine Erhöhung von Proteinen mit einem Molekulargewicht von 30 bis $150 \mathrm{kDa}$ im Urin. Diese Veränderungen traten im Alter von 7-10 Monaten auf. Der Urin anderer Scpep $1^{-/-}$-Mäuse war bis zu einem Alter von 16 Monaten völlig unauffällig. Bei den Scpep $1^{+/+}$-Kontrolltieren wurde kein Tier mit starker Proteinurie detektiert. Eine altersbedingte Erhöhung der hochmolekularen Proteine im Urin war jedoch auch bei Scpep $1^{+/+}$-Mäusen mit steigendem Alter zu erkennen. Eine vergleichende Analyse von Serum und Urin einer Maus mit starker Proteinurie zeigte 
keine Auffälligkeiten im Proteinmuster des Serums, so dass ein prä-renaler Defekt als Ursache für die Proteinurie ausgeschlossen werden konnte (nicht abgebildet).

Um den Ursprung der Proteinurie zu untersuchen, wurden Scpep $1^{-/-}$-Mäuse mit einer mittleren Proteinurie im Alter von neun Monaten und zwölf Monaten, sowie zwei gleichaltrige Kontrollmäuse mit Glutaraldehyd fixiert. Anschließend wurden die Nieren der Mäuse licht- und elektronenmikroskopisch von Frau Prof. Dr. Lüllmann-Rauch beurteilt. Bei der mikroskopischen Untersuchung wurden neben normalen Glomeruli teilweise verödete Glomeruli detektiert (Abb. 4.37 A-C). In den Glomeruli war stellenweise eine ungleichmäßige, verdickte Basalmembran zu sehen (Abb. 4.37 I). An manchen Stellen konnte zudem eine Auflösung der Porenstruktur der Podozytenfüße (Effacement) detektiert werden (Abb. 4.37 G-H). Diese Veränderungen können ursächlich für die detektierte Proteinurie sein. Im Bereich der proximalen und distalen Tubuli und im Bereich des Sammelrohrs waren keine Veränderungen bei den Scpep1-defizienten Mäusen gegenüber den Kontrollmäusen nachweisbar (Abb. 4.37 D-E). Die beschriebenen Veränderungen wurden im gleichen Umfang in Scpep $1^{+/+}$- und Scpep $1^{-/-}$-Nierengewebe detektiert.

In weiterführenden Experimenten ist statistisch zu klären, ob sich eine Proteinurie bei

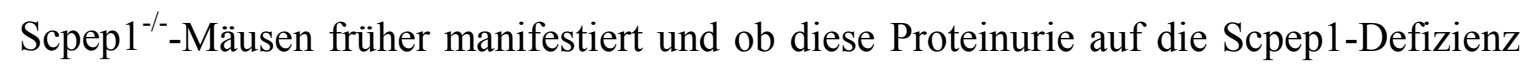
zurückzuführen ist. 


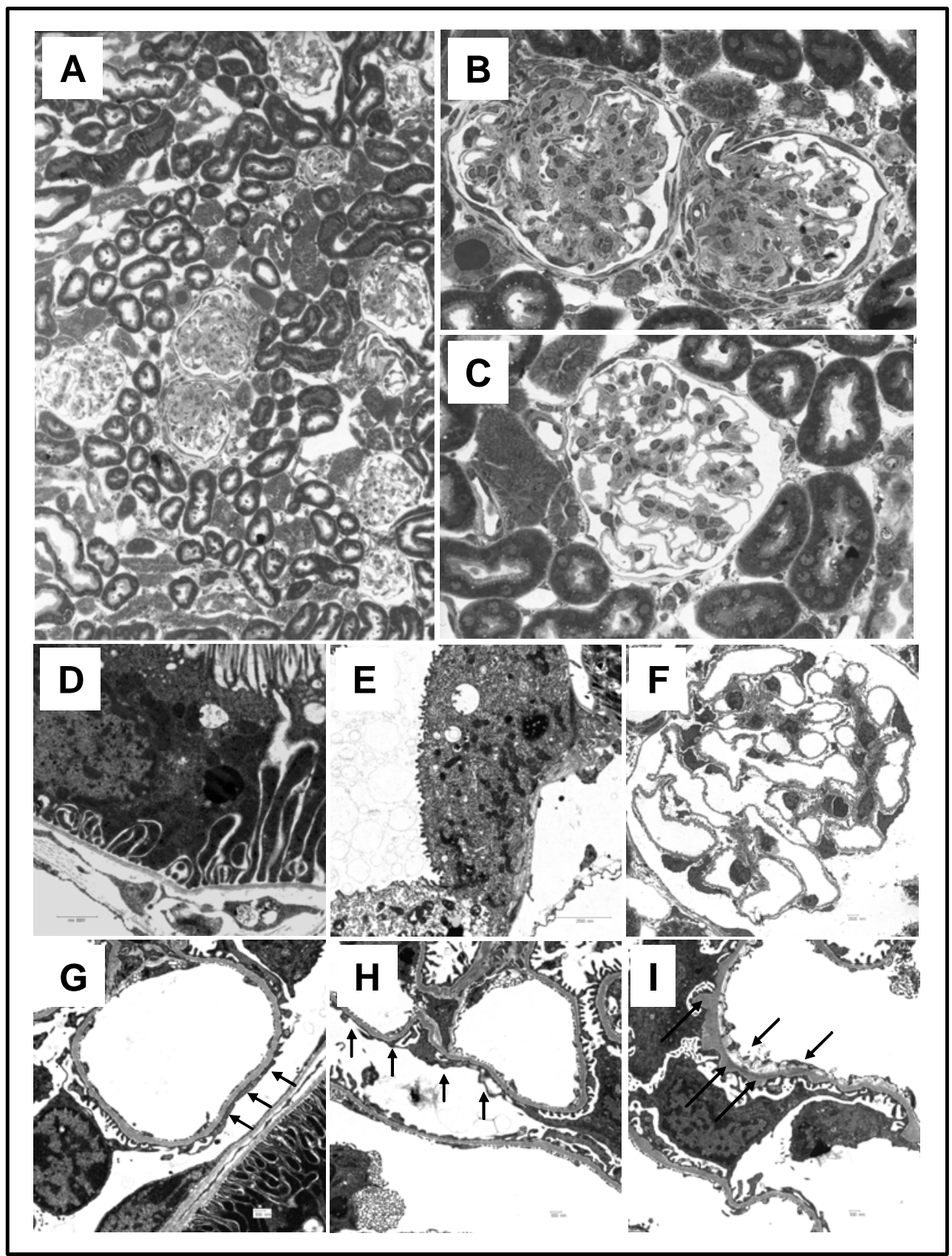

Abb. 4.37: Mikroskopische Untersuchung von Scpep1 ${ }^{-/-}$-Nierengeweben

(A) Semidünnschnitt der Nierenrinde. Angeschnitten sind distale und proximale Tubuli, sowie 9 Glomeruli, von denen 1 Glomerulus normal aussieht, 4 teilweise verödet sind und 4 ein vergrößertes Mesangium zeigen, (B) Ausschnitt aus A, zeigt zwei teilweise verödete Glomerulim mit hohem Mesangiumanteil, (C) Ausschnitt von A, zeigt normalen Glomerulus (D)-(I) Elektronenmikroskopische Aufnahmen (D) proximaler Tubulus, normal, (E) Hauptzellen des Sammelrohrs, normal, $(\mathrm{G})+(\mathrm{H})$ Glomeruluskapillare, Pfeile markieren veränderte Podozyten, (I) Glomeruluskapillare, Basalmembran und Podozyt, Pfeile zeigen verdickte Basalmembran und Ablösungen an der kapillarluminaren Seite der Basalmembran. 


\section{Diskussion}

\subsection{Identifizierung von neuen lysosomalen Matrixproteinen durch Proteomanalyse}

\subsubsection{Analyse M6P-markierter Proteine durch 2D-GE und MudPIT}

Ziel dieser Arbeit war die Identifizierung und Charakterisierung neuer lysosomaler Matrixproteine. Zur Isolierung lysosomaler Matrixproteine können im Prinzip zwei Methoden genutzt werden. Dabei stellt die subzelluläre Fraktionierung eine Methode dar, die zur Anreicherung lysosomaler Proteine verwendet wird (Chataway et al. 1998; Tribl et al. 2005; Schroder et al. 2007). Sie ermöglicht die Analyse von lysosomalen Matrixproteinen, als auch von lysosomalen Membranproteinen, da die Lysosomen als Gesamtorganellen in aufeinander folgenden Zentrifugationsschritten aus Gewebe- oder Zellhomogenaten angereichert werden. Die Identifizierung der lysosomalen Proteine nach subzellulärer Fraktionierung wird jedoch zumeist durch eine hohe Anzahl kontaminierender, nicht lysosomaler Proteine erschwert. Durch eine klassische subzelluläre Fraktionierung konnten Schröder et al. (Schroder et al. 2007) insgesamt 58 bekannte, sowie putativ lysosomale Membranproteine nachweisen, wobei 17 dieser Proteine Untereinheiten der lysosomalen V-Typ H-ATPase darstellten. Um lysosomale von kontaminierenden Proteinen zu unterscheiden, verwendeten sie ein differentielles Analyseverfahren bei dem die Konzentration der identifizierten Proteine in stark angereicherten und weniger stark angereicherten Fraktionen verglichen und der Anreicherungsfaktor als Auswahlkriterium herangezogen wurde.

Eine alternative Methode zur Isolierung lysosomaler Matrixproteine nutzt deren spezifische Modifikation mit M6P-Resten, anhand derer lysosomale Matrixproteine von anderen z.B. sezernierten Proteinen unterschieden werden können. Diese Modifikation vermittelt die Bindung der lysosomalen Matrixproteine an die Mannose-6Phosphatrezeptoren (MPR) (Kornfeld und Kornfeld 1985; von Figura und Hasilik 1986), so dass M6P-haltige Proteine aus Gewebehomogenaten, Körperflüssigkeiten, wie Urin 
oder Blutserum, oder aus Zellkulturüberständen mittels immobilisierter MPR affinitätschromatografisch aufgereinigt werden können (Pohlmann et al. 1995; Sleat et al. 1996; Journet et al. 2000). M6P-haltige Proteine wurden in früheren Studien durch 1D-GE und 2D-GE aufgetrennt und durch N-terminale Sequenzierung identifiziert (Sleat et al. 1996; Chataway et al. 1998) bzw. in den letzten Jahren zunehmend durch massenanalytische Verfahren (z.B. MALDI-TOF-MS) analysiert (Journet et al. 2000; Journet et al. 2002).

In der hier durchgeführten Proteomanalyse wurden M6P-markierte Proteine aus Zellkulturüberständen von MPR-defizienten, embryonalen Mausfibroblasten, die lösliche lysosomale Vorläuferproteine aufgrund der MPR-Defizienz konstitutiv sezernieren, isoliert und affinitätschromatografisch aufgereinigt (4.1.1). Anschließend wurden die isolierten Proteine durch zwei unabhängige Analyseverfahren identifiziert. Die Proteine wurden einerseits durch 2D-GE, gefolgt von tryptischem In-Gel-Verdau und MALDITOF-MS analysiert (4.1.2) und andererseits durch eine MudPIT-Analyse identifiziert (4.1.3). Dabei wurden die isolierten Proteine zunächst tryptisch verdaut. Die resultierenden Peptide wurden durch Ionenaustauscher- und Reverse-PhaseChromatografie zweidimensional aufgetrennt und anschließend durch ESI-MS/MS identifiziert. Insgesamt konnten 34 bekannte lysosomale Matrixproteine aus den Überständen der Mausfibroblasten identifiziert werden (Tab. 4.2). Zusätzlich wurden vier putativ lysosomale Proteine und vier kontaminierende, nicht lysosomale Proteine nachgewiesen (Tab. 4.2). Drei der putativ lysosomalen Proteine konnten durch 2D-GE als auch durch MudPIT identifiziert werden (MERP-2, 66.3 kDa-Protein und Scpep1), das vierte Protein (Progranulin) wurde nur durch die MudPIT-Analyse identifiziert.

Durch die 2D-GE wurden insgesamt 32 Proteine in 198 Spots identifiziert, dabei handelte es sich um 28 bekannte lysosomale Proteine, ein nicht lysosomales Protein und die drei Kandidaten für lysosomale Matrixproteine: MERP-2, $66.3 \mathrm{kDa}-$ Protein und Scpep1 (4.1.2). Die einzelnen lysosomalen Proteine wurden im 2D-Gel meist in mehreren Spots mit unterschiedlichen molekularen Massen und pI nachgewiesen. Lysosomale Proteine besitzen häufig eine starken Heterogenität in den N-glykosidisch verknüpften Oligosacchariden (von Figura und Hasilik 1986; Dittmer et al. 1997) und liegen meist in unterschiedlich proteolytisch gereiften Formen vor (Hasilik 1992). Einige Proteine wurden hingegen nur durch einen Spot im 2D-Gel identifiziert. So ist z.B. das PPCA 
(protective protein/cathepsin A) eines der Proteine, die sich im 2D-Gel sehr heterogen verhalten. Es ist in 19 verschiedenen Proteinspots nachweisbar, die verschieden glykosylierte und prozessierte Formen des Proteins darstellen.

Durch die MudPIT-Analyse wurden 28 bekannte lysosomale Proteine identifiziert. Davon wurden die sechs Proteine saure Ceramidase, saure Lipase I, Cathepsin F, Galactocerebrosidase, Niemann Pick Typ C2 und Prosaposin nur durch MudPIT nachgewiesen (4.1.3). Die Proteine CREG, $\alpha$-L-Fucosidase, CLN5, Neuraminidase, Ribonuklease und Tripeptidylpeptidase I wurden nur durch 2D-GE/MS und nicht durch MudPIT identifiziert. Die genannten Proteine wurden auch im 2D-Gel nur durch einen oder zwei Proteinspots mit geringer Intensität identifiziert. Dies lässt vermuten, dass schwach exprimierte Proteine durch MudPIT Analyse schlechter nachweisbar sind, da häufiger vorkommende Peptide anscheinend die Detektion seltener Peptide bei der MS/MS-Analyse behindern.

In dieser Studie konnten durch die verwendeten Analyseverfahren etwa zwei Drittel der heute bekannten, 50 lysosomalen Matrixproteine identifiziert werden. Einige der bekannten, lysosomalen Proteine entgingen der durchgeführten Analyse, da sie wahrscheinlich nicht in embryonalen Mausfibroblasten exprimiert werden. Dazu gehören z.B. die gewebespezifisch exprimierten Proteasen, wie das Cathepsin $\mathrm{M}$ das ausschließlich in Plazenta exprimiert wird (Bode et al. 2005). Die meisten nicht identifizierten Proteine sind jedoch ubiquitär exprimiert (z.B. $\alpha$-Galactosidase, $\alpha$-LIduronidase, Sulfamidase) und entgehen der Analyse offensichtlich aufgrund methodischer Limitierungen wie z.B. der Inkompatibilität der Proteine mit den Versuchsbedingungen (Löslichkeit, pI, MW, Glykosylierung) oder der Detektionsgrenze von schwach exprimierten Proteinen. Anhand beider Methoden wurden jeweils 28 bekannte lysosomale Proteine identifiziert. 22 Proteine wurden parallel in beiden Ansätzen nachgewiesen. Durch die Verwendung der zwei komplementären Analyseverfahren konnte die Anzahl der identifizierten Proteine gegenüber jeder einzelnen Methode erheblich gesteigert werden. Journet et al. (Journet et al. 2002) und Sleat et al. (Sleat et al. 2005) führten Proteomanalysen der lysosomalen Matrix durch, die der hier vorgestellten Analyse vergleichbar sind. Journet et al. identifizierte M6P-haltige Proteine, die er aus Zellkulturüberständen der humanen Zelllinien U937 und MCF7 
isolierte. Um die Sekretion M6P-haltiger Proteine zu fördern, wurden die Zellen mit $\mathrm{NH}_{4} \mathrm{Cl}$ behandelt, wodurch der MPR-abhängige Transport der Proteine $\mathrm{zu}$ dem endosomalen/lysosomalen Kompartiment inhibiert wurde (Braulke et al. 1987). Die affinitätschromatografisch isolierten, M6P-haltigen Proteine wurden anschließend durch 1D- und 2D-GE separiert und durch tryptischen Verdau und MALDI-TOF-MS und N-terminale Sequenzierung identifiziert. Durch die Analyse konnten zwölf bekannte lysosomale Proteine und drei putativ lysosomale Proteine identifiziert werden. In vielen Gewebe- und Zelltypen wird das M6P-Sortierungssignal im endosomalen/lysosomalen Kompartiment von einer noch nicht identifizierten Phosphatase von den lysosomalen Matrixproteinen entfernt (Einstein und Gabel 1991), was die affinitätschromatografische Isolierung lysosomaler Matrixproteine aus Gewebehomogenaten erschwert. Sleat et al. konnten zeigen, dass Gehirngewebe im Vergleich zu anderen Geweben einen hohen Anteil M6P-markierter Proteine besitzt (Sleat et al. 1996). Sie verwendeten aus diesem Grund Gehirnbiopsien als Ausgangsmaterial für eine Proteomanalyse M6P-haltiger Proteine (Sleat et al. 2005). Die affinitätschromatografisch aufgereinigten Proteine wurden analog zu unserer Studie durch zwei Methoden analysiert. Die Proteine wurden durch 2D-GE mit anschließendem tryptischen Verdau und MALDI-TOF-MS identifiziert. Zusätzlich wurden die M6P-haltigen Proteine durch tryptischen Verdau, Separation der resultierenden Peptide mittels Reverse-Phase-Chromatografie und durch MS/MS-Analyse (LC-MS/MS Analyse) nachgewiesen. Durch die Kombination der Analyseverfahren identifizierten Sleat et al. insgesamt 43 bekannte lysosomale Proteine und neun putativ lysosomale Proteine. Unter anderem identifizierten sie auch MERP-2, Scpep1 und das 66.3 kDa-Protein als M6P-markierte Proteine, was das Ergebnis unserer Proteomanalyse bestätigt. Der Vergleich der Analysen zeigt, dass die Verwendung von chromatografischen Methoden, wie der MudPIT-Analyse, eine Alternative zur klassischen 2D-GE darstellt und dass die Anzahl der identifizierten Proteine durch die Verwendung komplementärer Techniken zur Separation und Identifikation der Proteine maximiert werden kann. Offensichtlich konnten Sleat et al. aufgrund einer stärkeren Sensitivität eine höhere Anzahl an lysosomalen Proteinen identifizieren. Zudem beeinflussen zell- oder gewebespezifische Expressionsmuster die Proteomanalyse. 


\subsubsection{Eigenschaften der vier Kandidatenproteine}

Die bioinformatische Untersuchung der vier Kandidatenproteine Scpep1, 66.3 kDaProtein, MERP-2 und Progranulin identifizierte diese als potenziell lysosomale Proteine. Alle vier Proteine besitzen ein N-terminales Signalpeptid und Konsensussequenzen für die N-Glykosylierung (Tab. 4.1). Bei der Expression der C-terminal V5-His6-markierten Proteine wiesen die exprimierten Proteine ein höheres Molekulargewicht auf, als für die Proteine anhand der Primärsequenz berechnet wurde (Tab. 4.2, Abb. 4.3), was für eine Glykosylierung der Proteine spricht. Experimentell konnte gezeigt werden, dass die C-terminal markierte Proteinform von drei der vier Kandidatenproteine M6P-abhängig an immobilisierte MPR bindet (Scpep1, 66.3 kDa-Protein und MERP-2) (4.1.5) und dass diese drei Proteine MPR-abhängig in das lysosomal/endosomale Kompartiment von Fibroblasten endozytiert wurden (4.1.6). Eine Interaktion der C-terminal markierten Form des Progranulins an die immobilisierten MPR konnte hingegen nicht nachgeweisen werden (4.1.5). Dies schließt jedoch nicht aus, dass auch das Progranulin lysosomal lokalisiert sind könnte. Die M6P-generierende Golgi-Phosphotransferase (GNPT) erkennt lysosomale Enzyme anhand eines dreidimensionalen Strukturmotivs und initiiert nach dessen Erkennung die M6P-Markierung lysosomaler Proteine (Lang et al. 1984; Tikkanen et al. 1997). Möglicherweise behindert das C-terminale V5-His6-Peptid, dass das Progranulin durch die GNPT erkannt und phosphoryliert wird. Möglich ist auch, dass das Progranulin nicht selber M6P-markiert ist, sondern indirekt durch die Komplexbildung mit einem M6P-markierten Protein an die MPR bindet.

Die Ergebnisse dieser und anderer Proteomanalysen identifizieren das 66.3 kDa-Protein als ein glykosyliertes, M6P-haltiges, putativ lysosomales Protein (Kollmann et al. 2005; Sleat et al. 2005; Sleat et al. 2006). Das murine $66.3 \mathrm{kDa}$-Protein ist ein 594 Aminosäuren großes Protein mit einem 41 Aminosäuren langen, N-terminalen Signalpeptid und fünf putativen N-Glykosylierungssequenzen. Das $66.3 \mathrm{kDa}$-Protein ist evolutionär von den Säugetieren (Mensch 80 \% Homologie), bis zu den Nematoden (Trypanosoma brucei $28 \%$ Homologie) konserviert. Die lysosomale Lokalisation des endogenen $66.3 \mathrm{kDa}$-Proteins konnte in weiterführenden Untersuchungen mit spezifischen Antiseren bestätigt werden (Deuschl et al. 2006; Jensen et al. 2007). Das Protein wird als $75 \mathrm{kDa}$-Vorläuferprotein synthetisiert und anschließend durch limitierte 
Proteolyse in gereifte Proteinformen prozessiert, die im Lysosomen lokalisiert sind. Das 66.3 kDa-Protein gehört der Phospholipase B Familie an. Eine Phospholipase B-Aktivität konnte jedoch bis heute nicht nachgewiesen werden.

Das mammalian ependymin related protein 2 (MERP-2) wurde ebenfalls in verschiedenen Proteomanalysen als M6P-markiertes Protein (Kollmann et al. 2005; Sleat et al. 2005; Sleat et al. 2006) und als Protein in der Präparation von Lysosomenverwandten, neuromelanin-haltigen Granula in Neuronen der substantia nigra pars compacta (SN) des Mesencephalon identifiziert (Tribl et al. 2005). MERP-2 ist ein 224 Aminosäuren großes Protein mit einem N-terminalen Signalpeptid und zwei putativen N-Glykosylierungssequenzen. Es ist evolutionär konserviert. Orthologe Proteinformen findet man unter anderem in Ratte (92\% Identität), Mensch (80\%) und Zebrafisch (61\%). Die Proteinfamilie wurde nach dem Protein Ependymin benannt, das als dominierendes Protein in der Zerebrospinalflüssigkeit des Teleost-Fisches identifiziert wurde. Ependymin ist ein sezerniertes Glykoprotein, das als Zelladhäsionsmolekül mit Funktionen in der Gedächtniskonsolidierung beschrieben ist (Schmidt 1995). Die Funktion der ependymin related proteins (ERPs) ist jedoch noch unklar. Die Bindung an die MPR und die Internalisation des MERP-2 in die Lysosomen deuteten stark auf eine lysosomale Lokalisation hin. Della Valle et al. (Della Valle et al. 2006) konnten die lysosomale Lokalisation des Proteins mit spezifischen Antiseren bestätigen. Des Weiteren konnten sie zeigen, dass das Protein in Gehirn und Muskel exprimiert wird und zweifach N-glykosyliert ist.

Progranulin ist ein Wachstumsfaktor mit Funktionen in der Embryonalentwicklung, der Tumorgenese und bei der Wundheilung. Das Protein wird als $80 \mathrm{kDa}$ großes, glykosyliertes Vorläuferprotein synthetisiert, welches sieben verschiedene GranulinPeptidformen kodiert, die vermutlich durch posttranslationale limitierte Proteolyse aus dem Vorläuferprotein freigesetzt werden. Die Granuline sind eine Familie von Cysteinreichen Peptiden mit einer Größe von etwa $6 \mathrm{kDa}$, die verschiedene, zum Progranulin komplementäre biologischen Aktivitäten besitzen. Der Mechanismus der proteolytischen Prozessierung wurde noch nicht identifiziert. Das Progranulin ist konserviert und orthologe Proteine findet man unter anderem in Ratte (87\% Homologie), Mensch (75\%) und Zebrafisch (34\%). Das C-terminal V5-His-markierte Progranulin bindet nicht an 
immobilisierte MPR und eine Internalisierung des Proteins in Lysosomen konnte nicht nachgewiesen werden. Möglicherweise handelt es sich bei dem Protein um ein nichtlysosomales, kontaminierendes Protein. Eine lysosomale Lokalisation kann jedoch auch nicht völlig ausgeschlossen werden. Es ist bekannt, dass das lysosomale Kompartiment an der Regulation von Hormonen und Wachstumsfaktoren beteiligt ist (Brix et al. 2001) und es wäre denkbar, dass die Prozessierung des Progranulin im Lysosomen erfolgt.

Das Protein Scpep1 (Serincarboxypeptidase 1, Synonym: retinoid-inducible serincarboxypeptidase, RISC) wurde als weiterer Kandidat für die lysosomale Lokalisation identifiziert. Es ist ein 452 Aminosäuren großes Protein mit einem N-terminalen Signalpeptid und fünf putativen N-Glykosylierungssequenzen. Das rekombinante Protein bindet an immobilisierte MPR und wird MPR-abhängig in Fibroblasten endozytiert. Sequenzanalysen identifizierten die Scpep1 als Mitglied der Serincarboxypeptidase Familie S10. Die Carboxypeptidasen dieser Familie sind im eukaryontischen System in den Vakuolen bzw. in den Lysosomen lokalisiert und besitzen im sauren $\mathrm{pH}$ maximale proteolytische Aktivität (Rawlings und Barrett 1994). Die Serincarboxypeptidasen Carboxypeptidase Y (CPY) aus S. cerevisiae und das lysosomale protective protein/ cathepsin A (PPCA) aus Säugern sind Mitglieder dieser Peptidase Familie (Rawlings und Barrett 1994; Remington und Breddam 1994). Das paraloge PPCA aus Maus und die Scpep1 sind zu 33,7 \% homolog. Die Sequenzen von CPY und Scpep1 zeigen 31,2 \% Homologie. Das Scpep1-Protein ist evolutionär konserviert. Orthologe Proteinformen findet man unter anderem in Ratte (92,9 \% Identität), Mensch $(82,4 \%)$ und Zebrafisch $(64,4 \%)$.

Aufgrund der starken Hinweise auf eine lysosomale Lokalisation und der postulierten hydrolytischen Aktivität wurde die Scpep1 in weiteren Untersuchungen molekular und funktionell charakterisiert.

\subsection{Molekulare und funktionelle Charakterisierung der Scpep1}

\subsubsection{Gewebespezifische Expression der murinen Scpep1}

Mit Hilfe Scpep1-spezifischer Antikörper wurde zunächst die lysosomale Lokalisation der endogenen Scpepl durch indirekte Immunfluoreszenz (4.4.2.1) und subzelluläre 
Fraktionierung (4.4.2.2) bestätigt. Im Western Blot konnte gezeigt werden, dass die Scpep1 gewebespezifisch exprimiert wird, wobei in Darm und Niere eine besonders starke Expression detektiert wurde (4.4.3.2). Durch Reportergenfärbung im RST426 Mausmodell konnte die Expression der Scpep1 im embryonalen (4.4.3.3) und im adulten Gewebe (4.4.3.4) untersucht werden. Zusätzlich wurden immunhistologische Analysen von Lee et al. durchgeführt (Lee et al. 2006). Die Scpep1 weist eine zellspezifische Expression auf und ist dabei hauptsächlich in epithelialen Zellen zu finden. So beschränkt sich die Expression in den Nieren auf die Lysosomen-reichen, epithelialen Zellen des proximalen Tubulus (Abb. 4.21). Im lymphatischen Gewebe und in der Milz wird die Scpep1 ausschließlich in Makrophagen exprimiert (Lee et al. 2006). Zudem erfolgt eine Expression in den Belegzellen des Magens und in den Lieberkuhnschen Krypten und den Zotten des Darms. Die homologe Serincarboxypeptidase PPCA (protective protein/cathepsin A) zeigt eine sehr ähnliche Expression. Sie wird wie die Scpep1 unter anderem im Plexus chorioideus des Gehirns, im proximalen Tubulus der Niere und in den Zellen der Immunsystems (Satake et al. 1994; Rottier et al. 1998) exprimiert. Die Expression der Scpep1 in stark sekretorisch oder endozytotisch aktiven Zellen, als auch in phagozytotischen Zellen des Immunsystems ist typisch für eine lysosomale Hydrolase.

\subsubsection{Biosynthese und Prozessierung der Scpep1}

Die Scpep1 wird, wie die meisten anderen lysosomalen Matrixproteine, als Vorläuferprotein synthetisiert, posttranslational modifiziert und spezifisch prozessiert. Die Prozessierung der Scpep1 wurde in Abb. 4.28 schematisch dargestellt. Aus den Überständen von Scpep1-RGS-His6 exprimierenden HT1080 konnte ein 55 kDa großes, sezerniertes Vorläuferprotein der Scpep1 aufgereinigt werden. N-terminale Sequenzierung identifizierte Ile29 als N-terminale Aminosäure des sezernierten Scpep1Vorläuferproteins (4.4.1.1). Die 28 N-terminalen Aminosäuren wurden zudem bioinformatisch als Signalpeptid identifiziert. Das Scpep1-Vorläuferprotein ist glykosyliert (4.5.2), bindet an immobilisierte Mannose-6-Phosphat-Rezeptoren (4.1.5) und wird MPR-abhängig in Fibroblasten endozytiert (4.1.6). Dies identifizierte das Scpep1-Protein als lysosomales Protein, das M6P-abhängig zum endosomalen/ lysosomalen Kompartiment transportiert wird. Durch metabolische Markierung und 
Immunpräzipitation konnte gezeigt werden, dass das $55 \mathrm{kDa}$ große Scpep1Vorläuferprotein in MEF $\mathrm{zu}$ einem $34 \mathrm{kDa}$-Fragment und einem $18 \mathrm{kDa}$-Fragment prozessiert wird, wobei bei der Prozessierung des $34 \mathrm{kDa}-P e p t i d s$ zunächst eine intermediäre $37 \mathrm{kDa}$-Form entsteht (4.5.3). Western Blot Analysen (4.5.1, 4.5.2) wiesen daraufhin, dass es sich bei dem $34 \mathrm{kDa}$-Fragment um die N-terminale Form und bei dem 18 kDa-Fragment um das C-terminale Peptid des Scpep1-Proteins handelt (Abb. 4.28). Eine limitierte Deglykosylierung des Scpep1-Vorläuferproteins und der prozessierten Scpep1-Proteinformen zeigte, dass drei der fünf N-Glykosylierungssequenzen genutzt werden und diese ausschließlich auf dem 34 kDa-Fragment des Proteins lokalisiert sind (4.5.2). Die proteolytische Prozessierung der Scpep1 kann durch Inkubation der Zellen mit $\mathrm{NH}_{4} \mathrm{Cl}$ inhibiert werden (4.5.4), was für einen MPR-abhängigen Transport und für eine Prozessierung des Vorläuferproteins im endosomalen/lysosomalen Kompartiment spricht.

Bei der Prozessierung der intermediären 37 kDa-Proteinform zum 34 kDa-Fragment wird ein etwa 3 kDa großer Anteil des Proteins entfernt. Ob es sich um ein Peptid handelt, das aus der Proteinsequenz proteolytisch entfernt wird oder möglicherweise um eine Prozessierung der N-glykosidisch gebundenen Oligosaccharidketten, ist unklar. Im berechneten Strukturmodell der Scpep1 ragt in dem Sequenzbereich ein Peptidloops aus der globulären Proteindomäne heraus (Abb. 4.9), der das N-terminale und das C-terminale Fragment trennt. Dieses Peptid könnte möglicherweise bei einer proteolytischen Prozessierung der Scpep1 entfernt werden. Eine ähnliche Prozessierung ist für die homologe Serincarboxypeptidase PPCA beschrieben. Die PPCA wird zu einem $\mathrm{N}$-terminalen $32 \mathrm{kDa}$ - und einem C-terminalen $20 \mathrm{kDa}$-Fragment prozessiert, wobei ein $2 \mathrm{kDa}$ großes Peptid von einem N-terminalen, $34 \mathrm{kDa}$ großen Intermediät entfernt wird (Bonten et al. 1995). Auch andere weniger verwandte lysosomale Proteasen erfahren ähnliche Reifungsprozesse. Die lysosomale Cysteinprotease Cathepsin B wird auch in zwei Untereinheiten überführt, wobei an den Kettenenden sequenziell proteolytisch Peptide abgespalten werden (Mach et al. 1992).

Die Untereinheiten der Scpep1-homologen PPCA sind durch eine Disulfidbrücke verbunden (Galjart et al. 1988; Hiraiwa 1999). Die PPCA ist ein homodimeres Protein und die drei Glykosidasen $\beta$-Galactosidase (beta-GAL, EC 3.2.1.23), $\alpha$-Neuraminidase 
(NEUR, EC 3.2.1.18) und $\alpha$-N-Acetylgalactosaminidase (GALNS, EC 3.1.6.4) bilden mit der PPCA hochmolekulare Enzymkomplexe. Durch diese Komplexbildung schützt die PPCA die Glykosidasen vor einer schnellen intralysosomalen Proteolyse. Zudem vermittelt sie den korrekten intrazellulären Transport und die proteolytische Prozessierung ihrer Vorläuferproteine (Ostrowska et al. 2003). Trotz der ähnlichen Prozessierung der Scpep1 und der PPCA unterscheiden sich die beiden Proteine in anderen strukturellen Eigenschaften erheblich. Die Scpep1 eluiert bei der Gelfiltration unter lysosomalen Bedingungen bei einer Größe von etwa $70 \mathrm{kDa}$ (4.5.6). Hochmolekulare Komplexe, die mit der Scpep1 assoziiert sind, wurden nicht detektiert. Die Koelution der Scpep1-Fragmente bei der Gelfiltration deuten darauf hin, dass die Scpep1-Untereinheiten nach der Prozessierung des Proteins weiter interagieren und möglicherweise ein weiteres Peptid binden. Ein homodimerer Proteinkomplex ist unwahrscheinlich. Bei der nicht reduzierenden SDS-PAGE konnte zudem keine Verknüpfung der Scpep1-Untereinheiten durch Disulfid-Brücken festgestellt werden (4.5.1). Die Scpep1-Sequenz enthält fünf Cysteine von denen eine im Signalpeptid, drei im $34 \mathrm{kDa}$-Fragment und eine im $18 \mathrm{kDa}$-Fragment lokalisiert sind (4.2.4). Das Alignment der homologen Serincarboxypeptidasen PPCA, der CPY und der Scpep1 zeigte, dass die Cysteine, die an der Bildung der Disulfidbrücke beteiligt sind, in CPY (Cys 166) und PPCA (Cys 83) konserviert sind, jedoch in der Sequenz der Scpep1 durch ein Glycin ersetzt ist (Abb. 4.8).

\subsubsection{Funktionelle Inaktivierung der Scpep1 im Gene Trap Mausmodell RST426}

Mit Hilfe der ES Zelllinie RST426, die vom Baygenomics Konsortium bezogen wurde (Stryke et al. 2003), konnte ein Scpep1-Gene Trap Mausmodel zur Analyse der Scpep1Funktion etabliert werden. Bei der Gene Trap Methode wird ein Gene Trap Vektorkonstrukts ungerichtet in das Mausgenom integriert. Die Gene Trap Vektorsequenz enthält eine En2-Spleißakzeptorsequenz, die 3' von einem Reportergen-Konstrukt und einem Polyadenylierungssignal flankiert ist. Nach der Transkription des „getrappten“ Gens entsteht beim Spleißen eine Gene Trap mRNA aus der 5'-Exonsequenz des Genes an die 3' die Reportergensequenz des Vektors angefügt ist. Dies führt wiederum zur Expression eines Gene Trap Fusionsproteins mit N-terminalem Proteinanteil des 
„getrappten“ Gens an das C-terminal das Reportergen fusioniert ist. Es ist zu beachten, dass bei der Gene Trap Methode aufgrund des weiterhin exprimierten Proteinanteils keine Inaktivierung des Gens garantiert ist und für jedes Gene Trap Mausmodell gesondert untersucht werden muss.

Durch RT-PCR und Analyse der genomischen Scpep1-Sequenz konnte die Insertion des Gene Trap Vektors in das Intron 7 des Scpep1-Gens bestätigt werden (4.3.3; 4.3.4). Unter Verwendung einer Sonde gegen die Scpep1-Exonsequenz 8 - 13 konnte mit Northern Blot Analyse gezeigt werden, dass die Gene Trap Insertion zur vollständigen Deletion von Exon 8 bis 13 der Scpep1 führt (4.4.3.1). Die Deletion dieses 3'-terminalen Sequenzbereichs des Scpep1-Gens ist vermutlich für die enzymatische Inaktivierung des Scpep1-Proteins hinreichend. Die Aktivität der bekannten Serincarboxypeptidasen wird durch die katalytische Triade Serin-Aspartat-Histidin im aktiven Zentrum der Proteine vermittelt (Rawlings und Barrett 1994; Remington und Breddam 1994). Bei der Scpep1 bilden die Aminosäuren S167, D371 und H431 das aktive Zentrum des Proteins. Das Gene Trap Fusionsprotein besitzt N-terminal eine 219 Aminosäuren große Scpep1Domäne (Abb. 4.10). Der Sequenzbereich, der unter anderem für die Aminosäuren D371 und H431 kodiert, wurde deletiert, so dass das aktive Zentrum des Scpep1 im Gene Trap Fusionsprotein nicht vorliegt. Zudem konnte im Western Blot mit spezifischen Antiseren gegen das Scpep1-Protein bzw. gegen die Neomycin-Domäne des Reportergens gezeigt werden, dass das spezifische, lysosomal lokalisierte $34 \mathrm{kDa}$-Scpep1-Signal in Gewebe von Scpep1-defizienten Gene Trap Mäusen nicht nachweisbar ist (Abb. 4.17; Abb. 4.19). Im Gegenzug konnte dafür das Gene Trap Fusionsprotein als 200 kDa-Signal detektiert werden, das nach subzellulärer Fraktionierung jedoch in der mikrosomalen Fraktion und nicht in der lysosomalen Fraktion lokalisiert werden konnte (Abb. 4.17; Abb. 4.19), so dass von einem Funktionsverlust der Scpep1 in den RST426 Mäusen ausgegangen werden kann.

\subsubsection{Identifizierung der enzymatischen Aktivität der Scpep1}

Die Sequenzanalyse identifizierte die Scpep1 als eine Peptidase der Serincarboxypeptidase Familie S10 (4.2.2). Peptidasen stellen eine Untergruppe der Hydrolasen dar, die nach ihrem katalytischen Mechanismus klassifiziert werden können 
(Barrett 1980). Bei den Peptidasen findet man vier verschiedene Hydrolysemechanismen (Hartley 1960). Die Nomenklatur der Peptidasen beschreibt die katalytisch aktiven Aminosäurereste bzw. Metallionen, die im aktiven Zentrum der Peptidasen lokalisiert sind und die hydrolytische Aktivität des Enzyms vermitteln. Peptidasen werden daher als Serinpeptidasen, Cysteinpeptidasen, Aspartatpeptidasen oder Metalloproteasen klassifiziert. Die Serinpeptidasen besitzen im katalytischen Zentrum einen Serinrest, der für die Aktivität des Enzyms essenziell ist. Serinpeptidasen findet man in Eukaryonten, als auch in Viren und Bakterien. Sie sind Endo-, Exo- und Oligopeptidasen, die in 20 Peptidasefamilien unterteilt werden können (Rawlings und Barrett 1993). Die Peptidasen der Serinpeptidase Familie S10 gehören dem Serincarboxypeptidase Clan C an. Sie sind Carboxypeptidasen mit einer Triade aus den drei katalytisch aktiven Aminosäureresten Serin, Aspartat und Histidin im aktiven Zentrum. Sie kommen ausschließlich im eukaryontischen System vor, werden als Präproenzyme synthetisiert, proteolytisch prozessiert und sind in den Lysosomen bzw. in den Vakuolen lokalisiert, zudem besitzen sie im sauren $\mathrm{pH}$-Bereich maximale katalytische Aktivität (Remington und Breddam 1994). In höheren Eukaryonten wurden einschließlich der Scpep1 vier Enzyme als lysosomale Serincarboxypeptidasen identifiziert. Dabei handelt es sich um die orthologen Proteine Scpep1, PPCA und CPVL (vitellogenic-like carboxypeptidase) der Peptidase Familie S10, sowie die lysosomale Prolylcarboxypeptidase (Prcp), bei der es sich um eine Serincarboxypeptidase der Familie S28 handelt, die keine Sequenzhomologie zu den Proteinen der S10 Familie aufweist.

Um die Substratspezifität der Peptidasen darzustellen, wurde ein System eingeführt, das die Aminosäuren des Substratpeptids beschreibt. C-terminal an die spaltbare Peptidbindung angrenzende Aminosäuren werden als P1, P2, P3 usw. bezeichnet. Aminosäuren, die die Spaltstelle N-terminal flankieren, nennt man P1', P2' und P3' (Schechter und Berger 1967). Die Scpep1-homologe PPCA besitzt neben einer Carboxypeptidase-Aktivität, auch Desamidase- und Esterase-Aktivität und zeigt starke Affinität zu Substraten mit hydrophoben Aminosäuren an Position P1 und P1' (Pshezhetsky et al. 1995). Das PPCA-Vorläuferprotein ist enzymatisch inaktiv. Die enzymatische Aktivierung der PPCA erfolgt durch die proteolytische Prozessierung im endosomalen/lysosomalen Kompartiment (Bonten et al. 1995). In vitro hydrolysiert die 
PPCA eine Anzahl von regulatorischen Peptiden, wie Angiotensin I, Met-enkephalin, Oxytocin und Endothelin-1 (Jackman et al. 1990; Jackman et al. 1992). Die enzymatische Aktivität und Funktion der CPVL ist nicht bekannt (Harris et al. 2006). Aufgrund der Sequenzhomologie von Scpep1 und PPCA wurden für die Bestimmung der Scpep1Carboxypeptidase-Aktivität hydrophobe, N-terminal blockierte Dipeptide als artifizielle Substrate eingesetzt, die auch zur Bestimmung der PPCA-Aktivität genutzt wurden (Pshezhetsky et al. 1995). Wie das PPCA-Vorläuferprotein wies auch das aufgereinigte Scpep1-Vorläuferprotein keine enzymatische Aktivität auf (4.6.1). Zur Untersuchung der enzymatischen Aktivität des proteolytisch prozessierten Scpep1 wurde anschließend die saure Carboxypeptidase-Aktivität in Zell- und Gewebehomogenaten bestimmt. In Scpep1-defizienten embryonalen Mausfibroblasten und in Darmhomogenaten der Scpep1-defizienten Mäuse konnte eine signifikante Reduzierung der Serincarboxypeptidase-Aktivität gegenüber normalen embryonalen Mausfibroblasten gemessen werden (4.6.2). Die Scpep1-defizienten Gewebe (Darm, Leber, Niere) zeigten je nach Gewebetyp eine Reduzierung der Serincarboxypeptidase zwischen 10 und $50 \%$, während in Milz keine verminderte Aktivität gemessen wurde. Aufgrund der starken Hintergrundsaktivität, die durch andere Peptidasen, vor allem durch die PPCA-Aktivität verursacht wurde, konnte unter Verwendung der unspezifischen Dipeptid-Substrate nur eine Reduzierung der Gesamtaktivität aller Serincarboxypeptidasen in Scpep1-defizienten Geweben bestimmt werden, und keine völlige Inaktivierung. Es ist bekannt, dass auch PPCA-defiziente Mausgewebe eine Serincarboxypeptidase-Restaktivität von etwa $5 \%$ (Zhou et al. 1995) aufweisen. Differentielle Analysen an Scpepl-defizienten und Kontrollmäusen weisen aufgrund der verminderten Serincarboxypeptidase-Aktivität darauf hin, dass es sich bei der Scpep1 neben der PPCA tatsächlich um eine zweite, aktive, lysosomale Serincarboxypeptidase handelt. Zur Bestätigung der enzymatischen Aktivität der Scpep1, sowie für die Analyse der Enzymkinetik und der Substratspezifität der Scpep1 ist es jedoch notwendig, das endogene, proteolytisch prozessierte Protein aufzureinigen, um spezifische Aktivitätsbestimmungen ohne die beschriebene Hintergrundsaktivität durchführen zu können. 


\subsubsection{Scpep1-defiziente Mäuse zeigen keinen pathologischen Phänotyp}

Im Vergleich zu gleichaltrigen Geschwistertieren zeigten Scpep1-defiziente Mäuse keinerlei äußerliche Auffälligkeiten (4.7.1). Ihr Verhalten wurde in standardisierten Verhaltenstests untersucht und erwies sich als normal (4.7.2). Scpep1-defiziente Mäuse sind fertil und haben eine normale Lebensdauer (4.7.1). Bei der Analyse genereller, lysosomaler Parameter, wie der Integrität, der Größe und Verteilung der Lysosomen konnten keine Veränderungen bei Scpep1-defizienten Mäusen festgestellt werden (4.7.4). Durch diese Untersuchungen, sowie durch lichtmikroskopische, histologische Analysen an verschiedenen Geweben der Scpep1-defizienten Mäuse konnten keine Hinweise auf eine lysosomale Speicherung gefunden werden (4.7.3).

Eine Reihe von Knock Out-Mausmodellen für lysosomale Proteasen manifestieren sich mit vergleichsweise mildem Phänotyp. Beispiele für diese milden Phänotypen bei lysosomaler Protease-Defizienz sind Mausmodelle mit Cathepsin B- (Deussing et al. 1998), Cathepsin G- (MacIvor et al. 1999) und Asparaginylendopeptidase-Defizienz (Shirahama-Noda et al. 2003). Als eine Begründung für den milden Phänotyp könnte angeführt werden, dass einige lysosomale Proteasen eine funktionelle Redundanz besitzen (Nagler und Menard 2003). So zeigen Cathepsin B- oder Cathepsin L-defiziente Mäuse jeweils einen milden Phänotypen, eine Doppeldefizienz der beiden Cathepsine führt hingegen zu einer Hirnatrophie und zum Tod der vier Wochen alten Tiere. Andere lysosomale Proteasen besitzen hingegen essenzielle, spezifische Funktionen. So erfüllt die Aspartatprotease Cathepsin D spezifische Aufgaben, die offensichtlich nicht durch andere Proteasen abgedeckt werden können. Cathepsin D-defiziente Mäuse sterben im Alter von drei Wochen aufgrund von nekrotischen Veränderungen des Darmgewebes und massiver Destruktion der lymphatischen Gewebe. In Neuronen des ZNS wurden zudem lysosomale Ceroid Lipofuscin-Speicherungen nachgewiesen (Saftig et al. 1995; Koike et al. 2000). Mutationen des Cathepsin D führen beim Menschen zur Cathepsin Ddefizienten NCL (neuronal ceroid lipofuscinosis) (Steinfeld et al. 2006), einer neurodegenerativen Erkrankung mit motorischen und visuellen Beschwerden.

Der unauffällige Phänotyp der Scpep1-defizienten Mäuse und die fehlende lysosomale Speicherung lassen darauf schließen, dass zumindest der Hauptteil der allgemeinen, lysosomalen Proteolyse (die sogenannte Bulk Proteolyse) nicht beeinträchtigt ist. Neben 
der Scpep1 werden in Mausgeweben die paralogen Serincarboxypeptidasen PPCA und CPVL, sowie die lysosomale Prolylcarboxypeptidase exprimiert. Die Substratspezifität von PPCA und Scpep1 ist bei Verwendung der artifiziellen Substrate sehr ähnlich und eine funktionelle Redundanz der Serincarboxypeptidase-Aktivitäten könnte ursächlich für den milden Phänotyp der Scpep1-defizienten Mäuse sein. Nicht ausgeschlossen werden kann, dass Scpep1 für die Proteolyse definierter Peptidbindungen bestimmter Proteine verantwortlich ist, die noch nicht identifiziert werden konnten. Die Defizienz lysosomaler Glykosidasen führt fast in allen Fällen zu einer lysosomalen Speichererkrankung (LSD). Im Gegensatz dazu sind über 20 lysosomale Proteasen bekannt und nur fünf bekannte, lysosomale Speichererkrankungen lassen sich auf eine Protease-Defizienz zurückführen. Dabei handelt es sich um die bereits erwähnte Cathepsin D-defiziente NCL (Steinfeld et al. 2006), um die NCLs vom Typ CLN1 (Tripeptidylpeptidase-Defizienz) (Mitchison et al. 1998) und CLN 2 (Palmitoyl-Proteinthioesterase-Defizienz) (Ezaki et al. 2000), sowie um die Pycnodysostosis, die durch eine Cathepsin K-Defizienz verursacht wird (Saftig et al. 1998).

\subsection{Ausblick}

In weiterführenden Experimenten soll zunächst die Prozessierung der Scpep1 näher analysiert werden. Dabei ist $\mathrm{zu}$ untersuchen, ob es sich um einen sequenziellen, proteolytischen Prozess handelt oder ob eine zusätzliche Modifikation der N-glykosidisch gebundenen Oligosaccharide stattfindet. Zudem sollten die beteiligten Hydrolasen identifiziert werden. Dazu kann die Scpep1-Prozessierung in Pulse/Chase-Experimenten in Anwesenheit von Proteaseinhibitoren untersucht werden.

Im Mittelpunkt der Untersuchungen wird zudem die Untersuchung der Scpep1-Aktivität stehen. Zur Analyse der Enzym-Kinetik der Scpep1 soll die endogene, aktive Form der Scpep1 aufgereinigt werden und mit artifiziellen Substraten untersucht werden. Des Weiteren soll das endogene Substrat der Scpep1 identifiziert werden. Substrate und andere Bindungspartner können unter anderem affinitätschromatografisch unter Verwendung von immobilisiertem Scpep1 isoliert werden. Um die physiologische Bedeutung der Scpep1 zu ermitteln, soll zudem in Scpep1-defizienten Mäusen intensiv nach pathophysiologischen Veränderungen gesucht werden. Dabei könnte es hilfreich 
sein, die Untersuchungen auf Zelltypen zu konzentrieren, in denen die Scpep1 stark exprimiert wird. Im klassischen Knock Out-Mausmodell für die PPCA ist das gesamte PPCA-Protein deletiert, so dass neben der enzymatischen Aktivität des Proteins auch die Schutzfunktion für die Glykosidasen $\beta$-Galactosidase und $\alpha$-Neuraminidase fehlt (Zhou et al. 1995). Die Pathologie dieser PPCA-defizienten Mäuse kann größtenteils auf den Verlust der $\beta$-Galactosidase sowie der Neuraminidase-Aktivität zurückgeführt werden. Einige klinische Erscheinungsformen der Galactosialidosis, wie Hypertension und die Kardiomyopathie (Kyllerman et al. 1993; d'Azzo A. 1995; de Geest et al. 2002), lassen sich jedoch nicht durch den Verlust der $\beta$-Galactosidase- sowie der NeuraminidaseAktivität erklären. Es konnte gezeigt werden, dass PPCA in vitro eine Anzahl von regulatorischen Peptiden, wie Angiotensin I, Met-enkephalin, Oxytocin und Endothelin-1 hydrolysiert (Jackman et al. 1990; Jackman et al. 1992). Zudem zeigen Fibroblasten von Galactosialidosis-Patienten eine reduzierte Endothelin-1-Degradation, (Jackman et al. 1993; Itoh et al. 1995; Itoh et al. 2000). Möglicherweise ist die SerincarboxypeptidaseAktivität der Scpep1 an der Regulation von Peptidhormonen beteiligt, wie es bereits für die PPCA angenommen wird.

Eine Möglichkeit die physiologische Bedeutung der Gesamt-Serincarboxypeptidaseaktivität zu ermitteln, besteht darin, in einem doppelten oder auch dreifachen-Knock Out die Aktivität aller paraloger, lysosomaler Serincarboxypeptidasen auszuschalten. Um ausschließlich die Auswirkungen der Serincarboxypeptidase-Inaktivierung in einem Mausmodell zu untersuchen, wäre ein Knock-In-Mausmodell mit einer Mutation im aktiven Zentrum der PPCA sinnvoll, bei dem die Schutzfunktion der PPCA erhalten bliebe. Diese Mausmodell wäre wiederum zur Kreuzung mit der Scpep1-defizienten Maus besonders geeignet, um die Funktion der Serincarboxypeptidaseaktivität in vivo zu klären. 


\section{$6 \quad$ Zusammenfassung}

Zur Untersuchung des Proteoms lysosomaler Matrixproteine wurden M6P-haltige Proteine durch Mannose-6-Phosphatrezeptor (MPR)-Affinitätschromatografie isoliert und durch 2D-GE und MALDI-TOF-MS Analyse, sowie durch die Multidimensional Protein Identification Technology (MudPIT) identifiziert. Bei der Proteomanalyse konnten insgesamt 32 bekannte lysosomale Proteine und vier putativ lysosomale Proteine nachgewiesen werden. Bei den putativ lysosomalen Proteinen handelte es sich um die Proteine Scpep1, MERP-2, Progranulin und das 66.3 kDa-Protein. In ersten Analysen konnte gezeigt werden, dass die Proteine Scpep1, MERP-2 und das 66.3 kDa-Protein nach Expression mit einem C-terminalen Peptidtag an die MPRAffinitätschromatografiesäule binden und MPR-abhängig in die Lysosomen von Fibroblasten endozytiert werden. Das rekombinant exprimierte Progranulin zeigte hingegen keine Bindungsaffinität gegenüber den MPR.

Im Anschluss an die Proteomanalyse wurde das Scpep1-Protein näher charakterisiert. Mit Hilfe von spezifischen Antiseren konnte die lysosomale Lokalisation der endogenen Scpep1 durch indirekte Immunfluoreszenz, sowie durch subzelluläre Fraktionierung mit anschließender Western Blot Analyse nachgewiesen werden. Das Protein wird als Präproenzym mit einem N-terminalen Signalpeptid synthetisiert und als 55 kDa großes, dreifach glykosyliertes Proenzym zum endosomalen/lysosomalen Kompartiment transportiert. Dort wird das Proenzym durch limitierte Proteolyse zu einer Proteinform mit einer $\mathrm{N}$-terminalen $34 \mathrm{kDa}$ - und einer C-terminalen $18 \mathrm{kDa}$-Untereinheit prozessiert.

Zur Untersuchung der Scpep1-Funktion wurde ein Gene Trap Mausmodell etabliert. Der Knock Out des Scpep1-Proteins im Mausmodell RST426 konnte durch Northern und Western Blot bestätigt werden. Durch die differentielle Analyse der Serincarboxypeptidase-Aktivität bei $\mathrm{pH} 4,5$ in Zell- und Gewebehomogenaten von Kontrolltieren und Scpep1-defizienten Mäusen konnte eine signifikante Reduzierung der Gesamtaktivität aller lysosomaler Serincarboxypeptidasen nachgewiesen werden, was darauf hinweist, dass es sich bei der Scpep1 um eine aktive, lysosomale Serincarboxypeptidase handelt. 
Durch histologische Untersuchungen und biochemische Analysen konnten keine pathologischen Veränderungen der Scpep1-defizienten Mäuse identifiziert werden. Das physiologische Substrat der Scpep1 konnte nicht identifiziert werden und die physiologische Bedeutung der Scpep1 blieb ungeklärt. 


\section{$7 \quad$ Literaturverzeichnis}

Ahle, S. and E. Ungewickell (1989). "Identification of a clathrin binding subunit in the HA2 adaptor protein complex." J Biol Chem 264(33): 20089-93.

Alwine, J. C., D. J. Kemp, et al. (1977). "Method for detection of specific RNAs in agarose gels by transfer to diazobenzyloxymethyl-paper and hybridization with DNA probes." Proc Natl Acad Sci U S A 74(12): 5350-4.

Arnold, K., L. Bordoli, et al. (2006). "The SWISS-MODEL workspace: a web-based environment for protein structure homology modelling." Bioinformatics 22(2): 195-201.

Babel, D., G. Walter, et al. (1991). "Studies on human porin. VI. Production and characterization of eight monoclonal mouse antibodies against the human VDAC "Porin 31HL" and their application for histotopological studies in human skeletal muscle." Biol Chem Hoppe Seyler 372(12): 1027-34.

Barrett, A. J. (1980). "The many forms and functions of cellular proteinases." $\underline{\text { Fed Proc }}$ 39(1): 9-14.

Belmonte, S. A., A. Challa, et al. (1998). "alpha-Mannosidase from rat epididymal fluid is a ligand for phosphomannosyl receptors on the sperm surface." Int J Androl 21(5): 277-82.

Bode, S., C. Peters, et al. (2005). "Placental cathepsin M is alternatively spliced and exclusively expressed in the spongiotrophoblast layer." Biochim Biophys Acta 1731(3): 160-7.

Bonten, E. J., N. J. Galjart, et al. (1995). "Lysosomal protective protein/cathepsin A. Role of the "linker" domain in catalytic activation." J Biol Chem 270(44): 26441-5.

Bowers, W. E. and C. de Duve (1967). "Lysosomes in lymphoid tissue. III. Influence of various treatments of the animals on the distribution of acid hydrolases." J Cell Biol 32(2): 349-64.

Braulke, T., H. J. Geuze, et al. (1987). "On the effects of weak bases and monensin on sorting and processing of lysosomal enzymes in human cells." Eur J Cell Biol 43(3): 316-21.

Braun, M., A. Waheed, et al. (1989). "Lysosomal acid phosphatase is transported to lysosomes via the cell surface." EMBO J 8(12): 3633-40.

Brix, K., M. Linke, et al. (2001). "Cysteine proteinases mediate extracellular prohormone processing in the thyroid." Biol Chem 382(5): 717-25.

Caeyenberghs, K., D. Balschun, et al. (2006). "Multivariate neurocognitive and emotional profile of a mannosidosis murine model for therapy assessment." Neurobiol Dis 23(2): 422-32. 
Chataway, T. K., A. M. Whittle, et al. (1998). "Two-dimensional mapping and microsequencing of lysosomal proteins from human placenta." Placenta 19(8): 643-54.

Chen, J. W., T. L. Murphy, et al. (1985). "Identification of two lysosomal membrane glycoproteins." J Cell Biol 101(1): 85-95.

Cosma, M. P., S. Pepe, et al. (2003). "The multiple sulfatase deficiency gene encodes an essential and limiting factor for the activity of sulfatases." Cell 113(4): 445-56.

Cuppoletti, J., D. Aures-Fischer, et al. (1987). "The lysosomal H+ pump: 8-azido-ATP inhibition and the role of chloride in $\mathrm{H}+$ transport." Biochim Biophys Acta 899(2): 276-84.

d'Azzo A., A. G., Strisciuglio P., Galjaard H. (1995). Galactosialidosis. T he Metabolic and Molecular Bases of Inherited Disease. B. A. L. Scriver C.R., Sly W.S., Valle D., eds. New York, McGraw-Hill: 2825-2837.

Dahms, N. M., P. Lobel, et al. (1989). "Mannose 6-phosphate receptors and lysosomal enzyme targeting." J Biol Chem 264(21): 12115-8.

Dai, K. S. and C. C. Liew (2001). "A novel human striated muscle RING zinc finger protein, SMRZ, interacts with SMT3b via its RING domain." J Biol Chem 276(26): 23992-9.

de Duve, C. (1969). The lysosome in retrospect. Lysosomes in Biology and Pathology. D. J. D. a. F. H. Amsterdam, North-Holland Publishing Company. 1: 3-40.

de Duve, C. (1983). "Lysosomes revisited." Eur J Biochem 137(3): 391-7.

De Duve, C., B. C. Pressman, et al. (1955). "Tissue fractionation studies. 6. Intracellular distribution patterns of enzymes in rat-liver tissue." Biochem J 60(4): 604-17.

De Duve, C. and R. Wattiaux (1966). "Functions of lysosomes." Annu Rev Physiol 28: 435-92.

de Geest, N., E. Bonten, et al. (2002). "Systemic and neurologic abnormalities distinguish the lysosomal disorders sialidosis and galactosialidosis in mice." Hum Mol Genet 11(12): 1455-64.

Della Valle, M. C., D. E. Sleat, et al. (2006). "Demonstration of lysosomal localization for the mammalian ependymin-related protein using classical approaches combined with a novel density shift method." J Biol Chem 281(46): 35436-45.

Deuschl, F., K. Kollmann, et al. (2006). "Molecular characterization of the hypothetical $66.3-\mathrm{kDa}$ protein in mouse: lysosomal targeting, glycosylation, processing and tissue distribution." FEBS Lett 580(24): 5747-52.

Deussing, J., W. Roth, et al. (1998). "Cathepsins B and D are dispensable for major histocompatibility complex class II-mediated antigen presentation." Proc Natl Acad Sci U S A 95(8): 4516-21.

Di Bacco, A. and G. Gill (2003). "The secreted glycoprotein CREG inhibits cell growth dependent on the mannose-6-phosphate/insulin-like growth factor II receptor." Oncogene 22(35): 5436-45.

Dierks, T., B. Schmidt, et al. (2003). "Multiple sulfatase deficiency is caused by mutations in the gene encoding the human $\mathrm{C}(\mathrm{alpha})$-formylglycine generating enzyme." Cell 113(4): 435-44. 
Dittmer, F., A. Hafner, et al. (1998). "I-cell disease-like phenotype in mice deficient in mannose 6-phosphate receptors." Transgenic Res 7(6): 473-83.

Dittmer, F., R. Pohlmann, et al. (1997). "The phosphorylation pattern of oligosaccharides in secreted procathepsin D is glycosylation site-specific and independent of the expression of mannose 6-phosphate receptors." J Biol Chem 272(2): 852-8.

Dittmer, F., E. J. Ulbrich, et al. (1999). "Alternative mechanisms for trafficking of lysosomal enzymes in mannose 6-phosphate receptor-deficient mice are cell typespecific." J Cell Sci 112 ( Pt 10): 1591-7.

Docherty, K., G. V. Brenchley, et al. (1979). "The permeability of rat liver lysosomes to sugars. Evidence for carrier-mediated facilitated diffusion." Biochem J 178(2): 361-6.

Einstein, R. and C. A. Gabel (1991). "Cell- and ligand-specific dephosphorylation of acid hydrolases: evidence that the mannose 6-phosphatase is controlled by compartmentalization." J Cell Biol 112(1): 81-94.

Eskelinen, E. L., Y. Tanaka, et al. (2003). "At the acidic edge: emerging functions for lysosomal membrane proteins." Trends Cell Biol 13(3): 137-45.

Ezaki, J., M. Takeda-Ezaki, et al. (2000). "Characterization of endopeptidase activity of tripeptidyl peptidase-I/CLN2 protein which is deficient in classical late infantile neuronal ceroid lipofuscinosis." Biochem Biophys Res Commun 268(3): 904-8.

Fuchs, R. L., J. E. Ream, et al. (1993). "Safety assessment of the neomycin phosphotransferase II (NPTII) protein." Biotechnology (N Y) 11(13): 1543-7.

Fukuda, M. (1991). "Lysosomal membrane glycoproteins. Structure, biosynthesis, and intracellular trafficking." J Biol Chem 266(32): 21327-30.

Futerman, A. H. and G. van Meer (2004). "The cell biology of lysosomal storage disorders." Nat Rev Mol Cell Biol 5(7): 554-65.

Galjart, N. J., N. Gillemans, et al. (1988). "Expression of cDNA encoding the human "protective protein" associated with lysosomal beta-galactosidase and neuraminidase: homology to yeast proteases." Cell 54(6): 755-64.

Geuze, H. J. (1998). "The role of endosomes and lysosomes in MHC class II functioning." Immunol Today 19(6): 282-7.

Ghosh, P., N. M. Dahms, et al. (2003). "Mannose 6-phosphate receptors: new twists in the tale." Nat Rev Mol Cell Biol 4(3): 202-12.

Gieselmann, V. (1995). "Lysosomal storage diseases." Biochim Biophys Acta 1270(2-3): 103-36.

Haas, A. (2007). "The phagosome: compartment with a license to kill." Traffic 8(4): 31130.

Harris, J., N. Schwinn, et al. (2006). "A vitellogenic-like carboxypeptidase expressed by human macrophages is localized in endoplasmic reticulum and membrane ruffles." Int J Exp Pathol 87(1): 29-39.

Hartley, B. S. (1960). "Proteolytic enzymes." Annu Rev Biochem 29: 45-72.

Hartley, J. L., G. F. Temple, et al. (2000). "DNA cloning using in vitro site-specific recombination." Genome Res 10(11): 1788-95. 
Hasilik, A. (1992). "The early and late processing of lysosomal enzymes: proteolysis and compartmentation." Experientia 48(2): 130-51.

Helenius, A. and M. Aebi (2001). "Intracellular functions of N-linked glycans." Science 291(5512): 2364-9.

Heukeshoven, J. and R. Dernick (1988). "Improved silver staining procedure for fast staining in PhastSystem Development Unit. I. Staining of sodium dodecyl sulfate gels." Electrophoresis 9(1): 28-32.

Hiraiwa, M. (1999). "Cathepsin A/protective protein: an unusual lysosomal multifunctional protein." Cell Mol Life Sci 56(11-12): 894-907.

Hoflack, B., K. Fujimoto, et al. (1987). "The interaction of phosphorylated oligosaccharides and lysosomal enzymes with bovine liver cation-dependent mannose 6-phosphate receptor." J Biol Chem 262(1): 123-9.

Hoflack, B. and S. Kornfeld (1985). "Purification and characterization of a cationdependent mannose 6-phosphate receptor from murine P388D1 macrophages and bovine liver." J Biol Chem 260(22): 12008-14.

Honing, S., I. V. Sandoval, et al. (1998). "A di-leucine-based motif in the cytoplasmic tail of LIMP-II and tyrosinase mediates selective binding of AP-3." EMBO J 17(5): 1304-14.

Hughes, E. N. and J. T. August (1981). "Characterization of plasma membrane proteins identified by monoclonal antibodies." J Biol Chem 256(2): 664-71.

Hunziker, W. and H. J. Geuze (1996). "Intracellular trafficking of lysosomal membrane proteins." Bioessays 18(5): 379-89.

Itoh, K., R. Kase, et al. (1995). "Protective protein as an endogenous endothelin degradation enzyme in human tissues." J Biol Chem 270(2): 515-8.

Itoh, K., K. Oyanagi, et al. (2000). "Endothelin-1 in the brain of patients with galactosialidosis: its abnormal increase and distribution pattern." Ann Neurol 47(1): 122-6.

Jackman, H. L., P. W. Morris, et al. (1992). "Inactivation of endothelin I by deamidase (lysosomal protective protein)." J Biol Chem 267(5): 2872-5.

Jackman, H. L., P. W. Morris, et al. (1993). "Inactivation of endothelin-1 by an enzyme of the vascular endothelial cells." Hypertension 21(6 Pt 2): 925-8.

Jackman, H. L., F. L. Tan, et al. (1990). "A peptidase in human platelets that deamidates tachykinins. Probable identity with the lysosomal "protective protein"." J Biol Chem 265(19): 11265-72.

Jensen, A. G., M. Chemali, et al. (2007). "Biochemical characterization and lysosomal localization of the mannose-6-phosphate protein p76 (hypothetical protein LOC196463)." Biochem J 402(3): 449-58.

Journet, A., A. Chapel, et al. (2000). "Towards a human repertoire of monocytic lysosomal proteins." Electrophoresis 21(16): 3411-9.

Journet, A., A. Chapel, et al. (2002). "Proteomic analysis of human lysosomes: application to monocytic and breast cancer cells." Proteomics 2(8): 1026-40. 
Kasper, D., F. Dittmer, et al. (1996). "Neither type of mannose 6-phosphate receptor is sufficient for targeting of lysosomal enzymes along intracellular routes." J Cell Biol 134(3): 615-23.

Klose, J. (1975). "Protein mapping by combined isoelectric focusing and electrophoresis of mouse tissues. A novel approach to testing for induced point mutations in mammals." Humangenetik 26(3): 231-43.

Koike, M., H. Nakanishi, et al. (2000). "Cathepsin D deficiency induces lysosomal storage with ceroid lipofuscin in mouse CNS neurons." J Neurosci 20(18): 6898906.

Kollmann, K., K. E. Mutenda, et al. (2005). "Identification of novel lysosomal matrix proteins by proteome analysis." Proteomics 5(15): 3966-78.

Kopp, J. and T. Schwede (2004). "The SWISS-MODEL Repository of annotated threedimensional protein structure homology models." Nucleic Acids Res 32(Database issue): D230-4.

Kornfeld, R. and S. Kornfeld (1985). "Assembly of asparagine-linked oligosaccharides." Annu Rev Biochem 54: 631-64.

Kornfeld, S. (1986). "Trafficking of lysosomal enzymes in normal and disease states." $\underline{J}$ Clin Invest 77(1): 1-6.

Kornfeld, S. and I. Mellman (1989). "The biogenesis of lysosomes." $\underline{\text { Annu Rev Cell Biol }}$ 5: $483-525$.

Kornfeld, S., Sly, W.S. (2000). I-cell disease and pseudo-hurler polydystrophy: Disorder of lysosomal enzyme phosphorylation and localization. The metabolic and molecular bases of inherited disease. Scriver. New York, McGraw-Hill Professional: 3469-3482.

Kyllerman, M., J. E. Mansson, et al. (1993). "Infantile galactosialidosis presenting with congenital adrenal hyperplasia and renal hypertension." Pediatr Neurol 9(4): 31822.

Laemmli, U. K. (1970). "Cleavage of structural proteins during the assembly of the head of bacteriophage T4." Nature 227(5259): 680-5.

Lang, L., M. Reitman, et al. (1984). "Lysosomal enzyme phosphorylation. Recognition of a protein-dependent determinant allows specific phosphorylation of oligosaccharides present on lysosomal enzymes." J Biol Chem 259(23): 1466371.

Lawrence, B. P. and W. J. Brown (1992). "Autophagic vacuoles rapidly fuse with preexisting lysosomes in cultured hepatocytes." J Cell Sci 102 ( Pt 3): 515-26.

Lazzarino, D. A. and C. A. Gabel (1988). "Biosynthesis of the mannose 6-phosphate recognition marker in transport-impaired mouse lymphoma cells. Demonstration of a two-step phosphorylation." J Biol Chem 263(21): 10118-26.

Lee, T. H., J. W. Streb, et al. (2006). "Tissue expression of the novel serine carboxypeptidase Scpep1." J Histochem Cytochem 54(6): 701-11.

Leighton, F., B. Poole, et al. (1968). "The large-scale separation of peroxisomes, mitochondria, and lysosomes from the livers of rats injected with triton WR-1339. Improved isolation procedures, automated analysis, biochemical and morphological properties of fractions." J Cell Biol 37(2): 482-513. 
Lemansky, P., V. Gieselmann, et al. (1984). "Cathepsin D and beta-hexosaminidase synthesized in the presence of 1-deoxynojirimycin accumulate in the endoplasmic reticulum." J Biol Chem 259(16): 10129-35.

Lemansky, P., A. Hasilik, et al. (1987). "Lysosomal enzyme precursors in coated vesicles derived from the exocytic and endocytic pathways." J Cell Biol 104(6): 1743-8.

Link, A. J., J. Eng, et al. (1999). "Direct analysis of protein complexes using mass spectrometry." Nat Biotechnol 17(7): 676-82.

Liou, W., H. J. Geuze, et al. (1997). "The autophagic and endocytic pathways converge at the nascent autophagic vacuoles." J Cell Biol 136(1): 61-70.

Lowry, O. H., N. J. Rosebrough, et al. (1951). "Protein measurement with the Folin phenol reagent." J Biol Chem 193(1): 265-75.

Luzio, J. P., P. R. Pryor, et al. (2007). "Lysosomes: fusion and function." Nat Rev Mol Cell Biol 8(8): 622-32.

Mach, L., K. Stuwe, et al. (1992). "Proteolytic processing and glycosylation of cathepsin B. The role of the primary structure of the latent precursor and of the carbohydrate moiety for cell-type-specific molecular forms of the enzyme." Biochem J 282 ( Pt 2): 577-82.

MacIvor, D. M., S. D. Shapiro, et al. (1999). "Normal neutrophil function in cathepsin Gdeficient mice." Blood 94(12): 4282-93.

Meijer, A. J. and P. Codogno (2004). "Regulation and role of autophagy in mammalian cells." Int J Biochem Cell Biol 36(12): 2445-62.

Meyer-Siegler, K., D. J. Mauro, et al. (1991). "A human nuclear uracil DNA glycosylase is the 37-kDa subunit of glyceraldehyde-3-phosphate dehydrogenase." Proc Natl Acad Sci U S A 88(19): 8460-4.

Mitchison, H. M., S. L. Hofmann, et al. (1998). "Mutations in the palmitoyl-protein thioesterase gene (PPT; CLN1) causing juvenile neuronal ceroid lipofuscinosis with granular osmiophilic deposits." Hum Mol Genet 7(2): 291-7.

Moore, S. and W. H. Stein (1954). "A modified ninhydrin reagent for the photometric determination of amino acids and related compounds." J Biol Chem 211(2): 90713.

Morgan, D. O., J. C. Edman, et al. (1987). "Insulin-like growth factor II receptor as a multifunctional binding protein." Nature 329(6137): 301-7.

Mortensen, U. H., S. J. Remington, et al. (1994). "Site-directed mutagenesis on (serine) carboxypeptidase Y. A hydrogen bond network stabilizes the transition state by interaction with the C-terminal carboxylate group of the substrate." Biochemistry 33(2): 508-17.

Nagler, D. K. and R. Menard (2003). "Family C1 cysteine proteases: biological diversity or redundancy?" Biol Chem 384(6): 837-43.

Neuhoff, V., N. Arold, et al. (1988). "Improved staining of proteins in polyacrylamide gels including isoelectric focusing gels with clear background at nanogram sensitivity using Coomassie Brilliant Blue G-250 and R-250." Electrophoresis 9(6): 255-62. 
O'Farrell, P. H. (1975). "High resolution two-dimensional electrophoresis of proteins." $\underline{\mathrm{J}}$ Biol Chem 250(10): 4007-21.

Ohkuma, S. and B. Poole (1978). "Fluorescence probe measurement of the intralysosomal $\mathrm{pH}$ in living cells and the perturbation of $\mathrm{pH}$ by various agents." Proc Natl Acad Sci U S A 75(7): 3327-31.

Ostrowska, H., K. Krukowska, et al. (2003). "Lysosomal high molecular weight multienzyme complex." Cell Mol Biol Lett 8(1): 19-24.

Perkins, D. N., D. J. Pappin, et al. (1999). "Probability-based protein identification by searching sequence databases using mass spectrometry data." Electrophoresis 20(18): 3551-67.

Peters, C. and K. von Figura (1994). "Biogenesis of lysosomal membranes." FEBS Lett 346(1): 108-14.

Peterson, G. L. (1979). "Review of the Folin phenol protein quantitation method of Lowry, Rosebrough, Farr and Randall." Anal Biochem 100(2): 201-20.

Pohlmann, R., M. W. Boeker, et al. (1995). "The two mannose 6-phosphate receptors transport distinct complements of lysosomal proteins." J Biol Chem 270(45): 27311-8.

Pohlmann, R., C. Krentler, et al. (1988). "Human lysosomal acid phosphatase: cloning, expression and chromosomal assignment." EMBO J 7(8): 2343-50.

Preusser-Kunze, A., M. Mariappan, et al. (2005). "Molecular characterization of the human Calpha-formylglycine-generating enzyme." J Biol Chem 280(15): 1490010.

Prill, V., L. Lehmann, et al. (1993). "The cytoplasmic tail of lysosomal acid phosphatase contains overlapping but distinct signals for basolateral sorting and rapid internalization in polarized MDCK cells." EMBO J 12(5): 2181-93.

Pshezhetsky, A. V., M. V. Vinogradova, et al. (1995). "Continuous spectrophotometric assay of human lysosomal cathepsin A/protective protein in normal and galactosialidosis cells." Anal Biochem 230(2): 303-7.

Raas-Rothschild, A., V. Cormier-Daire, et al. (2000). "Molecular basis of variant pseudohurler polydystrophy (mucolipidosis IIIC)." J Clin Invest 105(5): 673-81.

Rawlings, N. D. and A. J. Barrett (1993). "Evolutionary families of peptidases." Biochem J 290 ( Pt 1): 205-18.

Rawlings, N. D. and A. J. Barrett (1994). "Families of serine peptidases." Methods Enzymol 244: 19-61.

Reczek, D., M. Schwake, et al. (2007). "LIMP-2 Is a Receptor for Lysosomal Mannose-6Phosphate-Independent Targeting of beta-Glucocerebrosidase." Cell 131(4): 77083.

Reitman, M. L. and S. Kornfeld (1981a). "Lysosomal enzyme targeting. NAcetylglucosaminylphosphotransferase selectively phosphorylates native lysosomal enzymes." J Biol Chem 256(23): 11977-80.

Reitman, M. L. and S. Kornfeld (1981b). "UDP-N-acetylglucosamine:glycoprotein Nacetylglucosamine-1-phosphotransferase. Proposed enzyme for the 
phosphorylation of the high mannose oligosaccharide units of lysosomal enzymes." J Biol Chem 256(9): 4275-81.

Reitman, M. L., A. Varki, et al. (1981). "Fibroblasts from patients with I-cell disease and pseudo-Hurler polydystrophy are deficient in uridine 5'-diphosphate-Nacetylglucosamine: glycoprotein N-acetylglucosaminylphosphotransferase activity." J Clin Invest 67(5): 1574-9.

Remington, S. J. and K. Breddam (1994). "Carboxypeptidases C and D." Methods Enzymol 244: 231-48.

Roeser, D., A. Preusser-Kunze, et al. (2006). "A general binding mechanism for all human sulfatases by the formylglycine-generating enzyme." Proc Natl Acad Sci U $\underline{\mathrm{S} A}$ 103(1): 81-6.

Rottier, R. J., C. N. Hahn, et al. (1998). "Lack of PPCA expression only partially coincides with lysosomal storage in galactosialidosis mice: indirect evidence for spatial requirement of the catalytic rather than the protective function of PPCA." Hum Mol Genet 7(11): 1787-94.

Rudenko, G., E. Bonten, et al. (1995). "Three-dimensional structure of the human 'protective protein': structure of the precursor form suggests a complex activation mechanism." Structure 3(11): 1249-59.

Saftig, P., M. Hetman, et al. (1995). "Mice deficient for the lysosomal proteinase cathepsin D exhibit progressive atrophy of the intestinal mucosa and profound destruction of lymphoid cells." EMBO J 14(15): 3599-608.

Saftig, P., E. Hunziker, et al. (2000). "Functions of cathepsin K in bone resorption. Lessons from cathepsin K deficient mice." Adv Exp Med Biol 477: 293-303.

Saftig, P., E. Hunziker, et al. (1998). "Impaired osteoclastic bone resorption leads to osteopetrosis in cathepsin-K-deficient mice." Proc Natl Acad Sci U S A 95(23): 13453-8.

Sahagian, G. G., J. Distler, et al. (1981). "Characterization of a membrane-associated receptor from bovine liver that binds phosphomannosyl residues of bovine testicular beta-galactosidase." Proc Natl Acad Sci U S A 78(7): 4289-93.

Sambrook, J., T. Maniatis, et al. (1989). Molecular cloning : a laboratory manual. Cold Spring Harbor, N.Y., Cold Spring Harbor Laboratory.

Satake, A., K. Itoh, et al. (1994). "Distribution of lysosomal protective protein in human tissues." Biochem Biophys Res Commun 205(1): 38-43.

Scales, S. J., M. Gomez, et al. (2000). "Coat proteins regulating membrane traffic." Int Rev Cytol 195: 67-144.

Schechter, I. and A. Berger (1967). "On the size of the active site in proteases. I. Papain." Biochem Biophys Res Commun 27(2): 157-62.

Schmid, S. L., R. Fuchs, et al. (1988). "Two distinct subpopulations of endosomes involved in membrane recycling and transport to lysosomes." Cell 52(1): 73-83.

Schmidt, R. (1995). "Cell-adhesion molecules in memory formation." Behav Brain Res 66(1-2): 65-72.

Schroder, B., C. Wrocklage, et al. (2007). "Integral and Associated Lysosomal Membrane Proteins." Traffic. 
Shakin-Eshleman, S. H., S. L. Spitalnik, et al. (1996). "The amino acid at the X position of an Asn-X-Ser sequon is an important determinant of N-linked coreglycosylation efficiency." J Biol Chem 271(11): 6363-6.

Shirahama-Noda, K., A. Yamamoto, et al. (2003). "Biosynthetic processing of cathepsins and lysosomal degradation are abolished in asparaginyl endopeptidase-deficient mice." J Biol Chem 278(35): 33194-9.

Sleat, D. E., H. Lackland, et al. (2005). "The human brain mannose 6-phosphate glycoproteome: a complex mixture composed of multiple isoforms of many soluble lysosomal proteins." Proteomics 5(6): 1520-32.

Sleat, D. E., I. Sohar, et al. (1996). "Rat brain contains high levels of mannose-6phosphorylated glycoproteins including lysosomal enzymes and palmitoyl-protein thioesterase, an enzyme implicated in infantile neuronal lipofuscinosis." J Biol Chem 271(32): 19191-8.

Sleat, D. E., H. Zheng, et al. (2006). "Identification of sites of mannose 6phosphorylation on lysosomal proteins." Mol Cell Proteomics 5(4): 686-701.

Southern, E. M. (1982). "New methods for analysing DNA make genetics simpler." Biochem Soc Trans 10(1): 1-4.

Stein, M., T. Braulke, et al. (1987). "46-kDa mannose 6-phosphate-specific receptor: biosynthesis, processing, subcellular location and topology." Biol Chem Hoppe Seyler 368(8): 937-47.

Steiner, A. W. and L. H. Rome (1982). "Assay and purification of a solubilized membrane receptor that binds the lysosomal enzyme alpha-L-iduronidase." Arch Biochem Biophys 214(2): 681-7.

Steinfeld, R., K. Reinhardt, et al. (2006). "Cathepsin D deficiency is associated with a human neurodegenerative disorder." Am J Hum Genet 78(6): 988-98.

Stromhaug, P. E. and P. O. Seglen (1993). "Evidence for acidity of prelysosomal autophagic/endocytic vacuoles (amphisomes)." Biochem J 291 ( Pt 1): 115-21.

Stryke, D., M. Kawamoto, et al. (2003). "BayGenomics: a resource of insertional mutations in mouse embryonic stem cells." Nucleic Acids Res 31(1): 278-81.

Thomas, S. M., R. A. Lamb, et al. (1988). "Two mRNAs that differ by two nontemplated nucleotides encode the amino coterminal proteins $\mathrm{P}$ and $\mathrm{V}$ of the paramyxovirus SV5." Cell 54(6): 891-902.

Tiede, S., S. Storch, et al. (2005). "Mucolipidosis II is caused by mutations in GNPTA encoding the alpha/beta GlcNAc-1-phosphotransferase." Nat Med 11(10): 110912.

Tikkanen, R., M. Peltola, et al. (1997). "Several cooperating binding sites mediate the interaction of a lysosomal enzyme with phosphotransferase." EMBO J 16(22): 6684-93.

Tong, P. Y., S. E. Tollefsen, et al. (1988). "The cation-independent mannose 6-phosphate receptor binds insulin-like growth factor II." J Biol Chem 263(6): 2585-8.

Tribl, F., M. Gerlach, et al. (2005). "'Subcellular proteomics" of neuromelanin granules isolated from the human brain." Mol Cell Proteomics 4(7): 945-57. 
Varki, A. and S. Kornfeld (1980). "Identification of a rat liver alpha-Nacetylglucosaminyl phosphodiesterase capable of removing "blocking" alpha-Nacetylglucosamine residues from phosphorylated high mannose oligosaccharides of lysosomal enzymes." J Biol Chem 255(18): 8398-401.

Vellodi, A. (2005). "Lysosomal storage disorders." Br J Haematol 128(4): 413-31.

Vinogradova, M. V., L. Michaud, et al. (1998). "Molecular mechanism of lysosomal sialidase deficiency in galactosialidosis involves its rapid degradation." Biochem J 330 ( Pt 2): 641-50.

von Figura, K. and A. Hasilik (1986). "Lysosomal enzymes and their receptors." Annu Rev Biochem 55: 167-93.

von Figura, K., B. Schmidt, et al. (1998). "A novel protein modification generating an aldehyde group in sulfatases: its role in catalysis and disease." Bioessays 20(6): 505-10.

Waheed, A., S. Gottschalk, et al. (1988). "Human lysosomal acid phosphatase is transported as a transmembrane protein to lysosomes in transfected baby hamster kidney cells." EMBO J 7(8): 2351-8.

Waheed, A., R. Pohlmann, et al. (1982). "Deficiency of UDP-Nacetylglucosamine:lysosomal enzyme $\mathrm{N}$-acetylglucosamine-1-phosphotransferase in organs of I-cell patients." Biochem Biophys Res Commun 105(3): 1052-8.

Walter, P. and A. E. Johnson (1994). "Signal sequence recognition and protein targeting to the endoplasmic reticulum membrane." Annu Rev Cell Biol 10: 87-119.

Washburn, M. P., D. Wolters, et al. (2001). "Large-scale analysis of the yeast proteome by multidimensional protein identification technology." Nat Biotechnol 19(3): 242-7.

Wasinger, V. C., S. J. Cordwell, et al. (1995). "Progress with gene-product mapping of the Mollicutes: Mycoplasma genitalium." Electrophoresis 16(7): 1090-4.

Wattiaux, R., M. Wibo, et al. (1963). "[Effect of the injection of Triton WR 1339 on the hepatic lysosomes of the rat.]." Arch Int Physiol Biochim 71: 140-2.

Wilkins, M. R., J. C. Sanchez, et al. (1996). "Progress with proteome projects: why all proteins expressed by a genome should be identified and how to do it." Biotechnol Genet Eng Rev 13: 19-50.

Zhou, X. Y., H. Morreau, et al. (1995). "Mouse model for the lysosomal disorder galactosialidosis and correction of the phenotype with overexpressing erythroid precursor cells." Genes Dev 9(21): 2623-34. 


\section{Anhang}

\subsection{Ergebnisse der Proteomanalyse}

\begin{tabular}{|c|c|c|c|c|c|}
\hline Protein & $\begin{array}{c}\text { gi } \\
\text { Nummer }\end{array}$ & $\begin{array}{c}\text { Theo- } \\
\text { retische } \\
\text { Masse } \\
\mathrm{M}_{\mathrm{r}}\left(\times 10^{3}\right) \\
\end{array}$ & $\begin{array}{c}\text { 2D-GE } \\
\text { Anzahl der } \\
\text { Spots (Spot } \\
\text { Nr.) }\end{array}$ & $\begin{array}{l}\text { MudPIT: Anzahl der Peptide } \\
\text { (Länge der Peptide in AS) }\end{array}$ & $\begin{array}{l}\text { Sequenze- } \\
\text { abdeckung } \\
\text { in MudPIT }\end{array}$ \\
\hline \multicolumn{6}{|l|}{ Bekannte lysosomale Enzyme } \\
\hline$\alpha$-Glucosidase & 20913867 & 106 & $4(37-40)$ & $\begin{array}{c}\mathrm{R}^{893} \text { VTKEGAELQL }{ }^{903} \mathrm{R} \\
\mathrm{R}^{107} \mathrm{GCCYVPAGQVL}{ }^{118} \mathrm{~K} \\
\mathrm{~K}^{77} \text { EAPTQCDVPPSS }{ }^{89} \mathrm{R}\end{array}$ & $3 \%$ \\
\hline$\alpha-L-F u c o s i d a s e$ & 12832063 & 52 & $1(140)$ & -- & -- \\
\hline$\alpha-\mathrm{N}$-Acetylgalactosaminidase & 3327016 & 47 & $\begin{array}{c}5(13,116,117 \\
124,194)\end{array}$ & $\begin{array}{c}\mathrm{K}^{155} \text { LDGCFSSS }^{163} \mathrm{R} \\
\mathrm{R}^{38} \mathrm{CNIDCVEDP}^{47} \mathrm{~K} \\
\mathrm{~K}^{305} \text { INQDPLGIQG }^{315} \mathrm{R} \\
\mathrm{R}^{69} \text { DLGYVYLNIDDCWIGG }{ }^{85} \mathrm{R}\end{array}$ & $11 \%$ \\
\hline$\alpha-\mathrm{N}$-Acetylglucosaminidase & 3329361 & 83 & $4(48-51)$ & $\begin{array}{c}\mathrm{R}^{556} \text { YDLLDVT }^{563} \mathrm{R} \\
\mathrm{R}^{719} \mathrm{GDTVDLS}^{726} \mathrm{~K} \\
\mathrm{~K}^{584} \mathrm{QELDLLL}^{591} \mathrm{R} \\
\mathrm{R}^{687} \mathrm{GVPFQQHEFE}^{697} \mathrm{~K} \\
\mathrm{~K}^{660} \mathrm{QLAGLVADYYQP}{ }^{672} \mathrm{R} \\
\mathrm{R}^{481} \text { YGVSQPDAVAAW }^{493} \mathrm{~K} \\
\mathrm{R}^{77} \text { GSTGVAAAAGLH }{ }^{89} \mathrm{R}\end{array}$ & $10 \%$ \\
\hline Arylsulfatase A & 1703420 & 54 & $1(198)$ & $\begin{array}{c}\mathrm{R}^{200} \text { YVSFS }^{205} \mathrm{R} \\
\mathrm{K}^{457} \mathrm{HIQLL}^{462} \mathrm{~K} \\
\mathrm{R}^{206} \text { DLMADAQ }^{213} \mathrm{R} \\
\mathrm{R}^{114} \mathrm{GYLTGMAG}^{122} \mathrm{~K} \\
\mathrm{R}^{288} \mathrm{MSNGGCSGLL}^{298} \mathrm{R} \\
\mathrm{K}^{463} \text { AQYDAAMTFGPSQIA } \\
{ }^{478} \mathrm{~K}\end{array}$ & $11 \%$ \\
\hline Arylsulfatase B & 33302601 & 43 & $\begin{array}{c}8(6,10,58- \\
62,87)\end{array}$ & $\begin{array}{c}\mathrm{K}^{129} \text { LLPQLL }^{135} \mathrm{~K} \\
\mathrm{R}^{329} \mathrm{GTGFVASPLL}^{339} \mathrm{~K} \\
\mathrm{~K}^{206} \text { EYNNIYSTNIFT }^{218} \mathrm{~K}\end{array}$ & $8 \%$ \\
\hline$\beta$-Galactosidase & 192185 & 73 & $\begin{array}{c}12(5,41- \\
47,106 \\
150,159,171)\end{array}$ & $\begin{array}{l}\mathrm{R}^{150} \mathrm{SSDPDYLVAVD}{ }^{161} \mathrm{~K} \\
\mathrm{~K}^{360} \text { EVPEGPIPPSTP }{ }^{372} \mathrm{~K}\end{array}$ & $4 \%$ \\
\hline$\beta$-Glucuronidase & 309257 & 74 & $\begin{array}{c}9(7,25-28 \\
63-66)\end{array}$ & $\begin{array}{c}\mathrm{K}^{365} \text { DFNLL }^{370} \mathrm{R} \\
\mathrm{K}^{156} \text { LVQSGPLTTC }^{166} \mathrm{R} \\
\mathrm{K}^{560} \text { AVLENYHSVLDQ }^{572} \mathrm{~K} \\
\mathrm{~K}^{468} \text { ALDLTRPVTFVSNA }^{482} \mathrm{~K}\end{array}$ & $7 \%$ \\
\hline$\beta$-Hexosaminidase alpha & 232255 & 61 & $\begin{array}{c}34(11,12,71- \\
83,88-91 \\
106-113 \\
130,154,174,1 \\
95,196,198 \\
199)\end{array}$ & $\begin{array}{c}\mathrm{K}^{241} \text { EVIEYA }^{247} \mathrm{R} \\
\mathrm{R}^{171} \mathrm{GVLLDTS}^{178} \mathrm{R} \\
\mathrm{K}^{436} \text { VEPLAFHGTPEQ }{ }^{448} \mathrm{~K}\end{array}$ & $5 \%$ \\
\hline
\end{tabular}




\begin{tabular}{|c|c|c|c|c|c|}
\hline$\beta$-Hexosaminidase beta & 1346280 & 61 & $\begin{array}{c}10(92-99 \\
151,193)\end{array}$ & $\begin{array}{c}\mathrm{R}^{183} \mathrm{GILIDTS}^{190} \mathrm{R} \\
\mathrm{K}^{283} \mathrm{NLLTPCYNQ}^{292} \mathrm{~K} \\
\mathrm{~K}^{445} \text { VEPLNFEGSE }{ }^{455} \mathrm{~K} \\
\mathrm{R}^{264} \text { VIPEFDTPGHTQSWG } \\
{ }^{279} \mathrm{~K}\end{array}$ & $8 \%$ \\
\hline$\beta$-Mannosidase & 13310141 & 101 & $6(3,32-36)$ & $\mathrm{K}^{569} \mathrm{VSSQEDWAYNS}^{580} \mathrm{R}$ & $2 \%$ \\
\hline Cathepsin A & 6679437 & 54 & $\begin{array}{c}19(14,111- \\
114,122,125- \\
129,152,153 \\
173-175,189- \\
191\end{array}$ & $\begin{array}{c}\mathrm{R}^{44} \mathrm{QYSGYL}^{50} \mathrm{R} \\
\mathrm{R}^{307} \mathrm{RFPEALM}^{314} \mathrm{R} \\
\mathrm{R}^{367} \mathrm{LYQSMNSQYL}^{377} \mathrm{~K} \\
\mathrm{R}^{227} \text { LWTSLQTHCCAQN }^{240} \mathrm{~K} \\
\mathrm{R}^{284} \text { HRYEDTLVVQDFGNIFT }\end{array}$ & $12 \%$ \\
\hline Cathepsin B & 6681079 & 37 & $\begin{array}{c}4(14,152,195- \\
197)\end{array}$ & $\begin{array}{c}\mathrm{K}^{238} \text { KEIMAEIY }{ }^{246} \mathrm{~K} \\
\mathrm{~K}^{58} \text { LCGTVLGGP }^{67} \mathrm{~K} \\
\mathrm{~K}^{210} \text { SCEAGYSPSY }{ }^{220} \mathrm{~K} \\
\mathrm{R}^{88} \text { EQWSNCPTIGQI }{ }^{100} \mathrm{R} \\
\mathrm{K}^{224} \text { HFGYTSYSVSNSV }{ }^{238} \mathrm{~K}\end{array}$ & $17 \%$ \\
\hline Cathepsin C / DPP-I & 31560607 & 52 & $10(131-140)$ & $\begin{array}{c}\mathrm{K}^{64} \text { VVVHL }^{69} \mathrm{~K} \\
\mathrm{~K}^{177} \text { AINTVQ }^{183} \mathrm{~K} \\
\mathrm{~K}^{327} \mathrm{DSPCKP}^{333} \mathrm{R} \\
\mathrm{K}^{184} \text { SWTATAY }^{191} \mathrm{~K} \\
\mathrm{~K}^{141} \mathrm{KVESHIE}^{148} \mathrm{~K} \\
\mathrm{R}^{167} \text { LYTHNHNFV }^{176} \mathrm{~K} \\
\mathrm{R}^{238} \mathrm{NVQGVNYVSPV}^{249} \mathrm{R} \\
\mathrm{K}^{327} \text { DSPCKPRENCH }^{338} \mathrm{R} \\
\mathrm{K}^{149} \text { VNMNAAHLGGLQE }^{162} \mathrm{R} \\
\mathrm{R}^{50} \text { SDINCSVMEATEE }\end{array}$ & $21 \%$ \\
\hline Cathepsin D & 115718 & 45 & $\begin{array}{l}10(141- \\
149,151)\end{array}$ & $\begin{array}{c}\mathrm{K}^{344} \text { NYELHPD }^{351} \mathrm{~K} \\
\mathrm{~K}^{183} \mathrm{QPGIVFVAA}^{192} \mathrm{~K} \\
\mathrm{~K}^{330} \text { VSSLPTVYL }^{339} \mathrm{~K} \\
\mathrm{~K}^{63} \text { TTEPVSELL }{ }^{72} \mathrm{~K} \\
\mathrm{R}^{234} \text { DPEGQPGGELMLGGTDS }{ }^{251} \mathrm{~K}\end{array}$ & $14 \%$ \\
\hline Cathepsin F & 4826565 & 52 & --- & 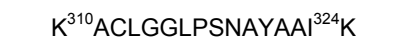 & $3 \%$ \\
\hline Cathepsin L & 200501 & 38 & $\begin{array}{c}6(168-170 \\
172,183,186)\end{array}$ & $\begin{array}{c}\mathrm{R}^{39} \text { LYGTNEEEW }^{48} \mathrm{R} \\
\mathrm{K}^{192} \text { ENGGLDSEESYPYEA } \\
\mathrm{K}^{207} \mathrm{~K} \\
{ }_{{ }^{2} \mathrm{~K}} \mathrm{NLDHGVLLVGEGTDSN}{ }^{29}\end{array}$ & $13 \%$ \\
\hline Cathepsin Z & 11066226 & 34 & $\begin{array}{l}9(15,16,18- \\
20,155-158)\end{array}$ & $\begin{array}{c}\mathrm{R}^{41} \text { GDQLALLG }{ }^{49} \mathrm{R} \\
\mathrm{R}^{264} \mathrm{NSWGEPWGE}^{273} \mathrm{~K} \\
\mathrm{~K}^{169} \mathrm{FNQCGTCTEF}^{179} \mathrm{~K} \\
\mathrm{R}^{72} \text { NVNGVNYASVT }^{83} \mathrm{R} \\
\mathrm{K}^{163} \text { DQDCDKFNQCGTCTEF }{ }^{179} \mathrm{~K}\end{array}$ & $19 \%$ \\
\hline Ceroid-lipofusc.neur.prot. 5 & 20881345 & 39 & $1(141)$ & 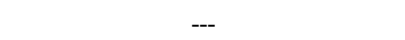 & -- \\
\hline Deoxyribonuklease II & 6753654 & 39 & $2(160,161)$ & $\mathrm{K}^{195}$ LPDLETVI ${ }^{204} \mathrm{~K}$ & $3 \%$ \\
\hline Dipeptidylpeptidase II & 13626390 & 56 & $7(8,100-105)$ & $\begin{array}{c}\mathrm{K}^{123} \text { SLPFGVQSTQ }{ }^{133} \mathrm{R} \\
\mathrm{R}^{214} \text { DVTADFYGQSP }{ }^{225} \mathrm{~K} \\
\mathrm{R}^{459} \text { ASNSEDPPSVVEV }{ }^{473} \mathrm{R}\end{array}$ & $7 \%$ \\
\hline Galactocerebrosidase & 2459856 & 76 & --- & $\mathrm{R}^{38}$ EFDGIGAVSGGGATS ${ }^{53} \mathrm{R}$ & $2 \%$ \\
\hline
\end{tabular}




\begin{tabular}{|c|c|c|c|c|c|}
\hline Legumain & 7242187 & 49 & $3(84-86)$ & $\mathrm{K}^{216}$ ESSYACYYDEE ${ }^{227} \mathrm{R}$ & $3 \%$ \\
\hline $\begin{array}{l}\text { N-Acetylglucosamine-6- } \\
\text { sulfatase }\end{array}$ & 29789239 & 61 & $7(4,52-57)$ & 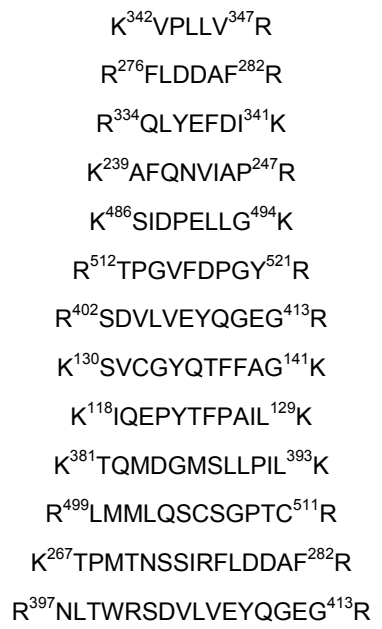 & $27 \%$ \\
\hline Neuraminidase 1 & 24496770 & 45 & $2(115,123)$ & --- & -- \\
\hline Niemann Pick Typ C2 prot. & 12963667 & 16 & --- & $\begin{array}{c}\mathrm{K}^{117} \mathrm{NEYPSI}^{123} \mathrm{~K} \\
\mathrm{~K}^{95} \mathrm{SGINCPIQKD}^{105} \mathrm{~K} \\
\mathrm{R}^{83} \text { VPFPIPEPDGC }{ }^{94} \mathrm{~K} \\
\mathrm{~K}^{36} \text { EVNVSPCPTDPCQLH }{ }^{51} \mathrm{~K}\end{array}$ & $31 \%$ \\
\hline Prosaposin & 1381582 & 61 & -- & 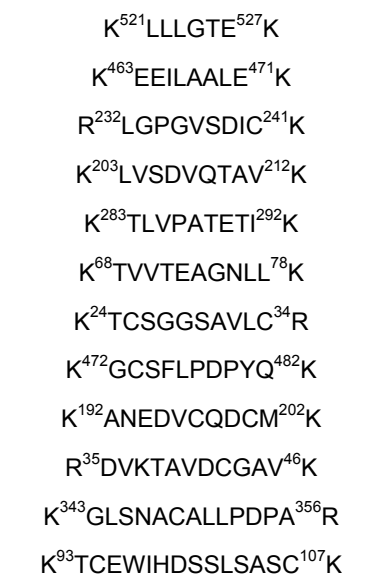 & $24 \%$ \\
\hline Ribonuklease 6 & 12858578 & 30 & $1(176)$ & -- & --- \\
\hline Saure $\alpha$-D-Mannosidase & 1914843 & 112 & $4(1,2,29,30)$ & $\begin{array}{c}\mathrm{R}^{433} \text { QNVVNDYA }{ }^{441} \mathrm{R} \\
\mathrm{K}^{964} \text { LDPTSVTLKPMEI }{ }^{977} \mathrm{R} \\
\mathrm{R}^{821} \mathrm{HLVLLSSVSDAAA}{ }^{834} \mathrm{R} \\
\mathrm{R}^{803} \mathrm{GVSEPLLETDTGD}{ }^{816} \mathrm{~K}\end{array}$ & $5 \%$ \\
\hline Saure Ceramidase & 9790019 & 45 & -- & $\begin{array}{c}\mathrm{R}^{313} \text { WYVVQTNYD }^{322} \mathrm{R} \\
\mathrm{K}^{33} \text { STYPPSGPTY }{ }^{43} \mathrm{R} \\
\mathrm{K}^{299} \text { ESLDVYELDP }^{309} \mathrm{~K} \\
\mathrm{~K}^{272} \text { TKIMAPVYFILGG }^{285} \mathrm{~K} \\
\mathrm{~K}^{100} \text { LPGMIGSLPDPFGEEM }^{116} \mathrm{R}\end{array}$ & $16 \%$ \\
\hline Saure Lipase I, lysosomal & 11496259 & 46 & -- & $\begin{array}{c}\mathrm{R}^{333} \text { LPTALWSGG }^{342} \mathrm{R} \\
\mathrm{K}^{303} \text { LQAFDWGSE }^{313} \mathrm{~K}\end{array}$ & $5 \%$ \\
\hline Tripeptidylpeptidase I & 12644085 & 61 & $1(77)$ & -- & -- \\
\hline $\begin{array}{l}\text { cellular repressor of } \\
\text { E1A-stimulated genes (CREG) }\end{array}$ & 6753520 & 25 & $\begin{array}{c}4 \\
(23,24,184,18 \\
5)\end{array}$ & -- & -- \\
\hline
\end{tabular}




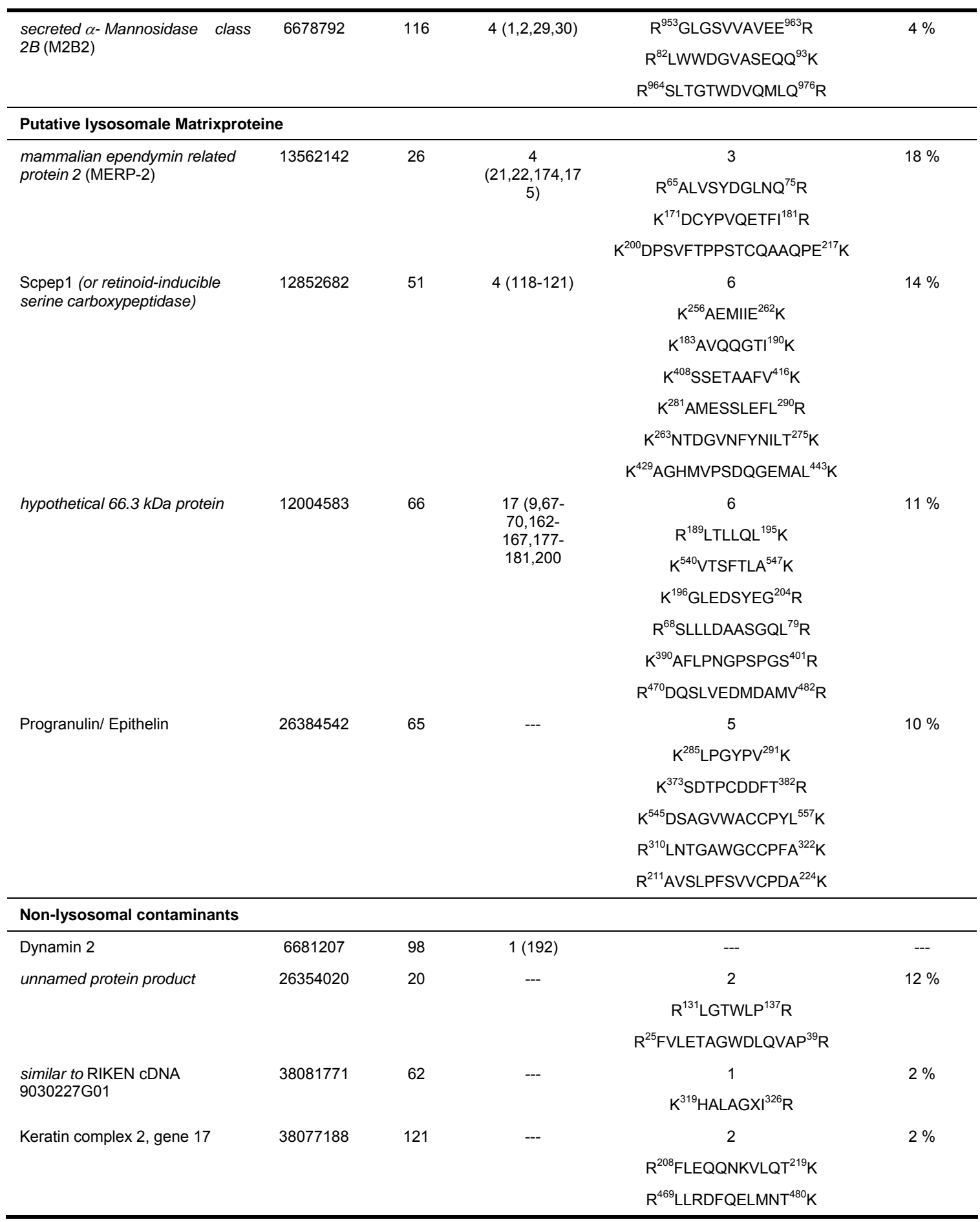

\section{Tab. 8.1: Bei 2D-PAGE/MALDI-TOF und MudPIT-Analyse identifizierte Proteine}

Durch 2D-PAGE/MALDI-TOF-MS und MudPIT-Ananlyse wurden insgesamt 34 bekannte lysosomale Proteine, sowie 4 putativ lysosomale und 4 nicht lysosomale Proteine identifiziert. In der Tabelle sind zum einen die Anzahl und die Nummern der Spots angegeben, durch die die M6P-markierten Proteine bei der 2D-PAGE identifiziert wurden. Zum anderen ist die Anzahl, sowie die Länge der Peptide angegeben, mit denen die M6P-markierten Proteine durch MudPIT-Analyse identifiziert wurden. 


\subsection{Primer zur Klonierung der Nukleotidsequenzen in den Vektor pDONR221}

8.2.1 Mus musculus serine carboxypeptidase 1, mRNA, gi:13436037

\begin{tabular}{ll}
\hline Primer Name & Sequenz \\
\hline Scpep1-PCR1-F & 5'-GCTGATGTTGCGGCGGGGTTT-3' \\
Scpep1-PCR1-R & 5'-CGCCTCCAGGGCCAGCCAGCT-3' \\
Scpep1-PCR2-F & 5'-GGGGACAAGTTTGTACAAAAAAGCAGGCTTCGAAGGAGAT \\
& AGAACCATGGAGCTCTCGCGGCGGATC-3' \\
Scpep1-PCR2-R & 5'-GGGGACCACTTTGTACAAGAAAGCTGGGTCCTCCTGCTTG \\
& GTCACCAGCTT-3' \\
Scpep1-Seq1 & 5'-CACCTGGCTGCAGTGGGCCAG-3' \\
Scpep1-Seq2 & 5'-TGCAGAGCAAGTCCTCGATGC-3' \\
Scpep1-Seq3 & 5'-CATGAAGCCTGCCATCGACGT-3' \\
\hline
\end{tabular}

8.2.2 Mus musculus Hypothetical 66.3 kDa protein RIKEN cDNA, gi:24047307

\begin{tabular}{ll}
\hline Primer Name & 'sequenz \\
\hline 66.3kDa-PCR1-F & 5'-GGGGACGCAGTCACGTGGCC-3' \\
66.3kDa-PCR1-R & 5'-CAGGTGTATGACCCACTGGC-3' \\
66.3kDa-PCR2-F & 5'-CGTGGCCCGGCTGCGGCTCG-3' \\
66.3kDa-PCR2-R & 5'-GAAGGCAGCTAGGCGGAGGC-3' \\
66.3kDa-PCR3-F & 5'-GGGGACAAGTTTGTACAAAAAAGCAGGCTTCGAAGGAGAT \\
& AGAACCATGGCGGCCCCCGTGGAT-3' \\
66.3kDa-PCR3-R & 5'-GGGGACCACTTTGTACAAGAAAGCTGGGTCCGTCCCATGG \\
& CACCCTGATGG-3' \\
66.3kDa-Seq1 & 5'-GCAGCTGGTGTGGTGGAGG-3' \\
66.3kDa-Seq2 & 5'-GCTGCTGCCTGGCGGGCATG-3' \\
66.3kDa-Seq3 & 5'-CCAGTGGATGATTGTGGACTAC-3' \\
66.3kDa-Seq4 & 5'-CTGACCTCAACCCCGCCAATG-3' \\
\hline
\end{tabular}


8.2.3 Mus musculus mammalian ependymin related protein-2 (MERP-2), mRNA, gi:14009839

\begin{tabular}{ll}
\hline Primer Name & Sequenz \\
\hline MERP-2-PCR1-F & 5'-CTCTGGAGCTCGGCTGACCCT-3' \\
MERP-2-PCR1-R & 5'-GGTTGGGTTCAGTTCGGCGAG-3' \\
MERP-2-PCR2-F & 5'-GGGGACAAGTTTGTACAAAAAAGCAGGCTTCGAAGGAGAT \\
& AGAACCATGCCCGCGCGCGCTCCCCGC-3' \\
MERP-2-PCR2-R & 5'-GGGGACCACTTTGTACAAGAAAGCTGGGTCCAAGGAGCAG \\
CCGTCACTCAT-3' \\
MERP2-Seq1
\end{tabular}

\subsubsection{Mus musculus Progranulin/Epithelin, mRNA, gi:142357784}

\begin{tabular}{ll}
\hline Primer Name & Sequenz \\
\hline Granulin-PCR1-F & 5'-AGCCCGGACCCCGACGCAGGC-3' \\
Granulin-PCR1-R & 5'-AGTTCCTTAAGTCTGTAGCCC-3' \\
Granulin-PCR2-F & 5'-GGGGACAAGTTTGTACAAAAAAGCAGGCTTCGAAGGAGAT \\
& AGAACCATGTGGGTCCTGATGAGCTGG-3' \\
Granulin-PCR2-R & 5'-GGGGACCACTTTGTACAAGAAAGCTGGGTCCAGTAGCGGT \\
CTTGGGACCGG-3' \\
Granulin-Seq1 & 5'-TCCTGCTTCCAGATGTCAGAT-3' \\
Granulin-Seq2 & 5'-TCCGACCACCTGCACTGCTGC-3' \\
Granulin-Seq3 & 5'-ACAATACCTGCTGCAAACTCA-3' \\
Granulin-Seq4 & 5'-GTTGGGAATGTGGAGTGTGGA-3' \\
\hline
\end{tabular}


8.2.5 Mus musculus cellular repressor of E1A-stimulated genes 1 (CREG1), mRNA, gi:31542419

\begin{tabular}{ll}
\hline Primer Name & Sequenz \\
\hline CREG-PCR1-F & 5'-GCGTCATGGCTGCCCGTGCTC-3' \\
CREG-PCR1-R & 5'-ACTCAGTCCACCATATCCTGC-3' \\
CREG-PCR2-F & 5'-GGGGACAAGTTTGTACAAAAAAGCAGGCTTCGAAGGAGAT \\
& AGAACCATGGCTGCCCGTGCTCCTGAG-3' \\
CREG-PCR2-R & 5'-GGGGACCACTTTGTACAAGAAAGCTGGGTCCTGCAGCGTG \\
& ACGTTAAAATA-3' \\
CREG-Seq1 & 5'-CTACATGTACCTGAGTCCACT-3' \\
\hline
\end{tabular}

8.2.6 Mus musculus mannosidase 2, alpha B2, mRNA, gi:42542424

\begin{tabular}{ll}
\hline Primer Name & 'sequenz \\
\hline M2B2-PCR1-F & 5'-GCCCTGGCAGCGTCCCACTGC-3' \\
M2B2-PCR1-R & 5'-TGGGGCCAATGCATTGATGTC-3' \\
M2B2-PCR2-F & 5'-GGGGACAAGTTTGTACAAAAAAGCAGGCTTCGAAGGAGAT \\
& AGAACCATGGGGCCGCTGCGCTGGCTG-3' \\
M2B2-PCR2-Rneu & 5'-GGGGACCACTTTGTACAAGAAAGCTGGGTCCTGCTGGAAT \\
& 'TTAATGAAGAAGGTC-3' \\
M2B2-Seq1 & 5'-GAGGCCAAGTCATGCATGATG-3' \\
M2B2-Seq2 & 5'-GTTAAACAGAGGGCTGCGTGG-3' \\
M2B2-Seq3 & 5'-AGGTGAAGAACATGTACACGG-3' \\
M2B2-Seq4 & 5'-AGCGCCTGGTGCCCGTGATGA-3' \\
M2B2-Seq5 & 5'-GCAAGTCCTCTACTCTGACAA-3' \\
M2B2-Seq6 & 5'-CtGGCTGGACGTACAGCAGGA-3' \\
\hline
\end{tabular}




\subsection{Primer zur weiteren Untersuchung der Scpep1}

\subsubsection{Primer zur RT-PCR auf die Scpep1-Gene Trap mRNA}

\begin{tabular}{ll}
\hline Primer Name & Sequenz \\
\hline Oligo-dT-Primer & 5'-TTTTTTTTTTTTTTTTTTT-3' \\
Scpep1-Ex7-FW & 5'-CTGTCCTGGGGACCTTACCTG-3' \\
Bay- $\beta-G a l-R V 1$ & 5'-GACAGTATCGGCCTCAGGAAGATCG-3' \\
Bay- $\beta-G a l-R V 2$ & 5'-CATTCAGGCTGCGCAACTGTTGGG-3' \\
\hline
\end{tabular}

\subsubsection{Primer zur Identifizierung der Gene Trap Insertionsstelle im Gen der} Scpep1

\begin{tabular}{ll}
\hline Primer Name & Sequenz \\
\hline Scpep1-Ex7-FW & 5'-CTGTCCTGGGGACCTTACCTG-3' \\
Scpep1-KO-RV & 5'-CCTCCAGTCTCCTCCACCCTGGG-3' \\
Scpep1-Ex8-RV & 5'-TAGAAGCCCTTGTTTACAGCATC-3' \\
\hline
\end{tabular}

\subsubsection{Primer zur Generierung einer Scpep1-5'-Southern Blot Sonde}

\begin{tabular}{ll}
\hline Primer Name & Sequenz \\
\hline Scpep1-5'-Sonde-FW & 5'-GTGGCCTTGGCCATCCTGGAATTC-3' \\
Scpep1-5'-Sonde-RV & 5'-GATACAAATTAGCTATGTCTTTCC-3' \\
\hline
\end{tabular}

\subsubsection{Primer zur Genotypisierung von Mäusen der RST426 Zucht}

\begin{tabular}{ll}
\hline Primer Name & Sequenz \\
\hline Scpep1 MP FW & 5'-ATCCTCACACATGCAAAGCA-3' \\
Scpep1 MP(+)-RV & 5'-TATTGGGCTGGAGTGGAGAC-3' \\
Scpep1 MP(-)-RV & 5'-CCTGGCCTCCAGACAAGTAG-3' \\
\hline
\end{tabular}


8.3.5 Primer zur Subklonierung der Scpep1-cDNA in pcDNA3.1/Hygro mit C-terminalem RGS-His6-Peptidtag

\begin{tabular}{ll}
\hline Primer Name & Sequenz \\
\hline Scpep1-Hind3-F & 5'-GTACAAGCTTATGGAGCTCTCGCGGCGGATC-3' \\
Scpep1-RGS-His-Not-RV & 5'-GTACAGCGGCCGCTTATCCGTGATGGTGATGGTGATG \\
& CGATCCTCTTCCCTCCTGCTTGGTCACCAGCTT-3' \\
\hline
\end{tabular}

\subsubsection{Primer zur Generierung von Northern Blot Sonden}

\begin{tabular}{ll}
\hline Primer Name & Sequenz \\
\hline Scpep1-Seq2 & 5'-TGCAGAGCAAGTCCTCGATGC-3' \\
3' NorthernRiscRV & 5'-CTCCTGCTTGGTCACCAGCTT-3' \\
GAPDH mus R1 & 5'-GCCGAGTTGGGATAGGGCCTC-3' \\
GAPDH mus R2 & 5'-GCCTCTCTTGCTCAGTGTCC-3' \\
GAPDH mus R3 & 5'-GGTGGTCCAGGGTTTCTTAC-3' \\
GAPDH mus F1 & 5'-CTCCCTGTTCCAGAGACGGC-3' \\
GAPDH mus F2 & 5'-CGCATCTTCTTGTGCAGTGC-3' \\
\hline
\end{tabular}




\section{$9 \quad$ Danksagung}

Herrn Prof. Dr. Dr. K. von Figura danke ich an dieser Stelle für die interessante Themenstellung und seine freundliche Unterstützung im Verlauf der Arbeit.

Bei Herrn Prof. Dr. G. H. Braus bedanke ich mich für die bereitwillige Übernahme des Korreferats.

Jun.-Prof. Dr. Torben Lübke gilt mein ganz besonderer Dank für das Vertrauen in meine Arbeit. Sein starkes persönliches Engagement und seine stete Diskussionsbereitschaft haben maßgeblich zum Gelingen dieser Arbeit beigetragen.

Ich möchte mich zudem für ich die Hilfsbereitschaft, die gute Zusammenarbeit und das herzliche Arbeitsklima innerhalb der Arbeitsgruppe bedanken. Mein besonderer Dank gilt dabei Ellen Eckermann-Felkl, Martina Balleiniger, Markus Damme und Florian Deuschl.

Frau Prof. Dr. R. Lüllmann-Rauch am Anatomischen Institut der Universität Kiel danke ich herzlichst für die sorgfältige, histopathologische Untersuchung. Dr. Rudi D'Hooge und Leen Van Aerschot vom Laboratory of Biological Psychology, Department of Psychology an der Universität Leuven in Belgien danke ich für die Verhaltensanalysen an unserem Mausmodell.

Allen Mitarbeitern der Abteilung von Figura gilt mein Dank für ihre große Hilfsbereitschaft und für die freundliche Atmosphäre.

Ellen Eckermann-Felkl, Markus Damme, Florian Deuschl, Jenny Baltes, Tanja Benkert und Nicole Eiselt möchte ich für ihre Freundschaft und Hilfsbereitschaft danken. Kira Späte, Jürgen Luebbehusen, Diego Prieto Roces und Andrea Rüger danke ich besonders für den netten Empfang und die Unterstützung in der Frühphase meiner Arbeit.

Meinen Freunden, insbesondere Verena, Petra und Angela, gilt mein Dank für Ihre offenen Ohren bei Kummer und Sorgen und Ihre Unterstützung während der letzten Jahre.

Schließlich geht ein großer Dank an meine Familie und an meinen Freund Alexander, die mich über all die Jahre meiner Ausbildung unterstützt haben. 



\section{Lebenslauf}

Am 03. Juli 1978 wurde ich als zweites Kind meiner Eltern Margot Kollmann, geb. Weber und Dieter Kollmann in Bad Hersfeld geboren. Von 1985 bis 1989 besuchte ich die Grundschule Haunetal. Anschließend wechselte ich zur Orientierungsstufe der Gesamtschule Obersberg in Bad Hersfeld. Ab dem Jahr 1991 war ich an dieser Schule Schüler des gymnasialen Zweigs. 1995 wechselte ich an die gymnasiale Oberstufe der Modellschule Obersberg, wo ich 1998 meine schulische Ausbildung mit dem Abitur abschloss. Im Wintersemester 1998 begann ich das Studium der Biochemie an der Universität Hannover. Meine Vordiplomsprüfung legte ich im Jahre $2000 \mathrm{ab}$. Die mündliche Diplomhauptprüfung erfolgte im Sommer 2003 mit der Fächerkombination Biochemie, biophysikalische Chemie und Immunologie. Meine Diplomarbeit fertigte ich unter Leitung von Herrn Prof. Dr. S. Lenzen und Frau Dr. S. Baltrusch am Institut für klinische Biochemie an der Medizinischen Hochschule Hannover an. Die Abgabe der Diplomarbeit mit dem Titel „Identifizierung von Proteinbindungspartnern der humanen $\beta$-Zell Glucokinase im Two Hybrid System“ erfolgte im Januar 2004.

Im März 2004 begann ich am Zentrum Biochemie und molekulare Zellbiologie, Institut für Biochemie II der Georg-August Universität zu Göttingen unter der Anleitung von Prof. Dr. Dr. K. von Figura in der Arbeitsgruppe von Jun.-Prof. Dr. T. Lübke den experimentellen Teil der hier vorgelegten Dissertation mit dem Thema: „Identifizierung und molekulare Charakterisierung des lysosomalen Matrixproteins Serincarboxypeptidase $1 “$. 